\title{
5. AUF KONFRONTATIONSKURS: BIS AUGUST 1939
}

\subsection{Verschärfter Ton zwischen Tokio und dem Westen}

Wie der Generalstab in Paris befürchtet hatte, interessierte sich Japan nach der Besetzung Kantons verstärkt für die Yunnanbahn. Japan verlor nach der Münchener Konferenz einen großen Teil des früheren Respekts vor Frankreich.

Am 24. Oktober drohten Japans Militärattaché General Tsuchihashi im französischen Generalstab und Botschaftsrat Miyasaki im Quai d'Orsay mit dem Bombardement der Yunnanbahn, falls diese Waffen transportiere. Miyasaki und Premierminister Konoe Fumimaro forderten von Henry, eine japanische Kontrollkommission zu akzeptieren oder Indochinas Grenzen zu schließen. Was passiere, falls Paris ablehne, ließen sie offen. Massigli, Henry, Hoppenot und der Marine-Geheimdienst nahmen an, Tokio suche einen Vorwand für einen Angriff auf Hainan oder Indochina, denn Japan wisse, daß über die Bahn nur alte Bestellungen abgewickelt würden. Henry zufolge bezweifelte das Gaimusho jedoch, daß sich alle Beamten in Indochina an das Transitverbot hielten. Begleitet wurden die Vorwürfe von einer Pressekampagne'.

Ende Oktober wiederholten der japanische Heeres- und der Marineattaché in Paris die Drohungen. In Shanghai warnte Tani Naggiar, Extremisten wollten alle Transporte auf der Yunnanbahn unterbinden. Am 4. November versicherte das französische Außenministerium der japanischen Botschaft, es gebe keinen Waffentransit. Japan habe bisher keinen Fall angeblichen Waffenschmuggels belegt. Die Entsendung einer Untersuchungskommission sei deshalb unnötig. Ein Sprecher des Gaimusho sagte daraufhin, der Waffentransit über Indochina sei unerheblich. Doch in Asien ging die Pressekampagne weiter ${ }^{2}$.

Die Lage an Indochinas Nordgrenze spitzte sich zu: Am 23. Oktober zog China die regulären Truppen von Hainan ab, wo nur fünf Milizbataillone blieben. Frankreichs Konsul in Longtchéou warnte, Japan könne bis Indochina

${ }^{1}$ EMA.2, compte rendu, 24.10., EMA.2, rapport du ministre, 24.10.1938 (SHAT $7 \mathrm{~N} 3311,7 \mathrm{~N}$ 2515); Note, 26.10., compte rendu, 26.10; Henry an Bonnet, T 587-92, 28.10., T 582-85, 27.10.1938 (DDF XII, 223, 224, 232, MAE Chine 729;); Note de la sous-direction d'Asie-Océanie, 21.11.; STSBulletin, 1.12.1938 (MAE Chine 713, 534); Grew an Hull, 2.11.1938 (FRUS 1938, III, S. 607); Domei, Statement by Spokesman, 28.10., Henry an Naggiar, T 328, 29.10.1938 (MAEN Pékin A 394).

${ }^{2}$ Compte rendu, 2.11.; Naggiar an Bonnet, T 1605-7, 30.10., Hoppenot an Henry, T 388-94, 4.11.1938 (SHAT 7 N 2525; MAEN Pékin A 394; DDF XII, 263); Massigli an Sugimura, L, 4.11., Hoppenot an Henry, T 423, 9.11., Henry an Bonnet, T 627-28, 11.11., Naggiar an Bonnet, T 1700-2, 11.11.; Wilson an Hull, 7.11.1938 (MAE Japon 127; FRUS 1938, III, S. 374f.). 
vorrücken. Naggiar, Henry, der Service de transit, der Generalstab in Paris und britische Geheimdienste befürchteten die Landung japanischer Verbände in Südchina. Das Deuxième Bureau der Armee beklagte Japans Aggressivität gegenüber dem Westen seit dem Fall Kantons ${ }^{3}$.

Der Quai d'Orsay, der im Januar und März 1938 nach japanischen Angriffen auf Hainan protestiert hatte, der im Mai die Insel unter französischen Schutz stellen und im Juni internationalen Schutz für sie mobilisieren wollte und dessen Warnungen so laut waren, daß Japans Konsul in Hanoi im Juli 1938 glaubte, Frankreich beantworte eine Besetzung Hainans militärisch, reagierte überhaupt nicht auf die Bedrohung. Nach dem Abzug der chinesischen Truppen hatte Paris die Insel aufgegeben. Der Quai d'Orsay hielt es nach der Münchener Konferenz offenbar für ein Überreizen seiner Macht, Japan vor dem Einmarsch in französisches Interessengebiet zu warnen. Die Anzeichen, daß Tokio nicht länger Rücksicht auf die Mächte nahm, verstärkten sich. Im Oktober 1938 übernahm Japan den Zoll in Kanton und löste ihn aus der internationalen Kontrolle heraus. Paris wollte die Frage erst nach Kriegsende diskutieren, protestierte aber nach Konsultation Londons und Washingtons doch gegen Japans Vorgehen. Chungking stellte am 15. Januar 1939 den Schuldendienst ein, weil es kaum noch über Zolleinnahmen verfügte. Washington deckte Chinas Entscheidung, so daß Knobel, Léger und das Foreign Office auf den geplanten Protest verzichteten ${ }^{4}$. Paris und London verfolgten die Frage der Zölle danach nicht weiter.

Sensibel registrierte der Quai d'Orsay einen Kurswechsel der US-Asienpolitik. Meldungen über Chinas Verfall hatten Washington beunruhigt, berichtete Botschafter René Doynel de Saint-Quentin am 24. Oktober. Es gab Gerüchte, Chiang Kai-shek schließe Frieden mit Japan oder trete zurück. Finanzminister H.H. Kung und Kuomintang-Vizevorsitzender Wang Ching-wei seien bereit, mit Japan zu verhandeln, schrieb Naggiar. Er hielt, wie Hoppenot und Mandel, Frieden für nicht völlig abwegig. Besonders beunruhigt hatte das State Depart-

${ }^{3}$ Diplomatic an EMG.2, T 236, 19.10., T 239-40, 25.10., T 242, 3.11., Rosati an EMG.2, T 138, 22.10., STS an EMG.2, T 1526-27, 22.10., Jankélévitch an Bonnet, T 33, 24.10.1938 (SHM 1BB9 41, MAE SDN 365); Brévié an Mandel, T 1220, 27.10., T 1264, 5.11, T 1299, 14.11.1938 (CAOM FM 678); Naggiar an Bonnet, T 1583-85, 27.10.1938 (MAE Japon 123); Naggiar an Bonnet, T 1623, 1.11., T 1664, 4.11., Henry an Bonnet, T 600, 3.11.1938 (MAE Chine 729); STS an EMG.2, T 1530, 8.11., EMG.2, bulletin, 16.11.1938 (SHM 1BB9 42, 1BB2 92); EMA.2, note, 6.11., EMG.2 an Diplomatie, T 7622, 9.11.1938 (SHAT 7 N 3300, MAE Chine 730).

${ }^{4}$ Charveriat an Henry, T 511-15, 31.12.1938; Saint-Quentin an Bonnet, T 40, 7.1., Knobel an Bonnet, T 57, 13.1., Léger an Henry, T 236, 2.6., Havas London, une décision du gouvernement chinois en matière financière, 15.1., note de la sous-direction d'Asie-Océanie, 20.1., 23.3.; Knobel an Bonnet, T 149, 28.1., Léger an Corbin, T 164-66, 1.2.1939 (MAE Chine 715, 875); Léger an Corbin, T 87-88, 17.1., L 497, 27.3., Léger an Saint-Quentin, T 110, 17.1., T 217-20, 6.2., Corbin an Bonnet, T 16364, 18.1., note de la sous-direction d'Asie-Océanie, 7.2., Léger an Knobel, T 41-44, 8.2.1939 (MAE Chine 847); Adams, Memorandum of Conversation, 10.2.1939 (FRUS 1939, III, S. 816f.). 
ment wohl, daß Chiang Kai-shek sich erstmals seit Januar 1938 wieder persönlich an US-Präsident Roosevelt wandte: Am 8. Oktober schlug Chiang Friedensgespräche vor, eine Woche später bat er um mehr Wirtschaftshilfe ${ }^{5}$. Davon erfuhr Paris nichts, doch als Washington am 26. Oktober bekanntgab, Botschafter Grew habe in Tokio gegen die Beeinträchtigung wirtschaftlicher Rechte der USA in China protestiert, erinnerte sich Léger an Saint-Quentins Bericht, wie sehr Chinas Lage Washington beunruhige. Am 27. Oktober nahm er eine Anregung Wellington Koos auf und fragte London und Washington, wie diese zum chinesischen Vorschlag einer gemeinsamen Äußerung zur Ausdehnung der Kämpfe nach Südchina stünden ${ }^{6}$.

Die Briten äußerten sich ablehnend. Washington reagierte zuerst nicht. Am 2. November aber stimmte sich US-Außenminister Cordell Hull erstmals vor einer Demarche in Tokio mit London und Paris ab. Hull teilte mit, er wolle in Tokio gegen Japans Monopol bei der Jangtse-Schiffahrt protestieren. Frankreich und Großbritannien könnten sich anschließen. Hoppenot war erfreut, daß die Amerikaner Bereitschaft zur diplomatischen Zusammenarbeit zeigten, und versprach, Henry werde der US-Initiative folgen. Die Briten schlossen sich an. Botschafter Saint-Quentin glaubte nicht an eine Abkehr der USA von ihrer unilateralen Politik, doch Bonnet widersprach: Erstmals hätten die Vereinigten Staaten eine konzertierte Aktion vorgeschlagen. Sumner Welles' Äußerung gegenüber Saint-Quentin, die Demokratien könnten ihre Interessen nur gemeinsam verteidigen, hatte den Quai d'Orsay elektrisiert: Da Frankreich ständig wegen des angeblichen Waffentransits attackiert wurde, werde das Bild einer westlichen Solidarität die Besitzungen aller drei Mächte schützen und Japans Spielraum einengen, telegraphierte Bonnet nach Washington?

Amerika engagierte sich stärker, weil die Münchener Konferenz gezeigt hatte, daß Washington nicht länger auf England zählen konnte, um den Status quo in Asien zu bewahren, und weil es China helfen mußte, wenn es Japan nicht Ostasien überlassen wollte. Die Verkündung einer »Neuen Ordnung in Asien«

\footnotetext{
${ }^{5}$ Havas Tokio, le règlement éventuel du conflit sino-japonais, 22.10.1938 (MAE Chine 728); Naggiar an Bonnet, T 1549-53, 25.10., T 1598-1600, 28.10.1938 (MAE Chine 729; DDF XII, 234); Note de la sous-direction d'Asie-Océanie, 25.10., Saint-Quentin an Bonnet, T 1181-82, 24.10.1938 (MAE SDN 365); Wilson an Hull, 29.10., Suritz an Litvinov, 29.10.1938 (FRUS 1938, lII, S. 351f.; SPE I, 37); Chiang an Roosevelt, 8.10., 15.10.1938 (SD 793.94/14047, 14335).

${ }^{6}$ Note au Japon, 26.10.1938 (MAE Chine 729); Saint-Quentin an Bonnet, T 1197-99, 27.10.1938 (MAE Japon 131); Note, cabinet du ministre, 17.10.1938 (MAE Chine 728); Bonnet an Corbin, T 3351, Saint-Quentin, T 744, 27.10.1938 (DDF XII, 228); Léger an Naggiar, T 576-78, 30.10.1938 (MAEN Pékin A 493); Halifax an Clark Kerr, 1.11.1938 (DBFP, $3^{\text {rd }}$ series, VIII, 190).

${ }^{7}$ Memorandum of Conversation, 5.11.1938 (SD 793.94/14405); Hull an Grew, 2.11.1938 (FRUS 1938, IV, S. 195f.); Wilson an Hull, 3.11.1938 (FRUS 1938, IV, S. 196); Kennedy an Hull, 5.11.1938 (SD 793.94/14295); Halifax an Craigie, 5.11 .1938 (DBFP, $3^{\text {rd }}$ series, VIII, 210); Saint-Quentin an Bonnet, T 1218-21, 6.11., T 1250-51, 10.11 .1938 (DDF XII, 274; MAE SDN 365); Bonnet an SaintQuentin, T 784-92, 9.11.1938 (DDF XII, 282).
} 
durch Premierminister Konoe beschleunigte die Kurskorrektur in Washing$\operatorname{ton}^{8}$. Der Regierungschef sagte am 3. November im Radio, Japan wolle eine Neue Ordnung (»Toa shinchitsu-jo«) errichten, die die bisherigen Prinzipien wie die Völkerbund-Charta ablöse. Später erklärte er, der Neun-Mächte-Vertrag sei nicht mehr anwendbar. Die USA reagierten, indem sie am 6. November eine handelspolitische Protestnote in Japan publik machten. Sumner Welles sprach gegenüber Frankreichs Botschafter erstmals von gemeinsamen Wirtschaftssanktionen. Daß die drei westlichen Botschafter am 7. November gegen die Schließung des Jangtse protestierten, erschien wie eine Reaktion auf die Konoe-Erklärung. Japans Presse beklagte die Formierung einer Front der drei Mächte gegen Japan. Am 25. November wiederholten die drei Botschafter ihren Protest zur Schließung des Stroms. In der Welt erschien Konoes Erklärung, so die »Neue Zürcher Zeitung«, als »das erste offene Eingeständnis einer imperialistischen japanischen Monopolisierungspolitik «?

Hoppenot versuchte am 7. November, die USA zu einer gemeinsamen Antwort auf Konoes Erklärung zu bewegen. Er sagte zu Geschäftsträger Wilson, die Verkündung einer neuen Ordnung lasse keinen Zweifel mehr an Japans Absichten. Nur gemeinsam könnten die drei Mächte ihre Rechte verteidigen. Hoppenot schlug vor, der Westen solle Japan in einer geheimen Nachricht die Bereitschaft erklären, nach Kriegsende eine neue Ordnung in Asien zu akzeptieren. Bis dahin sollten die Interessen der Mächte in China geschützt bleiben. Ein solches Vorgehen, das sicher mit Léger abgesprochen war, hätte sämtliche Widersprüche der französischen Fernostpolitik aufgelöst: Paris wäre in Tokio gemeinsam mit den USA aufgetreten, es hätte Tokio gleichzeitig gezeigt, daß es die neue Ordnung dulden würde, und es hätte zudem einen stabilen Status quo in China erhalten. Doch die USA antworteten nicht auf Hoppenots Vorschlag. Paris ließ nicht locker. Bonnet erklärte Wilson am 10. November, die USA müßten im Fernen Osten die Führung übernehmen. Amerikanischen und chinesischen Diplomaten sagte er, Frankreich beziehe gegen Japan Position, sobald er der Unterstützung der Briten und Amerikaner sicher sei.

Eine andere Strategie empfahl Naggiar vor seiner Abreise aus China. Er riet am 6. und am 17. November, den Vertrag von 1907 zu bekräftigen, um französische Interessen in Asien zu schützen und in Europa Bewegungsspielraum zu gewinnen. Auf Amerika zu zählen sei illusorisch. Folgenlose Verurteilungen, wie sie die USA aussprächen, gefährdeten die Position der Mächte. Georges-

\footnotetext{
${ }^{8}$ UTLEY, Going to War, S. 43; JUNKER, Der unteilbare Weltmarkt, S. 201, S. 218, S. 220.

${ }^{9}$ Henry an Bonnet, L 212, 4.11.; Havas, le Japon et les neuf puissances, 5.11., Henry an Bonnet, T 606-8, 5.11.1938 (MAE Chine 729, 730); Saint-Quentin an Bonnet, T 1218-21, 6.11.1938 (DDF XII, 274); Henry an Bonnet, T 359-60, 7.11., T 616, 8.11.1938 (MAEN Pékin A 394, MAE SDN 365); Grew an Hull, 7.11.1938 (SD 793.94/14308); Note de la Direction politique, 5.12.1938 (MAE Chine 731); Neue Zürcher Zeitung, 12.1.1939, zit. nach SOMMER, Deutschland und Japan, S. 205.
} 
Picot in Chungking plädierte hingegen für die Annäherung an China: Mit der Verweigerung öffentlicher Unterstützung und dem Transitverbot habe Paris gegen China Stellung bezogen. Japan sei dafür aber nicht dankbar, sondern verstehe Frankreichs Politik als Anerkennung seiner Hegemonie und Zeichen der Schwäche, die zu weiteren Erpressungen einlade ${ }^{10}$.

Mitte November erhöhte Japan den Druck: Botschaftsrat Miyasaki erklärte, wenn Frankreich keine Untersuchungskommission zulasse, solle zumindest Japans Generalkonsul in Hanoi den Waffentransit untersuchen dürfen. Als Hoppenot dies ablehnte, drohte Miyasaki, seine Regierung sehe die Untersuchung als letztes Mittel einer friedlichen Beilegung an. Miyasaki wollte das Ultimatum aber nicht schriftlich äußern. Naggiar berichtete, Japan habe 150 Bomber nach Südchina verlegt. Tatsächlich plante Japans Regierung einen Luftangriff auf die Yunnanbahn. Am 9. Dezember stimmte das Gaimusho dem Plan der Marine zu, die französische Bahnlinie aus der Luft zu bombardieren. Das Vorhaben wurde aber mehrfach verschoben und erst im Dezember 1939 erneut erwogen. Von alledem erfuhren die Franzosen nichts. Paris registrierte lediglich, $\mathrm{da} B$ in Osaka und Kobe tausende Demonstranten ihre Regierung aufforderten, die britische und französische Hilfe für Chiang Kai-shek zu unterbinden. Auch die Drohungen des Gaimusho wurden heftiger: Der Leiter der Europaabteilung Inoue warnte vor dem Zorn des Militärs, falls bekannt würde, daß Frankreich Kontrollen in Indochina ablehne und selbst 18 Monate nach Konfliktbeginn noch aufgrund alter Verträge Waffen an China liefere ${ }^{11}$.

In Vorbereitung des Treffens von Chamberlain, Daladier, Halifax und Bonnet am 24. November in Paris planten Hoppenot und Léger am 21. November die Fernostpolitik nach Washingtons Kurskorrektur. Vier Tage zuvor hatte das Gaimusho in Beantwortung der US-Protestnote vom 6. Oktober schriftlich erklärt, daß Japan die Prinzipien des Washingtoner Vertrages für überholt halte. Hoppenot und Léger urteilten, daß Japan vor allem wegen der Schwäche des Westens sein Versprechen gebrochen habe, westliche Interessen in China zu respektieren. Daß Amerika bei der Demarche zugunsten der Jangtse-Schiffahrt gemeinsam mit England und Frankreich auftrat, habe Takio tief beeindruckt. Frankreich dürfe sich keine Illusionen über die Reichweite des Kooperations-

\footnotetext{
${ }^{10}$ Wilson an Hull, 7.11., 16.11., 10.11.1938 (FRUS 1938, III, S. 374f., S. 609; SD 751.62/495); Naggiar an Bonnet, T 1675-81, 6.11., T 1737-44, 17.11., T 1824-28, 25.11.; Georges-Picot an Naggiar, T 173-90, 17.11.1938 (MAE Japon 127-128; DDF XII, 322, 396; MAEN Pékin A 395).

" Note de la sous-direction d'Asie-Océanie, 15.11.1938 (DDF XII, 307); Diplomatie an EMG.2, T 136, 18.11.1938 (SHM 1 BB9 42); Juristische Meinung zum Angriff auf die Yunnanbahn in China, 16.11.1938, Angriff auf den Yunnanzug: Juristische Meinung der Armee, 16.1.1939 (JA, S 1.1.1.028, S. 65f., S. 554f.); Business Report of 1939 published by the Board of South Seas 1941. The China Affair and French Indochina, Urteil (TWCT, III, S. 6801-6815 [S. 6802f.], XX, S. 48793); KREBS, Japans Deutschlandpolitik, S. 182; Henry an Bonnet, L 227, 22.11., T 648-50, 23.11.1938 (MAE Japon 128, DDF XII, 364); Craigie an Halifax, 2.12.1938 (FO 371/22177, F 13886/9/23).
} 
willens der USA machen, doch nur ein gemeinsamer politischer Widerstand werde den drei Mächten erlauben, etwas von ihren Interessen ist Ostasien zu verteidigen. Die Anregung in der Aufzeichnung, Franzosen und Briten sollten den USA versichern, daß sie jedes amerikanische Vorgehen unterstützten, um Japan zur Einhaltung des Neun-Mächte-Vertrages zu bewegen, setzte SaintQuentin Ende November um, als er Cordell Hull, der ihm gegenüber Deutsche und Japaner als "Barbaren" bezeichnete, und Sumner Welles ermunterte, Japan auch mit Taten, wie etwa Sanktionen, entgegenzutreten ${ }^{12}$.

$\mathrm{Zu}$ diesem Zeitpunkt hatte die französische Regierung noch nicht über Wirtschaftssanktionen gegen Japan nachgedacht. Erst Mitte Dezember erstellte die Sous-direction d'Asie-Océanie dazu eine Studie. Demnach sei die Beschränkung französischer Exporte nach Japan, vor allem von Eisenerz aus Indochina und Nickel aus Neukaledonien, sowie japanischer Exporte möglich, doch Paris könne dies nur mit britischen und amerikanischen Sicherheitsgarantien wagen. Auch London prüfte, wie schon im November 1937, Wirtschaftssanktionen, lehnte sie aber erneut ab, es sei denn, Paris und Washington nähmen teil ${ }^{13}$. Der im Januar 1939 von den Briten konsultierte Quai d'Orsay schwieg zunächst. Als Sumner Welles am 3. Februar 1939 erklärte, Washington erwäge derzeit keine Anwendung von Sanktionen, hatte sich für Paris eine Antwort erübrigt ${ }^{14}$.

Während des britisch-französischen Gipfels am 24. November 1938 sahen Bonnet und Chamberlain im gemeinsamen Auftreten mit den USA die einzige Möglichkeit, ihre Länder in Asien zu behaupten. Dieses Auftreten habe auch Folgen für Europa. Aber bisher habe sich Amerika, außer in der Frage der Jangtse-Schiffahrt, gegen die Kooperation gesträubt. Offenbar gingen London und Paris davon aus, daß ihre Strategie des Abwartens nach Konoes Kampfansage vor dem Scheitern stehe. Nur Amerikas Engagement konnte noch helfen. Berichte in Japans Presse, London und Paris wollten Tokios Vordringen auf dem Kontinent nicht aktiv entgegentreten und sich vielmehr auf den Schutz ihrer Rechte und Interessen in China beschränken, trafen den Kern ${ }^{15}$.

\footnotetext{
${ }^{12}$ China Year Book 1939, S. 448; Henry an Bonnet, T 645-46, 19.11.1938 (MAE Japon 134); Note de la sous-direction d'Asie-Océanie pour le ministre, 21.11.1938 (MAE Chine 713); Saint-Quentin an Bonnet, T 1294-99, 23.11., T 1348, 1.12.1938 (DDF XII, 363; MAEN Londres C 481).

${ }^{13}$ Note de la sous-direction d'Asie-Océanie, 21.12.1938 (MAE Japon 128); Advisory Committee on Trade Questions in Time of War, 5.11.1937 (DBFP, $2^{\text {nd }}$ series, XXI, 334); Corbin an Delbos, L 917, 13.11.1937 (MAE Chine 712); Memorandum, 16.11.1938 (FO 371/22176, F 12923/4727/61).

${ }^{14}$ Halifax an Clark Kerr, 24.11., Clark Kerr an Halifax, 10.12.1938; Halifax an Mallet, 23.1., Halifax an Phipps, 27.1., Craigie an Halifax, 12.12 .1939 (DBFP, $3^{\text {rd }}$ series, VIII, 277, 328, 440, 452, 332); Corbin an Bonnet, T 231-32, 28.1., Britische Botschaft, Note, 31.1.1939 (MAE Chine 733).

${ }^{15}$ Conversations Franco-Britanniques du 24 novembre 1938 (DDF XII, 390); Visit of Ministers to Paris. Record of the Conversations, 26.11.1938 (FO 371/21592, C 14652/13/17); Bullitt an Hull, 25.11.1938 (SD 741.51/312); Ott an Ribbentrop, 29.11.1938 (AA Botsch Paris 444 b Japan 4).
} 
$\mathrm{Ab}$ Ende November schien erneut ein Angriff auf Hainan bevorzustehen. Paris erfuhr, daß zehn Kreuzer und ein Flugzeugträger vor Hainan auffuhren und die Küste beschossen. Am 3. und 4. Dezember versuchten schwache japanische Verbände erfolglos, auf Hainan zu landen. Drei oder vier Divisionen wurden auf Taiwan für einen Einsatz in Südchina gesammelt; eine Operation im Golf von Tonkin sei sicher, falls sich die Extremisten in Tokio durchsetzten, hörte Henry. Ein ernsthafter japanischer Landungsversuch auf Hainan werde gelingen, analysierte der Generalstab in Paris. Auch Militärattaché Thiébaut, der von Tokio nach Indochina gereist war, um auf japanische Reporter einzuwirken, die reißerisch über Waffentransporte berichteten, sorgte sich. Er fürchtete, Japan lande in Pakhoi, um Indochina in einem Krieg in Europa angreifen zu können. Knobel vermutete, Tokio wolle ein Klima schaffen, in dem es jederzeit losschlagen könne. Aber um den 10. Dezember entfernten sich die Japaner von Hainan und griffen bis Mitte Januar 1939 die Küste nicht mehr $a n^{16}$. Grund dafür waren wohl geheime Konkakte der Japaner mit dem chinesischen Politiker Wang Ching-wei. Wie schon Anfang November verzichtete Paris auch bei dieser Bedrohung Hainans auf Proteste in Tokio.

Nach außen gaben sich die Franzosen selbstbewußt: Das Kolonialministerium sei sicher, daß man einen Angriff Japans auf Indochina leicht abwehren könne, versicherte Georges-Picot in Chungking seinem amerikanischen Kollegen; die meisten gemeldeten japanischen Kriegsschiffe seien Handelsschiffe, beruhigte Le Bigot den US-Konsul. Dem deutschen Konsul wurde erklärt, Japan sei keine ernsthafte Gefahr für Indochina. Wie sehr sich die Einschätzung Japans aber geändert hatte, zeigte die Marine in Paris: Sie erklärte Japan in dem regierungsamtlichen Grünbuch erstmals zur Bedrohung Indochinas ${ }^{17}$.

Gleichzeitig erhöhte Japan in Tientsin den Druck auf den Westen. Ende November nahm Japan die Evakuierung seiner Bürger aus den Konzessionen wieder auf. Am 26. November warnte London Paris, Tokio wolle gegen die Konzessionen vorgehen. Von den Konzessionen forderte Japan die Abschiebung einiger Chinesen, die Schließung chinesischer Funkstationen, die Vernichtung aller Schulbücher der Kuomintang sowie die Übergabe der in den Konzessionen eingelagerten Silberreserven der Nationalbank Chinas und die alleinige Verwendung der Währung ihres Marionettenregimes.

\footnotetext{
${ }^{16}$ Henry an Bonnet, T 662-63, 30.11.1938 (MAE Japon 123); Diplomatie an EMG.2, T 263, 26.11., T 268, 3.12., T 270-71, 5.12., T 276-77, 10.12.1938 (SHM 1 BB9 42); Jankélévitch an Knobel, T 225, 27.11., T 229, 2.12., T 234, 7.12., T 235, 9.12.1938 (MAE Chine 754); Henry an Bonnet, T 674, 9.12.1938 (MAE Chine 731); EMG.2, bulletin, 16.12.1938 (SHM 1BB2 92); SEH, renseignement, 30.12.1938 (CAOM CM 99); Knobel, Note, 5.12 .1938 (MAEN Pékin A 394); Knobel an Bonnet, T 1905-6, 8.12.1938 (MAE Chine 771); Henry an Bonnet, T 676-78, 10.12.1938 (DDF XIII, 83).

${ }^{17}$ Flood an Hull, 28.10., Peck an Hull, 23.12.1938 (SD 893.24/484, 517); Neumann an Ribbentrop, 25.12.1938 (AA Pol VIII 60 2); Marine nationale, livre vert 1939, Le Japon, S. 273f. (SHM 1BB2 98).
} 
Die französischen Diplomation waren sich uneinig, wie sie reagieren sollten. Léger schlug vor, Japan auf der Verwaltungs- oder Wirtschaftsebene entgegenzukommen. Lacoste in Peking empfahl, in wirtschaftlichen Fragen einen modus vivendi zu suchen und nur in prinzipiellen Fragen hart zu bleiben, falls Japan die Existenz der Konzessionen in Tientsin garantiere. Auch Geschäftsträger Knobel riet zum Nachgeben: Frankreich müsse entweder mit allen Konsequenzen eine entschlossene Haltung einnehmen oder aber an den Vertrag von 1907 anknüpfen. Er appellierte an Generalkonsul Charles Lépissier, mit Zugeständnissen die Beziehungen zu Japan zu verbessern und die Währung des Marionettenregimes zu akzeptieren. Léger stimmte zu und bat Lépissier, mit Japan zu kooperieren, soweit es französische Rechte erlaubten. Lépissier, dessen Rückkehr nach Frankreich bevorstand, wollte aber unnachgiebig den Status quo erhalten: Japan sei wirtschaftlich auf die Konzessionen angewiesen, zudem bewunderten die Japaner Entschlossenheit ${ }^{18}$. Légers Bitte, die neue Währung von der Konzessionsverwaltung annehmen zu lassen, ignorierte er.

Mitte Dezember 1938 eskalierte die Situation: Am 10. Dezember errichteten die Japaner Stacheldrahtverhaue um die Konzessionen, am 14. Dezember verhängten sie eine Blockade: Alle Chinesen und Japaner wurden beim Betreten und Verlassen der Konzessionen kontrolliert, die Lebensmittelversorgung wurde erschwert. Westliche Bürger konnten tagsüber ohne Kontrolle, nachts unter Vorzeigen des Ausweises die Sperren passieren. Im Londoner Unterhaus fiel das Wort, die britische Konzession sei »a Japanese concentration camp«. Knobel wurde unruhig. Am 15. Dezember forderte er Lépissier erneut zum Einknicken auf und erbat in Paris die Erlaubnis, Lépissier massiv zur Nachgiebigkeit drängen zu dürfen. Léger, der zuvor noch zum Einlenken geraten hatte, deckte nun allerdings Lépissiers Haltung.

Am 22. Dezember untersagten die Japaner den Abtransport von Müll und Särgen aus den Konzessionen. Lépissier blieb stur. Nur dort, wo sich Japans Forderungen eher gegen China richteten, gab er nach: Er ersetzte einige seiner 500 chinesischen Polizeibeamten und ließ alle Kuomintang-Bücher aus den Schulen entfernen. Den Briten riet er, Chinesen, die Anschläge verübt hatten, abzuschieben oder auszuliefern. Lépissiers feste Haltung und die Äußerung des britischen Botschafters, er sei für Härte gegenüber Japan, ließen Ende Dezember auch Knobel auf den robusten Kurs einschwenken. Zum Jahresende entspannte sich Japans Haltung etwas, als Briten und Franzosen versprachen,

${ }^{18}$ Knobel an Bonnet, T 1798, 23.11., T 1821-22, 25.11., T 1896-1906, 8.12., Léger an Knobel, T 678-80, 28.11., Lacoste an Knobel, L 652, 29.11.1938 (MAE Chine 771); aide-mémoire der britischen Botschaft, 26.11., Knobel an Clark Kerr, L, 2.12., Knobel an Bonnet, T 1872-75, 3.12., T 1886-90, 8.12., T 1957-61, 15.12., Lacoste an Knobel, T 539-43, 6.12., Tenshin Nippo, Le départ de M. Lépissier, 6.12.1938 (MAE Chine 830); Léger an Knobel, T 712, 12.12.1938 (MAE Chine 770). 
mit der japanischen Polizei zusammenzuarbeiten. Japans Geheimdienst, in Einzelfällen auch Japans Gendarmerie, durfte in der französischen Konzession kontrollieren. Im Februar 1939 schrieben Zeitungen, die französische Polizei habe Japan bei der Festnahme »antijapanischer Propagandisten « unterstützt ${ }^{19}$.

Ein Grund der Entspannung war die Berufung neuer japanischer Befehlshaber. Der Garnisonskommandeur in Tientsin, General Homma Masahuru, der Militärattaché in London gewesen war, und der in Nordchina kommandierende General Sugiyama lobten das Vorgehen der Konzessionen gegen »antijapanische Elemente«. Sugiyama suchte den Kontakt zum neuen französischen Kommandeur Henri Casseville. Er erinnerte an den gemeinsamen Kampf im Weltkrieg, sagte aber auch, er dulde keine Aktivitäten von Guerillas aus den Konzessionen. Der japanische Generalkonsul Tashiro und drei Mitarbeiter besuchten Lépissier zum Abendessen, General Sugiyama gab einen Empfang für ausländische Kommandeure. Französischen und japanischen Offizieren war es gelungen, an ihre entente, wie sie vor der Sudetenkrise geherrscht hatte, anzuknüpfen. Am 8. Februar hob das japanische Militär die Kontrollen in Tientsin auf und begründete dies damit, britische und französische Behörden hätten bei der Schaffung von Ordnung große Fortschritte gemacht. Doch durch die Blockade hatten auch japanische Firmen große Einbußen erlitten ${ }^{20}$.

Die Fertigstellung eines Elektrozauns um die Konzessionen am 20. Februar und die Ankündigung von Währungskontrollen für den 10. März zeigten, daß Japans Militär dennoch neue Zwangsmaßnahmen plante. Knobel, der gerade in Tientsin gewesen war, riet, einen modus vivendi mit Tokio auszuhandeln. Ohne aktuelle Bedrohung wartete Paris nur ab. Ende Januar 1939 protestierten die drei westlichen und Anfang März der britische und der französische Botschafter in Tokio gegen das japanische Verhalten in Tientsin ${ }^{21}$.

\footnotetext{
${ }^{19}$ SHAI, Origins of the War, S. 213; Knobel an Bonnet, T 1923-26, 11.12., T 1975-79, 15.12., T 2002-6, 19.12.; T 2010-11, 20.12., Havas, 15.12.1938 (MAE Chine 771, 830); Delsuc an Folliot, T 780, 15.12.1938 (SHAT 11 H 60); Knobel an Bonnet, T 2039-40, T 2043-45, 24.12., T 2048-52, 26.12., T 2076, 29.12.1938, Léger an Knobel, T 5, 6.1.1939 (MAE Chine 772); Knobel an Bonnet, T 2041-42, 24.12., Lacoste an Knobel, L 688, 27.12.1938 (MAE Chine 799, 830); Jamieson an Halifax, 28.12.1938 (DBFP, $3^{\text {rd }}$ series, VIII, 374); STS-bulletin, 22.1.1939 (MAE Chine 534); Lépissier an Knobel, L 1, 2.1., Lépissier an Bonnet, L 4, 9.1., L 13, 21.2.1939 (MAE Chine 732, 831).

${ }^{20}$ Lacoste an Knobel, T 11-12, 11.1., Knobel an Bonnet, T 45-48, 11.1., T 191-97, 14.2., T 199, 15.2., T 212-13, 17.2., Lépissier an Bonnet, L 9, 16.2.1939 (MAE Chine 831); Knobel an Bonnet, T 72-73, 14.1.1939 (MAE Japon 128); Note, Casseville, 19.1., Casseville an Mandel, L 17, 8.2., FTFC, EM.2, réunion des intelligence officers, 3.1., 7.2., 21.2.1939 (SHAT 11 H 63); FNEO, compte rendu, 1.2., 1.3.1939 (SHM 1 BB4 74); Lacoste an Knobel, L 33, 23.1.; Léger an Corbin, T 212-14, 8.2., Lacoste an Bonnet, T 35-36, 9.2.1939 (MAE Chine 563, 772); WATT, How War Came, S. 351.

${ }^{21}$ Knobel an Bonnet, T 256 S, 22.2., T 269-70, 24.2., T 300-2, 28.2., L 74, 25.2.1939 (MAE Chine 772, 837, 1070, MAEN Tokyo B 78); Henry an Bonnet, T 59, 30.1., Knobel an Bonnet, T 308, 2.3.1939 (MAE Chine 831); Léger an Henry, T 113, 1.3.1939; Henry an Bonnet, $T$ 135, 4.3.; STSbulletin, 1.3.; Lacoste an Knobel, T 154-55, 1.3.1939 (MAE Chine 772, 534, 884).
} 
Frankreichs Lage in Asien hatte sich von Mitte Oktober bis Mitte Dezember dramatisch verändert: Japan verstärkte seine Truppen in Südchina und drohte, Hainan und die Yunnanbahn anzugreifen. Die Blockade in Tientsin ließ daran zweifeln, ob Japan die Rechte der Mächte in China weiter respektierte. Konoe hatte eine Neue Ordnung verkündet und damit, wie Grew feststellte, nicht einmal mehr die Fiktion des Neun-Mächte-Vertrages und der Offenen Tür in China aufrechterhalten. Paris blieb nun kaum eine andere Wahl, als enge Tuchfühlung zu den USA zu halten, ohne sich gegenüber Japan zu exponieren. Am 16. Dezember betonte Bonnet im Parlament die Solidarität der Interessen Frankreichs, Großbritanniens und der USA in Asien. Die drei Regierungen lehnten einseitige Änderungen der Washingtoner Ordnung ab. Am 2. Dezember hatte das Foreign Office Paris erklärt, die USA seien geneigter als früher, gegenüber Japan energisch aufzutreten. Die Direction politique nahm an, vermutlich werde Washington China finanzielle Hilfe leisten. Gemeldet wurde, die USA hätten China 1000 Lastwagen auf Kredit verkauft. Doch Paris blieb vorsichtig. Als der japanische Außenminister Arita am 19. Dezember erklärte, Extraterritorialität und Konzessionen gehörten zur alten Ordnung, die abgeschafft werde, blieb Frankreich stumm. Während der britische und der amerikanische Botschafter Arita um Erläuterungen baten, der nun versicherte, Japan respektiere die Rechte der Mächte, verzichtete Paris auf Nachfragen ${ }^{22}$.

Weitere Schritte der USA beobachtete Paris vorsichtig. Die US-Regierung teilte am 15. Dezember mit, sie gewähre China einen Kredit über 25 Millionen Dollar. Weihnachten 1938 kündigte Sumner Welles Botschafter Naggiar bei dessen Rückreise nach Europa an, Amerika helfe China stärker wirtschaftlich und übe auf Japan ökonomischen Druck aus. Ohne London und Paris zuvor zu informieren, protestierte Washington am 31. Dezember 1938 gegen die Beschränkung des US-Handels in China und gegen Japans Abkehr vom NeunMächte-Vertrag. Erst auf massive Bitten der Briten, die am 14. Januar 1939 eine eng an das US-Papier angelehnte Note im Gaimusho abgegeben hatten, schloß sich Paris am 19. Januar dem US-Protest an. Die drei Regierungen betonten die Gültigkeit des Washingtoner Vertrages, zeigten sich aber bereit, mit Japan über eine Veränderung der Ordnung zu reden ${ }^{23}$.

\footnotetext{
${ }^{22}$ Palasse an EMA.2, L 531, 13.1.1939 (SHAT 7 N 3123); Grew an Hull, 2.12.1938 (FRUS 1938 III, S. 403f); Corbin an Bonnet, T 3101, 2.12.1938 (MAE SDN 365); Note de la Direction des affaires politiques et commerciales, 5.12., Knobel an Bonnet, T 1933-35, 12.12.1938 (MAE Chine 731); Knobel an Bonnet, T 1967, 15.12.1938; Paroles sur politique en Extrême-Orient, pour déclaration de G. Bonnet à la Chambre, 16.12.; Havas Tokio, 19.12., 27.12.1938 (MAE Chine 677, 732).

${ }^{23}$ Saint-Quentin an Bonnet, T 1435-38, 25.12.1938, T 4-7, 3.1.1939 (DDF XIII, 224, 266); Halifax an Craigie, 5.1., Phipps an Halifax, 13.1., 14.1.1939 (DBFP, $3^{\text {rd }}$ series, VIII, 395, 418, 422); Corbin an Bonnet, T 63-64, 6.1.1939 (MAE Japon 132); KING, China and the League, S. 93; Note de la sousdirection d'Asie-Océanie, 9.1.; Léger an Henry, T 18-21, 14.1., T 12, 9.1.1939 (DDF 326, 365; MAE Chine 760); Direction politique an britische Botschaft, Note, 14.1.1939 (MAE Chine 733).
} 
Henry hatte die Übergabe der Note verzögert, um die Wirkung in Tokio abzuschwächen. Japans Presse reagierte feindselig auf den britischen Protest, während sie die französische Kritik herablassend bewertete. Ein Sprecher des Gaimusho sagte, man sehe die Note als unbedeutende Geste Frankreichs, der Führung Amerikas und Englands zu folgen. Auch Bonnet blieb am 26. Januar vor der Kammer vorsichtig. Er lobte den heroischen Kampf Chiang Kai-sheks und seiner Armeen. Damit wiederholte Bonnet nur die Formulierung, die er im Mai 1938 vor dem Völkerbund verwandt hatte. Bonnet verkniff sich sogar, die im Redeentwurf seiner Beamten enthaltene "l'admiration du peuple français entier« für Chinas Kampf auszudrücken. Im Mai hatte Bonnet noch gesagt, der chinesische Heroismus verdiene die Bewunderung der ganzen Welt. Zugleich schloß Bonnet eine Intervention in Asien, wie sie etwa die kommunistische Zeitung »Humanité « forderte, kategorisch aus ${ }^{24}$.

$\mathrm{Daß}$ sich Paris zurückhielt, lag auch daran, daß Frankreichs und Japans Außenministerien seit Mitte Dezember 1938 um das Agrément für den von Tokio als neuen Botschafter vorgeschlagenen Diplomaten Tani rangen. Botschafter Sugimura Yatoro war im Dezember 1938 nach Tokio zurückbeordert worden, aus Gesundheitsgründen, wie es hieß. Sugimura starb im März 1939. Die Pariser Presse schrieb, Sugimura habe aus Protest gegen die pro-deutsche Politik um seine Abberufung gebeten. Am 6. Dezember bat Tokio um die Zustimmung zur Ernennung des Geschäftsträgers in China, Tani Masayuki, zum Botschafter in Paris. Tani war von 1918 bis 1923 Botschaftssekretär in Paris gewesen. Von 1930 bis 1933 war er als Asiendirektor im Gaimusho mit dem französisch-japanischen Nachrichtenaustausch befaßt. Naggiar nannte ihn einen Mann, mit dem man sich verständigen könne, Knobel bezeichnete ihn als gemäßigten Diplomaten ${ }^{25}$. Der Quai d'Orsay hätte zufrieden sein können.

Henry hatte Léger aber über eine frühere Äußerung Tanis informiert. Tani hatte am 25. Juni 1938 gegenüber Domei erklärt, in China rede man wenig über französische Hilfe, über die in Tokio soviel Lärm gemacht werde. Nach Kritik der Zeitung "Yamato« und unter Druck des Militärs äußerte Tani zwei Tage später bei Domei, es gebe Beweise für Frankreichs Hilfe an China. Beide Aussagen wurden von keiner Zeitung verbreitet. Henry verteidigte Tani, dieser

\footnotetext{
${ }^{24}$ Henry an Bonnet, T 16-18, 11.1.1939 (DDF XIII, 335); G-2 Digest of Information, 27.1., Grew an Hull, 9.2., 10.2.1939 (SD 793.94/14658, 14681, 751.94/75); Craigie, Political Diary, 14.2.1939 (FO 371/23567, F 2678/874/23); Chauvel an Saint-Quentin, T 99-103, 16.1., Chauvel an Henry, T 29, 18.1., Henry an Bonnet, T 36, 19.1., T 49-51, 25.1.1939 (MAE Chine 760); China Year Book 1939, S. 452; Note pour le ministre (en vue d'un discours à la Chambre), 18.1., STS-bulletin, 1.2.1939 (MAE Chine 733, 534); Mack an Halifax, 28.1.1939 (FO 371/22912, C 1183/90/17).

${ }^{25}$ Henry an Bonnet, T 665-66, 6.12.1938 (MAE Japon 128); Secrets nippons, L'Ordre, 14.12.1938 (AA Botsch Paris 444 b, Japan. 4); A. de Lens, Note pour M. Tani, 19.7.1933 (MAE Tokyo B 76); KLUGER, Les relations, S. 48; Knobel an Bonnet, T 1896-1906, 8.12.1938 (MAE Chine 771).
} 
habe sich aus Angst um sein Leben korrigiert und bleibe ein ausgezeichneter Botschafter. Vize-Außenminister Sawada Renzo kam in die französische Botschaft, um für Tani zu werben. In Shanghai sprach Tani mit Knobel.

Frankreich könne Tani nicht akzeptieren, urteilten Léger und Hoppenot, der trotz seines Wechsels in die Europaabteilung mitberiet. Tani habe die Pressekampagne gegen Paris unterstützt und Dementis der französischen Regierung widersprochen. Einen Diplomaten zu akzeptieren, der sich falsche Behauptungen zu eigen gemacht habe, schwäche Frankreich. Am 15. Dezember entschieden Staatspräsident Lebrun und Bonnet, Tani die Zustimmung zu verweigern. Die Entsendung eines Diplomaten, der unwahre Vorwürfe gegen Frankreich unterstützt habe, zerstöre das Vertrauen zwischen der französischen Regierung und Japans Botschaft. Dies sei auch eine Frage der Würde. Mit zwei weiteren Besuchen bei Henry versuchte Vize-Außenminister Sawada Ende Dezember vergeblich, die Franzosen umzustimmen. Henry und Léger schlugen vor, Tani solle seine Aussage öffentlich widerrufen, aber das lehnte Sawada $\mathrm{ab}^{26}$.

In Paris bemühte sich Geschäftsträger Miyasaki am 24. Januar letztmals um Légers Zustimmung. Zwei Tage später berichtete die »Japan Times«, das Blatt des Außenministeriums, von der Verzögerung des Agréments. Zeitungen wie »Nichi Nichi«, "Yomimuri« und »Kokumin« griffen Paris heftig an: Frankreich beschädige die Beziehungen zu Japan. Extremistische Blätter forderten die Besetzung Hainans. Henry glaubte, nationalistische Diplomaten hätten die Affäre bekanntgemacht, um einen schärferen Kurs zu erzwingen ${ }^{27}$.

Da Mitte Januar 1939 die französisch-italienischen Beziehungen höchst gespannt waren und ein deutscher Angriff auf die Niederlande möglich schien, wollte Bonnet den Streit mit Japan ausräumen. Er legte Léger nahe, Tani zu akzeptieren. Léger lehnte ab. Als Kompromiß schlugen Bonnet und Léger Tokio vor, auf Nachfrage dürfe Paris erklären, daß Tani die französischen Erklärungen für aufrichtig halte. Dies lehnte Außenminister Arita ab. Gegenüber Botschafter Ott nannte das Gaimusho die Lage »völlig verfahren«. Ende März bemühte sich Bonnet erneut, die Frage zu lösen, was Japan mit der SpratlysAnnexion durchkreuzte. Japans Botschaft verletzte Tanis Zurückweisung ${ }^{28}$.

\footnotetext{
${ }^{26}$ Henry an Bonnet, T 665-66, 6.12., T 675, 9.12., T 684-86, 15.12., T 687, 16.I2., T 688-89, 18.12., T 701, 22.12., T 715, 25.12.1938 (MAE Japon 128); Knobel an Bonnet, T 1982-88, 16.12.1938 (MAE Chine 769); Note, l'affaire Tani, ohne Datum (MAE PAAP Hoppenot 3); Hoppenot an Henry, T 470, 8.12., Note de la sous-direction d'Asie-Océanie, 14.12., Bonnet an Henry, T 479-81, 15.12., T 498, 23.12.; Léger an Henry, T 482-84, 15.12.1938, T 37-38, 27.1.1939 (MAE Japon 128).

${ }^{27}$ Henry an Bonnet, T 66-68, 2.2., L 9, 26.1., notes de la sous-direction d'Asie-Océanie, 1.2.; 24.1.1939 (MAE Japon 128, Chine 733); Grew an Hull, 27.1.1939 (SD 701.9451/19); BunkER, Peace Conspiracy, S. 126.

${ }^{28}$ Note, remise par M. Léger, 2.2.; Bonnet an Henry, T 54-58, 7.2., Henry an Bonnet, T 97-99, 14.2.1939 (MAE Papiers 1940, cabinet Bonnet 8, Japon 128); Ott an Ribbentrop, 14.3.1939 (ADAP IV, 549); Bonnet an Henry, T 159-61, 28.3.; EM-Col.2, 9.8.1939 (MAE Japon 123, SHAT 7 N 3304).
} 
Warum wählte Léger eine konfrontative Strategie in einer scheinbar nebensächlichen Frage? In einer Aufzeichnung schrieb er, ohne militärische Mittel habe Paris seine Position in Asien allein mit einer Haltung der Würde und der Entschlossenheit verteidigt.

Cette attitude, inspirée par l'expérience de la psychologie asiatique, nous a assuré le respect de nos intérêts et nous a valu dans tout l'Extrême-Orient un prestige moral que la presse anglo-saxonne, à maintes reprises, a signalé avec envie.

In der Tani-Frage Schwäche zu zeigen, gefährde Frankreichs Position und führe zu weiteren Erpressungen. Sugimura habe ihm vor der Abreise vertraulich erklärt, eine Zustimmung zu Tani sei mit Frankreichs Ehre unvereinbar ${ }^{29}$. Aus Gründen des Prestiges suchte der Generalsekretär den Streit mit Tokio und trat deshalb in anderen Fragen besonders zurückhaltend auf.

Deutlich wurde dies im Völkerbund: In der Ratssitzung am 17. Januar 1939 bemühte sich Wellington Koo um ein Embargo über Flugzeuge und Benzin gegen Japan sowie die Zusage von Wirtschafts- und Finanzhilfe und Transitmöglichkeiten für China. Am 18. und 19. Januar überzeugten ihn Émile Charvériat, der Leiter der Direction politique am Quai d'Orsay, und der britische Staatssekretär Butler, die Anträge zurückzuziehen. Allerdings ließen es sich Koo und der Neuseeländer Jordan nicht nehmen, Frankreichs Transitpolitik, ohne Paris direkt zu nennen, am 20. Januar im Rat öffentlich zu kritisieren. Die Resolution des Rates wiederholte nur frühere Beschlüsse. Auf Chinas Wunsch wurde die Formel aufgenommen, daß China Japans Anspruch, eine neue Ordnung für Asien zu schaffen, zurückweise. Der Rat enthielt sich eines Urteils über die Konoe-Erklärung. Charvériat wiederholte frühere französische Erklärungen: Frankreichs Öffentlichkeit sehe bewegt, mit wie viel Heroismus und Entsagung China die Leiden des Krieges ertrage. Frankreich werde sich an der Hilfe für China wie bisher so weit wie möglich beteiligen ${ }^{30}$. In Paris war die Bereitschaft, China praktisch zu helfen, nicht gestiegen.

Auch die unklare Lage in China, wo es zur Jahreswende 1938/1939 Anzeichen für Frieden gab, ließ Vorsicht ratsam erscheinen. Vize-Militärattaché Guillermaz hatte gehört, Japan wolle aus den Marionettenregimes in Peking und in Nanking eine Nationalregierung bilden. Gerüchten zufolge führte Japan mit Chiang Kai-shek und anderen Gruppen in China Friedensgespräche ${ }^{31}$.

\footnotetext{
${ }^{29}$ Note, remise par M. Léger, 2.2.1939 (MAE Papiers 1940, cabinet Bonnet 8).

${ }^{30}$ Procès-verbal, $104^{\circ}$ session du conseil, $3^{e}$ séance, 17.1., $5^{e}$ séance 20.1.1939 (JO-SDN, S. 66-69, S. 90-93); Arnal an Bonnet, T 13, 17.1., T 24-26, 18.1., T 30, 20.1.1939 (MAE Chine 663); Arnal an Bonnet, T 28, 19.1.1939 (MAE SDN 368); UK-Delegation an Halifax, 19.1.1939 (DBFP, $3^{\text {rd }}$ series, VIII, 434); Amal an Bonnet, T 33, 20.1.1939 (MAE Chine 760); C.57.1939.VII, appel du gouvernement chinois, projet de résolution, 20.1., lettre circulaire de la sous-direction de la SDN, 10.2.1939 (MAE SDN 368).

${ }^{31}$ Guillermaz an Daladier, N 127, 8.12., Henry an Bonnet, T 690-95, 19.12.1938 (DDF XIII, 68, 174).
} 
Die chinesisch-japanischen Beziehungen wurden noch undurchsichtiger, als der chinesische Politiker Wang Ching-wei im Dezember 1938 nach Hanoi flüchtete. Wang, prominentester Kuomintang-Politiker nach Chiang Kai-shek und Führer des linken Parteiflügels, war von 1933 bis 1935 Außenminister und 1935 elf Monate lang Premierminister gewesen. Ende 1938 war er Parlamentspräsident und Vize-Vorsitzender der Kuomintang, aber von der Macht ausgeschlossen. Als Chiangs Heer beim Abzug Wangs Heimatstadt Kanton verwüstete und die Münchener Konferenz zeigte, daß China vom Westen keine Hilfe zu erwarten hatte, unternahm Wang einen neuen Versuch, mit Japan Frieden zu schließen ${ }^{32}$. Japans Armee, die während des gesamten Krieges Geheimkontakte zu führenden chinesischen Politikern hielt, bot Wang Frieden an. Wang solle in neutrales Gebiet reisen und dort auf die Bekanntgabe der japanischen Bedingungen reagieren. Am 19. Dezember kamen Wang und einige Gefolgsleute mit dem Flugzeug in Hanoi an ${ }^{33}$. Daß Wang, der in Hanoi striktes incognito bewahrte, sich für Indochina entschied, mag an Frankreichs japanfreundlicher Politik gelegen haben, vor allem aber war von Chungking aus Indochina das am einfachsten zu erreichende neutrale Gebiet. Zudem war Wang französisch erzogen, er hatte in Frankreich sechs Jahre - von 1912 bis 1917 und von März 1926 bis April 1927 gelebt - und verstand Französisch ${ }^{34}$.

Ministerpräsident Konoe erklärte am 22. Dezember im Radio, Japan werde China unter einem neuen Regime volle Souveränität gewähren. Japan verzichte auf Reparationen und respektiere Chinas Territorium. Doch Konoe verlangte auch die Anerkennung der japanischen Herrschaft in Mandschukuo und anderen Teilen Chinas. Japan erwarte, daß die neue Regierung die extraterritorialen Rechte und die Konzessionen abschaffe. Während das Foreign Office die Vorschläge als Akt der Hegemonialpolitik bewertete, nannte Henry sie gemäßigt. Die Zerrissenheit der japanischen Führung werde die Friedensgespräche aber scheitern lassen. Wenig später stürzte Konoes Regierung ${ }^{35}$. Chiang wies am 27. Dezember Konoes Bedingungen zurück. Wang spreche nicht für Chinas Regierung. Wang begrüßte Japans Bedingungen. Am 1. Januar 1939

\footnotetext{
${ }^{32}$ KIndermann, Der Ferne Osten, S. 391; John King Fairbank, China. A New History, Cambridge MA, London 1992, S. 283; BIANCO, La Chine dans la guerre, S. 201; MONTGOMERY, Imperialist Japan, S. 407; STS-bulletin, 22.1.1938 (MAE Chine 534).

${ }_{33}$ Gerald E. BunKer, The Peace Conspiracy: Wang Ching-wei and the China War, 1937-1941, Cambridge (MA) 1972, S. 3, S. 57f., S. 109f.; zu Wangs Zeit in Hanoi: John Hunter BoYLE, China and Japan at War, 1937-1945. The Politics of Collaboration, Stanford 1972, S. $206 \mathrm{f}$.

${ }^{34}$ Knobel an Bonnet, T 2073-74, 28.12.1938 (MAE Chine 732); LU, From the Marco Polo Bridge, S. 79; ShIGEMITsU, Schicksalsjahre, S. 169; BoYLE, China and Japan, S. 20; MARTIN, Il faut comprendre la Chine, S. 134.

${ }^{35}$ Havas, la politique, 23.12.1938 (MAE Chine 732); Corbin an Bonnet, T 3238, 23.12., Henry an Bonnet, T 710-13, 24.12., T 722-25, 31.12.1938, T, 5.1.1939 (DDF XIII, 213, 217, 255, 290).
} 
wurde er aus der Kuomintang ausgeschlossen, schärfere Maßnahmen, die eine Versöhnung unmöglich gemacht hätten, verhängte Chiang nicht ${ }^{36}$.

Knobel und der neue Leiter der Asienabteilung, Jean Chauvel, hielten den Bruch zwischen Chiang und Wang für glaubhaft. Japanische und chinesische Zeitungen in Shanghai spekulierten aber über ein geheimes Einverständnis der beiden. Auch Brévié nahm an, Chiang wolle Wang als Friedensunterhändler einsetzen. Der rege Telegramm- und Briefwechsel zwischen ihnen und das rege Pendeln von Politikern zwischen Chungking und Hanoi paßten nicht zum Bild eines Zerwürfnisses. Für Englands Geheimdienst galt Wang bis Ende April 1939 als Emissär Chiangs, auch deshalb, weil Chiang im Januar die Ausstellung eines britischen Visas für Wang gebilligt hatte. John Hunter Boyle glaubt, daß Wang zumindest mit Chiangs Kenntnis nach Hanoi kam, Brian Crozier verweist darauf, daß Wang ohne Chiangs Zustimmung Chungking gar nicht hätte verlassen können. Wang selbst sah sich als Vermittler und Brücke zwischen Chiang und Japan. Auch Konoe betrachtete ihn so ${ }^{37}$.

Obwohl es in Indochinas Kolonialverwaltung nach Beobachtung des USKonsuls Sympathien für Wang gab, unterblieb doch jeder Kontakt. Die Behörden legten ihm zudem den Verzicht auf jede politische Aktivität nahe. Das Auswärtige Amt in Berlin verbot seinem Konsul Kontakte zu Wang, auch Tokio blieb auf Distanz. Politisch isoliert, bemühte sich Wang Ende Januar um Visa für Frankreich, Großbritannien und Deutschland ${ }^{38}$. Chiang ließ am 21. März 1939 ein Attentat auf Wang verüben, bei dem jedoch nur dessen Sekretär getötet wurde. Als die Briten seine Aufnahme in Hongkong ablehnten, fuhr Wang in Frankreichs Konzession in Shanghai, wo er ein Haus besaß. Auf französischen Druck zog er in den japanischen besetzten Teil Shanghais um ${ }^{39}$.

${ }^{36}$ Brévié an Mandel, T 1481-82, 23.12., Knobel an Bonnet, T 2064-65, 27.12.1938, T 6-7, 2.1.1939 (DDF XIII, 214, 232, 261); Lockhart an Hull, 14.1.1939 (SD 793.94/14812); Havas, Ouang Tsing Ouei approuve les conditions, 30.12.1938 (MAE Chine 732); CHINA HANDBOOK 1937-1945, S. 710.

${ }^{37}$ Knobel an Bonnet, T 1, 1.1., T 17-19, 4.1.1939, mit Anmerkung Chauvel (MAE Chine 732); Knobel an Bonnet, T 2-5 S, 2.1.1939 (DDF XIII, 260); Neumann an Ribbentrop, 14.1., 30.1.1939 (AA Pol VIII 60 2); BUNKer, Peace Conspiracy, S. 123f.; Peck (Chungking) an Hull, 30.1.1939 (793.94/14651); Boyle, China and Japan, S. 212, S. 220; CrozIER, The Man who Lost China, S. 212.

${ }^{38}$ Flood an Hull, 24.2.1939 (SD 793.94/14747); Mandel an Bonnet, L 399, 18.3.1939 (MAE Chine 734); Vermerk Pol VIII, 679/39, 9.5.1939 (AA Pol VIII 60 2); Brévié an Mandel, T 111, 26.1.1939 (CAOM FM Tel 80); BUNKER, The Peace Conspiracy, S. 125.

39 Bunker, Peace Conspiracy, S. 130f.; CrozIER, The Man who Lost China, S. 216f.; Chauvel an Henry, T 153, 23.3.; Knobel an Bonnet, T 452, 2.4., T 461-67, 4.4., Brévié an Mandel, T 547, 4.4.1939 (MAE Chine 734, 735); Walsh an Halifax, 24.4., 20.5.1939 (FO 371/22921, C 6776, 7743/249/17); Colonial Office, note, 22.4.; Clark Kert an Halifax, 24.4.1939 (FO 371/23444, F 3904, F 4404/ 69/10); Cosme an Bonnet, T 558, 28.4., T 640-44, 18.5., Léger an Cosme, T 191-92, 19.5.1939 (MAE Chine 805); Brévié an Mandel, T 804, 9.5.1939 (CAOM FM Tel 80); Cosme an Bonnet, T 29-30, 17.6., T 40, 21.6.1939 (MAE Chine 736). Im Juni 1939 wollte Wang in Italiens Konzession in Tientsin umziehen. Rom stimmte zu, doch Japan widersetzte sich dem Plan (Taliani an Ciano, 30.5., 12.6., 29.6., Auriti an Ciano, 17.6.1939, DDI Serie 8, XII, 58, 194, 394, 258). 
$\mathrm{Da}$ sich Paris China annäherte, zeigte die Berufung des neuen Botschafters: Paul-Émile Naggiar hatte Shanghai nur selten verlassen und damit die große Bedeutung der Konzessionen für Frankreich, aber auch eine nicht nur räumliche Distanz zu Chinas Regierung signalisiert. Sein Nachfolger Henri Cosme reiste bei Amtsantritt im März 1939 über Indochina direkt nach Chungking, um sein Beglaubigungsschreiben zu überreichen. Daß Cosme Frankreichs Privilegien nicht aufgeben wollte, demonstrierte er vor Übergabe des Schreibens, als er demonstrativ das in Chungking liegende französische Kanonenboot Balny und die Commandant-Odent-Kaserne der französischen Marine 30 Meter über dem Jangtse besuchte. Der Besuch deutete an, daß Frankreich bereit war, Chinas Regierung mehr Gewicht beizumessen als bisher. Paris hatte Cosme angewiesen, sein Hauptquartier in Shanghai aufzuschlagen, doch so oft wie nötig nach Chungking zu reisen. $\mathrm{Da} \beta$ die Chinesen sahen, daß sie von den Konzessionen profitierten, erleichterte seine Arbeit. Chinas Regierung beklagte sich bei Cosme nur über die geringe Hilfe der Franzosen. Die Japaner hingegen begrüßten Cosme in Shanghai kühl ${ }^{40}$.

Um das prekäre Gleichgewicht zwischen Japan und China mitsamt seinem mächtigen Freund USA zu halten, hatte sich Cosme, wie er in den Memoiren schreibt, vorgenommen, eine Doppelstrategie zu verfolgen:

[M]énager la Chine et éviter par là d'indisposer les États-Unis; composer avec le Japon et ne lui donner aucun prétexte à bousculer les intérêts considérables mais fragiles que nous possédons en Asie. Politique sans grandeur, peut on dire; politique nécessaire, repondrai-je, puisque nous étions en Extrême-Orient sans force militaire, sans marine, sans moyens d'aucune sorte et qu'en Europe les menaces de guerre étaient telles que nous ne pouvions envisager sérieusement l'éventualité d'une aventure orientale.

Die französische Politik, möglichst oft mit den USA und Großbritannien aufzutreten, aber zu zeigen, daß Paris Japans Expansion duldete und China nicht gegen Japan unterstütze, hatte sich bewährt, wie der deutsche Konsul in Hanoi anerkannte. Paris habe es verstanden,

allen Schwierigkeiten in Ostasien geschickt aus dem Weg zu gehen. Darüber hinaus ist es Frankreich noch gelungen, seine Einflußsphäre in den Indochina benachbarten chinesischen Gebieten zu sichern und seine Stellung durch die Neutralisienung Hainans gegen das Versprechen einer Bagatelle [Verbot des Waffentransits] noch weiter zu festigen ${ }^{41}$.

\footnotetext{
${ }^{40}$ ANTIN DE VAILLAC, Les canonnières, S. 61, S. 85; Diplomatie an Colonies, L 74, 19.1.1939 (MAE Indfr 24); Diplomatie an Knobel, T 20, 19.1., Cosme an FNEO, T 885, 7.3.1939 (MAEN Pékin A 106 bis); Peck an Hull, 11.3.1939 (FRUS 1939, III, S. 743).

${ }^{41}$ COSME, Chine 1939-1944, S. 6; Neumann an Ribbentrop, 25.12.1938 (AA Pol VIII 60 2).
} 


\subsection{Japan besetzt Hainan und annektiert die Spratlys}

Die Grundpfeiler der französischen Fernostpolitik wurden erschüttert, als am 10. Februar 1939 in Paris Meldungen über die Landung japanischer Truppen auf Hainan eingingen. Für Frankreich hatte die Insel große strategische Bedeutung, die der Marine-Geheimdienst mit "la Rhénanie de l'Extrême-Orient« umriß: Hainan war das Sprungbrett für einen Angriff auf Indochina.

Französische Zeitungen, vor allem "L'Humanité«, "Le Populaire«, "L'Euvre«, "L'Ordre« und "L'Époque«, die die Politik des apaisement bekämpften, stellten die Besetzung heraus und nannten sie den jüngsten Vormarsch des Antikomintern-Blocks. Gazetten der Rechten forderten Wachsamkeit. Blätter in Indochina warnten, Frankreichs Prestige und Interessen in Asien drohten, irreparablen Schaden zu nehmen ${ }^{42}$.

In Paris tobte Georges Mandel. Er verlangte von Generalgouverneur Brévié Erklärungen, warum die französischen Geheimdienste und Behörden in Asien von der Vorbereitung der Invasion nichts erfahren hatten. Der Quai d'Orsay sollte darlegen, was er für den Schutz Hainans getan habe. Brévié erklärte, daß man einen Angriff auf Kwangtung erwartet habe. Die japanischen Kapitäne hätten erst im letzten Moment das Ziel erfahren. Mandel ärgerte sich, weil die Pariser Zeitungen am 10. Februar die Nachricht von der Landung gedruckt hatten, ehe er davon wußte. Um Indochina sorgte sich Mandel nicht. Erst am 19. oder 20. Februar regte er Mobilisierungen an. Brévié hatte aber bereits am 10. Februar alle Garnisonen an der Nordgrenze auf Kriegsstärke gebracht ${ }^{43}$.

Doch es gab Indizen für die Landung. Ab dem 10. Januar verstärkte Japans Marine die Präsenz um Hainan und beschoß das Festland. Die Chinesen erwarteten eine japanische Landung in Pakhoi, fast alle Einwohner wurden evakuiert. Am 18. Januar setzte Japans Flotte Leuchtbojen in der Meerenge aus. Der Marine-Geheimdienst und Geschäftsträger Knobel hielten einen Vorstoß in Südchina dennoch für unwahrscheinlich, da Tokio gerade erst Truppen von Taiwan in die Mandschurei verlegt habe. Auch Militärattaché Thiébaut und Luftwaffenattaché de La Ferté Sénèctere rechneten mit Aktivitäten gegen die Sowjets. Allein Konsul Royère in Longtchéou wies am 1. Februar auf andauernde Gerüchte einer japanischen Landung in Pakhoi hin. Der französischen Regierung erschien die Lage in Südchina so stabil, daß sie am 19. Januar den

${ }^{42}$ STS-bulletin, 1.3.1939 (MAE Chine 534); Pingaud an Bonnet, T 2; Henry an Bonnet, T 79, 10.2.1939 (MAE SDN 366); Rosati an EMG.2, T 143, 10.2.1939 (SHM 1 BB9 43); Bullitt an Hull, 11.2.1939 (FRUS 1939, III, S. 104); Southard an Hull, 14.2.1939 (SD 793.94/14710).

${ }^{43}$ Charvériat an Mandel, T 36, 11.2.1939 (MAE Japon 128); Brévié an Mandel, T 201-4, 10.2., T 207, T 209, 11.2., T 220-22, 13.2., T 235-42, 14.2., T 245-49, 15.2., T 295-97, 20.2., T 391, 8.3.1939 (CAOM FM Tel 80). 
Kreuzer Primauguet aus Shanghai nach Europa beorderte. Am 2. Februar erhielt Henry in Tokio von einem Japaner den vertraulichen Hinweis, derzeit werde eine Operation gegen Hainan vorbereitet. Nach dem Scheitern japanisch-chinesischer Geheimverhandlungen in Macao und dem massierten Auftauchen japanischer Kriegsschiffe vor Pakhoi erwarteten der Quai d'Orsay und die Armeeführung eine neue Offensive Japans um Kanton. Brévié bat Marine und Luftwaffe um die Entsendung von Beobachtern in die Nähe Hainans; das Militär sah sich aber nicht in der Lage, dem Wunsch Folge zu leisten ${ }^{44}$.

Die Besetzung Hainans stand seit September 1937 auf der Wunschliste der japanischen Marine. Der Plan scheiterte aber damais wie im September 1938 an der an Südchina uninteressierten Armee und am Außenministerium, das einen Konflikt mit London und Paris vermeiden wollte. Nach dem vom Westen geduldeten Einmarsch in Kanton stimmte das engere Kabinett in Tokio der Operation am 25. November 1938 grundsätzlich und am 19. Januar 1939 endgültig zu. Hainan war Japan so wichtig, daß der Bruder des Tenno, Fürst Takamatsu, auf einem Schlachtschiff die Landung persönlich verfolgte ${ }^{45}$.

Wie sollte Paris reagieren? Der Quai d'Orsay entschied, die Invasion herunterzuspielen und sich um diplomatische Unterstützung durch die USA und Großbritannien zu bemühen. Vorsichtig erklärte Henry am 13. Februar Außenminister Arita, seine Regierung wünsche eine Erklärung. Paris habe sich an seinen Teil des stillschweigenden Einvernehmens gehalten und Waffentransporte durch Indochina unterbunden. Japans Regierung habe gegen den Vertrag von 1907 verstoßen. Paris behalte sich vor, seine Politik zu überprüfen.

Frankreichs Zurückhaltung beruhte auf der Einsicht in die eigenen Möglichkeiten. Hoppenot glaubte, Japan reagiere mit der Besetzung auf die Zusammenarbeit der drei Demokratien. Es gewinne ein Faustpfand für den Fall eines Krieges und könne den Golf von Tonkin kontrollieren. Als einzige Reaktion empfahl er die verstärkte Kontrolle der Paracels. Dies solle zeigen, daß Paris weitere Verstöße gegen französische Interessen nicht tatenlos dulde. Chauvel war ratlos. Daladier sagte Bullitt, daß Frankreich und England ihre Kräfte auf Europa konzentrieren müßten. Paris könne nur Tokio um das Versprechen bitten, sein Militär am Ende des Krieges mit China von Hainan abzuziehen.

\footnotetext{
44 Brévié an Mandel, T 36, 10.1., T 80-81, 20.1., T 209, 11.2.1939 (CAOM FM Tel 80); Jarvis an Hull, 13.1.1939 (SD 793.94/14722); Diplomatie an Marine, T 8, 13.1., T 16, 19.1., T 36, 3.2., T 42, 6.2., STS an Marine, T 1535, 24.1.; FNEO, compte rendu, 1.2.1939 (SHM 1 BB9 43, BB4 74); EMA, note, 7.2., Thiébaut an EMA, L, 17.2.1939 (SHAT 7 N 3301, 3332); Knobel an Bonnet, T 129-30, 22.1., Marine an Diplomatie, T 807, 30.1., Royère an Bonnet, T 5, 1.2., attaché de l'air, note, 1.2.; STS-bulletin, 22.1.; Henry an Bonnet, T 66-68, 2.2.1939 (MAE Chine 733, 534; Japon 128).

${ }^{45}$ Urteil (TWCT, Bd. XX, S. 48794); KREBS, Japans Deutschlandpolitik, S. 121f.; PELZ, Race to Pearl Harbor, S. 213; BARNHART, Japan Prepares for Total War, S. 136f;; R. T. PHILIPPS, The Japanese Occupation of Hainan, in: Modern Asian Studies 14.1 (1980), S. 93-109 (S. 95); David BERGAMINI, Japan's Imperial Conspiracy, London 1971, S. 699.
} 
Daß Paris bereit war, die Besetzung zu dulden, zeigte ein wohl inspirierter Leitartikel in »Le Temps« am 12. Februar: Eine begrenzte Besetzung Hainans im Krieg, hieß es, sei keine Verletzung des Vertrages von 1907. Die Zeitschrift »L'Asie française«, die im Juni 1937 den hohen militärischen Wert der Insel herausgestellt hatte, schrieb nun, Hainans strategische Bedeutung werde überschätzt, die Besetzung verstoße gegen keine Vereinbarung. Vor allem dürfe Frankreich nicht die traditionelle Freundschaft mit Japan aufgeben. Tokio versicherte, es hege keine aggressiven Absichten gegen Indochina ${ }^{46}$.

Ein Sprecher des Gaimusho erklärte, der Vertrag von 1907 gelte nicht im Krieg und bei Selbstverteidigung. Zudem hätten sich die Umstände gewandelt. Wenn Japan Hainan als Militärbasis Chinas ausschalte, habe dies mit dem Abkommen von 1907 nichts zu tun. Arita wiederholte nicht die Meinung japanischer Zeitungen, Frankreich breche durch die Unterstützung Chinas selbst den Vertrag, sondern versicherte, die Besetzung sei allein gegen Chiang Kai-shek gerichtet und werde nur aufrechterhalten, solange sie notwendig sei. Japan hege keine territorialen Ambitionen auf die Insel. Eine andere Geste Aritas fiel dem deutschen Botschafter auf: Das Gaimusho argumentierte, der Vertrag von 1907 sei nicht anwendbar und werde deshalb nicht verletzt. Daß der Vertrag ungültig geworden sei, behauptete Tokio nicht. Chauvel nahm an, daß die Besetzung Hainans dauerhaft sei, doch Paris wollte die Angelegenheit beilegen und verzichtete in Tokio auf weitere diplomatische Schritte ${ }^{47}$.

Die Verletzung französischer Interessen durch die Besetzung Hainans veränderte das Klima in Frankreich. Der Eindruck verfestigte sich, daß Japan die westlichen Kolonien im Visier habe, wie Marius Moutet in einem Zeitungsartikel warnte. Zudem beeinflußte die ab Dezember 1938 festere Haltung der Franzosen gegenüber Hitler und Mussolini auch das Bild Japans: In einer repräsentativen Umfrage urteilten im Dezember 193866 Prozent der Franzosen, daß Japans Vorrücken in China Indochina bedrohe, im Juli 1939 forderten 80 Prozent, daß England und Frankreich Japan energisch widerstehen sollten ${ }^{48}$.

\footnotetext{
${ }^{46}$ Bonnet an Henry, T 65-67, 10.2., Hoppenot, Note, 12.2.1939 (DDF XIV, 90, 103); Grew an Hull, 10.2., 15.2., Bullitt an Hull, 13.2.1939 (SD 793.94/14683, 14761, 851.248/139); Note de la sousdirection d'Asie-Océanie pour le ministre, 13.2.1939 (MAE Papiers 1940, cabinet Bonnet 8); Phipps an Halifax, 12.2.1939 (FO 371/23476, F 1380/186/10); L'Indochine et l'Ile de Hainan, in: L'Asie française 351 (Juni 1937), S. 185-186 (S. 186); Cl. MADROLlE, P.B. DE LA BROSSE, Le Japon et Hainan, in: L'Asie française 368 (März 1939), S. 94-99 (S. 97f.); Présidence du Conseil, état chronologique des événements [ohne Datum] (AN Fonds Daladiers, 496 AP 8).

${ }^{47}$ Henry an Bonnet, T 87, 10.2., T 92, 11.2.1939 (MAE Japon 128); Havas, l'occupation de l'lle de Hainan, 13.2.1939 (MAE RFD 28); Le conflit sino-japonais, in: L'Asie française 368 (März 1939), S. 92-93; Henry an Bonnet, T 95-96, 14.2.1939 (DDF XIV, 109); Ott an Ribbentrop, 10.2.1939 (AA Botsch Paris 444 b, Japan. 4); Bullitt an Hull, 16.2.1939 (FRUS 1939, III, S. 110); Note, réactions françaises à la suite de l'occupation de Hainan [ohne Datum] (MAE Papiers 1940, cabinet Bonnet 8). ${ }^{48}$ Marius Moutet, »Hainan aux Nippons: un canon braqué sur notre Indochine«, undatiert (CAOM Fonds Moutet 28/PA/3); HULL, Memoirs, Bd. 1, S. 628; AGERON, France coloniale, S. 266.
} 
Frankreich unterstützte China nun stärker und begrenzte den Handel mit Japan: Paris erlaubte den Transport von Maschinen über die Yunnanbahn. Die Eisenerzexporte nach Japan wurden auf Mandels Wunsch und gegen Bonnets anfänglichen Widerstand beschränkt. Der Minister stimmte zu, da Tokio nicht protestieren könne, wenn man die Mengenbegrenzung mit Eigenbedarf begründe. Statt der 864000 Tonnen Eisenerz und 12400 Tonnen Manganerz, deren Kauf japanische Firmen Anfang 1939 beantragt hatten, gab die Kolonialverwaltung Ende Februar nur 292000 Tonnen Erz frei, darunter 8400 Tonnen Mangan. Gemessen an dem zuvor nach Japan gelieferten Eisenerz (1936: 1160 Tonnen, 1937: 12600 Tonnen, 1938: 89200 Tonnen) unterstützte Indochina Japans Kriegsindustrie immer noch enorm. Die Verwaltung bearbeitete die Lieferanträge aber langsam. Als Botschaftsrat Miyasaki am 18. März 1939 fragte, ob Paris die Exportregeln geändert habe, bestritt Chauvel dies. Doch kurz zuvor waren die Exportbeschränkungen auf Antimon, Gold, Wolfram, Zinn und Zink ausgedehnt worden. Gleichzeitig ordnete Mandel an, daß parallel zur Yunnanbahn eine Straße nach China gebaut werde, auf der Chiang weiteren Nachschub erhalten konnte ${ }^{49}$.

Trotz der eigenen Zurückhaltung im Streit um Hainan bat Paris London und Washington um diplomatische Unterstützung. Bereits am 10. Februar ersuchte Bonnet die Briten um ein Zeichen britisch-französischer Solidarität. Das Foreign Office hielt die Landung zwar für gravierend, beschränkte sich aber darauf, Tokio nach einer Erklärung zu fragen. Der sowjetische Außenminister Litwinow gewann den Eindruck, England und Frankreich versuchten, die Besetzung Hainans herunterzuspielen. Verwundert hörte London von der Einigung zwischen Paris und Tokio vom Herbst 1937, daß Japan als Preis für das Waffentransitverbot auf der Yunnanbahn Hainan nicht besetzte und daß sich Paris und Tokio durch die Konvention von 1907 immer noch verbunden fühlten ${ }^{50}$.

Selbst durch die Warnung, die Besetzung Hainans gefährde Chinas Versorgung, ließ sich Washington von Paris nicht zum Handeln bewegen. Welles sagte Saint-Quentin, Japan habe nur einen Prestigeerfolg gesucht. Dem niederländischen Gesandten zeigte sich Welles beunruhigter. Er habe Informationen, daß Japan einen Krieg in Europa erwarte und dann England und Frankreich in

\footnotetext{
${ }^{49}$ Mandel an Bonnet, L 274, 22.2., Bonnet an Mandel, L 248, 4.3., note de la sous-direction d'AsieOcéanie, 18.3.1939 (MAE Japon 128); Brévié an Mandel, T 308, 24.2., T 381, 7.3.1939 (CAOM FM Tel 80); Walsh an Halifax, 17.3., 11.3., 24.4.1939 (FO 371/22921, C 4157, C 6776, C 4185/249/17); Bullitt an Hull, 6.3., 4.4.1939 (SD 793.94/14781, FRUS 1939, III. S. 746f.); Léger an Corbin, T 439, 13.3., T 518, 18.3.1939 (DDF XIV, 312; MAE Chine 734); VARENNE, Mon Patron, S. $152 \mathrm{f}$.

${ }^{50}$ Bonnet an Corbin, T 241-44, 10.2.1939 (MAE Japon 128); Corbin an Bonnet, T 285, 10.2., T 392, 11.2.1939 (MAE SDN 366, DDF XIV, 96); Memorandum, Gespräch Litwinow mit Seeds, 19.2.1939 (SPE 1, 129); Note Talbott, 14.2., Craigie an Halifax, 11.2., Halifax an Craigie, 11.2.; Minute Howe, 13.2.; Note Brenan, 16.2.1939 (FO 371/23476, F 1376, F 1322, F 1451, F 1431/186/10).
} 
Asien binden wolle. Er bat Grew, Tokio nach seinen Plänen mit Hainan zu fragen. Die USA schickten ein Torpedoboot zur Insel, um nach 22 US-Bürgern zu suchen. Bonnet wollte britische und französische Schiffe gemeinsam mit dem US-Boot entsenden. Aber London lehnte die Beteiligung ab, weil, so die interne Begründung, der Westen keine militärische Konfrontation riskieren könne. Ohne Kenntnis des Foreign Office waren am 13. und 22. Februar Royal-Navy-Schiffe vor Hainan erschienen ${ }^{51}$.

Frankreichs Marine brauchte länger. Trotz der Einigung zwischen Quai d'Orsay und Marineführung am 18. Februar, die Rigault de Genouilly zum Hafen Hoihao zu schicken, verschob Le Bigot die Fahrt viermal und fuhr erst Mitte März nach Hoihao. Erneut erwies sich die französische Marine als sehr konfliktscheu. Dafür errichtete Japans Marine eine Funkbrücke zwischen dem französischen Konsul in Hoihao und Frankreichs Konsul in Kanton ${ }^{52}$.

$\mathrm{Da}$ Japans Expansion bis vor die Tore Indochinas nicht bedrohlich sei und daß sich Zurückhaltung empfehle, war die herrschende Auffassung im französischen Militär. Der Generalstab der Armee hielt vier Motive Tokios für möglich: Japan könne Hainan besetzt haben, um eine Landung in Südchina vorzubereiten, um Waffentransporte im Golf von Tonkin zu unterbinden, um England und Frankreich einzuschüchtern oder um beide Demokratien in Asien zu binden, während im Mittelmeer eine Krise heraufziehe. Der Armeestab und französische Diplomaten in Asien spekulierten, daß das Vorgehen die Antwort auf die Ablehnung Tanis als Botschafter sei. Für Vize-Militärattaché Guillermaz war die Besetzung vor allem ein Einschüchterungsmanöver gegen Briten und Franzosen. Der Marine-Geheimdienst urteilte, Japan konzentriere sich ganz auf die Sowjetunion. Der Generalstab der Luftwaffe nahm an, Japan habe Hainan aus Freundschaft zu Rom und Berlin angegriffen, ein Angriff auf Südchina werde wohl folgen. Vize-Admiral Le Bigot schrieb, Japan mißachte französische Interessen offen und gehe gegen westliche Interessen in China vor. Dies zeige eine beunruhigende Aggressivität. Eine unmittelbare Gefahr für Indochina sah der Kommandeur der Fernostflottille nicht ${ }^{53}$.

\footnotetext{
${ }^{31}$ Charvériat an Saint-Quentin, T 230-34, 11.2., EMG.2, note, 2.3.1939 (DDF XIV, 98, 276); SaintQuentin an Bonnet, T 246-49, 13.2., Bonnet an Corbin, T 274, 15.2., Corbin an Bonnet, T 444, 16.2.; Saint-Quentin an Bonnet, T 232, 13.2, T 272, 18.2., Corbin an Bonnet, T 456-57, 17.2., T 749, 14.3.1939 (MAE RFD 28, SDN 366); Hull an Grew, 15.2.1939 (SD 793.94/14713A); Minute Howe, 16.2., Strang an Bland, 22.2.1939 (FO 371/23476, F 1574/186/10; FO 371/22965, C 2199/15/18).

${ }^{52}$ Brévié an Mandel, T 294, 20.2.1939 (CAOM FM Tel 80); Diplomatie an Marine, T 66, 18.2., T 73, 23.2., FNEO an Rigault de Genouilly, T 7300, 21.2.; FNEO an EMG.2, T 7313-15, 25.2., Diplomatie an Marine, T 108, 8.3.1939 (SHM 1 BB9 43, 44); FNEO, compte rendu, 29.3.1939 (SHM 1 BB4 74).

${ }_{53}$ EMA.2, note, 13.2., EMA.2, renseignement, 22.2., Guillermaz, note, 21.2.1939 (SHAT 7 N 3301, 3334, 3291); Grew an Hull, 15.2.1939 (SD 793.94/14761); STS an EMG.2, T 1538-41, 26.2.1939 (SHM 1 BB9 44); STS-bulletin, 1.3., Marine an Diplomatie, T 1954, 10.3. (MAE Chine 543, 783); EMAA.2, synthèse, 28.2., FNEO, compte rendu, 1.3.1939 (SHAA 2 B 81, SHM 1 BB4 74).
} 
Für Indochinas Sicherheit sorgte sich allein Militärattaché Thiébaut: Indochina sei ein unmitttelbares Ziel japanischer Expansionspolitik geworden. Die Besetzung Hainans bedeute eine Kehrtwende der japanischen Politik, die sich unter deutschem und italienischem Druck jetzt gegen die Sowjetunion, Frankreich und Großbritannien richte. Der Generalstab in Paris, der mit Italiens Aufmarsch in Nordafrika beschäftigt war und die Existenz einer weiteren Bedrohung wohl nicht zugeben wollte, beruhigte, die Besetzung richte sich vor allem gegen Briten und Chinesen. Auch in der französischen Öffentlichkeit ebbte die Erregung über die Besetzung Hainans rasch wieder ab. Man dürfe sich nicht von Europa ablenken lassen, war herrschende Meinung. ${ }^{54}$

Mitte Februar aber kam das Gerücht auf, Japan bereite einen Angriff im chinesisch-indochinesischen Grenzgebiet vor. Als zwei japanische Flugzeugträger und weitere Kriegsschiffe am 18. Februar vor Haiphong erschienen, alarmierte Brévié Grenztruppen und warnte vor einer japanischen Landung. Anfang März verlangten Le Bigot und der Quai d'Orsay mehr Präsenz der Marine in Indochina. Am 14. März verletzten erstmals zwei japanische Torpedo-Boote französische Territorialgewässer, am 3. und 8. April drangen einzelne japanische Flugzeuge, am 12. April sogar 30 Maschinen in den Luftraum Tonkins ein. Mit dem Abschuß der Flugzeuge zu drohen, wie die Briten dies taten, lehnte der Quai d'Orsay ab. Er beließ es bei diplomatischen Protesten ${ }^{55}$.

Auch auf den Inseln trat Japan ruppiger auf. Auf den Paracels begannen Ende Oktober 1938 Vorarbeiten für die Ausdehnung der japanischen Siedlung, Mitte November entstand ein Denkmal mit der Inschrift „Zur Ehre des größeren Japan«. Auf den Spratlys stieg Mitte Dezember die Zahl japanischer Soldaten auf 30. Die Japaner waren mit Gewehren und Maschinenpistolen bewaffnet und gaben an, für ein Jahr zu bleiben. Für eine lange Präsenz sprach auch die Menge an angelandetem Bauholz. 60 Kulis bauten Phosphat ab. Die Japaner produzierten Beton, holzten Wälder ab und zeigten sich leutselig. Erst Ende Dezember 1939 verließen die Japaner bis auf zwei Wetterkundler, zwei Funker, sechs Zimmerleute sowie ein Dutzend Kulis die Spratlys ${ }^{56}$.

\footnotetext{
${ }^{54}$ Thiébaut an EMA.2, L 34, 9.3., L 8, 17.2.1939 (SHAT 7 N 3332); Comité permanent de la défense nationale, séance du 24.2., EMG.2, note du renseignement, 2.3.1939 (DDF XIV, 196, 276), Welczeck an Ribbentrop, 15.2.1939 (AA Botsch Paris 444 b, Japan. 4).

${ }_{55}$ Diplomatie an EM.2 Marine, T 86, 28.2.1939 (SHM 1 BB9 44); Southard an Hull, 3.3.1939 (FRUS 1939, III, S. 145); Berichte in MAE Chine 734-735, CAOM FM Tel 80; FNEO, compte rendu, 29.3., EMG.2 an FNEO, T 4781, 18.3.1939 (SHM 1 BB4 74; BB9 184); Compte rendu, 8.3.1939 (DDF XIV, 286); Brévié an Mandel, T 460, 20.3., T 603, 13.4., T 621, 14.4.1939 (CAOM FM Tel 80); Bonnet an Henry, T 164, 1.4., Henry an Bonnet, T 224, 18.4.; T 227, 18.4.1939 (MAE Japon 129, 132). ${ }^{56}$ Brévié an Mandel, T 1242, 31.10., T 1441, 14.12.1938 (CAOM FM 678); Marine Saigon an EMG.2, T 1381, 13.12., L 410-C, 14.12.1938 (SHM 1 BB9 42); Compte rendu, 14.12.1938 (DDF XIII, 127); Garde Principal an Annam, T 5, 12.11.1938; Bonnet an Henry, T 3-5, 5.1., Burollaud (ItuAba) an Cochinchine, 18.2.1939 (MAE Chine 747, 752); EMA.2, note, 5.4.1939 (SHAT 10 H 75).
} 
Im Februar 1939 waren auf den Paracels 380 formosische Kulis und 22 Japaner tätig, während die indochinesische Mannschaft abgelöst, aber nicht vergrößert wurde. Die einzige zusätzliche Aktivität der Franzosen bestand darin, einige Milizionäre von der Insel Pattle zur Insel Roberts zu verlegen. Die Marine weigerte sich weiter, Schiffe zu den Archipelen zu schicken. Nur ausnahmsweise stellte sie den Hochseeschlepper Valeureux für eine Versorgungsfahrt zu den Paracels ab. Bis Ende März 1939 blieb die Lage auf den Paracels ruhig. Die japanische Gruppe auf der Île Boisée begrüßte die Franzosen herzlich und half beim Entladen eines Versorgungsschiffes ${ }^{57}$.

Am 27. Januar 1939 gab das Foreign Office Hinweise an Paris weiter, wonach Tokio Berlin und Rom mitteilen wolle, daß es die Spratlys als annektiert betrachte. Mandel verlangte die Entsendung eines Kriegsschiffes zu den Inseln. Der Kapitän solle Anweisungen erhalten, wie er sich im Konfliktfall zu verhalten habe. Am 11. Februar, einen Tag nach der Besetzung Hainans, forderten Bonnet und Mandel, die Abordnung eines Schiffes zu den Spratlys zu beschleunigen. Selbst die Marineführung in Paris befürwortete die Mission.

Diese Entscheidung wurde nach Le Bigots Protest widerrufen. Der Admiral warnte, die Präsenz französischer Schiffe in den Spratlys führe entweder zum Rückzug oder zum Konflikt. Da Japans Reaktion nicht vorhersehbar sei, wolle er selbst zu den Spratlys fahren, sobald ein Schiff verfügbar sei. Die Marine setzte alle Fahrten zu den Spratlys aus. Vergeblich äußerte Bonnet, nach der Besetzung Hainans sei die Spratly-Mission noch wichtiger, um die eigenen Rechte zu betonen. Zurückhaltung werde als Schwäche interpretiert. Während sich die Situation auf den Spratlys zwischen Vietnamesen und Japanern entspannte, braute sich in Tokio ein Sturm zusammen. Als Antwort auf Frankreichs Protest vom Januar gegen den Einsatz japanischer Soldaten auf den Spratlys erklärte das Gaimusho am 13. Februar, es dürfe Rechte, Leben und Eigentum seiner Bürger schützen. Frankreich solle rasch auf die Ansprüche auf die Spratlys verzichten. Paris erwiderte, es beanspruche die Souveränität über die Inseln. Mit Rücksicht auf die freundschaftlichen Beziehungen sei man aber bereit, die Frage von einem Internationalen Schiedsgericht lösen zu lassen $^{58}$. Das Gaimusho, das bisher auf Zeit spielte, drängte nun zur Eile.

\footnotetext{
${ }^{57}$ FNEO, comptes rendus, 1.2., 29.3.1939 (SHM 1 BB4 74); Brévié an Mandel, L 893, 17.2., Mandel an Brévié, T 191, 27.2., rapport de l'inspecteur principal Edmond Grethen, 15.3.1939 (MAE Chine 747); Brévié an Mandel, T 318, 26.2., T 436, 15.3.1939 (CAOM FM Tel 80); Marine Saigon an EMG.2, T 1435, 6.2., EMG.2 an Saigon, T 4556, 11.2 .1939 (SHM 1 BB9 43, 184).

${ }_{58}$ Corbin an Bonnet, T 228, très secret, 27.1., Mandel an Bonnet, L 171, 8.2., Marine an Diplomatie, L 202, 16.2.1939 (MAE Chine 752); EMG.2 an FNEO, T 4553, 11.2., T 4580, 16.2.1939 (SHM 1 BB9 184); FNEO an EMG.2, T 7281-85, 14.2., T 7289-90, 15.2 .1939 (SHM 1 BB9 43); Bonnet an Campinchi, D 207, 27.2.1939 (DDF XIV, 224); FNEO, compte rendu, 29.3.1939 (SHM 1 BB4 74); Henry an Bonnet, T 100-2, 14.2., Bonnet an Henry, T 77-79, 16.2.1939 (MAE Japon 123).
} 
Am 31. März 1939 um 20 Uhr in Hanoi meldete das deutsche Radio, Japan habe die Spratlys besetzt. Dies habe das Gaimusho Frankreichs Botschafter erklärt. Kurz darauf berichtete der französische Rundfunk, das Außenministerium in Tokio habe die Spratlys unter Japans Souveränität gestellt. Japan hatte die Inseln seiner Provinz Formosa unterstellt und damit annektiert. Truppen besetzten den Archipel aber nicht, auch wenn dies zeitgenössisch behauptet und später vom Internationalen Kriegsgerichtshof in Tokio verbreitet wurde sowie jahrzehntelang Eingang in die Literatur fand ${ }^{59}$.

Vizeaußenminister Sawada sagte Botschafter Henry, seit 30. März seien die Spratlys der Verwaltung Formosas zugeordnet. Es gebe keine konkreten Maßnahmen auf den Inseln. Henry schrieb, Tokio wolle nur juristisch mit Paris gleichziehen. Chauvel widersprach: Japans Akt stehe in Kontrast zu Frankreichs Angebot einer schiedsgerichtlichen Einigung und scheine keinen Weg für eine friedliche Lösung offen zu lassen. Die Mißachtung französischer Rechte in Südchina und auf den Paracels, die Besetzung Hainans und die Annexion der Spratlys zeigten, daß Japan Indochina einkreise. Deshalb müsse Paris den Waffentransit durch Indochina, dessen Verbot der Preis für die Achtung französischer Interessen gewesen sei, erlauben ${ }^{60}$.

Chauvel sagte Bullitt, dies sei das erste Mal, daß Japan französisches Territorium besetze. Die Spratlys würden japanische Flugzeug- und U-Boot-Basis. Für Hauptmann Aiby, den amtierenden Militärattaché in Tokio, zeigte das Vorgehen die Macht der Extremisten. Der Generalstab der Luftwaffe warnte, die Inseln seien eine erstklassige Basis für Angriffe auf Indochina. Die Führung der französischen Armee aber hielt Japans Schritt für ungefährlich: Die Annexion, als »le geste japonais« verharmlost, sei nur symbolisch und aus Prestigegründen erfolgt, um den Traum vom »Südstoß« am Leben zu halten. Japan sehe von der Besetzung der Inseln ab, so die französische Heeresführung, denn seine hohe moralische Kultur verbiete ihm, zu den Methoden

\footnotetext{
${ }^{59}$ Taliani an Ciano, 25.7.1939 (DDI Serie 8, XII, 666); Anklage durch Robert Oneto (TWCT, III, S. 6710); Quigley, The Far Eastern War, S. 183; ChINA HANDBooK 1937-1945, S. 710; RENOUvIN, La question, S. 415; William L. LANGER, S. Everett GLEASON, The Challenge to Isolation, 1937-1940, New York u.a. 1952, S. 52; Devillers, Histoire du Viêt-nam, S. 71; HAAS, Frans Indochina, S. 22, S. 247; BUTTINGER, Vietnam, Bd. 1, S. 229; HAAS, Französisch-Indochina, S. 33, S. 39; BERGAMINI, Japan's Imperial Conspiracy, S. 700; ClYDE, BeERS, The Far East, S. 661; DALleK, Franklin D. Roosevelt, S. 194; KREBS, Japans Deutschlandpolitik, S. 235; CLAYTON, The British Empire, S. 334; SAMUElS, Contest, S. 65; BINOCHE-Guedra, La France d'outre-mer, S. 177; DuROSELLE, Histoire diplomatique, S. 334, S. 338; BINOCHE, La politique extrême-orientale, S. 541; VALETTE, Indochine, S. 21; Jonathan MARSHALL, To Have and Have Not. Southeast Asian Raw Materials and the Origins of the Pacific War, Berkeley, Los Angeles, London 1995, S. 61; ONG, Operation Matador, S. 60, S. 94, S. 97; CATLeY, Keliat, Spratlys, S. 25.

${ }^{60}$ Brévié an Mandel, T 523-24, 31.3.1939 (CAOM FM Tel 80); Havas, l'occupation par le Japon des îles Spratly, 31.3.1939 (SHAT 10 H 75); Henry an Bonnet, T 193-95, 31.3., note de la sous-direction d'Asie-Océanie, 31.3.1939 (DDF XV, 217, 222).
} 
Deutschlands zu greifen. Japans Schritt sei vor allem gegen England gerichtet. Vermutlich wolle Japan Tauschobjekte erhalten, damit London und Paris japanische Gewinne in China akzeptierten. Den Grund für Japans "Geste« müsse man rasch finden, „si l'on ne veut pas qu'empirent les relations francojaponaises qui ne devraient avoir aucune raison d'être mauvaises«, schloß die Analyse aus dem französischen Heer. Die Anhänger der entente franco-japonaise hatten also selbst in dieser Krise in Paris eine starke Position ${ }^{61}$.

Als Bonnet drei Tage nach der Annexion eine Äußerung nach Tokio übermittelte, war klar, daß Japan auf den Spratlys keine Taten folgen ließ. Léger hatte seine Auffassung durchgesetzt, daß Frankreich bei einer Konfrontation nur verlieren konnte. Paris protestierte in Tokio gegen die Annexion, drückte Überraschung und Bedauern aus, doch die Drohung mit Konsequenzen formulierte Bonnet - zwei Wochen nach dem Einmarsch deutscher Truppen in Prag - zurückhaltend: Frankreich habe sich trotz des japanischen Vormarsches in China stets dafür eingesetzt, die Atmosphäre freundschaftlichen Vertrauens zu bewahren. Paris habe Japans Position immer respektiert, selbst da, so eine Anspielung auf das Verbot des Waffentransits, wo es nicht dazu verpflichtet gewesen sei. Mißachte Tokio weiter französische Interessen, behalte Frankreichs Regierung sich vor, Teile ihrer Asienpolitik zu ändern. Als Henry VizeAußenminister Sawada Bonnets Protest überbrachte, war fast eine Woche seit der Annexion vergangen. Das Gespräch fand in freundschaftlichem Ton statt. Henry klagte, man könne seit zwei Jahren den Eindruck haben, daß Tokio Paris in die Arme der Gegner Japans treiben wolle. Sawada erwiderte, Japans Öffentlichkeit glaube, Frankreich unterstützte Englands antijapanische Politik ${ }^{62}$.

Erstmals seit dem Russisch-Japanischen Krieg 1904/5 hatte Japan eine Region, die eine europäische Macht beanspruchte, förmlich annektiert. Tokio verzichtete allein auf den Einsatz von Truppen und ersparte den Franzosen die Bloßstellung. Allerdings kontrollierten japanische "Siedler« das Archipel ja bereits. Die französische Regierung reagiert auf die Annexion mit apaisement, weil sie um ihre Schwäche wußte. Sie untersagte auch die Entsendung eines Schiffes zu den Spratlys, die in einer Kraftprobe mit Japan hätte enden können. Chauvel hatte zunächst ein härteres Auftreten gegenüber Japan befürwortet und Bullitt angedeutet, der Waffentransit über die Yunnanbahn werde erlaubt. Léger erklärte hingegen, man könne mit Japans Schritt leben.

${ }^{61}$ Bullitt an Hull, 1.4., EMAA.2, synthèse de renseignements, 31.3.1939 (FRUS 1939, III, S. 113f., SHAA 2 B 81); Aiby an EMA.2, L 58, 19.4., note, Japon, [EMA.2], Paris, 6.4.1939 (SHAT 10 H 75).

${ }^{62}$ Brévié an Mandel, T 526, 529, 1.4.1939 (CAOM FM Tel 80); Bonnet an Henry, T 167-69, 3.4.1939, Corbin T 651-54, 4.4.1939 (DDF XV, 239); Henry an Bonnet, T 199-204, 5.4.1939 (DDF XV, 258); Grew an Hull, 6.4., 8.4.1939 (SD 85 lg.014/10, 15). Für die Annahme von TANAKA, Henry habe Sawada am 5. April Frankreichs Unterstützung im Fernostkonflikt versprochen, falls Japan auf die Spratlys verzichte (Les relations, S. 349), gibt es keinen Hinweis. 
Die Anbindung der Spratlys sei eine nur rechtliche Maßnahme und stelle keine Annexion dar. Das Archipel sei nun eine Art Kondominium. Am 18. April schloss sich Chauvel Léger an. Ein Kompromiß sei weiter möglich. Die Anfrage eines Abgeordneten, wie Frankreich seine Souveränität über die Spratlys herstellen wolle, wurde nicht beantwortet. Die Meinung, die Annexion habe nur juristische Bedeutung, herrschte auch in der Verwaltung in $\mathrm{Hanoi}^{63}$.

Zum apaisement gehörte, daß Léger sich auffällig spät, am 8. April, in London um diplomatische Unterstützung bemühte. Am 10. April zweifelte der britische Geschäftsträger gegenüber Sawada die Rechtmäßigkeit der Annexion an. Der britische Staatssekretär Butler hatte zuvor gesagt, es handele sich zunächst um eine Angelegenheit der Franzosen. In der britischen Botschaft in Tokio herrschte der Eindruck vor, die Franzosen hätten mit ihrer Hinhaltetaktik und der zögernden Besiedlung Japans Schritt erst ermöglicht ${ }^{64}$.

Nur in einem Feld zeigte Paris, wie schon nach der Besetzung Hainans, Japan die Zähne: Die Erzexporte nach Japan wurden gestoppt, ohne Tokio aber die Verbindung mit der Annexion zu erklären. Léger sagte dem japanischen Geschäftsträger, der am 7. April bat, bei der Erzabfertigung Japans Interessen zu berücksichtigen, nur, Japan müsse auch französische Interessen beachten. Alle Importeure würden gleich behandelt, Japan dürfe beim Stand der Beziehungen keine bevorzugte Behandlung erwarten. Léger bemühte sich, daß auch London und Washington ihre Erzexporte reduzierten ${ }^{65}$.

Obwohl die Japaner auf den Paracels und den Spratlys keine militärischen Schritte ergriffen, befürchtete der oberste Kolonialbeamte in Annam, der résident supérieur, einen Handstreich Japans. Brévié gab dem Chef des französischen Postens auf den Paracels die Anweisung, falls die Japaner die Gruppe mit Gewalt von der Insel entfernen wollten, solle er unter Protest die Insel räumen, um ein Blutvergießen zu vermeiden. Die Anweisung sorgte für Streit zwischen dem Kolonial- und dem Außenministerium: Der Quai d'Orsay hielt sie für übertrieben, weil Japan nach zehn Monaten friedlichen Zusammenlebens auf den Inselgruppen kaum die Absicht habe, gegen die französische

${ }^{63}$ Diplomatie an Marine, L 343, 6.4., Henry an Bonnet, L 67, 19.4., Question posée par M. Rethore, 18.4.1939 (MAE Chine 752); Bullitt an Hull, 6.4.1939 (FRUS 1939, III, S. 114f.); Léger an Henry, T 172-75, 8.4., note de la sous-direction d'Asie-Océanie, 18.4.1939 (MAE Japon 129); FNEO, compte rendu, 5.5.1939 (SHM 1 BB4 74); Walsh an Halifax, 24.4.1939 (FO 371/22921, C 6776/249/17).

${ }^{64}$ Léger an Henry, T 171, 8.4.1939 (MAE Japon 129); Léger an Saint-Quentin, T 291-96, 8.4.1939 (MAE RFD 28); Craigie, Annual Report, 1.1.1940 (FO 371/24743, F 2417/2417/23); Havas London, l'attitude britannique dans l'affaire des îles Spratley, 6.4., Corbin an Bonnet, T 1090, 7.4., Henry an Bonnet, T 211, 11.4.1939 (MAE Chine 752); Grew an Hull, 8.4.1939 (SD 851G.014/15).

${ }^{65}$ Brévié an Mandel, T 579, 8.4.1939 (CAOM FM Tel 80); Léger an Henry, T 176-78, 8.4.1939 (DDF XV, 305); Mandel an Bonnet, L 103, 10.4., Henry an Bonnet, T 224, 18.4.1939 (MAE Japon 129); Léger an Corbin, T 743-44, 14.4.1939 (DDF XV, 389); Corbin an Bonnet, T 1254-56, 18.4.1939 (MAE SDN 368); Bullitt an Hull, 18.4.1939 (FRUS 1939, III, S. 528f.). 
Gruppe vorzugehen. Mandel beharrte, falls die Japaner zur Gewalt griffen, müsse der Posten klare Anweisungen haben: weichen oder widerstehen. Da der Quai d'Orsay die Formel »weichen, aber protestieren« abgelehnt habe, gebe er nun den Befehl, der Posten solle Widerstand leisten. Diese Verantwortung wollte Bonnet nicht übernehmen: Zwischen der schnellen Evakuierung und dem Widerstand bis zum Schluß gebe es einen Mittelweg. In Hankou und Shanghai habe fester Widerstandswille gereicht. Falls die Japaner mit Gewalt drohten, könnten die Vietnamesen nur protestieren und weichen. Damit hatte sich Mandel durchgesetzt. In seinem Verantwortungsbereich handelte er vorsichtig. Mandel schlug auch nie vor, die Zahl der Milizionäre auf den Archipelen zu erhöhen. Am 10. April sorgte das Auftauchen sechs japanischer Boote kurz für Unruhe auf den Paracels. Im Mai 1939 unterhielten die je 25 Milizionäre auf den Archipelen freundliche Beziehungen zu den Japanern ${ }^{66}$.

Jean Decoux, seit Mai 1939 neuer Chef der Fernost-Flottille, ließ mehr Präsenz auf den Inseln zeigen: Mitte Mai fuhr der Kreuzer Lamotte-Picquet zu den Paracels, vier Offiziere gingen demonstrativ an Land. Die Franzosen brachten Baumaterial auf die Inseln Pattle und Boisée und intensivierten den Hausbau. Die Aviso Francis Garnier fuhr regelmäßig die Paracels an, im Mai 1940 kam die Lamotte-Picquet erneut zu den Paracels. Japanische Kriegsschiffe zeigten sich selten. Japan beschränkte sich auf den Phosphatabbau ${ }^{67}$.

Auf den Spratlys zeigten sich die Japaner offensiver: Im Frühjahr 1939 lebten auf Itu Aba nur acht Japaner und ein Dutzend Kulis aus Formosa. Im Juni und Juli kamen 50 Japaner auf die Insel. Anfang August bedrohten sie die Indochinesen und deren Chef Jean Burollaud. Decoux beschloß, ein Kriegsschiff zu entsenden, was das Wetter aber verhinderte. Die von Brévié geforderte diplomatische Intervention in Tokio unterließ Paris jedoch. Mit Ausbruch des Krieges in Europa entspannte sich die Lage auf den Spratlys ${ }^{68}$.

Insgesamt hatte sich die relative Zurückhaltung, die Japans Militär und Diplomatie im März bei der Annexion der Spratlys gezeigt hatte, im gesamten Sommer 1939 fortgesetzt: Japan baute seine Position aus, verzichtete aber darauf, eine Machtprobe zu suchen. Paris nahm den Ausbau der japanischen Positionen um Indochina weitgehend passiv hin.

\footnotetext{
${ }^{66}$ Brévié an Mandel, T 585 und 587, 9.4., T 614, 14.4., T 632, 16.4.1939 (CAOM FM Tel 80); Colonies an Diplomatie, T 104, 11.4., Diplomatie an Colonies, L 526, 12.5., Mandel an Bonnet, L, 17.5., Bonnet an Mandel, L 566, 24.5.1939; EMG.Col.2, 16.5.1939 (MAE Chine 747, 752).

${ }^{67}$ FNEO an EMG.2, T, 21.5.1939 (SHM I BB9 46); Decoux an Brévié, L 203, 26.5.1939; Catroux an Mandel, L 692 APE, 9.2., L, 7.5., L 43 SN/APE, 17.5.1940 (MAE Chine 747).

${ }^{68}$ Brévié an Mandel, T 925, 27.5., T 963, 5.6., T 1084, 1.7., T 1092, 3.7., T 1147, 12.7., T 1211, 22.7., T 1299, 8.8., T 1319, 11.8., T 1335, 13.8., T 1358, 18.8., T 1385, 25.8.; Catroux an Mandel, T, 5.9.1939 (CAOM FM Tel 80, 82); Burollaud an Brasey, L, 2.6.1939 (MAE Chine 752); FNEO, compte rendu, 6.6., 1.8.; Marine Saigon an EMG.2, T 1119, 13.8.1939 (SHM 1 BB4 74, 1 BB9 48).
} 


\subsection{Nervenkrieg in Tientsin}

$\mathrm{Da}$ es um die Konzessionen im nordchinesischen Tientsin 1939 zum Konflikt zwischen Japan und den Mächten kam, war angesichts der japanischen Ziele beinahe unausweichlich. Japans wichtigstes Nahziel war die Ausbeutung Nordchinas. Nordchina wollte Japan in einem Frieden behaupten. Weil die Konzessionen Japans Kontrolle dort untergruben, suchte die japanische Armee in Tientsin, dem Wirtschafts- und Bankenzentrum Nordchinas, die Machtprobe. Hier waren zudem die USA an keiner Konzession beteiligt. Politisch und wirtschaftlich wichtigste ausländische Macht in China war Großbritannien. Deshalb ging Japan vor allem gegen die britische Konzession vor.

Den nach Lieus Urteil in der Geschichte ökonomischer Kriegführung einzigartigen Währungskrieg eröffnete Japans Marionettenregierung in Peking im Februar 1938 mit der Gründung der Federal Reserve Bank (F.R.B.). Diese gab in Parität mit dem Yen Yuan aus, um den China-Dollar zu verdrängen und Nordchina in den Yen-Block zu integrieren. Da der Yuan nicht gedeckt war, konnte Japan ihn nur mit Wechselkontrollen am Leben erhalten. Hätte sich der F.R.B. Yuan durchgesetzt, hätten westliche Firmen nur noch zu Japans Bedingungen handeln können; Japan hätte mit Papiergeld die Besatzungskosten dekken und die Devisenerlöse abschöpfen können. Französische Unternehmen waren außerhalb der Konzessionen kaum vertreten und somit nicht bedroht. Für Paris ging es darum, ob es die drohende Verdrängung des Westens aus Nordchina dulden wollte. Frankreich mußte sich positionieren, weil in seiner Konzession 160 chinesische und zwei französische Banken arbeiteten. In der britischen Konzession hatten drei britische sowie je eine Bank aus den USA, Deutschland und Belgien ihren Sitz. Ob die Banken mit Japan kooperierten, wollte Henry jedem Institut selbst überlassen, Naggiar war dafür, die Banken zu unterstützen. Schließlich beschwerten sich die drei westlichen Botschafter in Tokio darüber, daß die neue Währung westliche Firmen diskriminiere ${ }^{69}$.

Im Sommer und Herbst 1938 baute Japan die Kontrolle des ausländischen Handels aus: Die in Nordchina erwirtschafteten Devisen mußten bei japanischen Banken gegen F.R.B.-Yuan eingetauscht werden, noch dazu zu einem

${ }^{69}$ D.K. LIEU, The Sino-Japanese Currency War, in: Pacific Affairs 12.4 (1939), S. 413-426 (S. 413); TAYLOR, The Struggle for North China, S. 128f.; LI, The Japanese Army, S. 141; Domei Peking: Reserve Bank to be set up in Peking, 26.12.1937; Lacoste an Naggiar, L 176, 11.3., Naggiar an PaulBoncour, T 439-40, 30.3., Lépissier an Naggiar, L 25, 26.4.; Lépissier an Delbos, L 9, 25.2., Naggiar an Delbos, T 318-19, 4.3., Henry an Paul-Boncour, T 152-55, 26.3., Léger an Corbin, T 991-96, 28.3., Henry an Gaimusho, L, 14.4.1938 (MAE Chine 847, 768); Lépissier an Delbos, L 9, 16.2.1939; Knobel an Delbos, T 359-67, 8.3.; Banque franco-chinoise, note, 19.12.1938 (MAE Chine 831, 761, 884); Hull an Grew, 4.4., Grew an Hull, 12.4.1938 (FRUS 1938, IV, S. 11f.). 
40 Prozent niedrigeren Kurs als am Markt. Auch Eisenbahn- und LastwagenTransporte verteuerte Japan. In den Konzessionen ging der Devisenhandel unvermindert weiter. Als Japan Fapi vom Markt nahm, brachten die Briten im Dezember 1938 per Kriegsschiff 4,5 Millionen China-Dollar nach Tientsin. Französische Diplomaten schlugen der Banque de l'Indochine und der Banque franco-chinoise die Bitte ab, Fapi-Noten aus Südchina nach Tientsin zu holen. Naggiar und der britische Finanzattaché Hall Patch glaubten im Spätsommer 1938 aber noch, daß Japan auf westliches Kapital angewiesen sei und deshalb wirtschaftlich nicht rücksichtslos gegen den Westen vorgehe ${ }^{70}$.

Im Frühjahr 1939 standen die Franzosen vor zwei Fragen: Sollte ihre Konzession in Tientsin den F.R.B.-Yuan akzeptieren, und wie sollte sie darauf reagieren, daß das Pekinger Marionetten-Regime westliche Banken aufforderte, Devisengeschäfte nur noch mit japanischen Instituten abzuwickeln? Charles Lépissier trat für Widerstand ein: Nachgiebigkeit führe nur zu weiteren Forderungen. Japans brutales Vorgehen zeige, welche ideelle, politische und wirtschaftliche Bedeutung die Konzessionen besäßen, schrieb der Generalkonsul im Februar 1939 kurz vor seiner Ablösung durch Lucien Colin. Mit dieser Haltung stand Lépissier allein. Westliche Rechte könnten am besten durch eine "gewisse Zusammenarbeit« mit Japan verteidigt werden, empfahl Henry. Botschaftsrat Lacoste in Peking meinte, man solle Japan nicht völlig nachgeben, aber eine unnachgiebige Entschlossenheit könne zu einer »brutalen Reaktion « Japans führen. Geschäftsträger Knobel räumte ein, daß Härte in Tientsin zu Frankreichs Prestige beitrage, doch diese Festigkeit halte die Konzession in ständiger Spannung. Man könne Japan vor Ort nachgeben, ohne Frankreichs prinzipielle Position zu kompromittieren. Jedes Risiko in Tientsin gefährde die französische Position in ganz Südostasien. Léger riet, Lépissier soll sich um eine Entspannung der Beziehungen und »eine gewisse Zusammenarbeit« mit den japanischen Behörden bemühen. Im Februar 1939 hielt es Léger für unmöglich, daß die Konzessionen Japans Druck lange widerstehen könnten ${ }^{71}$.

\footnotetext{
${ }^{70}$ Lacoste an Naggiar, T 358, 12.7., Léger an Henry, T 248, 28.7.; Georges-Picot an Naggiar, L 211, 11.9.1938 (MAE Chine 770, 830); Knobel an Bonnet, T 1842, 28.11., T 1845, 29.11., Léger an Corbin, T 3537-38, 30.11., Hoppenot an Knobel, T 715, 15.12.; Hoppenot an Knobel, T 688-91, 3.12., Knobel an Bonnet, T 2000-1, 19.12., T 2035, 23.12.1938, T 20, 4.1.1939 (MAE Chine 563, 884); Naggiar an Bonnet, L 581, 25.8.; Lacoste an Naggiar, L 625, 14.11.1938 (MAE Chine 627, 658); Franzosen exportierten für 2,9 Millionen Dollar Waren aus Nordchina. Am Export in den Westen besaßen sie einen Anteil von 3,3 Prozent (Knobel an Bonnet, L 32, 6.2.1939, MAE Chine 1070).

${ }^{71}$ Banque franco-chinoise pour le commerce et l'industrie, note, 2.3.; Banque franco-chinoise, M. Bar, an Bussy, directeur général, Paris, 25.2., note confidentielle, banque de l'Indochine, 17.1.1939 (MAE Chine 1071, 1070); Knobel an Bonnet, T 2004-6, 19.12., Henry an Bonnet, T 254-58, 1.6.1938 (MAE Chine 830, 847); Lépissier an Bonnet, L 9, 16.2., Knobel an Bonnet, T 371-72, 7.3., T 191-97, 14.2., T 346-50, 5.3.; L 74, 25.2., L 75, 25.2.1939 (MAE Chine 831, 772); Léger an Knobel, T 712, 12.12.1938, T 88-89, 2.3.1939 (MAE Chine 884); Note, Chinese Embassy, London, 3.2.1939 (MAE Chine 1070); Léger an Corbin, T 213-14, 8.2.1939 (MAE Chine 831).
} 
Die Banken, das Foreign Office und der Quai d'Orsay einigten sich Anfang März 1939 auf einen "passiven Widerstand«: Die Banken sollten keine Devisen herausgeben und mit Japan nur so weit kooperieren wie unbedingt nötig. In Tokio protestierten die drei westlichen Mächte gegen die Mißachtung des Prinzips der Offenen Tür. Bonnet warnte die chinesische, britische und die US-Regierung, Paris widersetze sich nur, solange die gemeinsame Front halte $^{72}$. Japan duldete den Widerstand der Banken, die Lage in Tientsin entspannte sich. Nur kurzzeitig durchsuchten Japaner Ausländer beim Verlassen der Konzessionen nach Fapi-Noten. Die alte Währung behauptete sich. Am 30. März 1939 boten Japans Generalkonsul und der kommandierende General den westlichen Vertretern normale Beziehungen an, wenn es keine antijapanischen Vorfälle in der Region gebe. Im Mai nahm Japan das Gesetz zurück, das Besitzern von Fapi-Noten lebenslange Haft androhte, und erklärte ihren Besitz für zulässig. Tokio hoffte, daß die Chinesen die alten Scheine umtauschten. Als hätte es eine stillschweigende Vereinbarung gegeben, akzeptierte die französische Stadtverwaltung die neue Währung, zunächst sogar zum gleichen Kurs wie die Regierungsnoten, obwohl das neue Geld auf dem Markt deutlich weniger wert war ${ }^{73}$.

Mitte Mai stieg jedoch die Spannung zwischen Japanern und Briten in Tientsin: Die Japaner forderten die Auslieferung von vier Chinesen, die sie beschuldigten, am 9. April in der britischen Konzession einen kollaborierenden Beamten erschossen zu haben. Das prominente Opfer war Cheng Chi-kung, Zollkommissar in Tientsin und Direktor der Filiale der Federal Reserve Bank in Peking. Die Briten befürchteten eine Invasion ihrer Konzession in Tientsin und des Botschaftsviertels in Peking. Der britische Generalkonsul Jamieson hatte den Japanern die vier Chinesen zum Verhör vorübergehend überstellt. Zwei der vier Beschuldigten gestanden ihre Tat vor den Japanern sowie vor dem britischen Generalkonsul und dem britischen Polizeichef. Kurz darauf widerriefen sie ihr Geständnis. Am 1. Juni verlangte das japanische Militär die Herausgabe der vier Chinesen innerhalb einer Woche. London überstellte zwar zwei chinesische Bombenleger, aber nicht die vier Beschuldigten. Am 8. Juni

\footnotetext{
${ }^{72}$ Léger an Corbin, T 346-49, Saint-Quentin, T 304-7, 3.3., Knobel an Bonnet, T 357, 5.3., Bonnet an Knobel, T 104, 9.3., Bonnet an Corbin, T 402-3, Saint-Quentin, T 326-27, 10.3.; Léger an Henry, T 117, 6.3., T 123, 9.3., Phipps an Léger, Note, 8.3.1939 (MAE Chine 831, 884); Léger an SaintQuentin, T 328-29, 10.3.; Corbin an Bonnet, T 689-90, 10.3., Henry an Bonnet, T 145, 10.3., T 154, 12.3., Léger an Saint-Quentin, T 340, 14.3.1939 (MAE Chine 761, 1071); Halifax an Clark Kerr, 7.3.1939 (DBFP, $3^{\text {rd }}$ series, VIII, 539); Hamilton, Memorandum, 11.3.1939 (FRUS 1939, III, S. 380).

${ }^{73}$ Knobel an Bonnet, T 396-97, 13.3., T 454, 2.4.1939 (MAE Chine 884, 773); Knobel an Bonnet, T 410-11, 17.3., T 445, 30.3., Léger an Henry, T 154, 23.3., Henry an Bonnet, T 192, 29.3., note de la sous-direction, 29.3.; Cosme an Bonnet, L 128, 13.4., Boissezon an Cosme, L 198, 12.5., Léger an Henry, T 211, 15.5., T 218, 20.5., Colin an Cosme, L 34, 4.5., Léger an Cosme,T 178-9, 15.5.1939 (MAE Chine 831, 1071); FNEO, compte rendu, 5.5.1939 (SHM 1 BB4 74).
} 
drohte Japan, binnen einer Woche eine Blockade über die britische Konzession zu verhängen, falls die Briten nicht nachgäben ${ }^{74}$.

Der britische und der amerikanische Generalkonsul, der französische Konsul Colin und Botschafter Cosme empfahlen, die Verdächtigen auszuliefern. Man dürfe nicht mutmaßliche Terroristen schützen und die Konzessionen gefährden. Colin, Cosme und Bonnet lehnten eine Demarche der Mächte in Tokio ab, weil dies Paris in den Konflikt verstricke. Bonnet ließ kein gutes Haar an der britischen Politik: London nehme eine Haltung ein, die von Tokio nie akzeptiert werde. Die Konfrontation gefährde alle Konzesssionen. Bonnet drohte Phipps mit dem Entzug der französischen Solidarität. Cadogan erwiderte Corbin, es gebe keine Beweise gegen die Beschuldigten, er glaube nicht, daß Japan Gewalt anwende. Zudem suche Japan nur einen Vorwand, um die seit langem gewollte Kraftprobe mit den Briten zu suchen. Selbstkritisch schrieb Cadogan aber in sein Tagebuch: $» I$ think this thing has been mishandled ${ }^{75}$.

Nach Beginn der Blockade am 14. Juni warnte Bonnet Phipps eindringlich, Hitler könne die Spannungen in Asien zu einem Angriff auf Polen nutzen. Deshalb solle London eine rasche Lösung in Tientsin suchen. In Washington erklärte der französische Botschafter, dessen Regierung den Briten soeben ihre Distanz klargemacht hatte, wie wichtig die Solidarität der westlichen Mächte sei. US-Präsident Roosevelt schob jedoch ebenso jede Verantwortung von sich: Er sagte Saint-Quentin zwar, die drei westlichen Mächte müßten zusammenstehen. Die US-Regierung ging aber über die Erklärung, sie verfolge mit besonderem Interesse die Entwicklung in Tientsin, nicht hinaus ${ }^{76}$.

Fast die gesamte Lebensmittelversorgung der britischen Konzession wurde unterbunden, Briten und Chinesen wurden beim Betreten und Verlassen des Gebietes auf demütigende Weise durchsucht. Das Foreign Office nahm an, daß Japan Großbritannien jetzt als Machtfaktor in China ausschalten wollte. In Asien drohte der Ausbruch eines Krieges: Vom 16. Juni bis Anfang August, als die Krise in Europa wieder oberste Priorität in London erhielt, erwogen

\footnotetext{
${ }^{74}$ Cosme an Bonnet, T 609, 11.5., T 625, 13.5.1939 (MAE Chine 837, Chine 1063); Colin an Cosme, L 37, 15.5., Phipps, Note, 18.5.1939 (MAE Chine 832); Joumal Yong Pao vom 20., 22., 25., 27.4., FNEO, compte rundu, 5.6.1939 (SHAT 11 H 63, SHM 1BB 4 74); Léger an Henry, T 221-22, 20.5., STS-bulletin, 1.6.1939 (MAE SDN 366, Chine 535); WATT, How War Came, S. 352; CufFORD, Retreat from China, S. 116f.; SHAI, Origins of the War, S. 214f.; Peter LowE, Britain and the Opening of War in Asia, 1937-41, in: NisH (Hg.), Anglo-Japanese Alienation, S. 103-122 (S. 105).

${ }^{75}$ Cosme an Bonnet, T 990, 10.6., Boissezon an Bonnet, T 707-10, 10.6., T 713-14, 11.6., Corbin an Bonnet, T 1846-47, 14.6., Bonnet an Corbin, T 1146-49, 14.6., Léger an Henry, T 253, 15.6.; Corbin an Bonnet, T 1818, 12.6.1939 (MAE Chine 837, SDN 366); Cosme an Bonnet, T 11-12, 13.6., Corbin an Bonnet, T 1829, 13.6., T 1834, 14.6., note de la sous-direction d'Asie-Océanie, 12.6.1939 (MAE Chine 1066); Wilson an Hull, 13.6.1939 (FRUS 1939, IV, S. 179f.); CADOGAN, Diaries, S. 187.

${ }^{76}$ Bonnet an Corbin, T 1186-87, Saint-Quentin, T 738-49, Boissezon, T 1066, 17.6.1939 (DDF XVI, 463); Saint-Quentin an Bonnet, T 952-54, 16.6., T 971-72, 19.6., T 973, 19.6., T 983, 21.6.1939 (MAE Chine 761, MAE RFD 27, DDF XVI, 471, MAE Chine 1066).
} 
Chamberlain und die Marineführung die Entsendung einer Schlachtflotte nach Ostasien. Die französische Regierung erfuhr von diesen Plänen nichts.

Mit Beginn der Blockade ließ sich Bonnet täglich direkt aus Tientsin über die Entwicklung informieren. Japan erhöhte nun die Forderungen: Großbritannien müsse japanische Polizei in der Konzession zulassen, die Silberreserven herausgeben und dürfe die Politik der Pekinger Regierung nicht behindern. Offenbar, so der Eindruck in London, wolle Tokio England zwingen, die japanische Ordnung in Nordchina zu akzeptieren. Die deutsche Presse schrieb, der ausländische Einfluß in China insgesamt stehe auf dem Spiel. Die TientsinKrise beherrschte die Schlagzeilen der internationalen Presse ${ }^{77}$.

Botschafter Cosme empfahl Konsul Colin Geschmeidigkeit gegenüber Japan, die aber nicht als Mangel an Solidarität mit den britischen Behörden erscheinen dürfe. Frankreichs und Japans Konsul vereinbarten, Frankreichs Konzession werde wie bisher versorgt. Täglich passierten fünf französische Lastwagen mit Lebensmitteln die Barrikaden. Die Versorgung des französischen Gebiets sei befriedigend, meldete Colin. Problemlos passierten Franzosen, Deutsche und Amerikaner die Kontrollen. Selbst den zuvor schwierigen Abtransport von Müll und Särgen aus der französischen Konzession erleichterte Japan. Als außergewöhnlich höflich und sehr korrekt schilderte Oberst Casseville die Haltung der Japaner. Daß Japan die westlichen Konzessionen auseinanderdividieren wollten, war offenkundig. Erstmals seit Juli 1937 suchte mit General Homma ein japanischer General das französische Hauptquartier im Ost-Arsenal auf. Er erinnerte an die alte Verbindung zwischen beiden Ländern und entschuldigte sich dafür, daß die Franzosen wegen der geographischen Nähe ihrer Konzession von der Blockade mitbetroffen seien. Die Franzosen revanchierten sich, indem sie Japan die Nutzung französischer Landungsbrücken an der Küste erlaubten. Ende Juli schrieb Militärattaché Yvon, in allen Konzessionen in China behandelten die Japaner die Franzosen ausgesprochen höflich. Frankreichs Position sei stabil wie selten ${ }^{78}$.

77 Ovendale, Anglo-American Relations, S. 34f.; DERS., »Appeasement«, S. 240; Bonnet an Boissezon, T 236, 15.6., Corbin an Bonnet, T 1852-53, 15.6.1939 (MAE Chine 837); Bonnet an Colin, T 12, 16.6.1939 (MAE Chine 838); Havas Tokio, les conditions nippones, 16.6.; Corbin an Bonnet, T 1865-68, 16.6.1939 (MAE Chine 773, 1066); EMG.2, bulletin de renseignement $\mathrm{n}^{\circ} 47$, 6.7.1939 (SHM 1BB2 92); HARVEY, Diplomatic Diaries, S. 297f.; CADOGAN, Diaries, S. 46; S. 187f.; PRITCHARD, Far Eastern Influences, S. 155f.; BARNHART, Japan and the World, S. 121.

${ }^{78}$ Cosme an Bonnet, T 17-18, 14.6.1939 (MAE Chine 837); Colin an Bonnet, T 11, 16.6., T 12, 17.6., T 13, 18.6., T 26, 29.6., Charvériat an Corbin, T 1352, Saint-Quentin, T 826, 3.7.1939 (MAE Chine 832); Colin an Daladier, L 2, 30.1.1940 (MAE Chine 1069); Colin an Bonnet, T 19, 23.6., T 20, 24.6., Yvon an Guerre, T 725-26, 20.6.; Boissezon an Bonnet, T 711, 10.6., T 749, 29.6.1939 (MAE Chine 838, 773); Colin an Bonnet, T 32, 19.7., Cosme an Bonnet, T 790, 11.7.1939 (MAE Chine 1067); Casseville an Guerre, T 24, 17.6., T 26, 23.6; Oberstleutnant Onno an Casseville, L 30/S, 22.6.; Casseville an Bührer, L 82, 21.6.1939 (SHAT 11 H 60, 61, 63); Militär Shanghai an EMG.2, T 1297, 14.6., FNEO, compte rendu, 5.7.1939 (SHM 1 BB4 74); Yvon, Note, 30.7.1939 (MAE Chine 737). 
Die Japaner lobten die Franzosen überschwenglich: Bei US-Generalkonsul Caldwell in Tientsin würdigte Japans Generalkonsul, die französischen Behörden verteidigten kraftvoll die Konzession, doch mit ihnen könne man reden, während die britschen Generalkonsuln stur und unvernünftig seien. Beim deutschen Generalkonsul stellten die Japaner heraus, die Franzosen seien entgegenkommend und respektierten "die besonderen Verhältnisse in Nordchina«. Dem britischen Militärattaché Piggott sagten die Japaner, daß sie mit der französischen Bekämpfung chinesischer »Terroristen« sehr zufrieden seien. Bei Casseville lobten japanische Stellen Colins "geschickte Politik «. In Tokio erklärten japanische Offiziere Italiens Botschafter Giacinto Auriti, die Franzosen in Tientsin betrieben eine versöhnliche Politik und distanzierten sich von den Briten. Bei US-Geschäftsträger Eugene Dooman und Botschafter Henry lobten japanische Diplomaten die »umfassende Zusammenarbeit« und die »konziliante Haltung« der französischen Behörden in Tientsin ${ }^{79}$.

Gegenüber den Briten blieben die Franzosen in Tientsin auf vorsichtiger Distanz: Im Rahmen des Möglichen gebe man den Briten, die sehr schlecht versorgt seien, jede Hilfe, schrieb Colin am 22. Juni. Wenig später jedoch stellten die französischen Behörden den Lebensmittel-Großhandel mit den Briten ein, um zu verhindern, so der Konsul, daß die Japaner der französischen Konzession vorwerfen könnten, sie versorge die britische Niederlassung. Die Briten durften aber individuell in Frankreichs Konzession Nahrung kaufen ${ }^{80}$.

Offenbar gelang den Franzosen der Spagat zwischen Geschmeidigkeit und Solidarität. Cosme lobte Colins Geschick, die Japaner zufriedenzustellen und sich die Anerkennung der Briten zu sichern. In britischen Akten findet sich keine Kritik an den Franzosen in Tientsin, auch bei amerikanischen, deutschen oder italienischen Diplomaten klagten die Briten nicht. Den britischen Verantwortlichen in Tientsin, Shanghai und London war wohl klar, daß sie durch unglückliches Taktieren einen Konflikt provoziert hatten, in dem sie nicht erwarten durften, daß sich ihr europäischer Partner selbst in Gefahr brachte.

Oberst Casseville und sein Geheimdienstchef Hauptmann Magnien in Tientsin sowie Botschaftsrat Baron Fain in Tokio gewannen den Eindruck, alle westlichen Mächte seien Ziel der Japaner. Lépissier, der in Versailles Urlaub machte, und Chauvel betonten Mitte Juni hingegen, der Konflikt bestehe nur zwischen Briten und Japanern. Dennoch untersuchte Chauvel, wie man

\footnotetext{
${ }^{79}$ Caldwell an Hull, 26.6.1939 (FRUS 1939, IV, S. 199f.); Stoller an Ribbentrop, 17.7.1939 (AA, Pol Il Po 3 England Bez GB-Japan 3); PIGGOTT, Broken Thread, S. 325; Casseville an Bührer, L 82, 21.6.1939 (SHAT 11 H 63); Auriti an Ciano, 16.6., 22.6.1939 (DDI Serie 8, XII, 242, 304); Dooman an Hull, 18.7.1939 (SD 894.00 P.R./139); Henry an Bonnet, L 161, 21.8.1939 (MAE Chine 1064).

${ }^{80}$ Thiébaut an EMA.2, L 89, 14.6.1939 (DDF XVI, 426); Colin an Bonnet, T 18, 22.6., L 49, 6.7.1939 (MAE Chine 832, 1067); Stoller an Ribbentrop, 19.6.1939 (AA Pol VIII 58 B 1); Colin an Daladier, T 8-9, 31.1.1940 (MAE Chine 1069).
} 
Tientsin verteidigen könne. Tatsächlich gab es starke Kräfte in Japans Militär, die auch Frankreich aus Nordchina herausdrängen wollten. Daß die Franzosen zunächst verschont blieben, lag an ihrem entgegenkommenden Verhalten, wie der deutsche Generalkonsul meldete, " Kollege zugab, nicht so wichtig sind und leicht serledigt` werden können, wenn erst einmal England in Ostasien niedergezwungen ist ${ }^{81}$.

Für Cosme war Flexibilität gegenüber Japans Militär nicht nur in Tientsin geraten. Einerseits stehe China wirtschaftlich und politisch vor dem Kollaps, andererseits werde sich Japan gegen Frankreich wenden, sobald Englands Widerstand gebrochen sei. Die Nähe zu Japan und seinen Marionettenregimen sei die einzige Möglichkeit, um die französische Position in China zu behaupten, argumentierte der Botschafter Ende Juli 1939: Zwischen den Konfliktparteien könne Paris nur eine neutrale, opportunistische Position einnehmen.

Kurz darauf wurde Cosme noch deutlicher: Falls Amerika die britischen und französischen Interessen vorbehaltlos unterstütze, müsse man energisch gegen Japan vorgehen. Wenn nicht, hätten Paris und London das Risiko ihrer Fernostpolitik allein zu tragen. "Dans ce cas, il m'apparaît que nous aurions tout intérêt à composer avec le Japon«. Dies gelte umso mehr, als Japan die Franzosen wohl bald zwingen werde, ihre geschmeidige und neutrale Politik zu beenden und sich zwischen Chungking und Tokio zu entscheiden ${ }^{82}$.

In Tientsin ging es auch um die in den Konzessionen gelagerten Silberreserven der chinesischen Regierung im Wert von 50 Millionen Dollar ${ }^{83}$. Schon 1935 hatte Japan verhindert, daß Silber von Tientsin nach Shanghai und damit aus seinem Einflußbereich heraus gebracht wurde. Im Juli 1938 erhob das Marionettenregime in Peking Anspruch auf die Reserven. Die Franzosen versicherten Chiang Kai-shek und Japan, sie gäben das Silber bis zum Kriegsende niemanden heraus. Mit chinesischer Zustimmung erklärten sich britische und

\footnotetext{
${ }^{81}$ Magnien an Casseville, T 210, 18.6., Casseville an Bührer, L 82-1/2-S, 21.6.1939 (SHAT 11 H 80, 63); Cosme an Bonnet, L 248, 30.7.; Fain an Chauvel, L, 15.6.1939 (MAE Chine 737, 736); Note Lépissier, 16.6., notes de la sous-direction d'Asie-Océanie, 17.6., 5.7.1939 (MAE Chine 1066, 785, 831); Stoller an Ribbentrop, 17.7.1939 (AA, Pol II Po 3 England Bez GB-Japan 3).

${ }^{82}$ Cosme an Bonnet, T 848-50, 27.7., T 857-58, 1.8.1939 (MAE Chine 1067); Cosme an Bonnet, L 248, 30.7.1939 (MAE Chine 737); Cosme an Léger, L, 5.8.1939 (DDF XVII, 443).

${ }^{83}$ Den Wert des Silbers schätzten Naggiar und Lacoste auf 37 bis 40 Millionen Dollar, Silber für weitere 16 Millionen Dollar hätten Chinas Banken im extraterritorialen Botschaftsviertel in Peking deponiert. Das Silber in Peking jedoch sprachen die Japaner nie an. Die Asienabteilung im Quai d'Orsay schätzte, daß Silber für sechs Millionen Dollar in Peking und 53 Millionen Dollar in Tientsin eingelagert war, davon für 48 Millionen in der französischen Konzession (Naggiar an Lacoste, T 658-59, 17.5.1938; Lacoste an Naggiar, L 462, 9.8.1939; Note de la sous-direction d'Asie-Océanie, 4.7.1939 [MAE Chine 769, Chine 884, Chine 1067]). CLIFFORD schätzt den Wert des Silbers in der britischen Konzession von Tientsin auf 14 Millionen Dollar sowie auf 20 bis 40 Millionen für die Bestände auf französischem Gebiet. In Peking habe Silber für 6,4 Millionen Dollar unter britischem sowie für wmehrere Millionen mehr« unter französischem Schutz gelagert (Retreat from China, S. 75).
} 
französische Behörden im Februar 1939 bereit, das Silber vor japanischen Zeugen zu versiegeln. Doch Japans Militär wollte nicht zusagen, die Reserven bis Kriegsende unangetastet zu lassen ${ }^{84}$. Ihre Forderungen, das Silber herauszugeben, richteten die Japaner 1939 und 1940 aber nicht an die Franzosen, in deren Konzession das meiste Silber lagerte, sondern stets an die Briten.

Die französische Regierung schaltete sich ein, als das Foreign Office am 27. Juni mitteilte, in Tokio stünden britisch-japanische Verhandlungen über die Konzessionen und die Lage in Nordchina bevor. Am 20. Juni hatte Craigie Außenminister Arita erklärt, London stimme Verhandlungen über alle Fragen $\mathrm{zu}$, wenn Tokio die diskriminierenden Maßnahmen beende und die britische Herrschaft über die Konzession respektiere. Der Quai d'Orsay fürchtete, daß die Briten westliche Rechte aufgaben. Charvériat warnte Phipps, britische Zugeständnisse träfen auch die französische Konzession. Die Briten sollten in allen Grundsatzfragen unnachgiebig bleiben, vor allem in den Fragen der chinesischen Währungen und des deponierten Silbers ${ }^{85}$.

Da sich die USA im März 1939 bereits zur Frage der Währungen in Nordchina geäußert hatten, fühlte Bonnet am 7. Juli vor, ob Washington sich an den Gesprächen in Tokio beteiligen wolle. London bat Paris, vereint zu versuchen, Amerika ins Spiel zu bringen. Um den USA die Intervention zu erleichtern, wies Bonnet Henry an, im Gaimusho die britische Position zu unterstützen. Henry, der Chamberlain für die Spannungen verantwortlich machte, führte den Auftrag jedoch nicht aus. Saint-Quentin erklärte Welles in Washington, Briten und Franzosen könnten sich ohne die USA Japans Hegemonie kaum widersetzen. Welles stimmte $\mathrm{zu}$, lehnte aber jedes US-Engagement $\mathrm{ab}^{86}$.

Craigie und Arita vereinbarten eine Erklärung, die am 24. Juli veröffentlicht wurde. Die britische Regierung erkannte die Lage in China an, und erklärte, sie werde japanische Maßnahmen, die der Sicherheit ihrer Truppe oder der

\footnotetext{
${ }^{84}$ WATT, How War Came, S. 54; Japanischer Generalkonsul an Lépissier, 17.8., Lacoste an Naggiar, T 276-77, 14.5.; T 381-82, 31.7., Naggiar an Lépissier, T 108-10, 20.7., Botschaftsrat Horiuchi an Lacoste, L, 30.7.1938 (MAE Chine 884, 770); Lacoste an Knobel, T 579, 23.12., Knobel an Bonnet, T 1962-66, 15.12.1938; T 20-22, 4.2., T 191-97, 14.2., Léger an Knobel, T 66, 14.2.; Corbin an Bonnet, T 2005, 27.6., Colin an Bonnet, T 23, 27.6.1939 (MAE Chine 830, 831, 838).

${ }^{85}$ Bonnet an Cosme, T 255-61, 27.6., Cosme an Bonnet, $T$ 752-53, 30.6.; Corbin an Bonnet, $T$ 2011, 28.6., T 2075-80, 4.7.1939 (MAE Chine 1066, 838, 885); Note pour l'ambassadeur, 29.6., Bullitt an Hull, 30.6.1939 (MAEN Londres C 482, FRUS 1939, IV, S. 210f.); Charvériat an Cosme, T 269-70, Corbin, T 1327-38, Saint-Quentin, T 819-20, 1.7., Phipps an Charvériat, Note, 6.7.; Colin an Bonnet, T 28, 3.7.1939 (MAE Chine 1067, 831); FNEO, compte rendu, 5.7.1939 (SHM 1 BB4 74); Charvériat an Phipps, L, 30.6., 6.7.1939 (MAE Papiers 1940, cabinet Bonnet 3; DDF XVII, 128).

${ }^{86}$ Phipps an Halifax, 6.7., 7.7., Halifax an Phipps, 11.7., Lindsay an Halifax, 12.7.1939 (DBFP, $3^{\text {rd }}$ series, IX, 288, 292, 303, 306); Chauvel, Note, 7.7.; Bonnet an Henry, T 294, 7.7.; Phipps an Charvériat, 12.7.1939 (MAE Chine 831, 885, 1067); Bonnet an Saint-Quentin, T 847-49, 7.7., Léger an Saint-Quentin, T 853-54, 8.7., Saint-Quentin an Bonnet, T 1147-51, 12.7., T 1154-56, 15.7., Henry an Bonnet, T 407-10, 18.7.; T 426, 29.7.1939 (DDF XVIl, 138, 146, 181, 208, 225, MAE Chine 773).
} 
Aufrechterhaltung der öffentlichen Ordnung dienten, nicht beeinträchtigen und antijapanische Aktivitäten in der Konzession unterbinden. Im Unterhaus sagte Chamberlain, London ändere seine Haltung nicht. Die Franzosen lobten die Vereinbarung. Henry nannte sie vernünftig, sie bewahre Englands Würde und gebe Japan keinen Blankoscheck. Bonnet und der Armeegeneralstab in Paris erklärten, die Entspannung in Tientsin verbessere die Lage in Europa. Für Vize-Admiral Decoux hingegen war die Erklärung ein Beweis des britischen Defätismus. Auch US-Zeitungen und Chinas Regierung warfen den Briten zu große Nachgiebigkeit vor. Die Presse in Italien und Deutschland jubelte über »die britische Kapitulation«. Trotz der Vereinbarung blieb die Blockade in Tientsin in Kraft, offenbar, weil japanische Soldaten auf das Bestechungsgeld, das Briten beim Passieren der Sperre zahlten, nicht verzichten wollten ${ }^{87}$.

Die Historiographie bewertet die Übereinkunft als »fernöstliches München« (Fabrice Abbad), als »ersten Schritt zum Appeasement Japans« (Bradford A. Lee), "wichtigen Teil der Erosion britischer Prinzipien in China (Aron Shai), »Legalisierung der Beschneidung westlicher Rechte« (Frederick Samuel Northedge), »Offenbarung der britischen Ohnmacht« (Harold S. Quigley), »wichtigen Propagandasieg Japans« (Nicolas R. Clifford) und »schweren Schlag für das westliche Prestige« (Wesley R. Fishel). Sir Robert Craigie verweist in seinen Memoiren aber darauf, daß die Alternative Krieg oder den Verlust der Konzession bedeutet hätte. England sei keine neuen Verpflichtungen eingegangen und habe keine Prinzipien aufgegeben. Peter Lowe hält den Preis, den Großbritannien gezahlt habe, für gering. Donald C. Watt schreibt, die Vereinbarung habe einen Rückzug, die Besetzung der Konzession und einen Krieg verhindert. Ein sehr edler Sieg sei es jedoch nicht gewesen, so Watt ${ }^{88}$.

Tatsächlich war es London ohne substantielle Verluste gelungen, einen Krieg in Asien zu vermeiden. Dabei wurde das britische Prestige, auf dem Großbritanniens Position im Fernen Osten stark ruhte, allerdings enorm beeinträchtigt. Eine Alternative besaß London nicht.

\footnotetext{
${ }^{87}$ Corbin an Bonnet, T 2335, 24.7., T 2365-67, 26.7., Cosme an Bonnet, T 848-50, 27.7., Colin an Bonnet, T 34, 27.7.1939 (MAE Chine 1067); Henry an Bonnet, T 415-18, 23.7., EMA.2, note, 23.7.1939 (DDF XVII, 281; SHAT 7 N 2524); Saint-Quentin an Bonnet, T 1209-14, 25.7.1939 (MAE Chine 1064); François-Poncet an Bonnet, T 3100-4, 27.7.1939 (MAE RFD 27); Steffenelli an Ciano, 16.7.1939 (DDI Serie 8, XII, 591); TAYLOR, The Struggle for North China, S. 138.

${ }^{88}$ ABBAD, Histoire du Japon, S. 139; LEE, Britain and the Sino-Japanese War, S. 195; Aron SHAI, Was there a Far Eastern Munich?, in: Journal of Contemporary History 9.3 (1974), S. 161-169 (S. 169), ähnlich in: DERS., Le conflit anglo-japonais de Tientsin en 1939, in: Revue d'histoire moderne et contemporaine 22 (1975), S. 293-302 (S. 302); Frederick Samuel NoRTHEDGE, The Troubled Giant. Britain among the Great Powers 1916-1939, London 1966, S. 478; QuigleY, The Far Eastern War, S. 238; ClIFFORD, Retreat from China, S. 123; FisHEL, The End of Extraterrioriality, S. 201; CRAIGIE, Behind the Japanese Mask, S. 75, S. 78; LOWE, Britain and the Opening of the War, S. 107; WATT, How War Came, S. 54, S. 350, S. 359.
} 
Das Klima der britisch-japanischen Verhandlungen, bei denen es nun um Währungen und Silberreserven ging, änderte sich grundlegend, als Roosevelt als Reaktion auf die im Tientsin-Abkommen demonstrierte britische Schwäche am 26. Juli das amerikanisch-japanische Handelsabkommen kündigte. Léger wies Henry an, Englands Position zu unterstützen, denn französisch-britische Solidarität erleichtere Amerika die Intervention in Tokio. Der Botschafter sagte Arita, Frankreichs und Großbritanniens Haltungen seien in der Silber- und Währungsfrage identisch. Chauvel hoffte, der Eindruck französischer Entschlossenheit in Tokio helfe, Amerikas Unterstützung in Europa zu gewinnen. Am 9. August betonte Paris öffentlich die Übereinstimmung französischer und amerikanischer Interessen in Asien - sicher erneut mit Gedanken an die Krise in Europa ${ }^{89}$. Um Bewegungsspielraum zu gewinnen, erklärte sich London am 11. August bereit, die vier beschuldigten Chinesen auszuliefern. Am 5. September erfolgte die Übergabe. Eine Woche später wurde ein chinesischer Guerilla-Führer, der seit einem Jahr in britischer Haft saß, ausgeliefert ${ }^{90}$.

Mit dem Durchbruch der Craigie-Arita-Erklärung wechselte die französische Aufmerksamkeit schlagartig von Nord- nach Südchina: Ab Mitte Juli glaubte Brévié, ab Ende Juli auch das Deuxième Bureau der Armee und der Marine-Geheimdienst in Shanghai, die Landung zweier japanischer Divisionen in Südchina stehe bevor. Viermal bombardierte Japans Luftwaffe Ende Juli die Straße von Langson nach Nanning. Mitte Juli und Anfang August verletzten bei sieben Zwischenfällen 17 japanische Flugzeuge indochinesischen Luftraum. Die französische Luftabwehr schoß ohne Folgen auf die Flugzeuge. Offenbar wollte Japan den Nachschubweg von Indochina nach Südchina zerstören. Wegen der Krise in Europa verzichtete Paris auf Proteste ${ }^{91}$.

${ }^{89}$ Léger an Henry, T 317-19, 27.7., Henry an Bonnet, T 421-24, 28.7., Corbin an Bonnet, T 2433, 31.7.1939 (MAE Chine 1067); Campbell an Halifax, 29.7., 1.8., Halifax an Campbell, 6.8., 17.8.1939 (DBFP, $3^{\text {rd }}$ series, IX, 416, 440, 485, 541); Léger an Henry, T 321-22, 29.7., Henry an Bonnet, T 439-40, 1.8.; T 442-43, 1.8., Charvériat an Phipps, L, 11.8.1939 (MAE Chine 885, DDF XVII, 376, 524); Dooman an Hull, 2.8.1939 (FRUS 1939, III, S. 438f.); Léger an Henry, T 331-33, 2.8., notes de la sous-direction d'Asie-Océanie, 8.8., 9.8.; Henry an Bonnet, T 447, 3.8.1939 (MAE Japon 132, Chine 761, 1068); Saint-Quentin an Bonnet, T 1147-51, 12.7., note de la sous-direction d'Asie pour le ministre, 16.8., Phipps an Charvériat, L, 18.8.1939 (DDF XVII, 181; XVIII, 81, 133); Présidence du Conseil, état chronologique des événements [ohne Datum] (AN Fonds Daladiers 496 AP 8).

${ }^{90}$ Cambon an Bonnet, T 2541, 11.8.1939 (MAEN Londres C 482); Cosme an Bonnet, T 969, 7.9.1939 (MAE Chine 838); Colin an Daladier, T 42, 16.9.1939 (MAE Chine 1068). Die vier Beschuldigten wurden Ende 1939 von den Japanem nach Peking gebracht, wo sich ihr Spur verlor (SHAI, Origins of the War, S. 233). Im Herbst 1940 bezichtigten sich drei junge Chinesen beim britischen Botschafter Clark Kerr so glaubhaft des Mordes in Tientsin, daß er annahm, die Männer, die Japan übergeben worden waren, seien unschuldig (Clark Kerr an Cadogan, 7.9.1940, FO 371/24652, F 3838/5/10).

${ }^{91}$ Brévié an Mandel, T 1161, 15.7., T 1173, 18.7., T 1280, 4.8., T 1287, 6.8., T 1288, 7.8.1939 (CAOM FM Tel 80); EMA.2, bulletin de renseignement, 27.7.1939 (SHAT 7 N 2516); STS-bulletin, 1.8., STS an EMG.2, T 1590, 3.8.1939 (MAE Chine 535, SHM 1 BB9 48); Walsh an Halifax, 11.8, 13.9.1939 (FO 371/22921, C 11770, C 16180/249/17). 
Vom 10. bis 14. August warnten Brévié und Cosme vor einer unmittelbar drohenden Landung in Pakhoi. Thiébaut hielt eine Blockade gegen Indochina und Luftangriffe auf die Kolonie für denkbar, schloß aber eine Landung aus: Japan richte sich nicht gegen den Westen oder die Sowjetunion, solange der Krieg in China andauere. Auch der Quai d'Orsay nahm an, Japan werde nichts gegen Indochina unternehmen und seinen Angriff auf Südchina beschränken ${ }^{92}$.

Mitte August entspannte sich in Tientsin die Lage, weil eine Flutwelle die Stadt überschwemmte und jede Kontrolle unterband. Nach der Craigie-AritaErklärung drohte der internationalen Ordnung die größte Gefahr nicht mehr in Asien, sondern wieder in Europa.

\subsection{Die weltpolitischen Lager bilden sich}

Die Weltpolitik war 1939 geprägt von Bündnisverhandlungen und der Verfestigung der Lager. Die Revisionisten in Tokio, Rom und Berlin rückten zusammen, doch ein Militärpakt zwischen Japan und einer Macht in Europa kam nicht zustande. Im Lager der Status-quo-Mächte vereinbarten allein London und Paris eine militärische Zusammenarbeit. Die USA hielten Distanz zu Europas Demokratien, übten aber zunehmend Druck auf Japan aus. Selbst wenn man die Sowjets 1939 - wohl zu Unrecht ${ }^{93}$ - zu den Status-quo-Mächten rechnete, so schwenkte Moskau nach langen Verhandlungen mit London und Paris mit dem Hitler-Stalin-Pakt im August 1939 doch in Hitlers Lager.

Schon im Sommer 1938 hatten von Ribbentrop und Japans Militärattaché Ochima über eine Umwandlung des Antikominternpaktes in ein Militärbündnis gesprochen. Am 29. August 1938 stimmte das engere Kabinett in Tokio Verhandlungen mit Berlin zu; das Bündnis solle jedoch in erster Linie gegen die Sowjetunion gerichtet sein. Den Westen dürfe man nicht alarmieren. Die Frage, ob Japan in ein Bündnis mit Hitler gegen die Demokratien eintreten solle, spaltete Japans Regierung: Der Tenno sowie die Führungen des Außenund des Marineministeriums lehnten einen Pakt gegen den Westen ab; das Heer und die Admiralität waren dafür. Bis August 1939 beriet das Kabinett in

\footnotetext{
${ }^{92}$ Brévié an Mandel, $\mathrm{T}$ 1313, 10.8., T 1333-34, 13.8 .1938 (CAOM FM Tel 80); Cosme an Bonnet, T 897, 14.8.1939 (DDF XVIII, 12); Thiébaut an EMA.2, L 44, 8.8.1939 (SHAT 7 N 3332); Bullitt an Hull, 17.8.1939 (SD 793.94/15312).

${ }_{93}$ Klaus HILDEBRAND betont, Moskau habe in der Zwischenkriegszeit die bestehende internationale Ordnung umfassend revolutionieren wollen, auch mit dem Mittel des Krieges (Krieg im Frieden und Frieden im Krieg. Über das Problem der Legitimität in der Geschichte der Staatengesellschaft 19311941, in: Historische Zeitschrift 244 [1987], S. 1-28 [S. 8f., S. 18f.]).
} 
Tokio 70 Mal über diese Frage. Die Marineführung um Minister Yonai Mitsumasa und seinen Stellvertreter Admiral Yamamoto Isoroku war der entscheidende Gegner eines Militärpaktes gegen den Westen. Ihr Argument war, daß Großbritannien und Frankreich bei einem solchen Pakt China helfen würden, während die Armee betonte, dieser Pakt verhindere westliche Hilfe an China ${ }^{94}$.

Anfang Januar 1939 erhielt der Quai d'Orsay, vielleicht aus Moskau, Hinweise, Japan, Deutschland und Italien strebten ein Militärbündnis an. Henry meldete, Japans Heer und die Marine wollten einen Pakt gegen Moskau, doch der Kaiser sei strikt dagegen. Die Reichsregierung erklärte, ein Partner wünsche die Ergänzung des Antikomintempaktes durch eine Militärklausel, aber nicht Deutschland. Ende Januar hörte Chauvel, japanische Diplomaten aus London, Rom, Brüssel und Berlin hätten sich in Paris getroffen, um über die Umwandlung des Antikominternpakts in eine Militärallianz zu sprechen ${ }^{95}$.

Mitte Februar 1939 meldete der französische Militärattaché aus Tokio, Japan, Deutschland und Italien stünden vor dem Abschluß eines Bündnisses. Japan wolle dann China Frieden anbieten, um Indochina angreifen zu können. Auch Henry hatte von einem Friedensschluß gehört. Den Gerüchten schenkte Léger keinen Glauben: In China werde ständig über Friedensschlüsse geredet, das Scheitern Wang Ching-weis zeige aber, daß es keine Ergebnisse gebe. Paris habe kein Interesse an diesem Frieden, weil der Krieg japanische Kräfte binde, die sich sonst gegen Moskau oder die Konzessionen richteten. Strittig war, wer die treibende Kraft der Gespräche war: Payart in Moskau und Henry nahmen an, Berlin und Rom wollten den Pakt gegen die Westmächte richten. Léger hingegen glaubte, vor allem Japan strebe den Militärpakt $a^{96}$.

Paris verfolgte die deutsch-japanischen Verhandlungen passiv. Die Asienabteilung schrieb, Japan werde einen Krieg in Europa ausnutzen - ob mit oder ohne Militärallianz. Vielleicht hatte Paris durch dechiffrierte Telegramme oder abgehörte Telefonate auch so viel erfahren, $\mathrm{da}$ ßes die Gespräche zwischen Berlin, Tokio und Rom entspannt verfolgen konnte. In Tokio wurden Briten und Franzosen von Gegnern des Bündnisses ständig informiert. Diplomaten, Vertraute des Ministerpräsidenten, Abgeordnete, Journalisten und der sowjetische Spion Voukélitch hielten Havas-Korrespondent Guillain auf dem neu-

\footnotetext{
${ }^{94}$ FeIs, Road to Pearl Harbor, S. 27f.; KreBS, Japans Deutschlandpolitik, S. 175, S. 228; OHATA, The Anti-Comintern-Pact, S. 55f.; IMAI Seiichi, Cabinet, Emperor and Senior Statesmen, in: BoRG, OKamoto (Hg.), Pearl Harbor, S. 53-79 (S. 71); JonEs, Japan's New Order, S. 99f.

${ }^{95}$ Henry an Bonnet, T 20-23, 13.1., Coulondre an Bonnet, T 272, 27.1.1939 (MAE Japon 148, RFD 28); Sorge an Rote Armee, 10.12.1938 (SPE I, 71); Bullitt an Hull, 30.1.1939 (SD 701.9451/20).

${ }_{96}$ EMA.2, note, 20.2.; Léger an Henry, T 80-81, 17.2., Léger an Cosme, T 158-59, 2.5.1939 (SHAT 7 N 2524, MAE Japon 123; DDF XVI, 6); Henry an Bonnet, T 108-11, 16.2., T 136-39, 6.3., T 144, 8.3., T 180-82, 23.3., T 221-23, 11.4.1939 (DDF XIV, 127, 265, 279; MAE Japon 123, Chine 735); Payart an Bonnet, D, 18.3.; Charvériat an Corbin, T 355, 4.3.1939 (DDF XV, 61, MAE Chine 761).
} 
esten Stand ${ }^{97}$. Die Verhandlungen zwischen Tokio und Berlin scheiterten, weil sich Tokio in keinen europäischen Krieg hineinziehen lassen wollte.

Die Sicherheit Indochinas beruhte auf dem Frieden in Europa. Als die Gefahr an Frankreichs Grenzen stieg, mußte Paris auch in Asien Verbündete suchen. Der natürliche Partner war Großbritannien. Den Grad an militärischer Kooperation bestimmten in Europa und Asien die Briten. Das britische Militär lehnte die Zusammenarbeit mit Paris bis 1935 ab. Mißtrauen gegenüber Franzosen nimmt William Gregory Perett als Ursache an; Anthony Clayton glaubt, daß das Militär in London Frankreich mit Mißtrauen sah, aber auch wußte, daß Paris keine andere Option hatte, als Englands Verbündeter zu sein. Daß die chiefs of staff auf dem Kontinent ihren Handlungsspielraum bewahren wollten, nehmen Buckley, Haslam und Neave-Hill an. Als die Royal Navy im Konflikt mit Rom über Abessinien im Herbst 1935 Partner suchte, kam es am 30. Oktober zum ersten britisch-französischen Stabsgespräch seit dem Weltkrieg. Im Dezember 1935 folgten Kontakte zwischen den Stäben des Heeres und der Luftwaffe. Militärabsprachen blieben aus. Mit der Entspannung im Mittelmeer im Januar 1936 wurden die Kontakte eingestelit, nur der 1935 begonnene Informationsaustausch der Geheimdienste blieb erhalten ${ }^{98}$.

Zwei Monate, nachdem Chautemps London im November 1937 vergeblich gebeten hatte, ein Spitzengespräch über europäische und fernöstliche Fragen zu führen, forderte Daladier die Teilstreitkräfte und das Kolonialministerium auf, Vorschläge für eine konkrete Zusammenarbeit mit den Briten im Mittelmeer zu machen. Daladier und General Gamelin gingen zwar davon aus, daß Japan einen Angriff Deutschlands und Italiens auf Frankreich möglicherweise ausnutzen werde, doch ein realistischer Konflikt schien nur im Mittelmeer zu drohen. Das Kolonialministerium regte am 17. Februar 1938 an, mit London über eine militärische Kooperation im Fernen Osten zu sprechen und dort eine Zusammenarbeit mit Niederländern und US-Amerikanern anzustreben ${ }^{99}$.

\footnotetext{
${ }^{97}$ SOMmER, Deutschland, S. 178; GullLAIN, Orient Extrême, S. 64f.; Note de la sous-direction d'AsieOcéanie, 9.8.1939 (MAE Chine 761). Auch der frankophile Staatsmann Fürst Saionji käme als Informant in Frage. Darauf gibt es aber keinen Hinweis (Saionji-Harada Memoirs. Fragile Victory. Prince Saionji and the 1930 London Treaty Issue from the Memoirs of Baron Harada Kumao. Translated with an Introduction and Annotations by Thomas Francis MAYER-OAKES, Detroit 1968; Lesley CoNNORS, The Emperor's Adviser. Saionji Kinmochi and pre-war Japanese politics, Beckenham u.a. 1987).

${ }_{98}$ Perett, French Naval Policy, S. 213f., S. 323f.; Clayton, The British Empire, S. 253; P.N. BUCKLEY, E. B. HASLAM, W.B.R. NEAVE-HILl, Anglo-French Staff Conversations, in: Les relations franco-britanniques de 1935 à 1939, S. 91-118 (S. 94); YouNG, In Command, S. 160; THOMAS, Britain, France and Appeasement, S. 166; PERETT, French Naval Policy, S. 33 If.

${ }^{99}$ Phipps an Eden, 22.11 .1937 (FO 371/20698, C 8039/3285/17); Daladier an Steeg, D, 1.2., Steeg an Billotte, D 265, 8.2., Daladier an Jamet, D, 7.3., Daladier à Paul-Boncour, D, 8.4.1938 (DDF VIII, 82, 128, 331; IX, 144); Gamelin an Daladier, L 238/DM.3, 4.4., général Jamet, note $\mathrm{n}^{\circ} 286 / \mathrm{DN}, 24.4 .1938$ (SHAT 2 N 224, 227); Billote an Steeg, D 28, 17.2.1938; Lelong an Daladier, D 16/S, 18.2., EMAA.2, note, 4.3.1938, Corbin an Daladier, D 223, 8.3.1938 (DDF VIII, 194, 206, 316, 345).
} 
Bei dem Gipfeltreffen am 28./29. April 1938 einigten sich Chamberlain, Halifax, Daladier und Bonnet, daß die Teilstreitkräfte beider Länder offizielle Kontakte aufbauten, jedoch nur auf Attachéebene, unverbindlich und nur auf Deutschland bezogen. Chamberlain stellte Daladier seine Zustimmung als britisches Zugeständnis dar. Tatsächlich hatten Chamberlain und Eden schon im Februar 1938 ihre Stabschefs aufgefordert, den Widerstand gegen Kontakte mit Frankreich aufzugeben. Das Militär hatte die Ablehnung damit begründet, daß Stabsgespräche mit Paris Londons Bemühungen um eine Annäherung an Deutschland erschwerten und Japan in das deutsche Lager drängen könnten ${ }^{100}$.

Dabei hatte Englands Marine die französische Flotte längst in ihre Strategie einbezogen: Im Konfliktfall sollten die Royal-Navy-Verbände im Mittelmeer und in Ostasien einander verstärken. London baute darauf, daß bei der Verlegung britischer Kräfte nach Asien die Franzosen die Vorherrschaft im westlichen Mittelmeer verteidigen würden. Die französische Flotte wußte nicht, daß sie Teil der britischen Mittelmeer-/Fernost-Strategie war, aber spätestens 1935, als die Briten Schiffe aus Asien ins Mittelmeer verlegten, wurde ihr die Verbindung beider Krisenregionen klar. Corbin klagte im Juni 1938, die Navy benutze die Mittelmeerflotte als Reserve-Fernostgeschwader ${ }^{101}$.

Während Paris in Europa seit den zwanziger Jahren den Schulterschluß mit London suchte, blieb der Quai d'Orsay in Asien lange auf Distanz zu den Briten, die erst Hauptfeind des chinesischen Nationalismus, dann Anführer der Bewegung zur Aufgabe der extraterritorialen Privilegien und schließlich Speerspitze des antijapanischen Widerstands waren. Westliche Interessen waren nie so konkret bedroht, daß dies eine französisch-britische Allianz in Asien erzwungen hätte. Wenn nötig, wie 1927 bei Chiangs Marsch auf Shanghai oder 1932 bei Japans Landung in dieser Stadt, traten beide Staaten ad hoc gemeinsam militärisch auf. Während der Sudetenkrise begannen die französischen und britischen Heeres- und Marineverbände in Asien erstmals, militärische Informationen auszutauschen. Im Oktober 1938 bauten Briten und Franzosen eine Funkverbindung zwischen ihren Hauptquartieren in Shanghai auf, vermieden es aber, gemeinsame Codes festzulegen ${ }^{102}$.

\footnotetext{
${ }^{100}$ FO-Memorandum, April 1938 (FO 371/21591, C 3687/13/17); Corbin an Bonnet, D 396, 29.4., Daladier an Gamelin, D 106, 14.5.; Darlan an Gamelin, L 93, 30.5.; Note, conversations d'état-majors, 29.4.1938 (DDF IX, 258, 341; SHM 1 BB2 182; SHAT 2 N 227); COOPER, Old Men Forget, S. 220; BELL, France and Britain, S. 214; YouNG, In Command, S. 200; HARVEY, Diplomatic Diaries, S. 89f.; S. 132f.; Werth, The Twilight, S. 171; PERetT, French Naval Policy, S. 343f.

${ }^{101}$ THOMAS, Britain, France and Appeasement, S. 162, S. 234; William Roger Lous, The Road to Singapore: British Imperialism in the Far East, 1932-42, in: Wolfgang J. MOMMSEN, Lothar KeTtENaCker (Hg.), The Fascist Challenge and the Policy of Appeasement, London, Boston, Sydney 1983, S. 352-388 (S. 370f.); Corbin an Bonnet, D 501, 1.6.; Darlan an Gamelin, Note No. 146, 17.10.1938 (DDF IX, 501; SHM 1BB2 171).

${ }^{102}$ FNEO an EMG.2, T 6869-71, 19.9, T 6958-60, 20.10.1938 (SHM 1 BB9 40-41).
} 
Als Reaktion auf Hinweise auf einen drohenden deutschen Angriff auf Holland stimmte London Militärverhandlungen mit Paris zu. Am 3. Februar 1939 regte London Stabsgespräche über Pläne für einen Krieg gegen Deutschland und Italien an und ergänzte am 25. Februar, auch für Asien sollten Konzepte entworfen werden. Am 6. Februar 1939 gab Chamberlain im Unterhaus Frankreich eine Beistandsgarantie ab, am 20. Februar äußerten die chiefs of staff intern, es liege im Interesse Großbritanniens, sich an Frankreichs Verteidigung zu beteiligen. Die Ankündigung der französisch-britischen Gespräche ließ den deutschen Konsul in Hanoi annehmen, »daß die politische und militärische Zusammenarbeit Englands und Frankreichs im Fernen Osten einen Grad erreicht hat, der von einer Allianz nicht mehr zu unterscheiden ist ${ }^{103}$.

Vor der ersten Runde der Stabsgespräche, die vom 29. März bis 4. April 1939 in London stattfand, dachte Paris über mögliche Ziele nach. Das Kolonialministerium schlug einen gemeinsamen Präventivschlag gegen Siam vor, damit britische und französische Kolonien an einer Front gegen Japan kämpfen könnten. General Gamelin stimmte zu. General Dentz vom Generalstab der Armee regte ein defensives Vorgehen an: Man solle die Briten für die Verteidigung Indochinas gewinnen. Die französische Marineführung lehnte jede Festlegung in Asien ab. Daladier wies Militärattaché General Albert Lelong an, für den Fall einer japanischen Intervention umfassende Hilfe für die Truppen Chiang Kai-sheks anzustreben. Um Chinas Versorgung zu sichern, sollten britische und französische Truppen Kanton und Hainan von den Japanern befreien. Ein gemeinsamer Angriff auf Siam solle für den Fall geplant werden, daß sich Bangkok auf die Seite Tokios schlage ${ }^{104}$.

Das Committee of Imperial Defence stand unmittelbar davor, die seit Jahrzehnten gültige strategische Annahme aufzugeben, im Falle eines Konfliktes mit Japan eine Schlachtflotte nach Singapur zu entsenden. Erwogen wurde nun, sich ganz auf Europa zu konzentrieren. Auf Wunsch der Briten sprachen beide Seiten deshalb zunächst nur über eine Zusammenarbeit in Europa ${ }^{105}$.

${ }^{103}$ PrITChARD, Far Eastern Influences, S. 191; Aide-mémoire, 3.2., Gamelin an Daladier, L 321, 22.2.1939 (SHAT 7 N 3439); Compte rendu, 10.2., Daladier an Diplomatie, Marine, Air, Colonies, L $150 \mathrm{DN}, 24.2 .1939$ (SHAT 5 N 579); Phipps an Halifax, 24.2., Phipps an Charvériat, 25.2.1939 (DBFP $3^{\text {rd }}$ series, IV, 143; FO 371/22923, C 2384/281/17); HARVEY, Diplomatic Diaries, S. 233; PERETT, French Naval Policy, S. 385f.; DU RÉAU, Daladier, S. 340f.; BELL, France and Britain, S. 222; Neumann an Ribbentrop, 10.2.1939 (AA, Botsch Peking Pol 5-12).

${ }^{104}$ YouNG, In Command, S. 227; Mandel an Gamelin, D, 27.9.; Bührer an Gamelin, L, 10.10., EMG marine, note $n^{\circ} 1265,29.12$; EMA, note $n^{\circ} 4685$, 13.10., Gamelin, note, 23.11.1938; Gamelin an Daladier, L 71, 18.1., Secrétariat général du Conseil supérieur de la défense nationale, directives, 7.3.1939 (DDF XI, 406, SHAT 2 N 227, DDF XII, 104, 376, SHAT 5 N 579, DDF XIV, 275).

${ }^{105}$ Committee of Imperial Defence, Strategical Appreciation Sub-Committee, Minutes, 13.3.; British Strat. Memor. AFC (39) 1, 18.3., Committee of Imperial Defence, Report, 22.3.1939 (FO 371/22923, C 4177, 3508, 3893/281/17); Lelong an Gamelin, L 56, 8.4.; Daladier, cabinet du ministre, notes, 29.3., 12.4.; Lelong an Daladier, D 56, 5.4.1939 (SHM 1 BB2 182; SHAT 5 N 579, DDF XV, 274). 
Nach Italiens Einmarsch in Albanien am 7. April verlangten Daladier, Bonnet und Léger, die Briten sollten sich auf das Mittelmeer konzentrieren. Am 13. April gaben London und Paris Garantien für die Sicherheit Rumäniens und Griechenlands ab. Großbritannien konnte in einer Krise in Asien kaum noch die Mittelmeerflotte entsenden. Vor der zweiten Runde der Gespräche, die vom 24. April bis zum 4. Mai in London stattfand, strebten der Quai d'Orsay und General Gamelin an, daß England seine Prioritäten in Europa setzte. Sie argumentieren, London könne Japan vernachlässigen, weil sein Heer in China gebunden und seine Marine Nachschub aus Amerika benötige. Die Briten sollten die Flotte im Krieg erst dann nach Asien entsenden, wenn Italiens Marine ausgeschaltet sei. Man müsse in Asien defensiv bleiben, um die Kontrolle im Mittelmeer zu behaupten. Zudem wollten sie über ein gemeinsames Vorgehen in Südchina, gegen Siam und bei der Verteidigung Indochinas sprechen ${ }^{106}$.

Während der Konferenz wollten die Briten nicht ausschließen, in einer Krise starke Kräfte nach Singapur zu entsenden, falls es den USA und der Sowjetunion nicht gelänge, Japan zur Zurückhaltung zu bringen. Die britische Delegation versprach aber, vor der Entscheidung über die Entsendung der Flotte nach Singapur die französische Regierung zu konsultieren.

London ging davon aus, daß Japan mit 19 Divisionen die Kolonien angreifen könne, Paris nahm an, Tokio könne vier Divisionen ins Feld schicken. Die französische Delegation erklärte, ihre Truppen in Indochina seien fähig, die Kolonie zu verteidigen und zudem mit chinesischen und britischen Verbänden offensiv in Südchina vorzugehen. Diese Offensive, die Hongkong entlaste, sei auch ohne britische Beteiligung möglich. Für diesen Feldzug könnten die Franzosen eine Division, die Chinesen acht Divisionen bereitstellen. Die Operation solle vom Kommandeur in Indochina geführt werden, so Frankreichs Vorschlag. Briten und Franzosen vereinbarten, daß ihre Kommandeure Pläne bei einer Konferenz in Singapur besprechen sollten. Themen seien dann die Militärhilfe an China, die Offensive im Raum Kanton sowie mögliche Operationen gegen Siam, falls sich dieses auf Japans Seite schlage ${ }^{107}$.

\footnotetext{
${ }^{106}$ Bullitt an Hull, 10.4., 11.4.1939 (SD 740.00/758, 770); Phipps an Halifax, 9.4., 10.4.1939 (DBFP, $3^{\text {rd }}$ series, V 106, 115); Diplomatie an Marine, T 153-65, 7.4., T 177, 13.4., T 181, 14.4.1939 (SHM 1BB9 44-45); EMG.2 an FNEO, T 4916, 9.4., T, 11.4.; Campinchi an Daladier, L 62, 5.5.1939 (SHM 1 BB9 185; 1BB2 172); WATT, How War Came, S. 259; EMA.3, note, 15.4.1939 (SHAT 7 N 3439); R. John PRITCHARD, The Far East as an Influence on the Chamberlain Governement's Pre-war European Policies, in: Millenium 2 (1973), S. 7-23 (S. 17); DERS., Far Eastern Influences, S. 196; Gamelin, Daladier, notes pour M. Lelong, 22.4.; Conseil supérieur de la défense nationale, secrétariat général, note, 24.4. 1939 (SHAT 7 N 4195, 5 N 579); PERETr, French Naval Policy, S. 434.

${ }_{107}$ General Lelong an Gamelin, L, 12.5., procès-verbal de la $9^{\mathrm{e}}$ séance. 24.4., note de la délegation, D.F. 16 [April 1939] (SHM 1BB2 182); EMG.3, instructions et renseignements, très secret [April 1939] (SHAT 7 N 3439); Intervention du Japon, A.F.C. (J) 17 (SHM 1BB2 182); Lelong an Gamelin, D 110, 5.5., procès-verbal de la $11^{\mathrm{e}}$ séance, 25.4.1939 (DDF XVI, 79).
} 
Überschätzten die Franzosen die Kampfkraft ihrer Truppen gewaltig, oder zeichneten sie den Briten bewußt ein rosarotes Bild der Lage? Da Daladier, Bonnet und Léger Amerikanern und Briten oft sagten, wie aussichtslos die Verteidigung Indochinas sei, liegt die Vermutung nahe, daß die Franzosen ihre Fähigkeiten in Asien übertrieben, damit die Briten dem Mittelmeer Priorität gaben. Das Committee of Imperial Defence und das britische Kabinett planten tatsächlich, die Flotte auf das Mittelmeer zu konzentrieren. Gamelin wies seine Kommandeure an, in Singapur über zwei Operationen zu sprechen, eine britisch-französische Aktion gegen Siam und eine Offensive in Südchina ${ }^{108}$.

Die Planung von Offensiven sollte dafür sorgen, daß kein Gedanke an die eigene Schwäche aufkam, was Rufe nach Verstärkungen aus Europa hätte auslösen können. Bis zur Konferenz von Singapur vergingen wegen Streits auf französischer Seite sechs Wochen: Die Flottenführung in der Rue Royale und Vize-Admiral Decoux lehnten das Treffen ab; das Kolonialministerium verlangte, in die Gespräche einbezogen zu werden; Oberst Casseville, Chef des Corps d'occupation en Chine, reiste erst gar nicht nach Singapur und erklärte, er fühle sich durch mögliche Vereinbarungen nicht gebunden. Die Franzosen reisten mit elf Mann, darunter Vize-Admiral Jean Decoux, General Maurice Martin, der Chef des Heeres in Indochina, und der Luftwaffenchef im Fernen Osten, Oberst Deveze, zur Konferenz, die Briten mit 31 Offizieren. Das zeigte den geringen Stellenwert, den die Franzosen dem Treffen einräumten ${ }^{109}$.

Bei der Konferenz in Singapur vom 22. bis 27. Juni herrschte ein pessimistischeres Klima als bei den Stabsgesprächen in London. Beide Seiten betonten, ihre Kräfte reichten nicht einmal aus, um die Schlüsselstellungen Singapur, Penang, Indochina und Hongkong zu behaupten. Von ihren Regierungen verlangten sie, in Asien aufzurüsten. Über die Offensive in Südchina wurde nicht mehr beraten. Mit China solle man erst nach Japans Kriegseintritt über die Entsendung von Militärberatern reden. Die Operation gegen Siam, die die Briten strikt ablehnten, wurde als starker Wunsch der Franzosen in den Beschlüssen erwähnt. Die Briten gaben zu, den Rückzug aus allen Positionen östlich von Singapur zu erwägen, und versuchten, französische Unterstïtzung für die Verteidigung ihrer Besitzungen zu organisieren. Die Franzosen lehnten

\footnotetext{
${ }^{108}$ Chiefs of Staff Sub-Commitee, Note, 11.5.1939 (FO 371/22924, C 7047/281/17); Christopher M. BELL, The 'Singapore Strategy< and the Deterrence of Japan: Winston Churchill, the Admirality and the Dispatch of Force Z, in: English Historical Review 467 (2001), S. 604-634 (S. 612f.); Lelong an Daladier, D 140, 18.5., L 183, 18.6.1939 (DDF XVI, 225; SHAT 11 H 60); Gamelin an Diplomatie, L 1 129, 2.6., Gamelin an Lelong, L 1137, 5.6.1939 (SHAT 5 N 579, 2 N 246).

${ }^{109}$ DECOUX, À la barre de l'Indochine, S. 14; PERETT, French Naval Policy, S. 437; EMG.3 an FNEO, T 5466, 24.5., FNEO an EMG.2, T 7650-52, 4.6.1939 (SHM 1 BB9 186, 47); Brévié an Mandel, T 933, 28.5.1939 (CAOM FM Tel 80); Bührer an Gamelin, L 140, 22.5., Gamelin an Stabschefs Marine, Air, T 1145, 5.6.1939 (SHAT 2 N 246); Patton (Singapur) an Hull, 22.6.1939 (SD 793.94/15195).
} 
dies ebenso ab wie den britischen Vorstoß, alle alliierten Truppen unter britisches Kommando zu stellen. Die Franzosen wiesen dies aus Prinzip zurück, aber auch, wie Decoux in seinen Memoiren schreibt, weil die Briten stärker unter japanischem Druck gestanden hätten als die Franzosen, die dann in einen Konflikt hineingezogen worden wären. General Bührer versuchte später, doch noch ein einheitliches Kommando zu erreichen, aber Admiral Darlan, der jede Unterordnung unter die Briten ablehnte, unterband dies. Auch Militärattaché Yvon lehnte es ab, den Briten mit ihrem Rückzugsgeist das Kommando anzuvertrauen ${ }^{110}$. Einzige konkrete Folge des Treffens war, daß im August 1939 zwei französische Verbindungsoffiziere in das Far East Combined Bureau in Singapur entsandt wurden, das die britischen Geheimdienste in Ostasien koordinierte. Weitere Konsequenzen wurden den Regierungen überlassen.

Das Ergebnis der Konferenz wurde in der Literatur als Ausdruck der Hilflosigkeit der Mächte (Gerhard Krebs), als für Frankreich besorgniserregend (Gottfried Haas) und enttäuschend (Étienne Le Baube) gewertet. Der spätere Außenminister Paul Baudouin klagte, die Singapur-Konferenz habe bei den wenigen Personen, die davon erfuhren, die Illusion zerstört, daß Paris bei der Verteidigung seiner pazifischen Besitzungen auf London würde bauen können ${ }^{111}$. Tatsächlich ist das Treffen aber als französischer Erfolg zu werten: London folgte nämlich, wie sich schon vor der Konferenz abgezeichnet hatte, Frankreichs Prioritäten, und räumte Europa unbedingten Vorrang ein ${ }^{112}$.

Die Ergebnisse der Konferenz wurden geheimgehalten und in den folgenden britisch-französischen Stabsbesprechungen nicht mehr erwähnt, mit Ausnahme des britischen Wunsches, über die Entsendung alliierter Militärberater für China zu sprechen. Nach Kriegsausbruch im September 1939 wurde dieser Plan nicht weiter verfolgt. Singapur, wo Briten und Franzosen erstmals ihre militärischen Pläne besprachen, war gleichzeitig die letzte alliierte Militärkonferenz über fernöstliche Fragen bis zum Untergang der Dritten Republik ${ }^{113}$.

\footnotetext{
${ }^{110}$ Rapport final, conférence de Singapour, 27.6.1939 (DDF XVII, 20); EMG-SE Les conversations d'état-majors navals en 1939 dossier $n^{\circ}$ A. 16 [Anfang August 1939] (SHM 1BB2 182); BÜHRER, Aux heures tragiques, S. 91f.; DeCoux, À la barre de l'Indochine, S. 18f.; ONG, Operation Matador, S. 95f,; Yvon, note, 29.7.1939 (SHAT 7 N 3292); EMG-SE, note, 1.8.1939 (SHM 1BB2 172).

${ }^{111}$ ELPHICK, Far Eastern File, S. 154; GARDER, La guerre secrète, S. 124; KREBS, Japans Deutschlandpolitik, S. 235; HAAS, Französisch-Indochina, S. 47f.; LE BAUBE, La perception, S. 124; Supreme Headquarters, Allied Expeditionary Force, an State Department, 8.11.1944 (SD 851 g.00/11-844).

${ }^{112}$ Pritchard, Far Eastern Influences, S. 195; G.C. Peden, The Burden of Imperial Defence and the Continental Commitment Reconsidered, in: The Historical Journal 27.2 (1984), S. 405-423.

${ }^{113}$ Guariglia an Ciano, 28.6., Patton an Hull, 6.7.1939 (DDI Serie 8, XII, 256, SD 793.94/15257); Procès-verbal, 13.7., note, très secret, 8.8., procès-verbal, $14^{\mathrm{e}}$ séance, 28.8.1939 (SHM 1BB2 182); Comité de défense impériale, projet d'ordre du jour, August 1939 (SHAT 7 N 3439); DECoux, À la barre de l'Indochine, S. 26; Bührer, instruction pour les conversations du 28.8.1939, 27.8., Bührer an Gamelin, D 184, 26.7.1939 (SHAT 11 H 64; DDF XVII, 318); Committee of Imperial Defence an Clarke, 6.12.1939 (FO 371/23551, F 12466/4027/61); EMA, note, 4.9.1939 (SHAT 7 N 3301).
} 
$\mathrm{Da}$ die Konferenz von Singapur ergebnislos blieb, hatte mehrere Ursachen: Das gegenseitige Mißtrauen war nur schwer zu überwinden; beide Seiten strebten vor allem an, Schutz für die eigenen Besitzungen zu vereinbaren; das wichtigste Ziel der Franzosen war, daß sich die Briten eben gerade nicht im Fernen Osten engagierten; und schließlich war die Bedrohung durch Japan offenbar nicht so drängend, daß sie Militärabsprachen erzwungen hätte.

Mit einem französischen Mißerfolg endeten dagegen die Bemühungen um die Kooperation britischer und französischer Kolonien: Georges Mandel bat Kolonialminister Malcolm MacDonald von Februar bis Juni 1939 mehrfach, die gemeinsame Verteidigung der Kolonien zu besprechen. Dieses Treffen sollte auch Härte gegenüber deutschen und italienischen Kolonialforderungen demonstrieren. Doch erst vertröstete das Colonial Office Mandel auf später, dann wurde ihm erklärt, seine Fragen würden bei den Stabsgesprächen mitbehandelt. Intern warnte das Foreign Office, Mandels Besuch werde Bonnet, Deutschland und Italien mißfallen. Erst am 16./17. März 1940 kam das Treffen von Mandel und MacDonald zustande. Mandel strebte die gleichzeitige Rekrutierung Wehrpflichtiger in den Kolonien an und wollte die Zusammenarbeit der Kolonialbehörden formalisieren, etwa durch den Austausch von Verbindungsbeamten. Das lehnte MacDonald ebenso ab wie Konferenzen der Gouverneure benachbarter Kolonien. Selbst den von Mandel angeregten Austausch von Radioprogrammen und stärkeren Handel zwischen den Kolonien schlug MacDonald aus. Jacques Valette nennt beiderseitiges Mißtrauen als Ursache der mangelhaften Zusammenarbeit in kolonialen Fragen ${ }^{114}$. Tatsächlich aber regierte das Mißtrauen vor allem im Colonial Office, weniger in der Rue Oudinot in Paris.

Die USA waren der Wunschpartner der Franzosen. Nur Amerika, so die seit Ende 1938 herrschende Meinung in der französischen Regierung, konnte einen Krieg in Europa verhindern und den Status quo in Asien bewahren. Eine USPolitik der Stärke im Pazifik sollte Japan mäßigen und die Briten davon abhalten, Kräfte von Europa nach Asien zu verlegen. Erstmals nach der Brüsseler Konferenz sprach am 10. November 1938 ein französischer Minister den USGeschäftsträger auf eine Kooperation im Fernen Osten an. Eine Woche zuvor hatte Hull mit dem Vorschlag, die drei Demokratien sollten vereint gegen die Sperrung des Jangtse protestieren, Paris Kooperationsbereitschaft signalisiert. Weil auch Welles nach der Münchener Konferenz Saint-Quentin erklärt hatte,

\footnotetext{
114 Note Moore, 10.2., Note Roberts, 11.2, Note Sargent, 13.2.1939 (FO 371/22922, C 2021/281/17); Phipps an Sargant, 10.3.1939 (FO 371/22923, C 2995/281/17); Paskin an Harvey, 7.6.1939 (FO 371/22932, C 8079/797/17); Colonial Office an Foreign Office, 6.3., 8.3., Harvey an Halifax, 21.3., Campbell an Halifax, 15.5.1940 (FO 371/24325, C 3771, 3772, 4456, 4456/3652/17); Note pour le ministre, conférence franco-anglaise (CAOM Fonds Mandel, 18/PA/1); Minutes of the Meeting on March $16^{\text {th }}$, Paris (SHAT 2 N 233); VALETTE, Problèmes des relations internationales, S. 171.
} 
daß für ihn nun Asien Vorrang habe, hielt es Bonnet für möglich, die USA über Ostasien ins französische Lager zu ziehen. Bonnet sagte Wilson, Amerika solle in Asien die Führung übernehmen. Er verstehe, daß sich Amerika aus Europa heraushalte, wo es nicht direkt betroffen sei, doch er hoffe, daß es in China, wo seine Interessen ernsthaft bedroht seien, eine aktivere Rolle spiele.

Wie Roosevelt machte nun auch Daladier die französisch-amerikanischen Beziehungen zur Angelegenheit des Regierungschefs. Daladier setzte stark auf Bullitt, der im Herbst 1938 seine Haltung zu Japan geändert hatte: Ende 1937 hatte der Botschafter dem Präsidenten noch von einem Engagement im Fernen Osten abgeraten. Japan gleiche das Gewicht der Sowjets aus und sei von einer Beherrschung Asiens weit entfernt. Im August 1938 drängte Bullitt Roosevelt, China gegen Japan zu helfen. Daladier setzte den Botschafter in Washington Saint-Quentin, mit dessen Arbeit er unzufrieden war, nur noch selten ein ${ }^{115}$.

Daladier und Léger waren überzeugt, daß man Washington am besten für sich gewinne, wenn man unterschwellig auf das amerikanische Interesse an einem Kräftegleichgewicht in Europa und Asien setze, ohne Amerika zu einer bestimmten Politik, oder gar zur Übernahme einer Führungsrolle zu drängen. Dazu dramatisierten sie die Lage. Im Februar und April 1939 warnte Daladier vor einem bevorstehenden Angriff Deutschlands und betonte, wie sehr sich Hitler und Mussolini nach den USA richteten. Bonnet tat dies, etwa bei einer Parteiversammlung am 25. Juni 1939, auch öffentlich: Die Aussage der USA, daß sie im Falle eines Krieges auf Seiten Frankreichs stehe, schrecke bereits ab. Die Atmosphäre zwischen beiden Ländern, die durch die von Frankreich nicht getilgten Weltkriegsschulden erheblich belastet war, versuchten Daladier und Finanzminister Reynaud im Frühjahr $1939 \mathrm{zu}$ verbessern, indem sie die Zahlung von 300 Millionen Dollar und die Abtretung von Inseln anboten. Roosevelt hielt eine rasche Lösung der Schuldenfrage aber für unmöglich ${ }^{116}$.

Als Deutschland Prag besetzte und die französische Regierung Washington warnte, daß ein japanischer Angriff auf Hongkong, Singapur, Indochina und die Konzessionen in Shanghai bevorstehe, handelte Roosevelt: Am 16. April

\footnotetext{
${ }^{115}$ Saint-Quentin an Bonnet, T 1084-86, 1.10.1938 (DDF XI, 515); Wilson an Hull, 10.11.1938 (SD 751.62/495); Bullitt an Roosevelt, 7.12.1937, in: Bullirt (Hg.), For the President, S. 243f.; Bullitt an Hull, 8.8.1938 (FRUS 1938, III, S. 544f.); Bullitt an Roosevelt, 8.8.1938 (zit. nach Norman A. GraEBNER, Hoover, Roosevelt, and the Japanese, in: BORG, OKOAMOTO [Hg.], Pearl Harbor, S. 2552 [S. 43]). Daladier nannte Saint-Quentin einen Idioten und wollte ihn durch Luftfahrtminister La Chambre ablösen lassen (Bullitt an Hull, 6.2.1939, SD 740.00/568). Welles klagte wiederholt über die Planlosigkeit ("his usual desultory manner«) des Botschafters (Welles, Memoranda of Conversation, 22.6., 21.12.1939, FRUS 1939, III, S. 676, S. 99f.).

${ }^{116}$ Bullitt an Roosevelt, Undated [Februar 1939], 4.4.1939 (BuLliTt, For the President, S. 311, S. 335); Bullitt an Hull, 5.6., 28.6., 13.9., 25.9.1939 (FRUS 1939, I, S. 269f., S. 277f.; SD 740.0011 European War 1939/284, 548); LANGER, GLEASON, The Challenge, S.141; BLUMENTHAL, Illusion and Reality, S. 200, S. 205; DALADIER, Journal, S. 67; Bullitt an Hull, 13.2.1939 (SD 851.248/139).
} 
verlegte er die US-Flotte vom Atlantik in den Pazifik. Der Generalstab der Armee in Paris, Vize-Admiral Decoux und Léger sahen die Anordnung erleichtert als Warnung an Japan. Roosevelt hatte aber nicht das Gleichgewicht in Asien, sondern in Europa im Blick. Der Präsident wollte den Briten ermöglichen, die Flotte, die in den Fernen Osten verlegt werden sollte, im Mittelmeer zu belassen. Bullitt hatte Roosevelt berichtet, Paris wolle für den Fall, daß London die Mittelmeerflotte nach Singapur schicke, den Widerstand gegen Hitlers Pläne in Osteuropa einstellen. Bullitt empfahl am 11. April die Verlegung der US-Flotte in den Pazifik. Roosevelt handelte entsprechend ${ }^{117}$.

Einen Monat später traten die USA so stark wie nie zuvor gemeinsam mit Frankreich und Großbritannien auf - ausgerechnet in der kleinen Internationalen Konzession auf der Insel Kulangsu vor der Hafenstadt Amoy in Südchina und ohne daß Paris oder London darum gebeten hätten. Amoy gehörte $1842 \mathrm{zu}$ den ersten fünf Häfen, die China dem westlichen Handel öffnete. Im Januar 1902 richteten Frankreich, Großbritannien, Japan, die USA, Deutschland, Spanien, Dänemark, die Niederlande, Schweden und Norwegen die eineinhalb Quadratmeilen große Internationale Konzession ein, in der 1937 neben 40000 Chinesen 300 Ausländer lebten. Die 20 Franzosen dort waren Beamte oder gehörten drei reichen chinesischen Familien an. Naggiar betonte, Frankreichs Interessen hier seien unbedeutend. Als Japan im Mai 1938 Amoy besetzte, organisierte der französische Konsul Lebocq als Doyen des konsularischen Korps die Versorgung von 60000 chinesischen Flüchtlingen ${ }^{118}$. Die Lage auf Kulangsu blieb ruhig. Das änderte sich, als am 11. Mai 1939 der chinesische Präsident der Handelskammer von Amoy erschossen wurde und am Folgetag japanisches Militär in die Internationale Konzession einrückte. Zum ersten Mal besetzte Japan eine westliche Konzession! Léger in Paris und das Foreign Office entschieden, den Konflikt herunterzuspielen: Ein Protest in Tokio reiche aus. Die Entsendung von Truppen wurde nicht erwogen ${ }^{119}$.

Daß Japan versuchen könnte, an einer unbedeutenden Konzession ein Exempel zu statuieren, oder daß der Westen eine Demonstration seiner Entschlossenheit geben könnte, spielte in Paris ebensowenig eine Rolle wie in London und Washington. Erst später äußerten die Fernostflotte, der Armee-

${ }^{117}$ Bullitt an Hull, 24.3., Memorandum, 11.4.1939 (SD 740.00/676, 851g.014/18); EMA.2, rapport, 30.4., EMA.2, bulletin, 4.5., Dentz, compte rendu, 20.4., FNEO, compte rendu, 5.5.1939 (SHAT 7 N 2515, 2516, 2525; SHM 1 BB4 74); UTLEY, Going to War, S. 57f;; HULL, Memoirs, Bd. 1, S. 630.

${ }^{118}$ QuigleY, The Far Eastern War, S. 147; WooD, No Dogs, S. 39; Consulat Amoy, note, 10.1.1930; Lagarde an Wilden, L, 26.11.1932; Naggiar an Bonnet, T 461, 1.4., T 633-35, 12.5., T 647-48, 15.5., T 705, 27.5., Lebocq an Naggiar, L 38, 14.5., L 39, 19.5., L 44, 6.6.1938 (MAE Chine 836, 790).

${ }^{119}$ Roy an Naggiar, L, 3.10., L, 12.11.1938; STS-bulletin, 1.4.; Cosme an Bonnet, T, T 613, 12.5.1939 (MAE Chine 790, 535, 791, 735); Léger an Corbin, T 943, 12.5.; Corbin an Bonnet, T 1534, 15.5., Henry an Bonnet, T 291, 16.5.; T 628-29, 16.5.1939 (MAE Chine 761, 791, 736); Broadmeat an Halifax, 13.5., Halifax an Craigie, 13.5.1939 (DBFP, $3^{\text {rd }}$ series, IX, 63, 65). 
Generalstab und das Kolonialministerium in Paris, Japan habe in Kulangsu testen wollen, wie entschlossen der Westen die Konzessionen verteidigte ${ }^{120}$.

Die britische und die amerikanische Fernostflotte entsandten jedoch Kreuzer. Als auch der Chef der britischen Asienflotte Sir Percy Noble nach Amoy kam, änderte Léger seinen Kurs. Am 16. Mai drängte er, sich mit einem französischen Kriegsschiff an der Flottendemonstration zu beteiligen. Die Marine schickte ohne Zögern das Patrouillenboot Rigault de Genouilly. Zugleich ließ Léger in Tokio gegen Japans Eingriff protestieren. Daß der Westen in Kulangsu triumphierte, hatte er der Entschlossenheit der britischen und amerikanischen Kommandeure zu verdanken. Angesichts ihrer Stärke - zwei amerikanische und vier britische Kriegsschiffe ankerten vor Amoy - entschieden die Kommandeure am 17. Mai auf Initiative des örtlichen US-Konsuls Karl MacVitty, am Nachmittag je 42 Soldaten anzulanden, die Anzahl, die Japan bereits in der Konzession stationiert hatte. US-Admiral Harry Yarnell, Chef der Fernostflotte, unterstützte dies; Außenminister Hull wurde nur informiert. Am Abend kamen von der Rigault de Genouilly 42 französische Matrosen ${ }^{121}$.

Die von der westlichen Entschlossenheit überrumpelten Japaner gaben nach. Die Presse in Tokio schäumte, doch das Gaimusho spielte die Frage herunter. Ein Beamter erklärte der deutschen Botschaft, die westlichen Mächte hätten mit den Truppen ihre Bürger vor chinesischen Terrorakten schützen wollen. Der deutsche Botschafter Ott äußerte, Tokio sei bestürzt und eilig kompromißbereit. Tatsächlich stand viel auf dem Spiel, wie Ott später schrieb:

Man legte sich an einem verhältnismäßig ungefährlichen Objekt fest und meinte beiderseits Shanghai, Tientsin, das ganze Problem der Konzessionen in China und letzten Endes die große Frage der Frontbildungen und Einkreisungsbestrebungen im Fernen Osten. Kulangsu wurde so zum symbolischen Miniaturschauplatz für einen weit größeren Austrag, zu einer Probe aufs Exempel, [...] einer Prestigefrage. [...] Die uneingeschränkte Mitwirkung Amerikas [...] hat denn auch hier zweifellos emüchternd gewirkt, dafür aber bei den Mächten, wie man Pariser Meldungen entnehmen konnte, große Befriedigung ausgelöst ${ }^{122}$.

In Amoy rangen die Japaner mit den westlichen Konsuln um die japanische Präsenz in der Verwaltung und der Polizei. Parallel verhandelten die vier

\footnotetext{
${ }^{120}$ Cosme an Bonnet, $\mathrm{T}$ 630, 16.5., T 636, 17.5., Léger an Cosme, T 181-82, 17.5., Henry an Léger, $\mathrm{T}$ 302-3, 22.5; Léger an Henry, T 215, 17.5.1939 (MAE Chine 791, 736); EMA.2, note, 22.5.1939 (SHAT 7 N 2524); Colonies, bulletin de renseignement, 10.7.1939 (CAOM FM, AP 1416); FNEO an EMG.2, T 1318, 17.5., FNEO, compte rendu, 5.6.1939 (SHM 1 BB9 46, 1 BB4 74).

${ }^{121}$ MacVitty an Hull, 17.5., 18.5.1939; Hull an MacVitty, 17.5.1939; (FRUS 1939, IV, S. 113f.); Saint-Quentin an Bonnet, T 816-17, 17.5., Cosme an Bonnet, T 646, 18.5.1939 (MAE Chine 791); Hamilton, Memorandum of Conversation, 5.6.1939 (FRUS 1939, IV, S. 119); Rigault de Genouilly an FNEO, T 155-56, 18.5.1939 (SHM 1 BB9 46). HERZOG schreibt, Hull sei die Landung unangenehm gewesen, und ihn habe sie beunruhigt (Closing the Open Door, S. 43f.), UTLEY zufolge waren die Beamten im State Department unglücklich über die Landung (Going to War, S. 74).

${ }^{122}$ Ott an Ribbentrop, 19.5., 30.5.1939 (AA Botsch Paris 444 b, Japan 4; AA Pol VIII 58 B 1).
} 
Kommandeure über einen Abzug ihrer Truppen. Angesichts der US-Präsenz sahen Briten und Franzosen keinen Grund, den Japanern nachzugeben, selbst als diese Ende Mai ihre militärische Stärke in Amoy erhöhten, mit Übergriffen drohten und am 21. Juni die benachbarte Hafenstadt Swatow besetzten ${ }^{123}$.

Ab Mitte Juli 1939 drängte Cosme den Quai d'Orsay zur Nachgiebigkeit in Kulangsu: Man habe sich mit Japan geeinigt, doch weigere sich der britische Botschafter, dem Ergebnis der Verhandlungen zuzustimmen. Diese Kompromißlosigkeit sei unverantwortlich. Bonnet stimmte Cosme zu und warb in London für ein Ende der Obstruktionspolitik. Das Foreign Office hielt es jedoch für besser, die Angelegenheit am Köcheln zu halten. Auch Fernand Roy in Amoy, der Frankreich seit 1911 in China als Konsul vertreten hatte, warnte vor dem Abzug der westlichen Soldaten. Nach Ausbruch des Krieges in Europa einigten sich die Konfliktparteien vor Ort rasch. Am 2. September rückten britische und französische Truppen ab; amerikanische und japanische Kontingente verließen am 18. Oktober 1939 die Konzession ${ }^{124}$.

Léger wollte den Erfolg von Kulangsu nutzen, um Amerikas Blick auf Indochina zu lenken. Der Generalsekretär sagte Bullitt am 15. Mai, er befürchte eine japanische Aggression gegen Indochina. Japan habe bereits sechs Mal dessen Territorium überflogen und Bomben abgeworfen. Léger dramatisierte. Die Überflüge Indochinas waren vor Angriffen auf Yunnan erfolgt, es fielen keine Bomben auf Indochina. Französische Akten berichten auch nur von drei Überflügen. Die Japaner entschuldigten sich, die Piloten hätten sich im Nebel verflogen. Die Überflüge trafen mit Nachrichten zusammen, wonach sich japanische Heeres- und Fliegereinheiten in Südchina sammelten.

Anfang Mai verstärkte Indochina die Grenztruppen, Mitte Mai bat Generalgouverneur Brévié dringend um die Erlaubnis, zur Verteidigung Waffen in den USA kaufen zu dürfen. Mehrfach warnte er vor einer Konzentration japanischer Kriegsschiffe bei Hainan. Auch von Bombenangriffen auf Südchina und einer geplanten Flottendemonstration der Japaner hatte er erfahren. Drei Japaner wurden wegen Spionage in Nordindochina festgenommen. Nach einem weiteren Überflug Indochinas durch ein japanisches Flugzeug Ende Mai brachen die bedrohlichen Meldungen aus Indochina zunächst ab. Daladier

${ }^{123}$ Cosme an Bonnet, T 663, 22.5., T 674, 25.5., T 680, 26.5., T 8-9, 12.6.1939 (MAE Chine 736).

${ }^{124}$ Cosme an Bonnet, $\mathrm{T}$ 823-26, 18.7., Charvériat an Corbin, $\mathrm{T}$ 1537-41, 22.7., Corbin an Bonnet, $\mathrm{T}$ 2371, 26.7., T 2479-81, 5.8., Charvériat an Cosme, T 318, 2.8.1939 (MAE Chine 1064); Cosme an Bonnet, L 248, 30.7.1939 (MAE Chine 737); Cosme an Bonnet, T 851, 28.7., T 859, 1.8., T 890, 10.8.1939; Corbin an Bonnet, T 2407, 28.7., Roy an Cosme, L 62, 1.8., L 63, 4.8., L 65, 6.8., L 68, 18.8., L 69, 22.8., L 70, 25.8., L 71, 27.8., L 72, 3.9., L 75, 8.9., L 76, 8.9., L 79, 13.9., L 82, 21.9.1939 (MAE Chine 791); BRossollet, Les Français de Shanghai, S. 94f.; MacVitty an Hull, 15.9., 18.10., Hornbeck, Note, 4.9.1939 (FRUS 1939, IV, S. 159, S. 162f., SD 893.0146/700). 
sagte Bullitt Anfang Juli übertreibend, Japan drohe fast täglich, Indochina anzugreifen $^{125}$.

Als sich die Lage in Tientsin verschärfte, machte der Quai d'Orsay ab Mitte Juni den USA erneut deutlich, daß Ostasien unter japanische Kontrolle falle, falls Amerika passiv bleibe. Komme es in Europa zum Krieg und griffen die USA nicht ein, könne Frankreich Indochina nicht verteidigen, sagte Bonnet am 16. Juni Wilson. Das State Department ließ sich nicht bewegen: Hornbeck urteilte, daß Briten und Franzosen die Kolonien in Asien im Falle eines Krieges in Europa weder verteidigen könnten noch wollten. Welles wies alle Bitten um ein gemeinsames diplomatisches Auftreten zurück: Die USA gingen keine Verpflichtung ein, die ihre Handlungsfreiheit beschränke. Der Frieden in Europa hänge auch stark davon ab, daß Briten und Franzosen Japan Widerstand entgegenbrächten. Roosevelt ging noch weiter: Er bat den französischen Bildungsminister Jean Zay und Botschafter René de Saint-Quentin beim Besuch des Weißen Hauses um mehr französische Hilfe für China. Die Aufforderung empörte Bonnet: Frankreich, das schon in Europa große Lasten trage, könne China nicht aktiver unterstützen, solange nicht Amerika seiner Verantwortung in Asien gerecht werde, klagte er ${ }^{126}$. Auch mit dem Hinweis, man sei bereit, ein Eisenerzembargo über Japan zu verhängen, versuchte der Quai d'Orsay, die USA zur Kooperation zu bewegen. Von Anfang Mai bis Mitte Juli 1939 informierte Paris Washington mehrfach über angebliche französische Sanktionspläne. Das State Department reagiert darauf nicht ${ }^{127}$.

Léger erhöhte den Druck auf Washington, als Ende Juni die Spannung in Tientsin stieg. Die Lage dort sei dramatisch. Japans Militär halte sich jetzt nur noch zurück, wenn sich die USA politisch in Tientsin engagierten. Wilson warnte Washington vor einer Zuspitzung in Paris: Die Krise in Asien, die England schwäche und den Franzosen den drohenden Verlust Indochinas bei einem Krieg in Europa vor Augen führe, stärke die appeaser in Frankreich. Womöglich stehe ein zweites München, diesmal hinsichtlich Polen, bevor. Léger und Daladier sagten Bullitt, daß der Frieden in Europa und Asien vom

\footnotetext{
${ }^{125}$ Bullitt an Hull, 15.5., 5.6.1939 (FRUS 1939, III, S. 118; I S. 269f.); Yvon an EMA.2, L 4, 18.4., L 14, 7.5.1939 (SHM 1 BB7 257, MAE Chine 538); Brévié an Mandel, T 760, 3.5., T 795, 7.5., T 824, 11.5., T 856, 18.5., T 865, 18.5., T 921-22, T 926, 27.5., T 1025, 20.6.; Brévié an Mandel T 765, 5.5., T 866, 19.5.1939 (CAOM FM Tel 80, 81); STS an EMG.2, T 1572, 29.4.; FNEO, compte rendu, 5.5., 5.6.1939 (SHM 1 BB9 46, 1 BB4 74); Henry an Bonnet, T 273-76, 7.5.1939 (MAE RFD 28).

${ }^{126}$ Bonnet an Saint-Quentin, T 734-35, 16.6.1939 (DDF XVI, 451); Phipps an Halifax, 17.6.1939 (DBFP, $3^{\text {rd }}$ series, IX, 223); Hornbeck, Memorandum, 11.5.1939 (FRUS 1939, III, S. 34f.); Léger an Saint-Quentin, T 767-68, 22.6., Saint-Quentin an Bonnet, T 959-64, 17.6., T 993-94, 23.6., T 939, 14.6.1939; Bonnet an Saint-Quentin, T 729-33, 16.6.1939 (DDF XVI, 502, 465, 509, 421, 447).

${ }^{127}$ Saint-Quentin an Bonnet, T 731-32, 27.4., note de la sous-direction d'Asie-Océanie, 24.5.1939 (MAE Chine 761); Bullitt an Hull, 3.5., 23.5., Hamilton, Welles, Memoranda of Conversation, 5.6., 21.7.1939 (FRUS 1939, III, S. 534f., S. 38f., S. 538f., S. 54lf.).
} 
Verhalten der USA abhänge. Washington reagierte kaum. Allein der Ton seiner Proteste gegen japanische Bombardements, die Verdrängung des Handels aus Nordchina und Übergriffe auf seine Bürger verschärfte sich $^{128}$.

Dies änderte sich, als London mit der Craigie-Arita-Erklärung seine Machtlosigkeit einräumte. Daladier und Bonnet sagten Bullitt, Großbritannien und Frankreich stünden davor, ihre Besitzungen in Asien zu opfern. Als Reaktion auf die britische Erklärung kündigte Roosevelt am 26. Juli den Handelsvertrag mit Japan. Nach Ablauf eines halben Jahres konnte Amerika nun Handelssanktionen gegen Japan verhängen. Zuvor war das State Department zu dem Schluß gelangt, Japan werde China völlig kontrollieren, falls Amerika keine festere Position beziehe. Tokio reagierte überrascht und irritiert. Léger dankte für die Intervention der USA, die die Lage in Europa und Asien entspanne, doch es bleibe dabei, daß Briten und Franzosen alle Positionen im Fernen Osten räumen müßten, wenn sie nicht auf aktive Unterstützung der USA rechnen könnten. Letzlich blieben Frankreichs Bemühungen, in Asien Amerikas Hilfe zu gewinnen, fruchtlos. Das zeigte sich Anfang August 1939 erneut. Welles bat Briten und Franzosen, die Birmastraße und die Yunnanbahn trotz japanischer Pressionen nicht zu schließen. Er könne aber keine Hilfe für den Fall versprechen, daß dies zu einer Aggression Japans führe ${ }^{129}$.

Allerdings nahm Tokio bereits Rücksicht auf die Verbindung zwischen den drei Demokratien: Japan trieb die Machtprobe mit Frankreich und England auch deshalb nicht auf die Spitze, um die USA nicht übermäßig zu reizen. Das Bemühen in London und Paris, den Eindruck der Solidarität der drei Mächte nicht zu schmälern, war so stark, daß sie auf Demarchen in Tokio verzichteten, wenn Washington die Teilnahme verweigerte. Briten und Franzosen versuchten auch auf dem Umweg über die US-Vertreter in Shanghai und Tokio, die USA für gemeinsames Handeln zu gewinnen, indem diese ihrer Regierung britische und französische Anregungen als eigene Vorschläge vorbrachten ${ }^{130}$. Erfolge brachte auch das nicht. Zu groß waren die Sorgen im State Depart-

${ }^{128}$ Wilson an Hull, 21.6., 24.6., Bullitt an Hull, 30.6., 28.6.; EMA, note, 26.6.; Memorandum, 10.7.1939 (FRUS 1939, IV, S. 191f.; I, S. 193f., S. 279f., S. 277f.; SHAT 7N3301, SD 793.94/15236). ${ }^{129}$ Saint-Quentin an Bonnet, T 1215-17, 27.7., T 1267-70, 5.8.1939 (DDF XVII, 261, 437); Bullitt an Hull, 26.7., 5.7., 31.7.1939 (SD 740.00/1955; FRUS 1939 I, S. 281f, S. 291; III, S. 698); FEIS, Road to Pearl Harbor, S. 21; UTLEY, Going to War, S. 62; Adams, Note, 6.7., Auriti an Ciano, 28.7., Lindsay an Halifax, 3.8.1939 (SD 793.94/15241, DDI Serie 8, XII, 711, 712, DBFP, $3^{\text {rd }}$ series, IX, 459).

${ }^{130}$ Phipps an Charvériat, 28.5.1939 (MAE Chine 761); Phipps an Halifax, 7.6.1939 (FO 371/23523, F 5508/4367/10); Henry an Bonnet, T 412-13, 19.7.1939 (DDF XVII, 236); Léger an Henry, T 305, 20.7.1939 (MAE Chine 1067); George E. TAYLOR, The Struggle for North China, New York 1940, Nachdruck New York 1978, S. 136; Léger an Corbin, T 1444.45, Saint-Quentin, T 869-70, 11.7., T 1016, 4.8., Corbin an Bonnet, T 2206-9, 14.7., Henry an Bonnet, T 448, 3.8., Saint-Quentin an Bonnet, T 1283, 8.8; Léger an Corbin, T 1488, 17.7.1939 (MAE Chine 1072, 885); Halifax an Corbin, Note, 10.6., Corbin an Léger, L 460, 12.6.1939 (MAEN Londres C 486, MAE Chine 761). 
ment, von beiden Mächten benutzt zu werden, um deren »Kastanien aus dem Feuer zu holen «, wie es in US-Dokumenten oft hieß.

Immerhin plante die U.S. Navy seit Mai 1939 für den Fall eines Konflikts mit Japan eine gemeinsame Kriegführung mit Frankreich, Großbritannien und den Niederlanden. Im August 1939 regte sie Allianzen der USA mit den drei Mächten an. Die Flotte, vor allem der Operationschef William D. Leahy und Admiral Harry E. Yarnell, der Flottenkommandeur in Asien, forderten eine feste US-Politik im Pazifik. Sie waren bereit, einen Krieg mit Japan zu riskieren, den sie ohnehin für unvermeidlich hielten. Yarnell bezeichnete im Juli 1939 gegenüber Hull die Franzosen als verläßliche Partner, auch im Kriegsfall. Bereits im Frühjahr 1938 war der Vizechef der U.S. Military Intelligence in Manila nach Saigon gekommen und hatte mit der französischen Armee den Austausch militärischer Informationen vereinbart ${ }^{131}$. Angesichts der Haltung des State Department blieben die Pläne der Flotte für eine westliche Militärallianz im Pazifik aber reine Theorie.

Der militärisch mächtigste potentielle Bündnispartner Frankreichs war, rückblickend betrachtet, die Sowjetunion. Allerdings sahen Frankreichs Bevölkerung und führende Politiker ab 1936 in Moskau eher einen Gegner der innen- und außenpolitischen Verhältnisse. Dies hatte vier Gründe. Die sowjetische Regierung mischte sich, erstens, massiv in die französische Innenpolitik ein. Daß Moskau die Weltrevolution über die Kommunistischen Parteien in die Staaten Europas hineinzutragen versuchte und dort auf die Zerstörung des kapitalistischen Wirtschaft und der bürgerlichen Gesellschaft abzielte, nennt Horst Möller eine der grundlegenden Konstellationen der Zwischenkriegszeit. Viele Franzosen befürchteten wegen des Siegs der Volksfront bei der Wahl im Mai 1936 und der vom Sommer 1936 bis zum Herbst 1938 aufflammenden Streiks einen Putsch. Als die KPF ein Eingreifen im Spanischen Bürgerkrieg forderte, glaubten viele Bürger, sie wolle Frankreich in den Krieg stürzen, um die Revolution zu entfachen ${ }^{132}$. Die Komintern höhlte Frankreichs Ansprüche in Indochina und China aus ${ }^{133}$. Über Moskaus Einfluß in Paris und Indochina beklagten sich Behörden und Politiker oft. Deshalb lehnten das Bürgertum und

\footnotetext{
131 Miller, War Plan Orange, S. 214, S. 227, S. 256; UtLeY, Going to War, S. 24f.; Waldo H. HeINRICHS, The Role of the U.S. Navy, in: Borg, OKOAMOTo (Hg.), Pearl Harbor, S. 197-223 (S. 211f.); Yamell an Hull, 20.7.1939, Flood an Hull, 19.10.1938 (SD 793.94/15339, 851g.20211/1).

${ }^{132}$ MŐLLER, Europa zwischen den Weltkriegen, S. 4; S. 129; Serge BERSTEIN, Jean-Jacques BECKER, Histoire de l'anticommunisme en France, Bd. I: 1917-1940, Paris 1987, S. 280f.; Maxime MourIN, Les relations franco-soviétiques 1917-1967, Paris 1967, S. 209, S. 219.

${ }^{133}$ Trotz der 1935 eingeschlagenen Volksfrontstrategie wurde die Komintern von den Behörden in Indochina als Gefahr angesehen, weil die KP Massendemonstrationen organisierte, die Trotzkisten bei der Kommunalwahl im April 1939 siegten und Chinas KP der KP Indochinas half (DuIKER, The Rise of Nationalism, S. 251; Pierre BrouÉ, Histoire de l'Intemationale communiste, 1919-1943, Paris 1997, S. 702; CHEN, Vietnam and China, S. 39, S. 42; MORLAT, La répression coloniale, S. 245).
} 
Politiker wie Chautemps, Delbos und Herriot, der sich bis 1936 für dieses Bündnis eingesetzt hatte, die Sowjets als Partner ab. Blum stellte die Bemühungen ein, als er hörte, daß Moskau Geheimkontakte zu Hitler pflege ${ }^{134}$.

Die Angst in der französischen Regierung, daß die Sowjetunion Frankreich außenpolitisch unterminierte, war der zweite Grund der Distanz zu Moskau. Delbos, Bonnet, Daladier und der Generalstab argwöhnten, die Sowjets wollten Frankreich in einen Krieg stürzen, um in einem zerstörten Europa den Kommunismus zu verbreiten. Auch im Fernostkonflikt, so schrieb damals ein Slawist, verfolgten die Sowjets diese Politik. Die Annahmen entsprangen keiner Hysterie: $\mathrm{Da} ß$ die Sowjets tatsächlich einen Krieg befürworteten, um die Revolution in erschöpften bürgerlichen Gesellschaften durchzusetzen, belegt Igor Lukes ${ }^{135}$. Daladier und Bonnet machten aus ihrem Antikommunismus und dem Mißtrauen gegenüber Moskau keinen Hehl ${ }^{136}$. Als Ende Mai 1940 der deutsche Einmarsch in Paris bevorstand, fürchtete Daladier den »kommunistischen Mob« mehr als die deutsche Armee. Noch in deutscher Gefangenschaft hatte er Angst vor der Sowjetisierung Europas. Im Dezember 1944 befürwortete er ein Bündnis Frankreichs mit Deutschland gegen Rußland ${ }^{137}$.

Schließlich stellte sich, drittens, die Frage nach dem Wert der sowjetischen Armee. Die französische Militärführung, die die Kampfkraft der Roten Armee ohnehin für gering hielt, wurde in ihrem Urteil durch die »Säuberungen« im Offizierskorps bestärkt. Die Massenmorde erhöhten das Mißtrauen gegenüber Stalin $^{138}$. Als großer Verlust galt die Hinrichtung von Marschall Blücher im

\footnotetext{
${ }^{134}$ Bullitt an Hull, 26.8., 22.11., 4.12.1937, 24.1., 25.1.1938 (FRUS 1937, III, S. 475f., SD 740.00/ 225, 239, 275, 277); CoUlondre, Von Moskau nach Berlin, S. 17f.; HerRIOT, Episodes, S. 10; MoURIN, Les relations, S. 222f.; John E. DREIFORT, The French Popular Front and the Franco-Soviet Pact, 1936-37: A Dilemma in Foreign Policy, in: Journal of Contemporary History 11 (1976), S. 217-236.

135 COUlondre, Von Moskau nach Berlin, S. 16, S. 28; DreiforT, Delbos, S. 108f.; Phipps an Halifax, 2.9.1938, (DBFP, $3^{\text {rd }}$ series, II, 750, 751); BONNET, Defénse de la paix, Bd. 2, S. 213; DERS., De Munich à la guerre, S. 44; TABOUIS, Cassandre, S. 342; Bräuer an Ribbentrop, 7.9 .1938 (ADAP D II, 439); VILlelume, Journal, S. 46; Michael Jabara CARLEY, Prelude to Defeat: Franco-Soviet Relations, 1919--39, in: Historical Reflections 22.1 (1996), S. 159-188 (S. 183); André PIERRE, L'U.R.S.S. et le conflit sino-japonais, in: Le Monde slave 15.1 (1938), S. 370-384; Igor LuKEs, Stalin and Czechoslovakia in 1938-39: An Autopsy of a Myth, in: LuKES, GoldSTEIN (Hg.), The Munich Crisis, S. 13-47 (S. 39f.).

${ }^{136}$ WERTH, The Twilight, S. 282, S. 295; Bullitt an Hull, 24.9.1937, 3.10.1938, 8.5., 13.2.1939 (SD 852.00/6545, 740.00/484, 1370, 851.248/139; Campbell an Halifax, 22.8., Phipps an Halifax, 28.9.1939 (FO 371/22976, C 11780/15/18, FO 371/22910, C 15288/25/17); BONNET, Defénse de la paix, Bd. 2, S. 394; Ders., Le Quai d'Orsay, S. 232; DERS., De Munich à la guerre, S. 337 . In den Fassungen der Memoiren, die nach Beginn der Entspannungspolitik erschienen, äußert sich BONNET nur noch positiv über Moskau (Vingt ans de vie politique, S. 231; DERS., Dans la tourmente, S. 35).

${ }^{137}$ Bullitt an Hull, 27.9.1938, 27.5.1940 (FRUS 1938, I, S. 686f., SD 740.0011 Europ. War 1939/ 3343 1/10); DALADIER, Joumal, S. 247, S. 252, S. 297, S. 302, S. 312 f., S. 330, S. 333, S. 338.

${ }^{138}$ Patrice BUFFOTOT, The French High Command and the Franco-Soviet Alliance, 1933-1939, in: Journal of Strategic Studies 5.4 (1982), S. 546-559; Michael Jabara CARLEY, Down a Blind-Alley: Anglo-FrancoSoviet Relations, 1920-39, in: Canadian Journal of History 29.1 (1994), S. 147-172 (S. 162f.).
} 
Oktober 1938, der in Changkufeng japanische Verbände geschlagen hatte. Die Generäle Gamelin und Weygand fragten, wie eine Armee, die ihre Führung erschoß, kämpfen solle. Sie hielten, wie Daladier und Bonnet, die Rote Armee für wertlos und Rußland für ein Land in tiefer Krise. Nur wenige Politiker wie Reynaud, Mandel und Herriot glaubten an die Stärke der Roten Armee ${ }^{139}$.

Der vierte Grund, der daran zweifeln ließ, ob Moskau ein geeigneter Bündnisgenosse war, lag in der Sorge, den die Sowjets bei Frankreichs Partnern auslösten. Bereits das französisch-sowjetische Bündnis von 1935 hatte Ostmitteleuropa, Belgien und Großbritannien, auch die Dominions Südafrika und Kanada, beunruhigt. Die Osteuropäer befürchteten territoriale Ansprüche der Sowjetunion. Die Regierungen im Westen hatten Angst, von Moskau und Paris in einen Krieg gegen Deutschland hineingezogen zu werden. Auch die USA sahen die französisch-sowjetische Verbindung mit Mißtrauen: Die USBotschaft in Paris beobachtete die Kontakte zwischen der PCF, der Komintern und Amerikas KP genau ${ }^{140}$. Solange die Sowjetunion nicht an Deutschland grenzte und im Bündnisfall durch ein osteuropäsches Land marschieren mußte, war ein französisch-sowjetisches Militärbündnis entweder praktisch wertlos oder stand in krassem Widerspruch zu Frankreichs Allianzen.

Die enorme Verschärfung der Lage nach der Münchener Konferenz ließen die französische und die britische Regierung über alle Bedenken hinweggehen und das Bündnis mit Moskau suchen. Italiens Parlament hatte Ende November 1938 Ansprüche auf Nizza, Korsika, Savoyen und Tunis erhoben, intern nannte Mussolini Djibouti. Das Deuxième Bureau hielt einen Krieg mit Italien für möglich. Italiens Einmarsch am 7. April in Albanien bedrohte die französische und britische Position im östlichen Mittelmeer und auf dem Balkan. Im westlichen Mittelmeer geriet Frankreich unter Druck, als Franco am 26. Januar 1939

\footnotetext{
${ }^{139}$ Colonies, bulletin, 15.10., STS-bulletin, 1.11.1938 (SHAT 11 H 76; MAE Chine 534); Palasse an EMA, L 509, 28.10.1938, L 531, 13.1.1939 (SHAT 7 N 3123); Service de police, rapport, 29.11.1938 (MAE Japon 148); WATT, How War Came, S. 109; Procès-verbal, Comité permanent de la défense nationale, 15.3.1938 (DDF VIII, 446); Mack an Halifax, 11.4.1939 (FO 371/22969, C 5261/15/18); PERTINAX, Les fossoyeurs, Bd. 1, S. 21; BARTEL, Frankreich und die Sowjetunion, S. 100; Bullitt an Hull, 6.2.1939, 3.10., Wilson an Hull, 10.11 .1938 (SD 740.00/568, 484, 751.62/495); CRÉMIEUXBRILHAC, Les Français, Bd. 1, S. 42.

${ }^{140}$ Diplomatic Diaries of Oliver HarveY, S. 42f;; Ovendale, "Appeasement«, S. 44; TACEL, La France et le monde, S. 150; MOURIN, Les relations, S. 211; WERTH, The Twilight, S. 89; DrEIFORT, The French Popular Front, S. 223f.; LANGER, GLEASON, The Challenge, S. 126; JUNKER, Franklin D. Roosevelt, S. 92; Berichte über die französische KP in: SD 851.00B; WolfERS, Britain and France, S. 140; HalifaX, Fullness of Days, S. 207. Roosevelt persönlich hatte gegenüber den Kommunisten keine Berührungsängste: Im Januar 1938 schlug er Litwinow einen Austausch geheimer Nachrichten über Asien vor, der auch begann, aber aus unbekanntem Grund später erstarb. Roosevelt entsandte Hauptmann Evans F. Carlton als Verbindungsmann zur chinesischen KP und ließ sich mehrfach vom Journalisten Edgar Snow über diese Partei informieren (LANGER, GlEAsON, The Challenge, S. 127; Haslam, The Soviet Unjon, S. 106f.; SCHALlER, The U.S. Crusade, S. 20).
} 
Barcelona und am 28. März Madrid eroberte. Am 27. und 31. März trat Spanien dem Antikominternpakt bei und unterzeichnete einen Freundschaftsvertrag mit Deutschland. Im Januar 1939 fürchtete London einen unmittelbar bevorstehenden deutschen Angriff auf die Niederlande oder Großbritannien ${ }^{141}$.

Letzte Zweifel, daß das apaisement gescheitert war, räumte Deutschlands Einmarsch am 15. März 1939 in Prag aus. Nach der Zerschlagung der »RestTschechei« warnte das Deuxième Bureau vor deutschen Angriffen auf Polen und Rumänien, nach Italiens Einmarsch in Albanien vor einem Angriff auf Frankreich. In Paris herrschte die Atmosphäre eines unausweichlich bevorstehenden Krieges. Bei einer Umfrage im April hielten nur 47 Prozent der Franzosen den Krieg mit Deutschland für vermeidbar. Im Februar waren es 57 Prozent gewesen, im Juni sollten es noch 35 Prozent sein. In dieser Lage verkündete Chamberlain am 23. April 1939 die Einführung der Wehrpflicht, fünf Tage später kündigte Hitler den deutsch-polnischen Nichtangriffspakt von 1934 und den deutsch-britischen Flottenvertrag von $1935^{142}$. London und Paris hatten sich in eine schwierige Lage manövriert, als sie Polen, Rumänien und Griechenland im März/April Beistand versprachen und erst dann die unverbindlichen Gespräche mit den Sowjets in konkrete Verhandlungen umwandelten. Um die Garantien einzulösen, brauchte der Westen zwingend sowjetische Unterstützung. Daladier musste aber auch aus innenpolitischen Gründen mit Moskau sprechen, denn die Bevölkerung erwartete Taten.

Als Bündnispartner in Asien kam die Sowjetunion für Frankreich lange nicht in Frage, da diese Verbindung französische Besitzungen japanischen Repressionen ausgesetzt hätte. Daladier hatte 1937 zwar einmal angeregt, das Potential der Sowjets gegen Japan zu nutzen, sich aber Gamelin und Léger gebeugt, die die Annäherung an Moskau ablehnten. Im März 1938 dachte Daladier nach Österreichs »Anschluß« über ein Generalstabsabkommen mit Rußland nach: Man könne die Sowjets bitten, gegen Japan vorzugehen. Naggiar überlegte nach der japanischen Besetzung Hainans im Februar 1939, wie man Moskau gegen Tokio in Position bringen könne, kam aber zu dem Schluß, daß dies unmöglich sei. Als im Frühjahr 1939 die Gespräche mit den Sowjets begannen, stand für Frankreichs Regierung fest, daß sie Unterstützung in

\footnotetext{
${ }^{141}$ Graf Galeazzo Clano, Tagebücher 1937/38, Hamburg 1949, S. 269f.; Jean-Pierre AZÉMA, La France de Daladier, in: DERS., BÉDARIDA, La France des années noires, Bd. 1, S. 11-35 (S. 29); Peter JACKSON, Intelligence and the End of Appeasement, in: BOYCE (Hg.), French Foreign and Defence Policy, S. 234-260 (S. 239f.); TACEL, La France et le monde, S. 159; HARVEY, Diplomatic Diaries, S. 245; WATT, How War Came, S. 101f.

${ }^{142}$ BONNET, Le Quai d'Orsay, S. 262f.; DERS., Dans la tourmente, S. 114; DALADIER, Journal, S. 225; CADOGAN, Diaries, S. 161; RÉMOND, Frankreich im 20. Jahrhundert, S. 268; TACEL, La France et le monde, S. 168; ADAMTHWAITE, French Military Intelligence, S. 196; JACKSON, Intelligence, S. 234f.; WaTt, How War Came, S. 21 lf., S. 194; CARLEY, 1939, S. $123 \mathrm{f}$.
} 
Europa, aber keinesfalls Gespräche über Asien wollte. Léger erklärte Wilson im Juni 1939 gar, ein sowjetischer Wunsch nach Ausdehnung des Paktes auf Asien werde jede Vereinbarung verhindern. Bonnet sagte im März in London, eine solche Ausweitung akzeptiere die französische Öffentlichkeit nicht. Der Außenminister war deshalb erleichtert, als sich der sowjetische Vorschlag eines Beistandpaktes von Mitte April 1939 nur auf Europa bezog. Der Generalstab der französischen Armee nannte in einem Papier zur Vorbereitung britisch-französischer Stabsgespräche das Ziel, die Sowjetunion und Japan in eine Konfrontation zu manövrieren, ohne daran beteiligt zu sein ${ }^{143}$.

Mandel jedoch verlangte Mitte Mai 1939 bei General Gamelin Gespräche zwischen dem russischen und dem französischen Generalstab über Ostasien: Moskaus Militärpotential bringe Indochina Sicherheit. Die Zusammenarbeit solle im Falle eines japanischen Angriffs auf die Kolonie gelten, doch müsse man sich zuerst auf ein Vorgehen in Europa einigen. Vielleicht ging es Mandel aber nur darum, mit dem Hinweis auf Indochina ein zusätzliches Argument für das Bündnis zu liefern. Daladier unterband die Diskussion: Er lasse es nicht zu, daß sich der Kolonialminister direkt an den Generalstab wende ${ }^{144}$.

Den Gerüchten, Tokio befürchte die Ausdehnung eines sowjetisch-französischen Bündnisses auf Asien und wolle deshalb einem Militärpakt mit Berlin und Rom beitreten, trat Léger Mitte Mai 1939 mit einer Freundschaftsadresse an Japans Regierung entgegen: Die französische Regierung habe niemals erwogen, den Pakt auf den Fernen Osten auszudehnen, werde dies weiter nicht tun, und habe bislang nicht einmal die Hypothese eines Konfliktes zwischen Frankreich und Japan bedacht. Paris könne die Haltung im Falle eines deutschitalienisch-japanischen Militärabkommens jedoch überprüfen. Vize-Außenminister Sawada nahm Légers Äußerung zur Kenntnis, wies aber darauf hin, daß jede Stärkung Moskaus in Europa Japans Position in Asien schwäche ${ }^{145}$.

Um Japan nicht in das deutsche Lager zu drängen, hatte London Tokio Ende April mitgeteilt, daß man den Pakt nicht auf Asien ausdehnen wolle. Halifax verzichtete auf die Ergebenheitsadresse, die Léger für nötig hielt, und drohte: Eine Ausweitung des Paktes auf Asien hänge von Japans Haltung gegenüber einem Bündnis mit Deutschland ab. Offenbar sahen auch die Sowjets die

\footnotetext{
${ }^{143}$ Daladier an General Jamet, D. 0876/3, très secret, 7.3.1938 (DDF VIII, 331); DU RÉAU, Daladier, S. 198f.; Seeds an Oliphant, 21.2.1939 (FO 371/23697, N 1459/1459/38); Wilson an Hull, 21.6.1939 (FRUS 1939, IV, S. 191f.); Maisky an Litvinov, 26.3., Suritz an Litvinov, 18.4.1939 (SPE I, 190, 240); PRITCHARD, Far Eastem Influences, S. $92 \mathrm{f}$.

${ }^{144}$ EMA, note, 31.3.1939 (SHM 1BB2 182); Mandel an Gamelin, L 117/EM.Col, 17.5., Gamelin an Daladier, L 1051/DN.3, très secret, 22.5.1939 mit Notiz Daladier (SHAT 5 N 579).

${ }^{145}$ Coulondre an Bonnet, T 1186, 2.5.1939; Léger à Henry, T 208-9, 12.5.1939 (DDF XVI, 12, 161); Bonnet an Coulondre, T 445-46, Corbin, T 884-85, Warschau T 408-9, 4.5.1939; Henry an Bonnet, T 290, 15.5.1939 (MAE Japon 148); Knoll an Paris, 19.5.1939 (AA Botsch Paris 444 b, Japan 4).
} 
Gerüchte über eine Allianz in Asien als hinderlich an: Sie erklärten öffentlich, der Ferne Osten werde bei den Gesprächen nicht behandelt ${ }^{146}$.

Die Distanz, die Frankreich zur Sowjetunion in Asien hielt, zeigte sich auch in China: Als Anfang August 1937 japanische Söldner das Sowjetkonsulat in Tientsin überfielen, weigerten sich die Franzosen, das Gebäude zu schützen. Nur der belgische Konsul begleitete den sowjetischen Vizekonsul in sein zerstörtes Konsulat. Naggiar gab seinem Konsul die Anweisung, sich von den Sowjets fern zu halten. Im November 1937 verbot Naggiar, in Nanking sowjetische Botschaftsmitarbeiter auf einem französischen Kriegsschiff mitzunehmen. In Peking und Shanghai lehnte die französische Polizei den Schutz sowjetischer Einrichtungen ab. Bei Japans Einmarsch in Hankou schlossen die französischen Beamten die sowjetische Botschaft, die neben der französischen Konzession lag, aber nur über die Konzession zu erreichen war, vom Schutz aus. Naggiar ordnete an, so vorzugehen, daß man nicht für russisch-japanische Zwischenfälle verantwortlich gemacht werden könne ${ }^{147}$. Als die Sowjets im Februar 1939 Botschaftspersonal und Archiv auf einem französischen Schiff aus Hankou evakuieren wollten, lehnten Vize-Admiral Le Bigot und der örtliche Kommandant mit Hinweis auf das französisch-japanische Verhältnis jede Hilfe ab. Mit Bonnets Zustimmung erklärten sie den Sowjets, daß man sie aus Platzgründen nicht mitnehmen könne. Mitte April bat Bonnet die Fernostflotille, die Russen wegen der Bündnisgespräche mit Moskau doch mitzunehmen. Da hatten die Sowjets die Stadt bereits auf US-Schiffen verlassen ${ }^{148}$.

Es war für Paris und London in Asien unnötig, die Sowjets für ein Bündnis zu gewinnen, weil die Sowjetunion Japan in tiefer Antipathie verbunden war und enorme japanische Kräfte band, wie die Schlacht von Nomonhan an der

${ }^{146}$ Craigie an Halifax, 30.3., 18.4., 22.4.1939 (FO 371/22944, C 4445/421/62; 371/23560, F 3781, 3944/456/23); Craigie an Halifax, 25.4., 27.4., 13.5., Halifax an Craigie, 26.4., 27.4.1939 (DBFP, $3^{\text {rd }}$ series, IX, 20, 24, 62, 23, 25); Note de la sous-direction d'Asie-Océanie, 24.4.1939 (MAE Chine 677); Halifax an Craigie, 16.5., Craigie an Halifax, 18.5 .1939 (FO 371/23561, F 4527, F 4807/456/23); Tass Communique, 21.6.1939 (SPE II, 336); MOORE, Soviet Far Eastern Policy, S. 109. DALLIN zufolge wollte Molotow das Bündnis auf Asien ausdehnen (Soviet Russia, S. 41f.). Dafür gibt es in den westlichen Akten aber keinen Hinweis.

${ }^{147}$ Hentschel an Le Bigot, T 208, 2.8., Militär Peking an Tientsin, T 390, 12.8.1937 (SHAT 11 H 60); Caldwell an Hull, 4.8.1937 (FRUS 1937, III, S. 324f.); Lépissier an Delbos, L 27, 27.8., Naggiar an Lépissier, T 263-64, 3.8.1937 (MAE Chine 828, Japon 145); Naggiar an Delbos, T 718, 17.11., T 3540, 8.1.1938 (MAE Chine 712, 717); Léger an Naggiar, T 315, 18.11.1937, T 2-3, 4.1., Knobel an Bonnet, T 1931-32, 12.12.; Delbos an Naggiar, T 61-62, 5.2., Naggiar an Delbos, T 186-90, 7.2.1938 (MAE Chine 712, 716, 799, 1062); Naggiar an Colin, T 1270-73, 8.9., T 165-66, 21.11.1938 (MAE Chine 798, MAEN Tokyo, série B, 78). Einen Angriff auf das sowjetische Konsulat in Shanghai, von dem MOORE berichtet (Soviet Far Eastern Policy, S. 86), vermelden die französischen Akten nicht.

${ }^{148}$ Diplomatie an Marine, T 102, 6.3., FNEO an EMG.2, T 7360, 9.3.; EMG.2 an FNEO, T 5235, 26.4.1939 (SHM 1 BB9 44, 185); Marine an Diplomatie, T 1953, 10.3,, Bonnet an Knobel, T 107, 16.3., note de la sous-direction d'Asie-Océanie pour le ministre, 20.4., Bonnet an Cosme, T 149, 24.4., Cosme an Bonnet, T 551, 27.4.; Cosme an Bonnet, T 547, 26.4.1939 (MAE Chine 576, 766). 
mongolisch-mandschurischen Grenze bewies. Monatelange Kämpfe begannen nach einem Zwischenfall am 11. Mai 1939, für den Hata Ikuhiko moskautreue mongolische Truppen, Jonathan Haslam hingegen japanische Verbände verantwortlich macht. Alvin D. Coox und O. Edmund Clubb machen keinen eindeutigen Urheber aus ${ }^{149}$. In der zweiten Augusthälfte brachten fünf sowjetische Infanteriedivisionen und fünf Panzerbrigaden unter General Schukow der japanischen Armee eine vernichtende Niederlage bei. Japan erlitt bei der ersten großen Panzerschlacht der Geschichte die erste Niederlage im 20. Jahrhundert ${ }^{150}$. Die Eskalation überraschte Paris angesichts japanischer Drohungen und Truppenkonzentrationen an der Grenze kaum ${ }^{151}$.

Beide Seiten ließen kaum Informationen nach außen dringen. Paris erfuhr erst am 30. Mai vom Ausbruch der Schlacht. Erste Angaben der Gegner, sie hätten 14 beziehungsweise 59 feindliche Flugzeuge abgeschossen, und es gebe mehrere hundert Tote, zeigten, daß in Nomonhan ein Grenzkrieg tobte. Der französische Konsul in Mukden und der Militärattaché in Moskau meldeten, mehrere Divisionen und einige hundert Flugzeuge seien in die Kämpfe verwickelt. Die Franzosen waren Grenzkonflikte zwischen Japan und Rußland gewohnt - allein 1938 zählte der Marine-Geheimdienst 166 Grenzzwischenfälle. Sie nahmen deshalb an, daß eine Ausweitung des Konflikts nicht zu befürchten war. Die französische Regierung erfuhr Anfang September, kurz bevor sich die Konfliktparteien auf einen Waffenstillstand einigten, daß die Sowjets einen Sieg errungen hatten ${ }^{152}$. Im gesamten Sommer 1939 war jedoch klar, daß die Rote Armee starke japanische Verbände in Asien band.

\footnotetext{
${ }^{149}$ Hata Ikuhiko, The Japanese-Soviet Confrontation, in: MORLEY (Hg.), Deterrent Diplomacy, S. 129-178 (S. 157); HaSLAM, Soviet Union, S. 128f; Alvin D. Coox, Nomonhan. Japan Against Russia, 1939, 2 Bde., Stanford 1985, Bd. 1, S. 191; CluBB, Conflict in the Chinese Borderlands, S. 36.

${ }^{150}$ Die Zahl japanischer Gefallener geben HATA (The Japanese-Soviet Confrontation, S. 175) und Coox (Nomonhan, Bd. 2, S. 1123) mit 8400 bzw. 8600 an, Dallin (Soviet Russia, S. 39), IENAGA (The Pacific War, S. 82) und CoOx (The Pacific War, S. 322) sprechen von 18000 japanischen Toten, die Zahl, die auch Tokio selbst angab (Craigie, Report, I. 1.1940 (FO 371/24743, F 2417/2417/23).

${ }^{151}$ Henry an Bonnet, T 660-61, 30.11.; T 710-13, 24.12.1938, Knobel an Bonnet, T 129-30, 22.1., Marine an Diplomatie, T 807, 30.1., Guillermaz an Guerre, note, 14.4.1939 (DDF, XII, 454; MAE Japon 148); Colonies, bulletin de renseignement, 15.12.1938, EMA.2, rapport du ministre, 29.1., 5.2., EMA.2, note, 12.3.1939 (SHAT 7 N 2507, 2515, 3301); STS-bulletin, 1.2.1939 (MAE Chine 534); STS an EMG, T 1538-41, 26.2., T 1542-44, 8.3., T 1547, 7.4., Diplomatie an Marine, T 100 , 4.3.1939 (SHM I BB9 44); Lacoste an Cosme, T 213-14, 12.4.1939 (DDF XV, 398).

${ }^{152}$ Havas, incidents de frontière, 30.5.; STS-bulletin, 1.8.; Thiébaut an Guerre, D 87, 4.6.1939 (MAE Japon 148, Chine 535, DDF XVI, 350); Germain an Bonnet, T 19, 24.6., Germain an Cosme, L 81, 18.7.1939 (MAE RFD 28, Chine 627); Palasse an EMA.2, L 589, 26.6., L 2310, 10.7., L 2317, 15.7., L 2323, 25.7., L 613, 7.8; Bullitt an Hull, 11.9.1939 (SHAT 7 N 3123, FRUS 1939, III, S. 242f.).
} 


\subsection{Nadelstiche mit der Waffe Wirtschaft}

Der die Weltwirtschaft dominierende Westen hatte zwei Möglichkeiten, sich mit friedlichen Mitteln Japan in Asien entgegenzustellen: Er konnte China wirtschaftlich helfen oder seinen Handel mit Japan einschränken. Ungefährlicher war die wirtschaftliche und finanzielle Unterstützung Chinas. Die ersten Kredite aus dem Ausland - neben dem 50-Millionen-Dollar-Darlehen der Sowjetunion vom Januar 1938 - erhielt China aus Paris: Im November 1937 bekam es einen Liquiditätskredit über 100 Millionen Francs gegen die Verpfändung von Silber, im April 1938 für den Bau der Nanning-Bahn 173 Millionen Francs. In beiden Fällen ging es den französischen Banken weniger darum, China zu helfen, als ein risikoloses Geschäft zu tätigen und den französischen Einfluß in Südchina zu stärken. Dennoch erhöhten die Gelder Chinas Widerstandskraft.

Gegen die Hinterlegung von Silber in London und Hongkong stellte das Bankenkonsortium Groupe uni im August 1937 mit Chautemps' Zustimmung 200 Millionen Francs bereit. Auf Drängen Cosmes verpflichtete sich China, mit dem Geld keine Waffen zu kaufen. Im Herbst 1937 schreckte London vor einer solchen Anleihe zurück, während die Schweizer Bankgesellschaft gegen die Verpfändung von Silber einen Kredit über 100 Millionen Schweizer Franken, umgerechnet 340 Millionen Francs, gewährte. Von dem Kredit des Groupe uni nahm China nur 100 Millionen Francs in Raten im Mai und im November 1938 in Anspruch, weil die USA für das Silber höhere Darlehen einräumten. Die auf ein Jahr befristete Kreditlinie wurde im November 1938 um ein Jahr verlängert. Dem Liquiditätskredit wurde kaum politische Bedeutung beigemessen. Die US-Regierung kaufte im November und Dezember 1937 für 45 Millionen US-Dollar, bis 1939 sogar für insgesamt 94 Millionen US-Dollar (etwa 2,35 Milliarden Francs) Silber aus China an, ohne daß dies in Japan oder im Kongreß für Proteste gesorgt hätte. In der Liste westlicher Kredite an China, die der für die chinesische Regierung tätige Finanzberater Arthur N. Young erstellte, taucht der französische Kredit auch nicht auf ${ }^{153}$.

\footnotetext{
${ }^{153}$ Welczeck an von Neurath, 5.6.1937 (AA, Botsch Paris, 433 b China, 12); Cosme an Naggiar, $T$ 205, 9.6., note de la sous-direction d'Asie-Océanie, 25.6., note pour le ministre, 5.8., Koo an Delbos, L, 7.8.; Central Bank of China an Groupe uni, L, 26.11.1937 (MAE Chine 853, MAEN Tchongking 8); Bullitt an Hull, 12.8.1937 (SD 893.51/6431, 6434); Welczeck an von Neurath, 19.11.1937 (AA Botsch Paris, 433 b China 12); Naggiar an Delbos, T 295, 10.8., note de la sous-direction d'AsieOcéanie, 12.8., Cambon an Delbos, L 660, 12.8., Monick an Reynaud, 18.8.1937; Naggiar an Bonnet, T 586, 4.5., T 608-11, 9.5., Hoppenot an Naggiar, T 210, 5.5.1938; Banque franco-chinoise an Chauvel, L, 20.3.1939 (MAE Chine 853); Naggiar an Delbos, L 441, 26.11.1937; Banque de Paris et des Pays-Bas an Finances, 9.9., 24.10., Marchandeau an Banque Paribas, 14.10.1938 (CAEF 32.816); Arthur N. YOUNG, China and the Helping Hand, Cambridge 1963, S. 32, S. 62, S. 440.
} 
Die Überlegung, China finanziell zu stärken, stellten im Juni 1938 erstmals die Briten an, als sie den Eindruck gewannen, daß China kollabierte. Bonnet, der von den englischen Erwägungen gehört hatte, versicherte Bullitt, Paris beteilige sich an der Währungshilfe - wenn auch Amerika mitmache. Mitte Juli lehnte das britische Kabinett eine Finanzhilfe an China ab, weil dies Japan provoziere $^{154}$. Für Paris war die Frage damit zunächst erledigt.

Am 23. November 1938 fragte China, von der festeren Haltung der USA ermutigt, nach einem gemeinsamen Darlehen der Briten, Franzosen und Amerikaner über 30 Millionen Pfund, etwa 5,3 Milliarden Francs. Bis dahin hatte nur Moskau China 100 Millionen Dollar (3,5 Milliarden Francs) geliehen. Washington und London prüften Mitte Dezember 1938, China Darlehen über 25 Millionen Dollar (920 Millionen Francs) beziehungsweise eine halbe Million Pfund (90 Millionen Francs) zu gewähren. Als Chamberlain in Paris am 26. November 1938 anregte, Chinas Währung zu stützen, sagte Bonnet, gegen britische Hilfe an China habe er nichts. Léger erläuterte Halifax, er lehne die Idee ab. Die Briten erwiderten, sie wollten Paris nach einer Zusage der USA um eine Beteiligung bitten. Als Welles London eine Absage erteilte, handelte das britische Kabinett Ende Februar 1939 allein: China erhielt keinen direkten Kredit, aber zur Stützung der Währung stellten britische Banken fünf Millionen Pfund, verbürgt vom Staat, zur Verfügung. Der gleiche Betrag kam von chinesischen Banken ${ }^{155}$. Corbin sah den Fonds als Demonstration, daß London seine wirtschaftliche Rolle in China nicht kampflos aufgab. Japans Vize-Außenminister Sawada nannte die Operation zwar öffentlich einen unfreundlichen Akt, Tokio verzichtete aber auf diplomatische Proteste ${ }^{156}$.

Der Fonds war ein Instrument im Währungskrieg in Nordchina. Solange Chiang Kai-shek seine Währung behauptete, bekam Tokio die Wirtschaft in Nordchina nicht unter Kontrolle. Phipps fragte Anfang März 1939 im Quai d'Orsay, ob die Besetzung Hainans Frankreichs Bereitschaft erhöhe, China zu helfen. Kurz darauf bat Chungking Paris um Teilnahme an dem Fonds. Die von Léger vorgeschlagene neue Liquiditätshilfe gegen die Verpfändung von Silber lehnte Kung ab: China habe sein Silber bereits an die USA verkauft.

\footnotetext{
${ }^{154}$ Naggiar an Bonnet, T 26-27, 13.6.1938 (MAE Chine 847); CADOGAN, Diaries, S. 84, S. 86; HARVEY, Diplomatic Diaries, S. 160f.; Bullitt an Hull, 7.7., 26.7., 8.8., 5.8.1938 (FRUS 1938, III, S. 534f., S. 541, S. 544f.; SD 760F.62/544).

155 YounG, China and the Helping Hand, S. 83f., S. 206; Halifax an Phipps, 23.11., Halifax an Clark Kerr, 9.12.1938 (DBFP, $3^{\text {rd }}$ series, VIII, 275, 326); Visit of British Ministers to Paris. Record of the Conversations, Cabinet Paper 269 (38), 26.11.1938 (FO 371/21592, C 14652/13/17); Johnson an Hull, 10.12.1937 (SD 893.24/330); Corbin an Bonnet, T 3089, 1.12.1938 (MAE Chine 731); Halifax an Mallet, 6.1., Mallet an Simon, 11.1.1939 (DBFP, $3^{\text {rd }}$ series, VIII, 397, 409); CADOGAN, Diaries, S. 150.

${ }^{156}$ Léger an Corbin, T 395, 9.3., Corbin an Bonnet, T 742-44, 13.3.1939 (MAEN Londres C 477); Corbin an Bonnet, T 679-80, 9.3., T 715, 11.3., Havas Tokio, le Japon et les crédits britanniques à la Chine, 9.3.; Henry an Bonnet, T 148-51, 11.3.1939 (MAE Chine 853, 721).
} 
Wellington Koo bat Léger am 13. April, Frankreich möge sich an dem Fonds beteiligen - mit zwei Millionen Pfund, etwa 350 Millionen Francs, so die Regierung in Chungking, in Paris sprach Koo von 250 Millionen Francs -, Kredite für Bahn- und Industrieprojekte in Südchina gewähren und die Transitzölle in Indochina senken. Die Zollsenkung befürwortete Léger: Dies werde Amerika erfreuen. Mandel bat Brévié, die Transitgebühr für Exporte nach China zu streichen. Dieser erfüllte nach einigen Wochen Widerstand Mandels Wunsch ${ }^{157}$. Zwei Wochen später teilte Paris der chinesischen Regierung mit, daß die staatliche Assurance Crédit der Bitte französischer Unternehmer nachkam, Ausgaben beim Bau der Bahnstrecke Yunnanfu-Suifu in Höhe von 500 Millionen Francs zu 80 Prozent zu versichern ${ }^{158}$.

Die Asienabteilung griff Koos Vorschlag, Südchina und Indochina vereint zu industrialisieren, auf und erarbeitete eine Studie. Die Chinesen hatten Paris nicht nur enorme Materialkäufe in Frankreich, sondern auch Südchinas weitere Durchdringung in Aussicht gestellt. Der bekannte Ökonom Paul Bernard betonte die Vorteile des Projekts. Doch Alexis Léger stoppte das Vorhaben. Schon im Sommer 1938 hatte das Außenministerium ähnliche Pläne, die Chinas Finanzminister T.V. Soong in Hanoi vorgelegt hatte, zurückgewiesen. Der Quai d'Orsay hatte 1938 argumentiert, daß man sich gegenüber Japan nicht zu sehr exponieren und Zweifel an Frankreichs Neutralität säen dürfe. Die Gründe galten auch noch im Frühjahr 1939. Dafür strebte der Quai d'Orsay eine indirekte Beteiligung am britisch-chinesischen Stabilisierungsfonds an: Der Staat sollte die Verluste der an dem Fonds beteiligten französischen Banken übernehmen. Im Finanzministerium setzte sich Bonnet am 25. April 1939 deutlich für die französische Teilnahme ein, die nicht nur die Zusammenarbeit mit London fördere:

Nous avons tout avantage, en effet, à faciliter les efforts de défense du Gouvernement chinois contre l'agression japonaise. [...] Enfin le Gouvernement japonais, par son attitude récente et notamment par l'occupation de l'île de Hainan et le rattachement des îles Spratley au Gouvernement général de Formose, nous a dégagé du souci de ménager ses susceptibiltés dans nos rapports avec le Gouvernement chinois.

\footnotetext{
${ }^{157}$ Corbin an Bonnet, $\mathrm{T}$ 627, 3.3., note de la sous-direction d'Asie-Océanie, 24.3.; Léger an Cosme, $\mathrm{T}$ 6, 21.3., Cosme an Bonnet, T 26, 28.3., Massigli an Cosme, T 152, 27.4.1939 (MAE Chine 734, 677, Indfr 42); Halifax an Phipps, 7.3.1939 (DBFP, $3^{\text {rd }}$ series, VIII, 538); Koo an Léger, Memoranda, 13.4., 19.4., Cosme an Bonnet, T 17, 20.3., T 531, 15.4., Diplomatie an Colonies, L 452, 25.4.1939 (DDF XV, 379; MAE Chine 853); Bullitt an Hull, 18.4., 1.6., 21.4.1939 (FRUS 1939, III, S. 665, S. 755; SD 651g.11251/14); Cosme an Georges-Picot, T 287, 30.4.1939 (MAEN Pékin A 395).

${ }^{158}$ Diplomatie an Finances, L 992, 17.5., Léger an Cosme, T 200, 22.5.1939 (MAE Chine 853). Reynaud zufolge gewährten staatliche Stellen einen Kredit über 300 Millionen Francs für Eisenbahnmaterial, aber vermutlich meinte auch der Finanzminister die Kreditversicherung. Der von ihm genannte niedrigere Betrag läßt sich nicht erklären (Bullitt an Hull, 23.5.1939, FRUS 1939, III, S. 38f.).
} 
Das letzte Wort über die Hilfe sprach Finanzminister Paul Reynaud. Dieser ließ sich trotz Légers Nachfragen Zeit. Bonnet war die Teilnahme als Zeichen französischen Widerstandsgeistes wichtig: Am 8. Mai kündigte er Cosme Frankreichs Beteiligung an. Diese Aussage wiederholte Chauvel am 23. Mai gegenüber Bullitt, nachdem Koo im Völkerbund die französische Mitwirkung angemahnt hatte. 200 Millionen Francs wollten die Franzosen bereitstellen ${ }^{159}$.

Reynaud versprach den Briten am 12. Juni seine Zustimmung, doch Frankreichs Teilnahme blieb aus. Das Finanzministerium fand ständig neue Hindernisse. Reynauds Haus forderte von den Briten erst einen, dann zwei Sitze in der Führung des Fonds und gab sich dann mit einem Sitz zufrieden. Reynaud und Paul Baudouin, der Direktor der Banque de l'Indochine, der die französischen Banken vertrat, verlangten Garantien für die Nutzung der beim Devisenhandel angesammelten China-Dollar und detaillierte Auskunft über den Fondszustand, was die Briten lange ablehnten. Cosme meldete am 5. Mai, der Fonds sei erschöpft. Einen Monat später schrieb er, Chinas Lage sei schwieriger als je zuvor. Vier Tage vor Reynauds Erklärung vom 12. Juni warnte Havas, der Fonds habe seine Unterstützungskäufe ausgesetzt, weil er bereits fünf Millionen Pfund verloren habe und Japan die Aufkäufe nutze, um Devisen zu erwerben. Am 9. Juni stellte das britische Schatzamt intern fest, man könne kein Geld mehr nachschießen, die 200 Millionen Francs seien wahrscheinlich zu wenig und kämen zu spät. Schon am 12. Juni stand die Operation also vor dem Scheitern. Das Finanzministerium in Paris spielte weitere zwei Wochen auf Zeit, dann wurde der Fehlschlag offenkundig: Ende Juni verlor der chinesische Dollar fast ein Viertel seines Wertes gegenüber dem Pfund, bis Ende Juli 1939 verlor er ein weiteres Viertel. Am 29. Juni nahm der Quai d'Orsay Abstand von dem Projekt. Léger hielt das Prinzip der Finanzhilfe an China weiter für richtig, doch der Fonds sei gescheitert. Zudem seien Chinas Silberreserven in Tientsin, die zur Währungsdeckung beitrugen, gefährdet ${ }^{160}$.

\footnotetext{
${ }^{159}$ Bonnet an Naggiar, T 331, 4.7., Naggiar an Brévié, T 994, 13.7., Diplomatie an Colonies, L 1356, 19.9.1938 (MAE Chine 676, Indfr 24); Neumann an Ribbentrop, 15.7., 1.8.1938 (AA Pol VIII 59, Bd. 1); Palmer an Hull, 5.8., 6.8.1938 (SD 893.51/6668, 893.014/218); Brévié an Mandel, T 1011, 12.9.1938 (CAOM FM 678); Note de la sous-direction d'Asie-Océanie, 25.5.1939 (DDF XVI, 280); Paul BERnARD, Regards sur l'Indochine, in: Revue de Paris 46 (1939) 2, S. $428-449$ (S. 445f); Diplomatie an Finances, L 822, 25.4.; L 1067, 25.5., mit Anmerkung Léger, 5.6.1939; Bonnet an Cosme, T 170, 8.5., SDN, $105^{e}$ session du conseil, procès-verbal, $2^{e}$ séance, 22.5.1939 (MAE Chine 677, 853, SDN 368); Bullitt an Hull, 23.5.1939 (FRUS 1939, III, S. 38f.).

${ }^{160}$ Commercial Secretary Hongkong an Halifax, 25.5., 20.5., 12.6., Halifax an Commercial Secretary Hong Kong, 27.5., 9.6., 13.6., 21.6.1939 (DBFP, $3^{\text {rd }}$ series, IX, 112, 131, 185, 124, 168, 193, 245); Reynaud an Monick, L 9595, 8.6. Diplomatie an Finances, L 1336, 29.6., Cosme an Bonnet, T 58586, 5.5.; L 182, 4.6.; Havas, le sort de la monnaie nationale chinoise, 8.6.; STS-bulletin, 1.8., Cosme an Bonnet, T 49-50, 23.6.1939 (MAE Chine 853, 736, 773, 535); Kennedy an Hull, 15.6., 10.7., Johnson an Hull, 26.6., 18.7.; Wilson an Hull, 17.6.1939 (FRUS 1939, III, S. 674f., S. 682f., S. 678f., S. 684f.; IV, S. 184f.); Monick an Reynaud, D 68.638, 19.6.1939 (DDF XVI, 475).
} 
Ende Juli und Anfang August bat Chungking die Regierungen in London, Paris und Washington erneut, den China-Dollar zu stützen. Aber die Regierungen hielten die Währungshilfe nicht mehr für erfolgversprechend. Léger sagte Bullitt, Frankreich bewillige Gelder, wenn England zusätzliches Geld bereitstelle. London ging aber von der Stützung der chinesischen Währung ab und gewährte Chinas Regierung am 18. August einen Direktkredit über 2,86 Millionen Pfund (500 Millionen Francs) zum Kauf britischer Waren. Damit wollte London seine Schlappe in Tientsin wettmachen, und mit den USA, die kurz zuvor ihren Handelsvertrag mit Japan gekündigt hatten, Schritt halten ${ }^{161}$.

Die wirtschaftliche Kooperation mit China hatte in Paris keine Freunde. Der einzige, der rastlos forderte, auf China zu setzen, war Alexandre Varenne. Der Sozialist und frühere Generalgouverneur Indochinas gehörte als délégué des Français du Tonkin dem Conseil supérieur des colonies an. Im Frühjahr 1938 und im Frühjahr 1939 argumentierte er in Briefen und Aufsätzen, daß China stets Indochinas dominierender Nachbar bleibe. Man müsse die »chinesische Karte« spielen, empfahl Varenne im März und April 1938 Léger, Daladier und Paul-Boncour: Wer China jetzt helfe, profitiere später davon. Im Februar und Mai 1939 riet er Daladier und Léger, mit China bei der Waffenproduktion zu kooperieren, ein Bündnis zu schließen und Militärberater zu entsenden. Daladier hielt dies für so interessant, daß er dem Generalstab eine Kopie des Briefs sandte. Die Diplomatie dafür zu gewinnen, versuchte Daladier aber nicht. Selbst der Jura-Professor René Cassin, Radikalsozialist und frühere Delegierte beim Völkerbund, ein Freund Chinas, plädierte für Frankreichs Rückzug aus China, um sich auf Indochina zu konzentrieren ${ }^{162}$.

Abgesehen von dem Liquiditätskredit und den Mitteln für den Eisenbahnbau in der französischen Einflußzone leistete Frankreich China keine finanzielle Hilfe. Die französische Regierung blieb passiv, weil sie - anders als London und Washington - keine größeren finanziellen oder politischen Risiken für China eingehen wollte. Dennoch setzte sich Léger im Sommer 1939 für Frankreichs Beteiligung an dem Währungsfond ein - gegen den Widerstand Bonnets, der einen Konflikt mit Japan vermeiden wollte ${ }^{163}$.

${ }^{161}$ Bullitt an Hull, 27.7., 31.7., Southard an Hull, 19.7.1939 (FRUS 1939, III, S. 692f.; S. 698; S. 686); Koo, Note, 27.7., Diplomatie an Finances, L 1718, 25.8., Memorandum, Foreign Office, 9.9., Cosme an Daladier, L 315, 15.9.; Koo an Léger, Memorandum, 4.8; Cosme an Bonnet, T 864-65, 2.8.1939 (MAE Chine 853, 885, 1072); Cosme an Léger, L, 5.8.1939 (DDF XVII, 443).

${ }_{162}$ Varenne an Léger, 7.3.1938, 15.5.1939 (MAE Ac 136, Chine 677); Ministère de la Défense nationale, cabinet du ministre, analyse, 28.3.1938 (SHAT $5 \mathrm{~N}$ 579); Varenne an Paul-Boncour, 8.4.1938 (MAE Chine 721); VARENNE, Les événements, S. 16f.; Varenne, note sur les événements d'Extrême-Orient, 25.2.1939 (DDF XIV, 215). In der US-Öffentlichkeit wante Alexandre VARENNE vor Japans expansiven Plänen (Indo-China in the Path of Japanese Expansion, in: Foreign Affairs 11.1 [Oktober 1938], S. 164-171); Note de René Cassin, 13.7.1939 (DDF XVII, 197).

${ }^{163}$ Bullitt an Hull, 6.6.1939 (FRUS 1939, III, S. 671f.). 
Vereitelt wurde Légers Plan durch Reynaud, der es ablehnte, 200 Millionen Francs in einer aussichtslosen Operation zu verlieren. Grundsätzlich vertrat Léger die Linie, daß Frankreich Japans Expansion in China keinen Widerstand entgegensetzen solle. Allerdings sollte Tokio nach flagranten Verletzungen französischer Interessen spüren, daß Paris nicht jede Zumutung hinnahm. Dazu setzte Léger auf kleine Nadelstiche, die Tokio spürte, die aber auch zeigten, daß Paris sich nicht auf die Seite der Feinde Japans schlug. Möglicherweise wollte Léger mit den Belegen französischer Gegenwehr seine Politik innenpolitisch absichern und demonstrieren, daß sich Paris den Aggressoren entgegenstellte. Letztlich harmlose Nadelstiche stellten die erwogene Teilnahme am Stabilisierungsfonds wie auch die Behinderung der Erzexporte an Japan dar.

Die französische Regierung hatte im Februar und März 1939 auf Mandels Drängen als Antwort auf die japanische Besetzung Hainans und die Annexion der Spratlys die Erzexporte aus Indochina reduziert. Diese Sanktion war ohne Rücksprache mit London und Washington verhängt worden. Anfang April, als Mandel sah, daß die Exportbeschränkung Indochina hart traf, suchte er internationale Rückendeckung oder eine Ausrede, um die Sanktionen aufzuheben. Der Kolonialminister forderte Bonnet auf, Briten und Amerikaner für Sanktionen zu gewinnen. Das gleiche Ziel verfolgte der Abgeordnete Jean de Beaumont, ein Anhänger Mandels, bei einem Gespräch mit Cadogan. Die Briten schlugen vor, einen Plan zu entwickeln, wie die Demokratien in China gemeinsam vorgehen könnten. Der Quai d'Orsay und das Foreign Office waren sich einig, daß Sanktionen gegen Japan zur Behauptung westlicher Präsenz in China erforderlich, aber riskant seien. Am 29. April forderte der Quai d'Orsay von London die Beteiligung an Indochinas Verteidigung, falls dieses durch Sanktionen in Gefahr gerate - eine Bedingung, an der die Gespräche scheitern mußten. Als die Briten erklärten, es sei schwierig, Malaysias Erzexporte zu reduzieren, zumal die USA die Eisenerzverkäufe aus den Philippinen kaum herabsetzten und Japan Abbau-Lizenzen besitze, lockerte Paris die Restriktionen bei den Erzexporten aus Indochina Ende Mai 1939 wieder ${ }^{164}$.

Anfang Mai 1939 forderte China vor der Ratstagung des Völkerbundes erneut Beschlüsse über Wirtschaftssanktionen. Der Westen und die Sowjetunion soltten ein Komitee gründen, das die Hilfe an China koordiniere. Bonnet und Léger schlossen Maßnahmen gegen Japan kategorisch aus. Gleichzeitig

\footnotetext{
${ }^{164}$ Ronald, Minute, 25.4.1939 (FO 371/23551, F 4027/4027/61); Jean DE BEAUMONT, Quand la tempête souffle sur l'Asie, in: Revue de Paris 46 (1939) 2, S. 134-144; Charvériat, Note, 28.4., Charvériat an Phipps, Note, 29.4.1939 (MAE Chine 761, DDF XV, 524); Phipps an Halifax, 2.5.1939 (DBFP, $3^{\text {rd }}$ series, IX, 35); Diplomatie an Colonie, L 470, 29.4., Léger an Corbin, T 941-42, 12.5., Diplomatie an Colonies, T 169, 19.5.1939 (MAE Japon 129); Corbin an Bonnet, T 1568-69, 18.5., T 1570-71, 18.5.1939 (MAE SDN 368, Chine 761); Halifax an Phipps, 18.5.1939 (DBFP, $3^{\text {rd }}$ series, IX, 85); Note de la sous-direction d'Asie-Océanie, 19.5.1939 (MAEN Tchongking 3).
} 
wies Bonnet die Botschafter in Shanghai, London und Washington an, den Regierungen darzulegen, daß Paris China praktisch helfen wolle. China solle aber die Forderung zurückziehen, die den Ruf des Völkerbundes schädige ${ }^{165}$.

Vor dem Rat wiederholte Koo Ende Mai sein Verlangen vom Januar 1939, nämlich ein Handelsembargo gegen Japan, die Bildung eines Koordinationsausschusses für Hilfe an China und die Untersuchung der Bombardements auf Zivilisten. Halifax und Bonnet sagten, angesichts der unveränderten Umstände, nämlich der andauernden Passivität der USA, lehnten sie dies ab. Bonnet versicherte, bisher schon habe Frankreich im Rahmen des Möglichen China geholfen. Auf britischen und französischen Druck beschloß der Rat zwei folgenlose Resolutionen: China wurde für seinen heroischen Kampf erneut das Mitgefühl der Staatenwelt versichert. Die Mächte wurden aufgefordert, sich mit den Mitgliedern des Konsultativkomitees - gemeint war Amerika - abzustimmen, um China zu helfen und Informationen über japanische Luftangriffe auf Zivilisten sammeln ${ }^{166}$. Von Zwangsmaßnahmen war keine Rede.

Ende Mai meldete Corbin, daß Wirtschaftssanktionen in der britischen Regierung Anhänger fänden. Als sich die Lage in Tientsin Mitte Juni verschärfte, stellte sich in London und Paris erneut die Frage wirtschaftlicher Druckmittel. In die Konfrontation in Nordchina wollte Paris auf keinen Fall ohne die USA verwickelt werden. Mehrfach warnte Bonnet den britischen Botschafter, England solle keine Maßnahmen ohne Amerika ergreifen, zumal Hilfe an China Indochina "gewissen Risiken « aussetze. Ohne Washington verfolgte London die Sanktionspläne nicht weiter ${ }^{167}$. Während Léger das Foreign Office noch energisch zu einer gemeinsamen Fernostpolitik drängte, vollzog er einen kompletten Kurswechsel: Paris unterzeichnete Mitte Juni einen Handelsvertrag, der Japans Versorgung mit wichtigen Rohstoffen sicherte.

${ }^{165}$ Koo an Léger, Memorandum, [2.5.1939]; Cosme an Bonnet, T 637-39, 18.5.; Léger an Cosme, T 197, 22.5.1939 (MAE Chine 664); Cosme an Bonnet, T 577-79, 5.5.; Bonnet an Cosme, T 166-69, Corbin, Saint-Quentin, 8.5.1939 (DDF XV1, 64, 104); Craigie an Halifax, 9.5.1939 (DBFP, $3^{\text {rd }}$ series, IX, 51); Notes de la sous-direction de la Société des nations, 10.5., 22.5.1939 (MAE SDN 368).

${ }^{166}$ Amal an Léger, T 43, T 48, 22.5., T 49, 23.5., T 56, 24.5., T 66, 27.5.1939 (MAE Chine 664); $\mathrm{SDN}, 105^{\mathrm{e}}$ session du conseil, procès-verbal, $2^{\mathrm{C}}$ séance, $22.5 .1939 ; 1^{\mathrm{er}}$ et $2^{\mathrm{c}}$ projet de résolution relatif à l'appel de la Chine, 24.5., Arnal an Bonnet, L 81094 P.L., 2.6., notes de la sous-direction de la SDN, 3.6., 12.6.1939 (MAE SDN 368); $105^{e}$ session du conseil, $4^{e}$ seánce, 27.5.1939, (JO-SdN, S. $271 \mathrm{ff}$ ). Kurz zuvor hatten sich Avenol und Daladier geeinigt, daß der Völkerbund, falls die Schweiz angegriffen werde, nach Frankreich fliehen werde - und zwar nach Vichy (Victor-Yves GHEBALI, La France en guerre et les organisations internationales 1939-1945, Paris, Den Haag 1969, S. 1-30).

${ }^{167}$ Corbin an Bonnet, T 1643-45, 26.5., T 1876-77, 17.6.1939 (MAE Chine 761, Chine 1066); Charvériat an Phipps, Note, 15.6.1939 (DDF XVI, 440); Halifax an Phipps, 16.6., 19.6., Phipps an Halifax, 16.6., 17.6.1939 (DBFP, $3^{\text {rd }}$ series, IX, 221, 237, 222, 223); EMG.2, bulletin, 6.7.1939 (SHM 1BB2 92); Léger an Corbin, L 916, 27.5., L 1146, 30.6.1939 (MAE Chine 761, MAEN Londres C 486); Louis Roché an Ronald, Memoranda, 3.6., Ronald an Roché, Memorandum, 10.6.1939 (FO 371/23551, F 5329, 5338/4027/61); Cambon an Bonnet, L 447, 8.6.1939 (MAE Japon 132). 
Paris hatte während der Sudetenkrise eine Handelsvereinbarung mit Japan getroffen, die japanische Exporte nach Frankreich erlaubte, wenn Japan für frühere französische Exporte Devisen zahlte. Als die Regierung in Tokio die Zahlung weiter blockierte und Gespräche über die Zahlungsrückstände hinauszögerte, beschränkte Paris Anfang März 1939 erneut den Import japanischer Produkte. Rohseide und Kampfer, die 90 Prozent der japanischen Exporte ausmachten, waren nicht betroffen. Am 15. Juni vereinbarte Henry mit dem Gaimusho die Normalisierung der Handelsbeziehungen. Japans Regierung versprach, ihre Außenstände, die das Abkommen mit 10 Millionen, eine Aufzeichnung der Direction des affaires politiques et commerciales mit 20 Millionen Francs angab, bis 15 . September 1939 zu begleichen. Tokio verpflichtete sich zudem, für das Handelsjahr vom 15. März 1939 bis 15. März 1940506 Millionen Francs für Importe aus Frankreich und seinen Kolonien bereitzustellen, was eine enorme Zunahme französischer Exporte ermöglicht hätte. Die Exporte aus der französischen Metropole sollten sich auf 200 Millionen Francs verdoppeln. Dieser Umfang war zuletzt 1929 erreicht worden. Paris durfte Importe unterbinden, wenn Japan seine Verpflichtungen brach $^{168}$.

Bevor Henry das Abkommen am 26. Juni unterzeichnete, bekam Bonnet Bedenken, ob der Vertrag - zwölf Tage nach Beginn der Blockade in Tientsin! nicht London brüskiere. Auch kritische Kommentare, wie der des Wirtschaftsblattes »Les Échos«, das die Vereinbarung als Zeichen der Schwäche und unfreundliche Geste gegenüber England kritisierte, ließen den Minister zögern. Léger beruhigte Bonnet: Es seien nur technische Verhandlungen zu dem Zahlungsabkommen geführt worden, das den Handelsvertrag von 1911 ergänze. Das Abkommen, das Frankreich große Vorteile und vermutlich eine um 100 Millionen Francs positivere Handelsbilanz bringe, habe man nach monatelangen harten Verhandlungen erreicht. Eventuelle Sanktionen, falls man dazu mit London und Washington greifen wolle, würden dadurch noch wirksamer. Während Frankreich auf japanische Rohstoffe wie Seide, Kampfer und Baumwolle angewiesen sei, erklärte Léger, könne Japan Frankreich als Maschinenlieferant leicht ersetzen. Paris habe bei dem Vertrag mehr zu gewinnen als Tokio. Mit der Ablehnung des Abkommens hingegen verliere Frankreich die traditionellen Exporte nach Japan. Bonnet befürchtete eine Irritation der Briten und Amerikaner und suchte deshalb Daladiers Zustimmung. Als der Ministerpräsident zustimmte, gab Bonnet grünes Licht. Britischen und deutschen

\footnotetext{
${ }^{168}$ STS bulletin $n^{\circ} 15,1.2$., Domei, exportations japonaises vers les colonies françaises, 31.1., Phipps an Bonnet, 27.3.1939 (MAE Chine 534, 1070, 734); Ott an Ribbentrop, 9.3., Campe an Ribbentrop, 3.5., Bulletin quotidien, 23.6.1939 (AA Botsch Paris, 863a 2); Henry an Bonnet, T 170, 18.3.; T 23943, 24.4., T 263, 4.5., T 270-71, 5.5., Léger an Henry, T 255-57, 17.6.1939 (MAE Japon 128, 129); Phipps an Central Department, 1.9.1939 (FO 371/22938, C 12991/6841/17).
} 
Diplomaten wurde der Vertrag als Erfolg dargestellt, den Paris Tokio abgerungen habe. Offiziell teilte die Agence Economique et Financière mit, es sei nur ein technisches Zahlungsabkommen unterzeichnet worden. Die Aufregung, die darum gemacht werde, sei nicht gerechtfertigt. Trotz des Abkommens könne Frankreich an Wirtschaftssanktionen teilnehmen ${ }^{169}$.

War der Vertrag vom 15. Juni ein technisches, unpolitisches Zahlungsabkommen? Half die Regelung den straditionellen französischen Exporten«? René Girault nimmt an, daß viele französische Politiker und Diplomaten 1938 und 1939 den wirtschaftlichen Aspekt der Macht unterschätzten. Tatsächlich spielten Wirtschaftsfragen in den Beziehungen zu Japan keine große Rolle. Frankreich war für Japan ein wichtigeres Absatzgebiet als umgekehrt: Frankreich nahm Mitte der dreißiger Jahre 1,8 Prozent der japanischen Exporte auf; doch nur 0,2 bis 0,7 Prozent der französischen Exporte gingen in den 1930er Jahren nach Japan. 1937 betrug dieser Anteil 0,65 Prozent, 1938 und 1939 je 0,3 Prozent. Tokio war politisch und militärisch für Paris wichtig, nicht ökonomisch. Japan erwirtschaftete im Handel mit Frankreich stets Überschüsse, die in der zweiten Hälfte der dreißiger Jahre zu rund drei Vierteln durch Rohstofflieferungen aus Indochina an Japan ausgeglichen wurden ${ }^{170}$.

Angesichts des insgesamt geringen Warenaustausches liegt es nahe, daß Léger den Handelsvertrag nutzte, um zu politischen Übereinkünften mit Japan zu kommen, wie es Fernostexperte Roger Lévy schon 1936 geraten hatte. Dies wird klar, wenn man betrachtet, welche Lieferungen Henry und das Gaimusho vereinbarten. In den ersten elf Monaten des Jahres 1939 stiegen Frankreichs Exporte im Vergleich zum Vorjahr um zehn, die Exporte aus Indochina nach Japan sogar um 28 Prozent. Von dem Gesamtlieferumfang von 506 Millionen Francs sollten Frankreich und seine Kolonien für 143 Millionen Francs Kohle, für 55 Millionen Francs die Sprengstoff-Grundlage Phosphat und für 33 Millionen Francs Kautschuk liefern. Ganz oben auf Tokios Bestelliste standen Metalle: Für 90 bis 142 Millionen Francs wollte Tokio Eisen und für fünf bis zwölf Millionen Francs Nickel erwerben. Paris sollte für zwölf Millionen Francs Zink, für insgesamt elf Millionen Francs Aluminium und Magnesium sowie »Maschinen und Ersatzteile« für 46 Millionen Francs liefern. Der

\footnotetext{
${ }^{169}$ Note de la sous-direction d'Asie-Océanie pour le ministre, 21.6., Bonnet an Henry, T 263, 22.6., T 266, 23.6; Direction des affaires politiques et commerciales, notes pour le ministre, 21.6., 23.6.1939 (MAE Japon 129; RFD 28; Papiers 1940, cabinet Bonnet 8); Phipps an Halifax, 22.6., 24.6., 30.6., 12.7.; Campe an Ribbentrop, 22.6., 27.6., Thin an Ribbentrop, 24.6.; Dooman an Hull, 18.7.1939 (FO 371/22938, C 8832, 8932, 9213, 9929/6841/17; AA, Botsch Paris, 863a 2; SD 894.00 P.R./139).

${ }^{170}$ René GiraulT, En forme de bilan, in: GiraUlT, FraNK (Hg.), La puissance en Europe, S. 387-391 (S. 390); SAUVY, Histoire économique, Bd. 2, S. 344; The Japan Year Book 1937, 1938/39; Ott an Ribbentrop, 9.3.1939 (AA, Botsch Paris, 863a 2). Die Prozentzahlen wurden vom Autor errechnet. Generell zu den Handelsbeziehungen LÉVY, La politique française, S. $27 f$.
} 
britische Konsul in Saigon, der annahm, daß das Exportverbot für Erz noch galt, wunderte sich im Herbst 1939, daß der Export nach Japan so weiterging wie 1938, als Japan Indochinas gesamte Eisenproduktion aufkaufte ${ }^{17 !}$.

Léger, Bonnet und Daladier signalisierten Tokio mit dem Abkommen, daB Paris bereit war, Indochinas Wirtschaft in die japanische Kriegswirtschaft zu integrieren. Wohl auch deshalb stellte Paris den Briten, die Anfang August 1939 nachgefragt hatten, erst im September den Text der Vereinbarung vom Juni zur Verfügung. Eine Kolonie, die Japans Wünsche erfüllte, konnte für das japanische Militär kein lohnendes Ziel mehr sein. Mit dem Handelsvertrag reagierte Paris auch auf Signale, die zeigten, daß Tokio das Klima verbessern wollte: Japans Vizekriegsminister empfing Anfang Mai Oberstleutnant Perretier, den Kommandeur der französischen Streitkräfte in Shanghai, herzlich. Der Direktor des Institut franco-japonais von Kyoto erhielt einen japanischen Orden. Im Juni und Juli wurde Henry diskret erklärt, welche Vorteile es habe, wenn Frankreich zu Großbritannien auf Distanz gehe. Ein ähnliches Angebot machten die Japaner dem niederländischen Botschafter Pabst. Als Henry nach Details fragte, wichen die japanischen Diplomaten aus. Als Reaktion schlugen Bonnet und Cosme vor, in der Frage des abgelehnten japanischen Botschafters Tani auf Tokio zuzugehen. Léger lehnte dies aber als schwächlich ab. Immerhin schickte Frankreich im Juni und im Juli Offiziere zu Sprachstudien nach Japan - sicher kein Zeichen entschlossener Konfliktbereitschaft ${ }^{172}$.

Die enge Verknüpfung der indochinesischen und der japanischen Wirtschaft erschien wegen der Kriegsgefahr in Europa aber nicht nur als apaisement politisch sinnvoll, sondern sie war auch wirtschaftlich klug: Im Krieg konnte Indochina die Verbindung zur Metropole kaum aufrechterhalten und mußte sich in die von Japan dominierte pazifische Wirtschaft integrieren. Indochina lieferte nach dem Kriegsausbruch in Europa große Mengen Reis nach Japan und ließ dort auch Münzen prägen. Tokio zeigte sich im Februar 1940 sehr zufrieden über die Entwicklung des Handeis mit Frankreich und Indochina ${ }^{173}$.

\footnotetext{
${ }^{171}$ Roger LÉVY, Les conséquences du developpement économique du Japon pour l'empire français, Paris [1936], S. 97, S. 108; Handelsattaché B. de Tascher an Handelsminister Gentin, L, 17.1.1940 (MAEN Tokyo, B 79); Walsh an Halifax, 1.9.1939 (FO 371/23567, F 10439/982/23).

${ }^{172}$ Henry an Bonnet, T 338-39, 9.6.1939 (DDF XVI, 380); Wilson an Hull, 13.6.1939 (FRUS 1939, IV, S. 179f.); Note Howe, 12.7., Craigie an Halifax, 4.9.1939 (FO 371/23548, F 7250, F 11345/ 1821/61); Corbin an Bonnet, T 2488, 6.8., Cosme an Bonnet, T 764, 4.7., note de la sous-direction d'Asie-Océanie, 29.6., Henry an Bonnet, T 388-91, 4.7.1939 (MAE Japon 129); FNEO, compte rendu, 5.5., FNEO an EMG.2, T 7648, 3.6., Rosati an EMG.2, T 157-58, 30.6.1939 (SHM 1 BB9 47). ${ }^{173}$ Delenda an Henry, $T$ 539, 19.10.; Henry an Daladier, T 761, 5.12., T 772, 9.12.1939 (MAE Indfr 33); Colonies an Diplomatie, L 3129, 17.12.1939, Saint-Quentin an Daladier, T 265, 14.2.1940 (MAE Indfr 45); Pullan (Saigon) an Halifax, 30.1.1940 (FO 371/24655, C 2423/166/17); Havas Tokio, l'accord commercial provisoire franco-nippon, 13.2.1940 (MAE Japon 129).
} 


\subsection{Die Entsendung einer Militärmission nach China}

Im Januar und Februar 1939 bemühte sich China erneut um die Entsendung französischer Militärberater. Aus ihrem Scheitern im Juni 1938 hatten die Chinesen und ihre Helfer in Paris gelernt: Das Haupthindernis im Vorjahr, das Außenministerium, wurde hintergangen. Chiang Kai-sheks Interesse an französischen Militärs war militärischer und politischer Natur: Nach dem Abzug der deutschen Mission stützte sich seine Armee allein auf 300 sowjetische Berater. Eine westliche Militärdelegation hätte ein Gegengewicht zu den Sowjets gebildet $^{174}$. Zudem hätten sich französische Ausbilder der Weltöffentlichkeit als Beweis der Unterstützung Chinas durch Frankreich präsentieren lassen.

Die Domei-Meldung vom 12. Februar, Frankreich entsende 49 Offiziere nach China, ignorierte der Quai d'Orsay. Doch am 13. März verfestigten sich in Paris Gerüchte, die Regierung stelle Militärberater ab. Am 6. April erhielt das Außenministerium erste konkrete Hinweise auf die Mission: Demnach hatten französische Offiziere am 22. März Marseille auf einem Schiff in Richtung China verlassen. General Barrault von den Kolonialtruppen habe die Gruppe zusammengestellt, ihr Chef sei Luftwaffen-General Berger.

Die Ursprünge der Mission stehen in enger Beziehung zu Waffenverkäufen an China. General Paul Berger, ehemaliger Leiter der Akademie der Armée de l'air, vom Kriegsministerium mit der Abwicklung von Waffenlieferungen an China betraut, gehörte den Aufsichtsräten verschiedener Rüstungsbetriebe an. Anfang 1937 lernte er Chinas Finanzminister Kung kennen, als dieser in Paris französisches Kriegsgerät erwarb. H.H. Kung bot dem General, der Luftfahrtminister Pierre Cot nahestand, ein Engagement in China an. Im August 1937 bat Berger erstmals um Erlaubnis, in China tätig werden zu dürfen, doch Léger widersprach, so wie bei drei weiteren Nachfragen Bergers ${ }^{175}$.

Ende August 1937 hatte das Luftfahrtministerium auf den Hinweis des Quai d'Orsay, Berger suche Militärberater für China, geantwortet, die Gespräche zwischen Kung und Berger seien privater Natur, der 57-jährige gehöre auch nicht mehr dem aktiven Kader der Luftstreitkräfte an. Im Frühjahr 1938 rekrutierte Berger für die von Waffenhändler Jean Audinet an China verkauften Flugzeuge Piloten und Mechaniker. Als Japan gegen den Einsatz französischer Piloten protestierte, erwiderte der Quai d'Orsay, die Regierung habe keinen

\footnotetext{
${ }^{174}$ Nolde, Mission, S. 982; Yvon an EMG.2, L 11, 24.4.1939 (SHAT 7 N 3291), Prideaux Brune (Chungking) an Broadmead (Shanghai), 28.6.1939 (FO 371/23483, F 9371/362/10).

${ }^{175}$ Liste des correspondances échangées avec le ministère des Colonies, 30.6., Yvon an EMA.2, L 1, 10.4., note de la sous-direction d'Asie-Oceanie, 6.4., André Nègre an Cosme, L, 14.5.1939 (MAEN Pékin A 344); Phipps an Halifax, 18.5 .1939 (FO 371/23483, F 4764/362/10); BÜHRER, Aux heures tragiques, S. 86; Diplomatie an Air, L 603, 11.8.1937 (MAE Ac 133).
} 
Einfluß auf Zivilisten. General Berger, den China habe verpflichten wollen, sei die notwendige Erlaubnis verweigert worden sei ${ }^{176}$. Wenn Berger 1939 nach China reiste, mußte er die Zustimmung der Regierung erhalten haben.

Wie gelangte 1939 eine Gruppe französischer Offiziere nach China? Bonnet macht in seinen Memoiren Mandel dafür verantwortlich. Auch Mandels Generalstabschef Bührer schreibt, der Kolonialminister habe entschieden, Offiziere nach China zu entsenden, was Daladier gebilligt habe. Generalgouverneur Georges Catroux, den Mandel im August 1939 über die Mission informierte, und der Chef des Kolonial-Geheimdienstes Raoul Salan behaupten ebenfalls, der Kolonialminister habe die Mission entsandt ${ }^{177}$. Salan zufolge wollte Mandel mit der Mission Chinas Nachschubbedarf erkunden, falls Paris chinesische Hilfe zur Verteidigung Indochinas brauche; laut General André Nolde war es Mandels Ziel, China so zu stärken, daß es Japan ausbalancierte und Indochina die Metropole in einem Krieg in Europa unterstützen konnte; General Bührer folgend wollte Mandel Chiang Kai-shek französischen guten Willen beweisen. Militärattaché Sabattier hingegen schreibt, der integre Mandel sei bei der Mission Opfer der Intrigen Bührers geworden, der mit chinesischer Hilfe Indochina habe verteidigen wollen. Auch Chinas Generalkonsul in Paris erklärte, Bührer habe die Zusammensetzung der Mission vorbereitet ${ }^{178}$.

Tatsächlich verantworteten, womöglich auf Anregung Bührers, Kolonialminister Mandel und Ministerpräsident Daladier - trotz Konflikten in anderen Bereichen ${ }^{179}$ - gemeinsam die Mission der sieben Offiziere. Übereinstimmend erklärten Chinas Regierung dem Militärattaché Yvon sowie Berger und der entsandte Major Legrand dem britischen Vizekonsul Mackenzie, die Mission sei Anfang Januar 1939 zwischen General Yang Chieh, Chinas Botschafter in der Sowjetunion, und Ministerpräsident Daladier in Paris vereinbart worden. Daladiers Zusage war daran geknüpft, daß die Mission inoffiziell sei und daß seine Regierung jede Beteiligung leugnen könne. Auch Nolde spricht von »Monsieur Daladiers Entscheidung«. Der Regierungschef sagte Bullitt wieder-

\footnotetext{
${ }^{176}$ Note de la sous-direction d'Asie-Océanie, 6.4.1939 (MAEN Pékin A 344); Bonnet an Henry, T 230-33, 13.7.1938 (DDF X, 201).

${ }^{177}$ BoNNET, Tourmente, S. 108; BÜHRER, Heures tragiques, S. 85f.; NoldE, Mission, S. 983; CATRouX, Deux actes, S. 9; Préface Catroux, in Legrand, L'Indochine, S. 7f.; Salan, Mémoires, S. 58.

${ }^{178}$ Salan, Mémoires, S. 59; NoldE, Mission, S. 982f; BŪHRER, Aux heures tragiques, S. 85; SABATTIER, Le destin, S. 29f.; Note de la sous-direction d'Asie-Océanie., 30.6.1939 (MAE Chine 677); BALINSKA nimmt an, die Mission sei gänzlich Mandels Werk gewesen (Le »Plan Mandel«, S. 36).

${ }^{179}$ Mandel hielt Daladier für schwächlich. Der Ministerpräsident seinerseits wollte im März 1939 den Kolonialminister entlassen, weil dieser gegen ihn intrigiere (WORMSER, Georges Mandel, S. 230; Bullitt an Hull, 18.3.1939, SD 740.00/632). Daladier wußte von Mandels gescheitertem Versuch, bei der Wahl des Staatspräsidenten am 5. April 1939 Daladiers Kandidaten Lebrun durch Jeanneney zu ersetzen, von dem Mandel zum Regierungschef emannt werden wollte (FAVREAU, La passion, S. 359). Mitte Oktober 1939 erklärte Daladier, er könne sich vorstellen, Reynaud zum Außenminister zu machen, allerdings nur, wenn sich dieser von Mandel distanziere (VILLELUME, Joumal, S. 66).
} 
holt, es sei seine Entscheidung gewesen, die Mission zu entsenden. Daladier und Bührer galten im Quai d'Orsay als Freunde ${ }^{180}$.

Indizien legen nahe, daß Daladier von Waffenhändlern um die Entsendung gebeten wurde. Der für die Waffenkäufe verantwortliche Finanzminister Kung rühmte sich früh der Verpflichtung seines »persönlichen Freundes Berger«; der französische Konsul brachte den Waffenhändler Audinet mit Bergers Rekrutierung in Verbindung; Audinet selbst berichtete Frankreichs Militärattaché schon im März 1939 von der »Mission Berger« und wurde von Cosme als »intimer Freund Bergers $«$ bezeichnet ${ }^{181}$. General Yang, der die Mission vereinbarte, beschaffte Waffen: Er pendelte zwischen Moskau und Paris und war in Frankreich in Waffenkäufe und Bestechungen verwickelt ${ }^{182}$. Yang bat, weder Wellington Koo noch Chinas Militärattaché über seine Gespräche zu informieren. Dafür waren der chinesische Generalkonsul und Li Yu Ying an den Verhandlungen beteiligt. Auch Militärattaché Yvon war sicher, daß China über Jean Audinet die Entsendung der Militärberater eingefädelt hatte ${ }^{183}$.

Daladier wurde die Zusage durch Chinas verbesserte militärische Lage im Winter 1939 erleichtert: Nach dem Verlust Kantons am 21. Oktober 1938 und Hankous vier Tage später hatten Vize-Militärattaché Guillermaz, die Geheimdienste von Armee und Marine, der Generalstab in Paris sowie Militärattaché Thiébaut in Tokio Chinas Kollaps befürchtet, da China das letzte große Wirtschaftszentrum und den Versorgungsweg über das Meer verloren hatte. Allein das Kolonialministerium urteilte, Chiang habe seine besten Divisionen gerettet, der Verlust des Nachschubs sei unerheblich, da China große Vorräte besitze und über Birma und Rußland versorgt werde. Ende November 1938 änderte sich in Paris das Klima: Es häuften sich die Einschätzungen, daß China den Widerstand würde fortsetzen können, während die Zweifel an Japans Ausdauer wuchsen. Anfang 1939 schrieb Militärattaché Yvon, Chinas Kriegspotential steige, die Moral des Volkes bessere sich. Erstmals seit langem berichtete ein französischer Militärattaché im Mai 1939 wieder mit

${ }^{180}$ Yvon an EMA.2, T 588, 19.4., note de la sous-direction d'Asie-Océanie, 25.5., Nègre an Cosme, 14.5.1939 (MAE Chine 677, Indfr 42, MAEN Pékin A 344); Willys R. Peck an Hamilton, 21.6.1939 (SD 893.20/703); Prideaux Brune an Broadmead, 28.6.1939 (FO 371/23483, F 9371/362/10); NOLDE, Mission, S. 982; Bullitt an Hull, 28.4., 5.6.1939 (SD 740.00/1230, FRUS 1939, I, S. 269f.).

${ }^{181}$ Clark Kerr an Halifax, 25.4.1939 (FO 371/23483, F 4122/362/10); Nègre an Cosme, 14.5.1939 (MAEN Pékin A 344); Yvon an EMA.2, L 1/S, 10.4.1939 (MAEN Pékin A 344); CoSME, Chine 1939-1944, S. 11. Cosme urteilt dort sogar, Audinet habe die Mission veranlaßt (déterminé).

${ }^{182}$ GARVER, Chinese-Soviet Relations, S. 42. Yang beteiligte sich auch am Verkauf von Visa an jüdische Flüchtlinge, so Garver. Ein Anhänger Wang Ching-weis, der in Paris Jura studierte, offenbarte Japans Botschafter, General Yang Chieh und Chinas Generalkonsul hätten Daladier und wichtige Militärs getroffen. Der Student konnte Kopien von zwischen Li Yu Ying und Yang Chieh ausgetauschten Telegrammen vorlegen (Sawada an Arita, 7.2.1940, JA, S 1.1.1.0-28, S. 316f.).

${ }^{183}$ Note de la sous-direction d'Asie-Océanie, 30.6.1939 (MAE Chine 677), BüHRER, Aux heures tragiques, S. 89; Yvon an EMA.2, L 144, 7.10.1939 (SHAT 7 N 3292). 
Respekt von Chinesen, während zuvor etwa der Armee-Geheimdienst in Indochina, die Section d'études de Hanoi, mehrfach die Dummheit der chinesischen Soldaten beklagt hatte ${ }^{184}$. Damit erschien die Entsendung französischer Militärberater nach China weniger gefährlich als noch einige Monate zuvor.

Wer initierte in Paris die Mission, Mandel oder Daladier? Daladier mochte China. Doch dies brachte ihn in keiner anderen Situation dazu, sich so deutlich zu engagieren wie für die Militärmission. Es erscheint wenig wahrscheinlich, daß der sonst so zögerliche Daladier in Paris die treibende Kraft der Mission war. Glaubhaft ist Bührers Darstellung, Mandel habe die Initiative ergriffen, und Daladier habe sie abgesegnet, zumal auch Bonnet, Catroux und Salan den Kolonialminister als Initiator der Mission darstellen. Das von Salan und Nolde genannte Motiv, Mandel habe mit Hilfe Chinas ein Gegengewicht zu Japan schaffen wollen, erscheint jedoch ergänzungsbedürftig. Die französische Fernostpolitik, sofern sie nicht die Verteidigung Indochinas betraf, war alleinige Sache des Außenministeriums. Die Militärmission war für Mandel ein geeignetes Mittel, in die Fernostpolitik einzugreifen und Bonnets und Légers Asienpolitik, die Provokationen Japans sorgsam vermied, gründlich zu sabotieren. Der sowjetische Botschafter Jakob Suritz sah bei Mandel einen starken Hang zur Verschwörung und Intrige. Mandel untergrabe heimlich Bonnets Position, schrieb der Diplomat im Februar 1939:

Er sammelt Tatsachen, Gerüchte, Material und wartet den richtigen Moment ab. Während der sieben Tage [im September 1938], als er mit dem Ausbruch eines Krieges rechnete und erstmals die Rolle eines zweiten Clemenceau spielte, hatte er den [Henker-]Strick schon vorbereitet. Er hält sich jetzt ruhig, aber sein $\mathrm{HaB}$ auf Bonnet hat nicht nachgelassen. Wer etwas über Bonnet wissen will, muß zu Mandel gehen.

Ein Mitarbeiter des Foreign Office notierte im Februar 1939: »M. Mandel has an outstanding reputation even in France for political intrigue and overthrowing ministries «. Anthony Adamthwaite belegt, daß Mandels Opposition zu Bonnets Außenpolitik von der Politik gegenüber Deutschland, Italien und Spanien bis zur Fernostpolitik reichte. In der Sudetenkrise verlangten die britische und die französische Regierung am 20./21. September 1938 von der Prager Regierung, Hitlers Forderungen nachzugeben, um einen Krieg zu verhindern. Mandel rief mehrfach Staatspräsident Eduard Benes an und riet zur

${ }^{184}$ EMA.2, rapport du ministre, 17.10., 24.10., 7.11., 21.11.1938, 23.1., 6.3.1939; Notes, Guillermaz, 16.10., 28.10.; EMA.2, note, 18.10., 27.11.; Thiébaut an EMA.2, L 60, 4.11.1938 (SHAT 7 N 2515, 3291, 3300, 3331); EMG.2, bulletin de renseignement, 16.11., 16.12.1938 (SHM 1BB2 92); Colonies, bulletin de renseignement, 15.11., 15.12.1938 (SHAT $7 \mathrm{~N}$ 2507); STS-bulletin 1.11., 1.12., 1.2., 1.4.1939 (MAE Chine 534-535); Palasse an EMA.2, L 531, 13.1., Yvon an EMA.2, L 10, 24.4., L 14. 7.5.1939 (SHAT 7 N 3123, 3291); Guillermaz an Daladier, L 20, 7.2., L 29, 5.3.1939 (DDF XIV, 64, 264); SEH, renseignements, 24.11.1938, 17.3.1939 (CAOM CM 98, 87). 
Härte. Alexander Werth zufolge hoffte Mandel, dies werde eine Regierungskrise in Paris auslösen. In jedem Fall mußte es einen Krieg näherbringen ${ }^{185}$.

Als Paris und London im Frühjahr und Sommer 1939 mit Moskau über ein Militärbündnis verhandelten, informierte Mandel Botschafter Suritz detailliert über Frankreichs Position. Mandel stellte Bonnets Haltung als noch nachgiebiger dar, als sie ohnehin war. Dem Sowjetbotschafter, der ihn regelmäßig besuchte, sagte er im Juli 1939, Moskau solle den westlichen Unterhändlern mißtrauen. Am 2. August berichtete er, die französische Verhandlungsmission reise ohne Plan nach Moskau. Die Demokratien wollten keinen echten Pakt abschließen, sondern sie hofften weiter auf eine Einigung mit Berlin und sähen den Vertrag mit Moskau als Mittel, dabei ihre Postion zu verbessern. JeanLouis Crémieux-Brilhac nennt Mandels Worte »unvorsichtig und gut geeignet, Stalins Mißtrauen zu bestätigen ${ }^{186}$. In Moskau herrschte ohnehin Argwohn gegenüber dem Westen ${ }^{187}$. Mandel war nicht unvorsichtig. Er wußte, was er tat, als er Bonnets und Daladiers Bemühungen um ein Bündnis mit Moskau für Paris der letzte Ausweg, um dem Krieg zu entgehen - torpedierte.

Den dritten Akt politischer Sabotage beging Mandel im April 1940: Während sich die französische Regierung um eine Annäherung an Rom bemühte, rechnete Mandel Italiens Botschafter Raffaele Guariglia vor, gleichsam um Rom das geringe Risiko eines Angriffs zu zeigen, daß das Reich über mehr Divisionen als Frankreich verfüge, und präsentierte zum Beweis eine britische Generalstabskarte, die 180 deutsche Divisionen verzeichnete. Er rechne mit der Besetzung eines großen Teils Frankreichs, so Mandel. Der Krieg zwischen Italien und Frankreich sei unvermeidlich ${ }^{188}$. Mandels Auftritt war nicht gerade ein Versuch, Rom von einer friedlichen Einigung zu überzeugen.

${ }^{185}$ Suritz an Litwinow, 11.2.1939, zit. nach CARLEY, 1939, S. 93f. (Übersetzung des Autors, V.N.); Note Roberts, 11.2.1939 (FO 371/22922, C 2021/281/17); ADAMTHWAITE, France and the Coming of the Second World War, S. 121; BONNET, De Munich à la guerre, S. 250f.; DERS., Dans la tourmente, S. 55; Flandin, Politique française, S. 273 (ohne Mandels Namen zu nennen); FaVreau, Passion, S. 348; WERTH, The Twilight, S. 230.

${ }_{186}$ Suritz an Litvinow, 8.12.1938; 24.4., 26.4.1939 (SPE I, 67; 251; 256); Suritz an Molotow, 7.7.1939, 3.8.1939 (SPE II, 365; 395); CRÉMIEUX-BRILHAC, Les Français, Bd. 1, S. 40.

${ }^{187}$ CoT, Le Procès, Bd. 1, S. 89; M. V. ZaKHARov, On the Eve of World War II (May 1938September 1939), in: Soviet Studies in History 23.3 (1984-85), S. 83-122 (S. 118f.); Michael Jabara CARLEY, End of the sLow, Dishonest Decades: Failure of the Anglo-Franco-Soviet Alliance in 1939, in: Europe-Asia Studies 45.2 (1993), S. 303-341; Geoffrey ROBERTS, The Alliance that Failed: Moscow and the Triple Alliance Negiotiations, 1939, in: European History Quarterly 26.3 (1996), S. 383-414 (S. 408).

${ }^{188}$ Reynaud an Mussolini, 22.4., Guariglia an Ciano, 26.4.1940 (DDI Serie 9, IV, 166, 216); REYNAud, La France a sauvé l'Europe, Bd. 2, S. 194f.; Raffaele GuaRIGLIA, Ricordi 1922-1946, Napoli 1950, S. 448f. Anfang Mai meldete Guariglia, bestimmte Kreise, die auf Mandel verwiesen, hätten ihm signalisiert, daß Paris einen italienischen Angriff auf Jugoslawien tolerieren könnte (Guariglia an Ciano, 1.5., 6.5.1940 (DDI Serie 9, IV, 269, 311). Ob der Kolonialminister für diese Aufstachelung Italiens verantwortlich war, bleibt offen. 
In allen drei Fällen waren Mandels Handlungen geeignet, die Politik der Regierung völlig zu sabotieren. Offenbar wollte Mandel das apaisement gegenüber Deutschland und Italien zu Fall bringen. Ähnlich sollte die Entsendung der Militärmission nach China die Fortsetzung des apaisement gegenüber Japan unmöglich machen. Mandel wollte sicher auch Bonnet persönlich treffen, da er aber seine Eskalationspolitik im Frühjahr 1940 fortsetzte, kann man Mandels Vorgehen nur damit erklären, daß er einen militärischen Konflikt mit Deutschland, Italien und Japan heraufbeschwören wollte.

War Mandel ein Bellizist, wie die rechtsextreme Presse schrieb? Der Abgeordnete Montigny, ein Freund Caillaux', nannte Mandel bei Botschafter Phipps wthe leader of the war-party in France and the most dangerous man in the country and [...] a real danger for peace «; Bonnet bezeichnete Mandel mehrfach als Kriegstreiber; Phipps warf ihm vor, im Herbst 1938 über Monate einen Präventivkrieg gegen Deutschland befürwortet zu haben. Als Motiv unterstellte ihm Caillaux, daß er keine Kinder habe, die in den Krieg müßten. Montigny ließ offen, ob Mandel als Jude das Land gegen Hitler aufbringen oder ob er, wie unter Clemenceau, wieder große Macht ausüben wollte. Selbst Delbos rief im März 1938 in der Kammer im Streit mit Mandel aus, die Juden suchten ihr Heil in einem Weltkrieg; Bonnet unterstellte, Mandels Kriegslust lasse sich auf dessen jüdische Abstammung zurückführen ${ }^{189}$.

Mandels Biograph Bertrand Favreau nimmt Mandel in Schutz: Im März 1936 und im September 1938 habe er Militärmaßnahmen gegen das Reich gefordert, weil er annahm, daß die Zeit gegen Frankreich arbeitete. Mandel habe keinen Krieg um jeden Preis, sondern den Krieg im günstigsten Moment führen wollen. Da Mandel seit dem »Anschluß« von der Unvermeidlichkeit des Krieges ausgegangen sei, habe dieser so früh wie möglich geführt werden sollen. Erst nach dem Ausbruch eines Krieges, so Mandels Annahme, ergreife Frankreich die zum Sieg notwendigen Maßnahmen. Wer Frieden um jeden Preis wolle, gebe einem entschlossenen Gegner nach. Nur wer zum Krieg bereit sei, könne den Frieden retten. Favreau schildert Mandel als Mann, der den Krieg nicht fürchtete: Er liebte die absolute Macht, die der Kriegszustand verlieh. Der Krieg brauchte Männer mit starkem Charakter, und er hatte gezeigt, daß er diesen besaß. Er war einer der wenigen Politiker, der die Erfahrung einer Kriegsregierung aufwies. So wie ihn der Erste Weltkrieg an die Spitze der Innenpolitik gebracht hatte, glaubte er, so werde ihn ein zweiter

\footnotetext{
${ }^{189}$ Le voyage du Lord de la Paix, Candide, 23.11.1938 (CAOM Fonds Mandel 17/PA/1); Phipps an Halifax, 5.12.1938 (FO 371/21601, C 15350/55/17); Phipps an Halifax, 14.9., Phipps an Chamberlain, 4.11.1938, beide zit. nach Herman, The Paris Embassy, S. 105, S. 134; Phipps an Halifax, 2.9., 26.9.1938 (DBFP, $3^{\text {rd }}$ series, II, 751, 1099); FaVreaU, Clemenciste, S. 212; Sherwood, Mandel, S. 204; VILLELUME, Journal, S. 280.
} 
Konflikt als Staatsmann international fordern. Mandel träumte davon, einmal Außenminister zu werden. Im April 1939 versuchte er, durch eine Intrige Ministerpräsident zu werden. Mandel hoffte, wie er seinem Freund Jeanneney anvertraute, daß in großer Gefahr seine politische Stunde kommen würde. Als der Krieg in Europa ausbrach, litt Daladier unter der Verantwortung, während Mandel sich nach der Beobachtung von Senator Bardoux in bester geistiger und körperlicher Verfassung und "plus impérial et plus impérieux que jamais» zeigte. Als Mandel im Mai 1940 Innenminister wurde, von Léon Blum bejubelt als Mann, »dessen Autorität [...] begleitet wird von einer Legende und fast einem Mysterium «, kam er seinem Ziel ein großes Stück näher ${ }^{190}$.

Mandels Engagement für die Militärmission speiste sich deshalb wohl aus zwei Motiven: Einerseits sympathisierte er mit China, das mit französischer Hilfe zum Gegengewicht gegen Japan werden sollte, um Indochinas Sicherheit zu erhöhen. Andererseits strebte Mandel eine Verschärfung des Fernostkonfliktes an, ohne daß ihm eine Beteiligung nachgewiesen werden konnte. Die Mission ist ein gutes Beispiel für seine, von John M. Sherwood beschriebene, parallele Außenpolitik. Mandel wollte mit einem weiteren Projekt China helfen: Über den früheren Völkerbunddirektor Rajchman schlug er im Sommer 1939 der Regierung in Chungking vor, im Militärbereich und beim Waffentransit zu kooperieren. Der Plan verlief aber im Sande ${ }^{191}$.

Die Chinesen hatten jedenfalls mit ihrer Entscheidung, mit Mandels und Daladiers Hilfe die Mission geheim einzufädeln, die richtige Entscheidung getroffen. Daß ihnen der offizielle Weg nicht weitergeholfen hätte, erkannte Chinas Militärattaché General Tang Che, als die Mission schon vereinbart war: Am 6. Februar 1939 fragte er General Georges, ob Paris drei Offiziere an die Militärakademie abordnen könne. Ihre Tätigkeit werde mit dem Krieg nichts zu tun haben. General Dentz signalisierte dem Chinesen, Generalstabschef Gamelin wolle die Bitte erfüllen, doch der Quai d'Orsay widersetze sich. Zwei Tage später sagte Charvériat Dentz, das Außenministerium werde die Anfrage nach französischen Ausbildern ablehnen ${ }^{192}$, woraufhin die Chinesen nicht weiter fragten. Sie hatten ihre Mission ja bereits bekommen.

Offenbar war ursprünglich geplant, 40 französische Offiziere - also eine Mission in der Größe der abgezogenen deutschen Mission ${ }^{193}-\mathrm{zu}$ entsenden. Diese Zahl wurde dem französischen Militärattaché Yvon im Januar 1939 ge-

\footnotetext{
${ }^{190}$ FaVReaU, Clemenciste, S. 212f.; S. 34; DerS., La passion, S. 344f., S. 358f; JEANNENEY, Journal, S. X, S. 36; BARDOUX, Joumal, S. 160f.; REYNAUd, La France a sauvé l'Europe, Bd. 2, S. 126.

191 SHERwOOD, Mandel, S. 215 ; BalinSKA, Le »Plan Mandel«, S. $38 \mathrm{f}$.

${ }^{192}$ Militärattaché General Tang Che an General Georges, 6.2.1939 (SHAT 7 N 3301); BüHRER, Aux heures tragiques, S. 84; Compte rendu de liaison hebdomadaire, 8.2.1939 (DDF XIV, 75).

${ }^{193}$ Die Zahl der Berater betrug 193077 und lag von 1934 bis 1938 zwischen 53 bis 33 Offizieren (MARTIN, Die deutsche Beraterschaft: Ein Überblick, S. 29; WUU, Die deutsche Beraterschaft, S. 52).
} 
nannt. Auch die in Chungking, Hanoi und Hongkong und dann von der japanischen Presse verbreiteten Gerüchte erwähnten 40 Offiziere. Daladier nannte die Zahl 40 noch, als sich die Mission bereits auf der Reise nach China befand. Die am 12. Februar 1939 in einer ersten Meldung von Domei genannte Zahl von 49 Militärs weist ebenfalls diese Größenordnung auf. Von immerhin noch 15 entsandten Offizieren ging die Asienabteilung des Außenministeriums Anfang April aus. Warum die Mission dann nur sieben Offiziere umfaßte, kann an Hindernissen in Paris liegen, doch auch in Chinas Militär gab es Widerstände gegen die Gruppe ${ }^{194}$. Möglicherweise bekam der zögerliche Daladier zuletzt Zweifel und entsandte deshalb nur eine kleine Mission.

Nach China reisten Divisionsgeneral Paul Berger und Brigadegeneral Lucien Magnin von der Luftwaffe, Oberst Salel, die Bataillonskommandeure Dominique Renucci und Legrand von der Kolonialinfanterie sowie Schwadronchef Dumont und Hauptmann André Nolde von der Kolonialartillerie. Legrand und Nolde hatten in Frankreichs Truppen in China gedient. Offiziell wurden die Offiziere aus dem Dienst entlassen. Sie erhielten von Daladier aber einen Brief, der sie in geheimer Mission in den Fernen Osten entsandte und feststellte, ihre Entlassung sei fiktiv. Sie verlören weder ihren Rang noch die Anwartschaft auf Beförderung ${ }^{195}$. Ihre Aufgabe bestand darin, an der Kadettenschule in Chengtou und an der Kriegsakademie in Tsun Yi Offiziere auszubilden. Sie nahmen aber um Changsa auch an Kriegsoperationen teil und organisierten die Luftverteidigung von Chungking. General Berger wurde persönlicher Berater Chiang Kai-sheks, den er teilweise dreimal wöchentlich traf. Der Schwerpunkt lag in der Ausbildung. Dies war der Wunsch der Franzosen, um nicht die Verantwortung für militärische Mißerfolge zu tragen ${ }^{196}$.

Als Cosme am 13. April von der Mission erfuhr, forderte er, Paris müsse die Mission aufhalten. Aus einer chinesischen Quelle erfuhr Cosme am 18. April, die Offiziere kämen am 24. April in Haiphong an. Cosme verlangte erneut, die Mission aufzuhalten, da sie Paris kompromittiere. Einen Tag später bestätigte

\footnotetext{
194 Note de la sous-direction d'Asie-Océanie, 6.4., Yvon an EMA.2, L 1, 10.4.; T 510, 13.4.1939 (MAEN Pékin A 344, MAE Chine 677); Bullitt an Hull, 28.4.1939 (SD 740.00/1230); FNEO, compte rendu, 5.6.1939 (SHM 1 BB4 74). BONNET schreibt noch in seinen Memoiren, die Mission habe 60 Offiziere umfaßt (Dans la tourmente, S. 108); Yvon an EMG.2, L 11, 24.4.1939 (SHAT 7 N 3291 ). 195 Note de la sous-direction d'Asie-Océanie, 6.4., Cosme an Bonnet, L 206, 5.7., Gandon an Cosme, T 930, 15.10.1939 (MAEN Pékin A 344), NOLDE, Mission, S. 976f.; État des officiers de l'armée de l'air au 1/7/39, Paris u.a. 1939, S. 38f. Cosme zufolge erhielt Berger ein Monatssalär von 1500 USDollar, Magnin und Salel bekamen 1000 Dollar, die anderen je 800 Dollar. Dafür, daß die Offiziere falsche Namen benutzten, wie BONNET schreibt (Dans la tourmente, S. 108), gibt es keinen Hinweis. ${ }^{196}$ NoldE, Mission, S. 983; Nègre an Cosme, T 496-97, 13.5., Yvon an EMA.2, L 1, 10.4.1939 (MAEN Pékin A 344); Prideaux Brune an Broadmead, 28.6.1939 (FO 371/23483, F 9371/362/10); Cosme an Bonnet, T 508, 13.4, T 200, 4.7.1939 (MAE Chine 677, 783). Major Renucci klagte, die Chinesen fragten nach Rat, befolgten ihn aber nicht (Peck an Hamilton, 21.6.1939, SD 893.20/703).
} 
Chinas Regierung das Kommen der Mission. Die ahnungslosen Léger und Cosme, die sich gegen japanische Proteste verteidigen mußten, waren empört über die Intrigen in ihrer Regierung. Als Cosme, Informationen aus Paris vertrauend, den Japanern sagte, die Mitglieder der Mission seien Privatpersonen, hielt ein japanischer Diplomat ihm ein französisches Armee-Jahrbuch unter die Augen. Demnach waren sechs der sieben Militärs aktive Offiziere. Cosme wollte vor Scham in den Boden versinken. Er sei in seiner langen Laufbahn in keine peinlichere Lage versetzt worden, schrieb er später. Ihn ärgerte auch, daß kein Minister die Verantwortung für die Mission übernahm ${ }^{197}$.

Bonnet beschwerte sich förmlich bei Mandel. Die Asienabteilung war überzeugt, daß die Abordnung nur mit Billigung des Luftfahrt- und des Kriegsministeriums erfolgt sein konnte; Bonnet selbst hatte Mandel als Initiator in Verdacht. Bonnet betonte, jede Beteiligung von Dienststellen an der Organisation von Militärmissionen ins Ausland, von der sein Ministerium nichts wisse, sei unzulässig. Die Mission solle gebeten werden, zunächst in Indochina zu bleiben. Mandel antwortete Bonnet kurz und trocken: Da sein Ministerium keine Mission nach China entsandt habe, werde er dem Generalgouverneur in Hanoi keine Anweisung zu der Mission kabeln. Sein Ministerium schrieb, es sei nicht zuständig und wisse von nichts. Dem Botschafter in China übermittelte der Quai d'Orsay die Stellungnahmen des Kriegs-, des Kolonial- und des Luftfahrtministeriums, sie hätten mit der Militärmission nichts zu tun, und die Offiziere hielten sich privat in China auf ${ }^{198}$.

Die französischen Diplomaten hielten Distanz zur Militärdelegation. Jede offizielle Beziehung unterblieb. Nur der Konsul in Chungking bemühte sich auf Bitten Cosmes um persönlichen Kontakt zu den Offizieren, die in China zivil trugen. Als Domei die Regierung in Paris für die Mission verantwortlich machte, dementierte Cosme jede Verbindung zwischen der französischen Regierung und der Mission. China unterminierte die Bemühungen der Franzosen um Diskretion: Der Kriegsminister begrüßte General Berger bei der Ankunft auf dem Flughafen in Chungking. Chiang empfing die eigentlich geheime Mission mit den Ehren einer militärischen Gesandtschaft. Chinas Oberbefehls-

${ }^{197}$ Cosme an Bonnet, T 508, 13.4., T 536, 18.4., Bonnet an Mandel, L 453, 25.4., Yvon an EMA.2, T 510, 13.4., T 588, 19.4.; Cosme an Henry, L 90, 13.5.1939 (MAE Chine 677, MAEN Pékin A 344); Clark Kerr an Halifax, 25.4, Broadmead an Halifax, 16.5.1939 (FO 371/23483, F 4122, F 4687/362/10); Brévié an Mandel, T 675, 21.4.1939 (CAOM FM Tel 80); BONNET, Dans la tourmente, S. 108, NoldE, Mission, S. 983; Cosme, Chine 1939-1944, S. 8; Cosme an Vichy, L 35, 31.3 .1941 (MAE Vichy-Asie 124).

198 Notes de la sous-direction d'Asie-Océanie, 6.4., 13.2.1939 (MAEN Pékin A 344, MAE Chine 733); Bonnet an Mandel, L 453, 25.4., Mandel an Bonnet, L 185, 29.4.1939 (MAE Chine 677); Liste des correspondances, 30.6., Chauvel an Cosme, T 173, 12.5., T 163, 6.5.1939 (MAEN Pékin A 344, MAE Chine 514), Léger an Cosme, T 198-99, 22.5.1939, Léger an Henry, T 224-25, 22.5.1939 (MAE Japon 129); Nègre an Cosme, T 496-97, 13.5.1939 (MAEN Pékin A 344). 
haber unternahm alles, wie General Nolde klagte, um die öffentliche Meinung - und Japan - zu überzeugen, daß Paris für China Partei ergriffen habe ${ }^{199}$.

Wegen dieser Publizität glaubten US-Beobachter, die französische Mission nehme den Platz der deutschen Militärberater ein. Das Foreign Office war sich sicher, daß der 1937 pensionierte General Berger von aktiven Offizieren begleitet werde und die Mission offiziell genehmigt sei. Erklärungen aus Paris, man habe mit der Mission nichts zu tun, bewertete das Außenministerium in London als "rather machiavellian and very typical of the French«. »A strangely friendly gesture on the part of the French" nannte der Leiter der Asien-Abteilung Robert Howe die Entsendung. Léger erklärte den Briten, die Mission der »Reserveoffiziere« habe das Kolonialministerium irrtümlich genehmigt. Die Berger-Mission irritierte London auch, weil das Foreign Office eine Entsendung von Luftwaffen-Offizieren plante, um die China gebeten hatte. Auch wegen der französischen Gruppe wurde das britische Projekt verschoben, ehe am 29. August eine Mission mit zwei Offizieren genehmigt wurde. Mit Beginn des Krieges in Europa stoppte London den Plan ${ }^{200}$.

In Paris protestierte Japans Geschäftsträger Miyasaki am 26. Mai und am 10. Juni gegen die Mission, die er als »Beweis der Feindschaft französischer Militärkreise« bezeichnete. Miyasaki drohte nicht, aber er verlangte den sofortigen Abzug der Mission. Selbst wenn die Offiziere als Privatleute reisten, erwarte er den Befehl zur Abreise. Domei warnte, falls die Berichte über die Mission stimmten, stelle sie einen unfreundlichen Akt gegen Japan dar, das reagieren müsse $\mathrm{e}^{201}$. Bonnet verlangte, daß der Ministerrat entscheiden müsse, egal, ob die Offiziere als Privatiers nach China gereist seien oder nicht. Was die Regierung beschloß, ist unklar. Bonnet telegraphierte Cosme am 3. Juli aber, er möge General Berger mitteilen, es sei in der aktuellen Lage vorzuziehen, daß er den Aufenthalt in China beende. Daladier und Mandel, schrieb der Außenminister, teilten seine Meinung. Mandel sabotierte Bonnets Bitte, indem er Berger mit einem persönlichen Telegramm aufforderte, er möge im Moment in Chungking bleiben, egal, wie offizielle Befehle lauten mögen ${ }^{202}$.

\footnotetext{
${ }^{199}$ Cosme an Bonnet, T 611-12, 12.5., Nègre an Cosme, 14.5.1939 (MAE Chine 677, MAEN Pékin A 344); Domei, French Advisers reported reorganizing chinese army, 23.5., Cosme an Bonnet, T 671, 24.5.1939 (MAEN Pékin A 344); Lt de Vaisseau Le Gendre, STS-bulletin, 1.6.1939 (MAE Chine 535); Cosme an Bonnet, T 622, 13.5.1939 (MAEN Pékin A 344); NOLDE, Mission, S. 983.

${ }^{200}$ Barrett an War Department, 17.5., Peck an Hull, 18.5.1939 (SD 893.20/700, 699); Note HunnikerMajor, 18.5., Broadmead an Halifax, 16.5., Note Scott, 24.5., Phipps an Halifax, 18.5., Clark Kerr an Halifax, 25.4., Halifax an Clark-Kerr, 29.8.1939 (FO 371/23483, F 4122, 4687, 4764/362/10); Campbell an Howe, 16.11., Note Howe, 24.11.1939 (FO 371/23462, F 11986/87/10).

${ }^{201}$ Brévié an Mandel, T 909, 25.5.; Note de la sous-direction d'Asie-Océanie, 26.5.; Bonnet an Daladier und Mandel, L 2581, L 654, 15.6.1939 (CAOM FM Tel 80; DDF XVI, 291; MAE Chine 677).

${ }^{202}$ Bonnet an Daladier, cabinet du ministre, L 2286, 27.5., Nègre an Cosme, T 698, 27.7.1939 (MAEN Pékin A 344); Bonnet an Cosme, T 271, 3.7.1939 (MAE Chine 676).
} 
Cosme bat Berger in einem Brief um die Abreise. Der General lehnte ab: Berger verlangte ein offizielles Telegramm, das er Chiang zeigen könne. Cosme lehnte dies ab. Doch so sehr Cosme die Entsendung der Mission empört hatte, wehrte er sich nun gegen den plötzlichen Abzug, auf den sich die Minister offenbar geeinigt hatten. Wenn die Offiziere jetzt unvermittelt abreisten, demütige Paris den Generalissimus ${ }^{203}$. Ob dieses Argument Paris überzeugte, ob die Mission in den Hintergrund trat, weil Berger mit schwerer Ruhr im Krankenhaus lag und Japan die Proteste nicht wiederholte, ob die Regierung mit der Krise in Europa beschäftigt war oder ob Mandels heimlicher Widerstand Erfolg hatte: Weiteren Druck, um den Abzug der Gruppe zu erreichen, übte Paris bis zum September 1939 nicht aus. Bonnet wiederholte im August nur gegenüber Cosme, daß er die Abreise der Gruppe weiter wünsche ${ }^{204}$. Die militärische Lage Chinas war zudem so stabil, daß der Abzug nicht überstürzt werden mußte: Chinas Widerstand erlahme nicht, sein Kriegspotential wachse, während Japans Armee und die Reserven an Soldaten und Material erschöpft seien, berichteten die französischen Beobachter. Nur Völkerbund-Ingenieur Henri Maux und Botschafter Henri Cosme glaubten im Sommer 1939, Chinas Regierung sei ermattet und verzweifelt ${ }^{205}$.

Mit dem Krieg in Europa stellte sich die Frage der Abberufung der Mission neu. Cosme fordert einen Tag nach der französischen Kriegserklärung gegen das Deutsche Reich den Abzug der Mission. Bonnet bat zunächst wegen der Unsicherheiten in Ostasien um Aufschub. Am letzten Tag im Amt des Außenministers ordnete Bonnet an, General Berger möge mit der Gruppe vaus Gründen der nationalen Verteidigung « nach Frankreich zurückkehren. Mandel trug die Entscheidung diesmal mit. Bührer wollte die Mission in Chungking lassen, doch der Kolonialminister wollte Japan keinen Vorwand liefern, gegen Frankreich vorzugehen. Mandel sagte dem US-Botschafter, die Militärmission werde abgezogen, weil die Offiziere mobilisiert worden seien ${ }^{206}$.

\footnotetext{
${ }^{203}$ Cosme an Nègre, T 378, 6.7., Berger an Cosme, T 665-67, 15.7., Cosme an Nègre, T 388, 12.7., Cosme an Bonnet, L 238, 22.7.1939 (MAEN Pékin A 344), Cosme an Bonnet, T 817, 16.7.1939 (MAE Chine 536); Memorandum for the Councellor, 3.12.1939 (SD 793.94/15569).

${ }^{204}$ Bonnet an Cosme, T 278-79, 8.9.; T 327, 8.8., Cosme an Bonnet, T 868-69, 5.8.1939 (MAEN Pékin A 344, MAE Chine 536), Yvon an EMA.2, L 144, 7.10.1939 (SHAT 7 N 3292).

${ }^{205}$ Thiébaut an EMA.2, 18.5., 15.6.; Yvon an EMG.2, 1.6., 7.6.1939 (SHAT 7 N 3332, 3291); Compte rendu, 31.5., EMA.2, bulletin, 8.7.; EMA.2, notes, 16.6., 3.7., 7.8.1939 (SHAT 7 N 2525, 2516, 2524, 3301); FNEO, compte rendu, 5.7.1939 (SHM 1 BB4 74); EMG, bulletin, 10.7.1939 (CAOM FM, AP 1416); STS-bulletin, 1.6., Cosme an Bonnet, T 770, 5.7.1939 (MAE Chine 535, 737).

${ }^{206}$ Cosme an Bonnet, $T$ 952, 4.9., Bonnet an Cosme, $T$ 278-79, 8.9., T 423, 13.9., Cosme an Gandon (Chungking), 14.9.1939 (MAEN Pékin A 344), NOLDE, Mission, S. 985; BüHrER, Aux heures tragiques, S. 87; Bullitt an Hull, 14.9.1939 (SD 893.20/705). NOLDE zufolge übermittelte Mandel Berger über einen "Freund in Indochina « die Nachricht, er solle in China bleiben, selbst wenn er andere Befehle erhalte (Mission, S. 984). Ziemlich sicher wurde eine solche Botschaft Mandels im Juli 1939 überbracht. Daß Mandel im September diese Nachricht erneut übermittelte, ist unwahrscheinlich.
} 
General Berger akzeptierte den Rückruf. In den Briefen, die jeder Offizier vor der Mission von Daladier erhalten hatte, war bestimmt, daß sie im Mobilisierungsfall neue Befehle abwarten sollten. Berger setzte eine geringe Verschiebung der Abreise durch, damit er den Kurs an der Kriegsakademie beenden und die Mission geordnet abschließen konnte. Zum Abschied empfing Chiang Kai-shek die Offiziere zum Essen, dankte ihnen, verlieh Orden und beklagte sich über die unfreundliche Politik der französischen Regierung, die auch in dem Abzug der Mission zum Ausdruck komme. Berger erwiderte, Mandel verfolge eine prochinesische Politik, doch der Quai d'Orsay und vor allem der Generalsekretär hätten eine gegenteilige Haltung. Am 19. Oktober reiste die Gruppe französischer Offiziere aus China $\mathrm{ab}^{207}$.

Rückblickend beurteilten alle Beteiligten die fünf Monate dauernde Mission mit Bitterkeit. Enttäuschung und Groll waren aber unvermeidlich, denn die französische Militärmission war politisch nicht eingebettet. Sie blieb ein isoliertes Element einer Annäherung an China, die das Außenministerium nicht wünschte und für die auch Ministerpräsident Daladier sonst nichts tat. Schon der Ursprung der Mission war ja kein weitreichender politischer Plan, sondern die Lobbytätigkeit französischer und chinesischer Rüstungskreise. Der damalige Hauptmann Nolde klagte, daß die Mission auf sich allein gestellt und ohne politische Direktiven blieb. Unterstuitzt und gefolgt von Wirtschafts-, Handels- und Industriemissionen hätte sie wichtige Ergebnisse erzielen und Frankreichs Einfluß auf China vergrößern können, so Nolde. Das aber hätte eine Abkehr von der gesamten Fernostpolitik erfordert, die ja bemüht war, einer Konfrontation mit Japan aus dem Weg zu gehen. Allerdings wurde die Mission auch nicht zu der gefährlichen Parteinahme Frankreichs im Fernostkonflikt, wie Cosme in seinen Memoiren schreibt ${ }^{208}$. Letztlich verpuffte die Mission. Japan ignorierte sie nach erstem Protest, weil die Mission der sieben Offiziere mit Frankreichs übriger Politik in keinem Zusammenhang stand, sie ohne große Folgen blieb und weil Tokio die Berater als kleinen Nadelstich abtun konnte. Der Quai d'Orsay, der sich im Sommer 1939, auch mit Blick auf die USA, um ein besseres Verhältnis zu China bemühte, konnte die Mission als sichtbaren, wegen Japans Nachsicht aber ungefährlichen Beitrag zur Klimaverbesserung in China ansehen.

Schon im Februar 1939, nachdem die Militärmission vereinbart worden war, begannen Chinas Bemühungen um eine breite militärische Zusammenarbeit

\footnotetext{
${ }^{207}$ Gandon an Cosme, T 930, 15.10., T 880-82, 22.9.1939 (MAEN Pékin A 344); Cosme an Daladier, T 1176-79, 23.10.1939 (MAE Chine 739); Johnson (Chungking) an Hull, 23.10.1939 (SD 893.20/706); Yvon an EMA.2, T 1165, 20.10.1939 (MAEN Pékin A 344). NOLDE zufolge fand am 19. Oktober das Abschieds-Diner statt, was für die Abreise am 20. Oktober spricht (Mission, S. 985)

${ }^{208}$ NOLDE, La Chine, S. 186; Cosme, Chine 1939-1944, S. $8 f$.
} 
mit Indochina. Der Moment, den Chungking wählte, um die im April und Mai 1938 Daladier und Bonnet erfolglos vorgelegten Angebote zu erneuern, schien günstig: Eine Woche nach der Besetzung Hainans bot Chinas Militärattaché General Tang Che Leutnant Gauché, dem Chef des Militär-Geheimdienstes, vage eine Zusammenarbeit der Regierungen und der Oberkommandos beider Länder an. Details ersparte sich auch Chiang Kai-shek, als er vier Tage später Cosme in Chungking vorschlug, Frankreich und China sollten im Falle einer japanischen Aggression Indochina gemeinsam verteidigen. Er wolle zunächst nur Frankreichs Neigung zu einer möglichen Kooperation ausloten. Chiang bot auch London eine verstärkte militärische und wirtschaftliche Zusammenarbeit an. Bührer stellte die chinesische Initiative dem französischen Generalstab als ideales Mittel zur Verteidigung Indochinas dar. Brévié, dem die Chinesen ähnliche Vorschläge unterbreitet hatten, sah die Zusammenarbeit aber mit Mißtrauen: Es genüge, wenn man nach einem Angriff auf Indochina zusammenarbeite. Zu großer Vorsicht riet Cosme: Wegen Chinas Schwäche werde die Hilfe sehr einseitig sein. Man könne den Vorschlag aber als Basis einer Zusammenarbeit mit den USA in Asien und Grundlage für Gespräche über die Lieferung kriegswichtiger Rohstoffe aus China nutzen. Als Wellington Koo Alexis Léger am 29. März wieder vage eine Militärkooperation anbot, bat der Generalsekretär um konkrete Vorschläge. Der Plan, den China London und Paris dann vorlegte, übertraf Légers Befürchtungen: China, Großbritannien und Frankreich sollten einen militärischen und wirtschaftlichen Aktionsplan entwerfen, ihre Truppen in Asien einem gemeinsamen Kommando unterstellen, um den Krieg gemeinsam fortzusetzen, und sich verpflichten, keinen Separatfrieden mit Japan zu schließen. London und Paris sollten alle verfügbaren Schiffe und Flugzeuge nach Ostasien entsenden, Chinas Währung stützen und Wirtschaftssanktionen gegen Japan verhängen ${ }^{209}$.

$\mathrm{Daß}$ Frankreich und Großbritannien am Fernostkrieg teilnehmen sollten, war für den Quai d'Orsay absolut unannehmbar. Nur weil die japanische Kontrolle Chinas gegen westliche Interessen verstoße, könne er China keine Hilfe versprechen, schrieb Bonnet Corbin. Dennoch wolle er freundlich antworten. Bührer hielt die chinesischen Vorschläge hingegen für realistisch. Als die politischen und militärischen Spitzen der Teilstreitkräfte am 9. April 1939 mit Daladier, Bonnet und Léger zusammentrafen, erklärte er, man müsse Japan binden, allein, um zu verhindern, daß England einen Teil seiner Flotte nach

209 EMA, compte rendu, 17.2., Bührer an Gauché, 7.2.1939 (SHAT 7 N 3301, 3313); Cosme an Bonnet, T 18-20, 21.3., L 23, 22.3.1939 (DDF XV, 99; MAE Chine 734); Procès-verbal, réunion des chefs d'EMG, 27.3.1939 (SHAT 2 N 225); Brévié an Mandel, T 467, 20.3., T 590-91, 10.4.1939 (CAOM FM Tel 80); Chinesische Botschaft an französisches Außenministerium, Mémorandum, 4.4.1939 (DDF XV, 252); Note Howe, 27.3.1939 (FO 371/23517, F 3024/2882/10). 
Asien entsende. Binden könne man Japan einerseits durch sowjetische Kräfte, andererseits, indem man China helfe. Zwölf Tage später erklärte Bührer den Generalstabschefs, China verfüge über sechs gute Divisionen und sei ein wertvolles Mittel gegen Japan. Die Generäle nahmen das Szenario auf, um den Briten ein positives Bild von der Lage zu zeichnen und um sie zu überzeugen, ihre Kräfte auf Europa zu konzentrieren ${ }^{210}$ - eine echte Militärhilfe für China strebte aber außer Bührer keiner der Generäle an.

Das Außenministerium blieb bei seiner unverbindlich freundlichen Haltung. Grund dafür war die Sorge im Quai d'Orsay, daß Chiang bei einer glatten Zurückweisung Frieden mit Japan schließen könnte. Um Wellington Koo Interesse zu zeigen, sprach Léger am 2. Mai eine Stunde mit ihm über dessen Plan. Die Asienabteilung war aber nicht sicher, ob die Chinesen nicht schon, wie bei der Berger-Mission, hinter dem Rücken des Quai d'Orsay Fakten schufen: Chauvel glaubte, der Militärstab des Kolonialministeriums plane, im Falle eines Krieges eine französische Division nach China zu senden, um chinesische Truppen auszubilden und zu stützen ${ }^{211}$.

Das Bemühen, in China die Hoffnung auf eine Zusammenarbeit mit Frankreich am Leben zu erhalten, war Léger so wichtig, daß er Cosme bat, Vorschläge für eine konkrete Kooperation auszuarbeiten. Cosme regte an, Chinas Haltung im Fall eines japanischen Angriffs auf Indochina während eines Krieges in Europa zu diskutieren; China könne Rüstungsbetriebe in der Kolonie aufbauen; man könne mit den Chinesen über die Lieferung von Rohstoffen sowie den Ausbau grenzüberschreitender Straßen sprechen. Auch Kontakte zwischen den Generalstäben »im gewissen Maße« konnte Cosme sich vorstellen $^{212}$. In seiner Antwort an Cosme stutzte Léger die Anregungen auf ein unverfängliches $\mathrm{Maß}$ zurück: Solange China seine Unterstützung anbiete, müsse man keine Eventualitäten eines Krieges in Europa diskutieren; an einer Rüstungsproduktion in Indochina werde China sich nur beteiligen, wenn es die Güter über die Yunnanbahn ins Land bekomme, was Paris ablehne. Über Straßenverbindungen könne man reden. Kontakte zwischen Generalstäben lehnte Léger ab, es reiche, wenn es häufige Treffen zwischen französischen

${ }^{210}$ Bonnet an Corbin, T 563, 7.4., procès-verbal, conférence tenue au ministère de la Guerre, 9.4., réunion des chefs d'état-major généraux, procès-verbal, 21.4.1939 (DDF XV, 298, 316, 466).

${ }^{211}$ Bullitt an Hull, 3.5.1939 (FRUS 1939 III, S. 534f.); Bonnet an Saint-Quentin, L 258, 13.5.1939 (DDF XVI, 178; dem Umdruck in MAE Chine 677 zufolge stammt der Brief vom 8.5.1939); Note de la sous-direction d'Asie-Océanie, 23.5.1939 (DDF XVI, 261).

${ }^{212}$ Cosme an Bonnet, T 593-94, 8.5.1939 (MAE Chine 677). Georges-Picot in Chungking hatte Cosme vorgeschlagen, die Gruppe Berger in eine offizielle Mission umzuwandeln, die Yunnanbahn gemeinsam zu verteidigen und in Indochina einen tragbaren Mörser für China zu produzieren, doch das ging Cosme zu weit (Georges-Picot an Cosme, T 418-21, 3.5.1939, MAEN Pékin A 494). 
und chinesischen Militärs gebe. Ernsthaft besprechen, so Léger, solle man allein die Lieferung von Rohstoffen aus China ${ }^{213}$.

Der Generalsekretär und die Asienabteilung hielten Chinas Angebote für sehr gefährlich. Bei Ausbruch eines Krieges in Europa, so Léger und Chauvel im Sommer 1939, sei es möglich, daß Japan neutral bleibe. Französischchinesische Militärgespräche würde China aber sofort publik machen, was Tokios Neutralität gefährde. Ein neues Angebot Anfang Juli von Chiang Kaishek an Botschafter Cosme, in einem Krieg Japans gegen England und Frankreich Truppen bereitzustellen, wenn Paris diese ausrüste und ausbilde, sowie von Botschafter Quo Tai Chi an das Foreign Office, 200000 Mann für die Verteidigung Hongkongs abzustellen, stießen bei Abteilungsleiter Robert Howe und bei Cosme auf das gleiche Urteil: China wolle die Europäer in seinen Krieg hineinziehen. Diesmal antwortete Paris nicht einmal mehr auf Chiangs Kai-sheks Angebot ${ }^{214}$.

Paris versuchte dennoch, das Interesse Washingtons auf Chinas Vorschläge zu lenken. Bonnet räumte ein, daß es schwierig sei, die USA zur Teilnahme an einem Projekt zu bewegen, das Frankreich selbst ablehne. Bonnet bat Koo, China möge die Vorschläge den USA selbst unterbreiten. Wellington Koo hatte den Plan aber bereits US-Botschafter Bullit übergeben. Léger mahnte Bullitt eindringlich, Großbritannien werde die Besitzungen in Asien räumen müssen, falls es von den USA nicht unterstützt werde. Diese Befürchtung hatte der britische Botschaftsrat Campbell gegenüber dem Politischen Direktor Charvériat geäußert. Doch Washington ließ sich nicht erpressen. Als Frankreichs Botschafter Anfang Juni Sumner Welles und Asienabteilungsleiter Max Hamilton auf den chinesischen Vorschlag ansprach, stieß er auf eisige Ablehnung: Kurz, informell und mündlich, also auf der niedrigsten protokollarischen Stufe, habe man Chinas Botschafter erklärt, daß er die Haltung der US-Regierung zur Zusammenarbeit sicher kenne $\mathrm{e}^{215}$.

\footnotetext{
${ }^{213}$ Léger an Cosme, T 221-22, 5.6.1939 (MAE Chine 677).

${ }^{214}$ Note de la sous-direction d'Asie-Océanie, 6.6.1939 (DDF XVI, 356); Cosme an Bonnet, T 758-60, 3.7., Corbin an Bonnet, T 2118, 6.7.1939 (DDF XVII, 77, 119).

${ }^{215}$ Halifax an Phipps, 14.4.1939 (DBFP, $3^{\text {rd }}$ series, IX, 7); Bonnet an Saint-Quentin, L 258, 13.5.1939 (DDF XVI, 178); Phipps an Halifax, 18.4.1939 und Note Brenan (FO 371/23517, F 3776/2882/10); Note de la sous-direction d'Asie-Océanie, 18.4., Bonnet an Cosme, 24.4., Bonnet an Saint-Quentin, L 258, 13.5.1939 (DDF XV, 439, 481; XVI, 178); Bullitt an Hull, 18.4.1939 (FRUS 1939 III, S. 528f., SD 793.94/14901, 14902); Note Brenan, 24.3., Phipps an Halifax, 18.4.1939 (FO 371/23517, F 2882, 3776/2882/10); Memoranda of Conversation, 1.6., 5.6.1939 (SD 751.93/61, 62).
} 


\subsection{Der dritte Feind: Siam}

Frankreichs Position in Ostasien war nicht nur durch Chinas Nationalismus und Japans Expansionismus bedroht, sondern an der Westgrenze Indochinas auch durch Siams Revisionismus. Siams Ansprüche auf die Grenzgebiete, die es bis 1907 an Indochina hatte abtreten müssen, seine Aufrüstung und die Nähe der Regierung in Bangkok zu Japan verschärften die französische Lage im Fernen Osten von 1937 bis 1940. Von den drei asiatischen Mächten, die Frankreichs Besitzungen gefährlich werden konnten, annektierte allein Siam im Frühjahr 1941 - indochinesisches Territorium. Zu dem kritischen Blick der Franzosen auf Bangkok trug bei, daß Siam in Frankreichs Innenpolitik keine Freunde hatte, während Japan als Gegengewicht zur Sowjetunion auf der Rechten Freunde besaß und die Linke mit China sympathisierte.

Frankreichs Siampolitik unterschied sich in ihren Mitteln und ihrer Formulierung von der übrigen Fernostpolitik. Einerseits erwog das Militär in Paris als Instrument der Siampolitik ab 1938 für den Fall einer unfreundlichen oder unklaren Haltung Bangkoks einen Einmarsch in Siam. Andererseits spielte der Kolonialminister bei der Beratung eine größere Rolle: Er war über den Generalgouverneur in Indochina oft eher über die Lage in Siam informiert als der Quai d'Orsay; die indochinesische Sûreté besaß Geheimagenten in Siam. Bilaterale Fragen wie den Bau einer Bahnlinie von Kambodscha nach Bangkok entschied der Kolonialminister allein, und schließlich stand Indochina im Mittelpunkt der Beziehungen zu Siam. Kolonial- und Außenministerium einigten sich stets auf eine gemeinsame Politik, wobei die Kolonialminister Moutet und Mandel immer die unnachgiebigere Position vertraten.

$\mathrm{Zu}$ Beginn seiner territorialen Expansion hatte Frankreich versucht, Siam, das an der geopolitischen Bruchlinie zwischen dem britischen und dem französischen Kolonialreich lag, Indochina einzuverleiben. 1893 und 1904 verlor Siam Territorien an Indochina. Doch durch hartnäckigen Widerstand und vor allem die Unterstützung Londons, das Siam als Puffer zwischen britischen und französischen Kolonien erhalten wollte, gelang es dem Land, Frankreichs Herrschaft zu entgehen. Allerdings zwang Frankreich 1907 den König in Bangkok, die drei Grenzprovinzen Battambang, Siemreap und Sisophon (Angkor) an Indochina abzutreten. Die Franzosen machten damit eine Grenzveränderung, die Siam am Ende des 18. Jahrhunderts Kambodscha aufgezwungen hatte, rückgängig. In den französisch-siamesischen Verträgen von 1925, 1926 und 1937 bestätigte Bangkok die Abtretungen. Sie wurden in Siam jedoch nie akzeptiert und blieben Quelle für Spannungen. Im Juni 1936 schrieb der britische Gesandte Sir Josiah Crosby, die Siamesen hätten die Gebietsverluste niemals vergessen; der deutsche Konsul in Hanoi meldete im Dezember 1938, Siams Ansprüche auf Kambodscha und weite Teile von Laos bestünden 
fort $^{216}$. Die Franzosen vergifteten die Atmosphäre, indem sie Siam von oben herab behandelten; die Siamesen unterminierten Frankreichs Position, indem sie Nationalisten und Kommunisten aus Indochina Asyl gewährten ${ }^{217}$.

Nach dem Staatsstreich vom 24. Juni 1932, bei dem eine Gruppe hoher Beamter und Offiziere König Prajadhipok absetzte, wurde die Forderung nach der Rückkehr der drei Provinzen lauter, die Regierung und die Armee veröffentlichten Landkarten mit Siams alten Grenzen. Sorgen bereitete Paris Siams Zusammenarbeit mit Japan. Daß sich Bangkok 1933 bei der Abstimmung im Völkerbund über den Bericht der Lytton-Kommission enthielt, um sich zwischen Japan und China nicht zu exponieren, galt Frankreich als Zeichen der Sympathie für Japan. In Verfolgung seiner panasiatischen Pläne entsandte Tokio Offiziere, Ingenieure und Ökonomen nach Siam. Im August 1935 hörte Frankreichs Militärattaché Roux, daß Japan und Siam Indochina angreifen und teilen wollten. Kurz darauf forderte der japanische Botschafter Matsushima die Siamesen auf, das französisch-britische Joch abzuschütteln. Oberstleutnant Roux meldete, Japan wolle einen Kanal durch die Landenge von Kra bauen und so Singapur bedrohen ${ }^{218}$. Alle Gerüchte stellten sich als haltlos heraus.

Im November 1936 kündigte Bangkok die Verträge, die den Angehörigen westlicher Staaten vor allem wirtschaftliche Privilegien gewährten. Frankreich hatte 1925 bereits auf die Extraterritorialität verzichtet. Gegenüber Indochina wollte Siam zudem einen günstigeren Verlauf der Grenze im Mekong und die Gleichberechtigung in der gemeinsamen Mekong-Kommission erreichen. Bisher verlief die Grenze im Mekong, wo dieser mehrere Arme hatte, nicht in der Flußmitte, sondern in dem Arm, der Siam am nächsten lag. In der Kommission besaß Frankreich den ständigen Vorsitz. Bangkok wollte auch die Verpflichtung abschaffen, französische Juristen als Berater zu beschäftigen.

\footnotetext{
${ }^{216}$ Patrick SouTy, La Guerre du Pacifique 7 juillet 1937-2 septembre 1945. L'Asie du Sud-Est au centre des enjeux, Lyon 1995, S. 22; Patrick TUCK, The French Wolf and the Siamese Lamb. The French Threat to Siamese Independance, 1858-1907, Bangkok 1995; Niels P. PETERSSON, Imperialismus und Modernisierung: Siam, China und die europäischen Mächte 1895-1914 (Studien zur internationalen Geschichte, Bd. 11), München 2000, S. 9lf., S. 277f;; ANDREW, KANYAFORSTNER, France Overseas, S. 33f.; MARTIN, L'Empire triomphant, Bd. 2, S. 195; ALDRICH, Key to the South, S. 40f., S. 162; Neumann an Ribbentrop, 25.12.1938 (AA Pol VIII 60, 2).

${ }^{217}$ KarNow, Vietnam, S. 135; CHEN, Vietnam and China, S. 29; ReNouvIN, La question, S. 356; DuIKER, Ho Chi Minh, S. 150f; Lépissier an Delbos, L 51, 11.3.1938 (MAE Siam 82); Lépissier an Bonnet, L 165, 21.4.; Lépissier an Bonnet, L 505, 12.6., L 255, 15.6.1939 (MAE Indfr 36, Ac 90).

218 HAAS, Französisch-Indochina, S. 29; Gesandter Marcel Ray (Bangkok) an Flandin, L 64, 16.5.1936; Note, relations franco-thailandaises [Juni 1940] (MAE Siam 82); E. Bruce REYNOLDS, Anomaly or Model? Independant Thailand's Role in Japan's Asian Strategy, 1941-1943, in: Peter Duus (Hg.), The Japanese Wartime Empire, 1931-1945, Princeton 1996, S. 243-273 (S. 244); Notes de la sous-direction d'Asie-Océanie, 9.6.1936, 10.2.1937 (MAE SDN 2143, Chine 1045); Ray an Flandin, 27.5.1936 (DDF II, 253); Hanoi an Moutet, T 2451, 21.8.1936 (MAE Siam 82); ALDRICH, Key to the South, S. $183 \mathrm{f}$.
} 
Fast alle betroffenen Nationen lehnten die Vertragsrevision ab: Deutsche, Italiener, Japaner, Niederländer, Portugiesen, Dänen und Norweger strebten den gemeinsamen Widerstand der Mächte an. Die entscheidenden Nachbarn Siams aber setzten auf Zugeständnisse: Die Briten waren bereit, Sonderrechte aufzugeben, wenn ihre wirtschaftlichen Dominanz gewahrt bleibe. Auch der Quai d'Orsay entschied sich angesichts der britischen Haltung für Konzessionen, obwohl der Geschäftsträger in Bangkok Georges-Picot und Kolonialminister Moutet für Härte eintraten. Im Dezember 1937 unterzeichneten Bangkok und Paris einen Vertrag über Freundschaft, Handel und Schiffahrt. Frankreich gab wirtschaftliche Privilegien auf, behauptete aber den günstigen Grenzverlauf im Mekong. Die 25 Kilometer breite entmilitarisierte Zone auf beiden Seiten des Mekong blieb erhalten; 14 Franzosen blieben im siamesischen Staatsdienst beschäftigt. Nach den 22 Briten und vor den fünf US-Amerikanern stellten die Franzosen die zweitgrößte Beratergruppe ${ }^{219}$. Der Quai d'Orsay verfolgte die Verhandlungen in der zweiten Hälfte des Jahres 1937 nur noch desinteressiert. Ihm waren die inneren Verhältnisse Siams gleichgültig geworden.

Dabei sahen Politiker und Militärs in Paris Siam als Bedrohung. Im Frühjahr 1937 erwarteten Moutet und Brévié, daß Japan und Siam im Falle eines Weltkriegs Indochina angriffen. Das Kolonialministerium, das Deuxième Bureau der Armee, Georges-Picot und Brévié warnten vor Siams Rüstung und vor Roms und Berlins wachsendem Einfluß. Im März 1937 lobte Kriegsminister Luang Pibul, einer der Drahtzieher des Putsches von 1932, öffentlich Hitler und Mussolini. Siams Presse attackierte im Sommer 1937 die Rüstung und angeblich aggressive Absichten Indochinas. Im September 1937 kamen in Bangkok Gerüchte über einen drohenden Krieg zwischen Indochina und Siam auf. Brévié und das Kolonialministerium hielten die Kampfkraft Siams für gering, doch im Fall eines mit Japan abgestimmten Angriffs sei sein Militär sehr gefährlich ${ }^{220}$. Dies blieb die Auffassung der französischen Experten: Der Marineausschuß der Abgeordnetenkammer, der Generalstab der Luftwaffe,

219 Malkul, L'Indochine, S. 125f.; Ray an Delbos, T 26-29, 20.10., Corbin an Delbos, L 698, 5.11.1936, Ray an Delbos, L 5, 5.1., L 27, 13.2., Portugiesische Botschaft an französische Regierung, aide-mémoire, 14.5., Ray an Delbos, L 89, 1.5.1937 (MAE Siam 76); Bilan de l'Action, 16.10.1937 (CAOM Fonds Moutet 28/PA/5); Georges-Picot an Delbos, L 159, 2.11., Delbos an Georges-Picot, T 24, 6.11.1936; Moutet an Delbos, L, 2.8., Georges-Picot an Delbos, L 185, 2.10., L 224, 27.11., Léger an Georges-Picot, T 89-90, 23.10.1937 (MAE Siam 82, 84); ALDRICH, Key to the South, S. 379.

${ }^{220}$ Comité permanent de la défense nationale, procès-verbal de la séance du 15.2.1937 (SHAT $2 \mathrm{~N}$ 22); Brévié an Moutet, L 71, 16.6.1937 (MAE Siam 82); EMA.2, rapport du ministre, 8.3.1937, 31.7.1938 (SHAT 7 N 2514-2515); ALDRICH, Key to the South, S. 175; Ray an Delbos, L 61, 31.3.; L 78, 17.4., Ray an Brévié, L 102, 13.4., L 106, 20.4.; Georges-Picot an Delbos, L 239, 27.9.1937 (MAE Siam 76, 82); Georges-Picot an Delbos, D 267, 19.10.1937 (DDF VII, 112); Brévié an Georges-Picot, L 1690, 29.10.1937, Brévié an Mandel, L 860, 6.5.1938 (MAE Siam 76, 84); Colonies, bulletin de renseignement, 15.8., 1.3.1937, 15.7.1938 (SHAT 7 N 2507; CAOM FM, AP 1416). 
Militärattaché Pichon in Bangkok und Chauvel in der Asienabteilung des Quai d'Orsay schätzten noch 1939 Siams militärische Fähigkeiten gering; nur im Falle einer Koalition mit Japan stellten diese eine große Gefahr dar ${ }^{221}$.

Der Quai d'Orsay stritt 1937 über die Einschätzung Siams. Cosme warnte vor dessen Rüstung und dessen wachsenden Nationalismus. Siam sei keine konkrete Gefahr, doch werde Bangkok bei einem Krieg in Europa die früheren Provinzen zurückerobern wollen. Cosmes Nachfolger Hoppenot schrieb hingegen, Siam hege keine aggressiven Absichten, die Aufrüstung sei nur Ausdruck des Nationalismus. Bangkok habe sich 1933 und 1937 im Völkerbund neutral verhalten, um seine Unabhängigkeit zu bewahren. Siam wisse um die Risiken der japanischen Freundschaft und bleibe auf Distanz. Es sei aber möglich, daß Siam einen Krieg in Europa ausnutzen wolle. Cosme und Hoppenot waren sich einig, daß die Haltung Bangkoks vom Ausgang eines Machtkampfs abhing: Außenminister Luang Pradist Manudharm, der in Frankreich in Jura promoviert hatte, stand für die Nähe zu den Demokratien, während Kriegsminister Luang Pibul Nationalsozialismus und Faschismus bewunderte und die Mächte unter Druck setzen wollte. Sein Vorbild war Napoleon ${ }^{222}$.

Alarmismus prägte 1937 die Atmosphäre in Paris: Der prominente Oberst Bernard, Ex-Präsident der Französisch-Siamesischen Grenzkommission, warnte im August 1937 vor der Aufrüstung Siams, das 300000 Mann mobilisieren könne. Im November sagte Henry Bérenger, Vorsitzender des Auswärtigen Aussschusses im Senat, Siams Armee besitze 100000 Mann und moderne Waffen. Pierre Taittinger sagte im Dezember in der Abgeordnetenkammer, Siam habe 300000 Mann mobilisiert. Siam besitze die am schnellsten wachsende Flotte der Welt, warnte das "Journal de Rouen ${ }^{223}$. Der Aufbau siamesischer Truppen im Dezember 1937 und der Straßenbau in Grenznähe sowie Gerüchte über Siams Beitritt zum Antikominternpakt verstärkten die Sorgen. Frankreichs Öffentlichkeit erwartete fast einen siamesischen Angriff. Britische Diplomaten hielten die Ängste - Robert Aldrich spricht von einer Paranoia für überzogen, aber die Franzosen ließen sich kaum beruhigen ${ }^{224}$.

${ }^{221}$ Bousquet, rapport, 20.1., EMAA.2, note, 1.2.1939 (SHAT 2 N 247, SHAA 2 B 81); Pichon an EMG.2, 6.7., note de la sous-direction d'Asie-Océanie, 28.7.1939 (SHM 1BB2 257, DDF XVII, 352).

${ }^{222}$ Ray an Delbos, L 149, 26.9.1936; Notes de la sous-direction d'Asie-Océanie, 4.6.; 22./23.11., 20.8.; Georges-Picot an Delbos, T 68-69, 17.10.1937 (MAE Siam 76, 82; Ac 133, SDN 357); Sir Josiah Crosby, Siam. The Crossroads, London 1945, S. 103; REYNOLDS, Anomaly or Model, S. 245.

${ }^{223}$ Roberts (Saigon) an Hull, 1.9.1937 (SD 851G.00 PR./5); Phipps an Eden, 15.11., Eden an Phipps, 16.11.1937 (FO 371/20979, F 9577/130/10); JO n ${ }^{\circ} 85,16.12 .1937$, Chambre des députés, $1^{\text {re }}$ séance, 15.12.1937 (S. 3067); Bangkok Times, 5.10.1938 (MAE Indfr 35). Seine Warnungen verbreitete Colonel BERNARD auch in: La sécurité de l'Indochine et l'impérialisme siamois, Paris 1937.

${ }^{224}$ Brévié an Georges-Picot, L 2133, 17.12., Georges-Picot an Brévié, L 310, 21.12.; an Delbos L 255, 31.12.1937 (MAE Siam 82, 76); Palmer an Hull, 25.3.1938 (SD 893.113/1682); Crosby an Eden, 9.11.1937 (FO 371/20980, F 9823/130/10); ALDRICH, Key to the South, S. 181, S. 185, S. 188. 
In diesem Klima entwickelte das Militär in Paris Offensivpläne. Im November 1937 riet der Generalstab der Marine zur Wachsamkeit an der Grenze zu Siam; das Secrétariat général du conseil supérieur de la défense nationale warnte Anfang 1938, Siams Kräfte müsse man denen Japans hinzurechnen. Im Februar 1938 gingen zwei von drei Hypothesen, auf die das Comité consultatif de défense des colonies die Verteidigungspläne für Indochina aufbaute, davon aus, daß Siam und Japan Indochina attackierten. Ende April 1938 änderte das Komitee die Rangfolge der Hypothesen: Bisher galt, nach einem Angriff durch China, eine siamesische Aggression als zweitwahrscheinlichste Bedrohung. Nun wurde ein gemeinsamer Angriff durch Japan und Siam als wichtigstes Szenario angesehen, eine Hypothese, von der 1937 auch ein Manöver in Indochina ausging. Als Antwort empfahl Billotte die Offensive: Der General regte im Februar 1938 an, gemeinsam mit den Briten einen Angriff auf Siam zu planen, um es schnell auszuschalten, falls England und Frankreich nicht sicher von Bangkoks Neutralität ausgehen könnten.

Von Daladier erhielt Billotte grünes Licht für seine Planungen: »[L]a réduction éventuelle du Siam hostile pourrait être envisagée dès maintenant«, schrieb der Kriegsminister Anfang April 1938. Auch die Briten faßten einen Präventivschlag gegen Siam ins Auge. Das britische Militär in Malaysia begann bereits im November 1937, eine Offensivoperation gegen Siam zu planen; Crosby hielt es für richtig, Siam bewaffnete Stärke zu zeigen ${ }^{225}$.

Im Juni 1938 nahmen die Franzosen an, daß Japans Druck auf Siam und die siamesische Spionage in Indochina stark zugenommen hätten. Hinzu kamen Gerüchte, Japan habe Siam einen Militärpakt angeboten. Auch verdächtige siamesische Truppenbewegungen wurden Anfang Juni gemeldet. Mitte Juni informierte die chinesische Regierung Paris, japanische Offiziere in Siam bereiteten Operationen vor. Trotz der Aussage von Außenminister Luang Pradist, ein siamesisch-japanischer Pakt sei ausgeschlossen, die Frankreichs Gesandter Paul Lépissier für glaubwürdig hielt, fürchteten der Quai d'Orsay und Alexandre Varenne doch ein solches Bündnis: Indochina solle Vorsichtsmaßnahmen ergreifen. Auch Mandel hielt die französische Kolonie für stark bedroht, zumal Siam über 200 Flugzeuge, darunter 100 moderne Maschinen, verfüge. Lépissier empfahl eine stärkere Spionage und Propaganda in Siam. Er warnte, Kriegsminister Luang Pibul könne putschen, in der Presse würden die

\footnotetext{
${ }^{225}$ Marine, section d'études générales, note, 3.11 .1937 (SHM 1BB2 170); Note du secrétariat général du Conseil supérieur de la défense nationale, très secret, 8.2., Billote an Steeg, D 28 I.G.S., 17.2.1938 (DDF VIII, 127, 194); Général Gaston Billotte, plan d'ensemble de défense des colonies, février 1938; Comité consultatif de défense des colonies, plan de défense de l'Indochine 24.4.1938 (SHAT 2 N 246, $7 \mathrm{~N}$ 4194); Note du Conseil supérieur de la défense nationale, très secret, 8.4.1938 (DDF IX, 144); Brévié an Mandel, L 860, 6.5.1938 (MAE Siam 84); Crosby an Halifax, 12.3.1938 (FO 371/22168, F 4226/318/61); ALDRCH, Key to the South, S. $189 f$.
} 
antifranzösischen Töne lauter, Tokio dränge Bangkok immer heftiger zu einem Bündnis. Als Quelle der wiederholten Gerüchte machte Crosby den französischen Spion Dô Hung in Bangkok aus, der schlecht informiert sei und Fakten verdrehe, damit sie das Bild siamesischer Angriffsvorbereitungen ergäben. Dô sei es gelungen, erst Lépissier und dann den Quai d'Orsay zu ängstigen. Lépissier sei geradezu hysterisch, klagte der britische Gesandte ${ }^{226}$.

Von Mitte bis Ende September, als die Sudetenkrise Europa in Atem hielt, überschlugen sich die aus Bangkok und Hanoi kommenden Nachrichten: Zehn japanische Offiziere hielten sich an der Grenze zu Laos auf, hörte Brévié. Siam habe Reservisten einberufen und Truppen an der Grenze konzentriert. Als am 14. September drei siamesische Flugzeuge angeblich in Indochinas Luftraum eindrangen, sah der Generalgouverneur beide Länder in einen Krieg schlittern. Lépissier drohte Bangkok, falls es die Vorgänge nicht aufkläre, ergreife Paris Gegenmaßnahmen. Kriegsminister Luang Pibul beschwichtigte: Es gebe weder Einberufungen, noch Truppenkonzentrationen, noch Überflüge, noch japanische Offiziere an der Grenze. Französische Offiziere könnten sich vor Ort davon überzeugen. Am 20. September mobilisierte Siams Militär, weil es einen Krieg in Europa erwartete. Geheimdienstinformationen aus siamesischen Kreisen in Brüssel, wonach im Falle eines Krieges in Europa Japans und Siams Truppen Indochina angriffen, verunsicherten Paris. Durch die Münchener Konferenz litt Frankreichs Prestige. Der Frankreich sonst wohlgesonnene Außenminister Luang Pradist fragte Lépissier, ob bei der nächsten internationalen Konferenz über das Schicksal der französischen Besitzungen in Asien gesprochen werde. Die Siamesen spürten, daß die Ordnung in Asien in Bewegung geraten war. Bangkok ging davon aus, daß nun der japanische Druck auf Indochina, Hainan, aber auch auf Siam zunehmen werde ${ }^{227}$.

Als Reaktion auf die Krise entwickelten die Behörden in Hanoi und Bangkok vertrauensbildende Maßnahmen. Siamesische Offiziersschüler besuchten

\footnotetext{
${ }^{226}$ Lépissier an Bonnet, T 52-53, secret, 27.5., T 61, 6.6., T 64, 9.6., T 73, 17.6., T 81, 13.7., Léger an Lépissier, T 80-81, 16.6., Cambon an Bonnet, L 611, 4.7.; Lépissier an Bonnet, T 62-63, 9.6., Lépisser an Luang Pradist, L, 19.8.1938 (MAE Siam 76, 82); Diplomatie an Colonies, D 831, 24.6., Colonies an Diplomatie, D 937, 27.6., Varenne an Bonnet, L, 26.7.1938 (DDF X, 91, 102, 272); Lépissier an Bonnet, T 1, 28.6., T 91-92, 2.8., Diplomatie an Colonies, T 849, 29.6.1938 (MAE Siam 83); Brévié an Mandel, T 746, 28.6., T 831, 16.7., T 904, 4.8., T 930, 11.8., T 940, 16.8.1938 (CAOM FM 678); Ronald, Minute, 4.7., Crosby an Halifax, 3.5., 30.8., 23.12.1938 (FO 371/22207, F 7178, 5098, 10430/113/40, FO 371/22921, C 875/249/17). Paul Lépissier und sein jüngerer Bruder Charles, Generalkonsul in Tientsin, verkörpern die Dauerhaftigkeit der Präsenz Frankreichs in Asien. Sie waren 1882 bzw. 1884 in Kanton geboren worden, wo ihr Vater als Zollangestellter arbeitete.

${ }^{227}$ Lépissier an Bonnet, T 116, 14.9., T 151, 31.10.; T 121-24, 26.-27.9.; T 145, 20.10., T 173, 20.12.1938 (MAE Siam 77,83, DDF XII, 179, XIII, 180); Brévié an Mandel, T 1026, Priorité absolue, 14.9., T 1041-42, 16.9., T 1113, 30.9.1938 (CAOM FM 678); Crosby an Halifax, 14.9., 16.9., 21.9.1938 (FO 371/22207, F 10967, 10968, 10970/113/40); Lépissier an Bonnet, T 113, 13.9., Bargeton an Bonnet, L 601, 27.9., Diplomatie an Guerre T 301, 28.9.1938 (MAE Indfr 35).
} 
Hanoi. Im August 1938 informierten die Truppen einander über ihre Stärke. Im November 1938 erleichterte Indochina die Passage siamesischer Kriegsschiffe, im Februar 1939 besuchte Vize-Admiral Le Bigot Siam ${ }^{228}$. Kriegsminister Luang Pibul, der schon die Zahl der Offiziere an französischen Akademien erhöht und die Gründung einer Maison de Siam in Paris angekündigt hatte, regte Mitte September 1938 an, daß Generalstabsoffiziere die Grenzgarnisonen des Nachbarn besuchten. Lépissier, Pichon und Mandel begrüßten den Vorschlag als Signal der Annäherung. Die vier französischen Offiziere, die im Februar 1939 siamesische Einrichtungen inspizierten, und die vier Siamesen, die im März nach Indochina kamen, wurden herzlich empfangen. Die Franzosen glaubten, daß sie Siam von Indochinas militärischer Stärke überzeugt hätten, und daß die Besuche Mißtrauen reduziert hätten. Bührer empfahl den Generalstabschefs, weiter einen Militärschlag gegen Bangkok zu planen ${ }^{229}$.

Wie sehr das französische Militär in Hanoi Siam weiter mißtraute, zeigte sich, als Bangkok anregte, einen ständigen militärischen Vertreter nach Hanoi zu entsenden. Siam war mit einem Militärattaché in Paris, aber nicht in Hanoi vertreten, während Oberst Pichon mit diplomatischer Immunität in Bangkok arbeitete. Kriegsminister Luang Pibul erlaubte den Franzosen im Juni 1938, einen Marineoffizier als Vize-Militärattaché in Siam zu installieren und hoffte, nun auch einen Offizier nach Saigon entsenden zu dürfen. Lépissier und Pichon unterstützten den Wunsch. Brévié und General Martin, Oberkommandierender der Truppen in Indochina, warnten jedoch, der Offizier aus Siam werde als Spion arbeiten. Mandel genehmigte im Oktober 1938 den Verbindungsoffizier in Hanoi. Doch mit einer Verzögerungstaktik sabotierte das französische Militär die Zulassung des Kontaktmannes. Im September wurden lediglich Offiziere aus Siam zu Manövern nach Indochina eingeladen ${ }^{230}$.

\footnotetext{
${ }^{228}$ Brévié an Mandel, T 589, 18.5.1938 (CAOM FM 678); Lépissier an Brévié, L 215, 15.7., L 315, 3.9.1938 (MAE Siam 83, Indfr 35); Léger an Lépissier, T 38, 30.11.1938; Diplomatie an Marine, L 11, 14.1.1939 (MAE Ac 78); Colonel Pichon an EMG.2, L 56-M, 24.2.1939 (SHM 1 BB2 257).

${ }^{229}$ Mandel an Brévié, T 723, 6.10.1938; Brévié an Mandel, T 313, 25.2., T 337-40, 28.2.1939 (CAOM FM 672, Tel 80); Mandel an Diplomatie, L 1893, 7.10., Hoppenot an Lépissier, T 115, 13.10., Luang Pibul Songgram an Lépissier, L, 19.10., 29.10., 3.11., Pichon an Martin, L 39-I, 24.10., Lépissier an Brévié, T 26, 3.2.; Lépissier an Bonnet, T 126, 28.9., T 153, 2.11.1938, T 34, 22.2., T 59, 7.4., L 132, 7.4., T 42-43, 4.3., L 91, 8.3.1939; Lépissier an Bonnet, T 62-63, 9.6.1938; Lépissier an Brévié, T 37-39, 24.2.1939 (MAE Indfr 35, 36, Siam 82, 83); Pichon an EMG.2, L 56, 24.2., rapport, 27.4.1939 (SHM 1 BB2 257); BÜHRER, Heures tragiques, S. 91; Colonies, bulletin de renseignement, 15.11.1938, procès-verbal, réunion des chefs d'EMG, 27.3.1939 (SHAT 11 H 76, $2 \mathrm{~N} 225$ ).

${ }^{230}$ Diplomatie an Marine, L 106, 23.1., L 522, 11.4., L 890, 30.6.1938 (SHM 1 BB3 20); Lepissier an Bonnet, L 294, 23.8.1938 (MAE Siam 82); Bührer an Brévié, L 104, 15.11.; Pichon an Lépissier, L 22, 30.8., Diplomatie an Colonies, L 1147, 17.9., Brévié an Lépissier, L 2097, 23.9., note, général Martin, 9.9., Lépissier an Bonnet, T 126, 28.9., T 152, 1.11., Hoppenot an Lépissier, T 114, 30.9., T 120, 19.10., Mandel an Diplomatie, L 1893, 7.10.1938, Lépissier an Brévié, T 2, 7.1.; L 343, 12.8., Pichon an Lépissier, L 28, 25.7, Lépissier an Luang Pibul, 26.9.1939 (MAE Indfr 24, 35, 36).
} 
Auch im Zivilbereich bemühten sich beide Seiten um Entspannung: Vermessungsmissionen arbeiteten auf der jeweils anderen Seite des Mekong, im Juli 1938 wurden visafreie Besuche im Nachbarland möglich; siamesische Studenten bekamen Stipendien. Kunstfunktionäre und Verwaltungsbeamte besuchten einander, 60 Akademikerinnen aus Siam wurden nach Indochina eingeladen. Innenminister Luang Dhamrong Navasavsti und Außenminister Luang Pradist verbrachten im Herbst 1938 zwei Wochen Urlaub in Indochina $^{231}$. Den Vorschlag Pradists vom Januar 1939, eine wetterfeste Straße von Siam nach Indochina zu bauen, lehnte Léger ab. Die Ernennung eines französischen Handelsbeauftragten in Bangkok scheiterte an Finanzgründen. Mandel griff im Juli 1939 eine Idee des Quai d'Orsay auf und trieb mit Bangkoks Billigung Pläne für den Bau der Bahnlinie Pnomh Penh-Bangkok voran. Nach Kriegsbeginn in Europa versandete der Plan ${ }^{232}$.

Schon im August 1937 hatte Kolonialminister Moutet auf Anregung der Behörden in Indochina dem Quai d'Orsay vorgeschlagen, mit Siam einen Nichtangriffspakt zu unterzeichnen. Gesandter Georges-Picot unterstützte den Vorschlag. Auch Mandel befürwortete ihn, falls London zustimme. Der Quai d'Orsay stoppte aber im Juni 1938 alle Überlegungen: Einen Nichtangriffspakt vorzuschlagen, komme einem Eingeständnis der Schwäche gegenüber einer zweitrangigen Macht gleich. Siam lasse sich durch den Vertrag auch nicht von einem Angriff abhalten. Während der Sudetenkrise regte Lépissier erneut einen Pakt an, ebenso wie Marius Moutet am 13. Dezember 1938 in der Abgeordnetenkammer. Doch Léger lehnte den Vertrag weiter $\mathrm{ab}^{233}$.

Trotz der Entspannungsbemühungen kam Frankreichs Position 1939 ins Rutschen. Siam wollte sich nicht an Mächte binden, deren Schwäche nach der Besetzung Hainans und der Annexion Albaniens offenkundig war, klagte Vize-Admiral Le Bigot im Mai 1939. Schon im April hatte Siam die Truppen an der Grenze verstärkt. Mandel traute Siams Neutralitätsversprechen nicht und entsandte vier Kompanien in die Grenzregion. Im Frühjahr und Sommer

${ }^{231}$ Lépissier an Brévié, L 41, 15.2.1938 (MAE Siam 82); Diplomatie an Colonies, L 864, 2.7.; Siam Chronicle, 30.8., Lépissier an Bonnet, T 137-38, 15.10., Lépissier an Brévié, T 405, 5.11.1938 (MAE IndFr 44, 35); Mandel an Brévié, T 763, 20.10.1038 (CAOM FM 672); Euvres françaises an Cité Universitaire, 27.3., Lépissier an Bonnet, L 365, 22.8., T 62, 13.4.1939 (MAE Indfr 36).

${ }^{232}$ Lépissier an Bonnet, T 19-20, 29.1., Léger an Lépissier, T 11, 31.1., Chauvel, note pour la sousdirection des relations commerciales, 27.6.1939 (MAE Siam 77); Mandel an Diplomatie, L 1133, 26.7.1939 (MAE Siam 79); Note de la sous-direction d'Asie-Océanie, 28.7.1939 (DDF XVII, 352); Brévié an Mandel, T 1276, 4.8., T 1296-97, 8.8.1939 (CAOM FM Tel 81); Brévié an Mandel, T 1351, 18.8., T 1356, 19.8.1939 (CAOM FM Tel 80); Note de la sous-direction d'Asie-Océanie, 4.10.1939 (MAE Japon 129); Lépissier an Daldier, T 209, 31.10., T 219-21, 10.11.1939 (MAE Indfr 36, Siam 84); Léger an Lépissier, T 27-30, 6.3.1940 (MAE Siam 85).

${ }^{233}$ Moutet an Delbos, L, 2.8.1937; Mandel an Diplomatie, T 764, 20.5., note de la sous-direction d'Asie-Océanie, 22.6., Lépissier an Bonnet, T 119, 17.9.1938 (MAE Siam 84); BARBIER, Henri Hoppenot, S. 92; Lépissier an Bonnet, T 113, 13.9., Léger an Lépissier, T, 17.9.1938 (MAE IndFr 35). 
1939 hielten die Franzosen ein japanisch-siamesisches Bündnis als Ergebnis japanischen Drucks für immer wahrscheinlicher. Paul Lépissier nahm der Regierung in Bangkok ab, daß sie in einem Konflikt des Westens mit Japan neutral bleibe wolle, aber er bezweifelte, ob sie angesichts der Schwäche Siams und der Demokratien Japans Druck widerstehen könne. Dem Quai d'Orsay, Lépissier und Pichon war klar, daß Frankreich außer diplomatischen und propagandistischen Anstrengungen und der Demonstration von Ruhe und Selbstbewußtsein nicht viel tun konnte. Mandels Vorschlag von Anfang Juli, die Regierung in Bangkok mit einem britisch-französischen Ultimatum zur Distanzierung von Japan zu bewegen, fehlte jede Basis ${ }^{234}$.

Ab Juli 1939 wurden die Meldungen aus Asien noch bedrohlicher: Das Kolonialministerium verbreitete, die Generalstäbe Japans und Siams hätten einen Geheimvertrag geschlossen. Siam ordne sich Japan unter, akzeptiere japanische Offiziere im Land, dürfe aber neutral bleiben. Auch Brévié, der britische Geheimdienst und der US-Gesandte Edward Neville hatten von einer Geheimallianz erfahren. Daladier hielt die Hinweise für ernstzunehmend. Daß Siam im Juli Wehrpflichtige nach Ablauf der Dienstzeit in den Kasernen behielt und die Regierung in Bangkok gegen die chinesische Minderheit im Land vorging, verstärkte in Paris die Angst vor einem japanisch-siamesischen Bündnis. Anfang August 1939 sahen alle mit der Siam-Politik befaßten französischen Stellen die Lage kritisch: Siam stehe unter starkem Druck Japans, so der Generalstab der Armee und das Kolonialministerium. Militärattaché Pichon und General Bührer schrieben, Siam wolle mit Japan gegen Indochina vorgehen. Der Quai d'Orsay und der Generalstab der Marine nahmen an, daß sich Siam im Kriegsfall der stärkeren Seite anschließe. Deshalb müsse man Siam zeigen, daß Großbritannien und Frankreich eine größere Gefahr für seine Landgrenzen darstellten als Japan zur See. Vor allem dürfe man keine Nervosität zeigen. Der Quai d'Orsay riet, zunächst abzuwarten. Der Hitler-StalinPakt beruhigte die Lage an Indochinas Westgrenze schlagartig ${ }^{235}$.

${ }^{234}$ Lépissier an Bonnet, T 32-33, 14.2., T 63, 13.4., T 65-66, 13.4., T 85-90, 23.6.; Lépissier an Brévié, L 514, 19.6., L 516, 19.6., Mandel an Diplomatie, L 995, 3.7., Léger an Lépissier, T 60, 4.7., Lépissier an Bonnet, T 95-97, 7.7., T 100-1, 7.7., Phipps an Charvériat, aide-mémoire, secret, 12.7.; 1939 (MAE Siam 77, 79); Brévié an Mandel, T 616, 14.4., T 680, 21.4., T 721, 27.4., T 748, 30.4., T 1134, 9.7.1939 (CAOM FM Tel 80); Léger an Lépissier, T 57, Corbin, T, 26.6., Lépissier an Bonnet, T 93-94, 13.7.1939 (MAE Indfr 36); FNEO, compte rendu, 5.5.; Pichon an EMG.2, compte rendu, 23.6., 22.7.1939 (SHM 1 BB4 74, 1 BB2 257); ALDRICH, Key to the South, S. $218 f$.

${ }^{235}$ Pichon an EMG.2, compte rendu, 29.7., 5.8., 19.8.; EMA.2, note, 6.8.1939 (SHM 1 BB2 257, SHAT 7 N 2524); Brévié an Mandel, T 1367, 21.8.1939 (CAOM FM Tel 80); Colonies an Diplomatie, L, 19.7., Daladier an Bonnet, L 1528, DN.3, 31.7., Lépissier an Bonnet, L 312, 22.7., T 143, 28.8., Charvériat an Lépissier, T 87, 7.8., Bührer an Diplomatie, L 1062, 9.8., L 1047, 7.8., Lépissier an Brévié, L 597, L 600, 14.8., Cambon an Bonnet, T 2513, 8.8., L 633, 17.8; Lépissier an Graffeuil, T 105-6, 25.8.; Marine an Diplomatie, T 474, 27.5.1939 (MAE Siam 79, 80, 77); Note de la sousdirection d'Asie-Océanie, 28.7., Diplomatie an Colonies, D 879, 24.8.1939 (DDF XVII, 352, XVIII, 394). 
Ob Frankreichs Diplomaten wußten, daß ihr Militär weiter einen Überfall auf Siam plante, ist unklar. Jedenfalls kannte der Quai d'Orsay bis Ende August 1939 nicht die Vereinbarungen von Singapur vom Juni, als Frankreichs Militär einen Angriff auf Siam angeregt hatte. In Singapur hatte General Martin erklärt, Siams zweifelhafte Neutralität sei eine Belastung. Briten und Franzosen sollten von Bangkok verlangen, daß es westlichen Truppen erlaube, Siam zu durchqueren und dort Häfen und Luftwaffenbasen zu nutzen. Siam müsse sich auch japanischen Landungsversuchen widersetzen. Dafür garantiere man Siams territoriale Integrität. Weise Bangkok den Vorschlag zurück, sollten Franzosen und Briten Siam einer Seeblockade unterwerfen und Bangkok besetzen. Das britische Militär billigte, Siam diplomatisch unter Druck zu setzen, weil es für die Verteidigung Indochinas, Malaysias und Birmas von überragender strategischer Bedeutung sei, lehnte aber Militärmaßnahmen ab. Das Foreign Office hielt selbst diplomatischen Druck auf Bangkok für töricht. In Paris hingegen entwickelte General Bührer die Vorschläge General Martins weiter. Der Chef des Generalstabs der Kolonien verlangte in einem Brief an General Gamelin, chef d'état-major général de la défense nationale, eine sehr wohlwollende Haltung Siams:

[I]l est certain que cette bienveillance ne peut être acquise que par une manifestation de force, sinon même par son emploi. Une action militaire offensive contre le Siam apparaît comme nécessaire [...]. L'Angleterre et la France doivent non seulement l'envisager, mais s'y préparer.

Bührer ergänzte, Frankreich könne eine Division gegen Bangkok entsen$\operatorname{den}^{236}$. Daß die Regierung in Bangkok am 24. Juni 1939, dem Jahrestag der Revolution von 1932, den Namen des Landes von Siam in Thailand änderte, gilt in der Literatur als Symbol eines wachsenden Imperialismus (Jean Cogniet/Jules Bührer), schwere Drohung (Claude Hesse d'Alzon) und Beleg des Ehrgeizes der Regierung, alle Gebiete Westindochinas, in denen ethnisch verwandte Thai-Völker lebten, zu annektieren (E. Bruce Reynolds). Italien erkannte die Änderung sofort an. Paris, das auf die Anerkennung verzichtete, registrierte die Veränderung, ohne daraus neue Sorgen abzuleiten ${ }^{237}$. Paris war sicher, daß Bangkok eine günstige Konstellation in Südostasien zur Grenzrevision nutzen würde - ob unter dem Staatsnamen Siam oder als Thailand.

\footnotetext{
${ }^{236}$ Diplomatie an Colonies, D 879, 24.8., rapport final, 27.6., Bührer an Gamelin, D 184, très secret, 26.7.1939 (DDF XVIII, 394, XVII, 20, XVII, 318); ALDRICH, Key to the South, S. 221f.

${ }^{237}$ SOUTY, La Guerre du Pacifique, S. 13, S. 23; COGNIET, BÜHRER, Histoire et épopée des troupes coloniales, S. 252; HESSE D'ALZON, L'armée française d'Indochine, S. 77; REYNOLDS, Anomaly or Model, S. 245; Ciano an Perego, 4.7.1939 (DDI Serie 8, XII, 457); EMA.2, note, 10.7.1939 (SHAT 7 N 2524). Als Tag der Umbenennung nennt Fabienne MERCIER-BERNADET den 23. Juni (Le rôle du Japon dans le conflit franco-thailandais [juin 1940-mai 1941], in: Guerres mondiales et conflits contemporains 199 [2001], S. 25-39 [S. 26]).
} 
Diplomaten und Offiziere in Paris hielten Siam für einen konstanten Unsicherheitsfaktor. Sie nahmen an, daß Bangkok versuchen würde, eine Verschärfung der Lage in Europa oder Asien auszunutzen. Das französische Militär hatte zwar keine klaren Erkenntnisse über die Absichten der Regierung in Bangkok, ging aber davon aus, die Lage an Indochinas Westgrenze im Falle eines Konfliktes mit einem Präventivschlag rasch klären zu können. Daß das Gewicht Japans einen französischen Überfall auf Siam ausschließen könnte, erwog das französische Militär nicht. Vielmehr war die Ausschaltung Siams ein Mittel, um Indochina im Falle eines drohenden japanischen Angriffs in Sicherheit zu bringen. Offenkundig gaben die Anhänger eines expansiven Kolonialismus in den Beziehungen zu Siam in Indochina und in Paris den Ton an.

\subsection{Kollaboration und Widerstandswille in den Konzessionen}

Als Japan nach der Münchener Konferenz die Mächte in China ruppiger behandelte, wurden auch die Kontakte zwischen japanischen und französischen Soldaten kaum noch gepflegt. Die Kollaboration zwischen Japans und Frankreichs Zivilbehörden in den Konzessionen zeigte aber, daß die französischen Beamten im Zweifel eher auf Japans als auf Chinas Seite standen.

Frankreichs kleinste Konzession befand sich in Kanton auf der Insel Shameen. Die Insel war zu vier Fünftel britische Konzession, die restlichen 3,5 Hektar machte Frankreichs Konzession aus. 250 Chinesen und 150 Ausländer wohnten auf der Insel, davon 20 bis 30 französische Zivilisten. »A Canton même, notre concession, dont la superficie ne dépasse pas celle du ministère des Affaires étrangères, ne représente plus guère qu'une survivance sentimentale«, schrieb die Asienabteilung im Quai d'Orsay im Herbst $1938^{238}$. Das bekannte französische Doumer-Krankenhaus war im Juni 1938 zerstört worden.

Die französisch-japanische Zusammenarbeit in Kanton war eng. Als die Japaner im August 1937 Kanton verließen, übernahmen die Franzosen Schutz und Pflege des japanischen Konsulats, der Gärten und zweier japanischer Privathäuser. Dies hatten die Konsuln Laurent Eynard und Nakamura Toyoichi vereinbart. Eynards Nachfolger Philippe Simon klagte, er sei praktisch Japans Immobilienverwalter, was für unfreundliche Worte der Chinesen sorge. Tokio übernahm alle Kosten der Aufsicht. Ab August 1938 bezahlte Japan auch die französischen Polizisten, die sein Konsulat bewachten. Als die Japaner Ende

${ }^{238}$ Note, intérêts français à Canton, 1940; Note de la sous-direction, 25.10.1938 (MAE Chine 794, SDN 365); FNEO, tableau des nationaux français en Chine, 11.2.1939 (SHM 1 BB4 74). 
Oktober 1938 in Kanton einrückten, baten sie die westlichen Konzessionen um Hilfe bei der Herstellung der Ordnung gegenüber Plünderern und Brandstiftern in der Stadt. Briten und Franzosen entsandten Polizeipatrouillen ${ }^{239}$.

Japans Militär dankte den Franzosen die Kooperation nur wenig: Bis Januar 1939 überflogen japanische Kampfflugzeuge ständig die Konzession. Die beiden Brücken zwischen den Konzessionen und Kanton wurden von Japanern streng überwacht. Beim Überqueren der Brücke wurden die Ausländer zwar nicht durchsucht, aber nachts durften sie die Konzession nicht verlassen. Westliche Handelsschiffe konnten Kanton nicht mehr anlaufen. Der Handel kam zum Erliegen. Im Frühjahr 1939 wanderten die meisten westlichen Händler und Produzenten nach Hongkong ab. Nur die Banque de l'Indochine verdiente mit Devisengeschäften weiter Geld. Versorgt wurden die 50 Familien auf der Insel von westlichen oder japanischen Kriegsschiffen. Post wurde von Japan zensiert. Bücher, Zeitschriften und Fotoapparate nahmen japanische Schiffe nicht mit. Das Klima in der Konzession verdüsterte sich. Die Zustände auf der isolierten Insel ähnelten denen eines Konzentrationslagers, schrieb Konsul Simon im Dezember 1939. Ein französischer Soldat beging Selbstmord. Für den Quai d'Orsay hingegen war die Lage in Kanton akzeptabel: Japan hielt sich aus Fragen der Konzession heraus und strebte sachliche Beziehungen zu den französischen Behörden an. Im Dezember 1938 besuchten 39 japanische Offiziere, darunter Admiral Kanao, die Konzession ${ }^{240}$.

So verzweifelt wie in Kanton war die Stimmung oft auch unter den Franzosen in Hankou. Konsul Reynaud und der örtliche Marinekommandeur unterbreiteten Cosme im April 1939 einen Plan, wie man im Kriegsfall aus Hankou fliehen könnten. Cosme rügte dies: Man müsse Japan zeigen, daß Franzosen alles täten, um ihre Rechte und ihre Ehre zu verteidigen. Nach Ausbruch des Krieges im September 1939 bat der Heereskommandeur von Hankou um die Evakuierung der Truppen ${ }^{241}$. Für Besucher sah Hankou mit den ausländischen Kriegsschiffen und Passagierdampfern an den Kais und den am Fluß aufgereihten Konsulaten und Banken aus wie ein kleines Shanghai, 950 Kilometer

\footnotetext{
${ }^{239}$ Philippe Simon an Naggiar, L 58, 4.7., L 79, 3.8., Naggiar an Bonnet, T 1016-17, 16.7., Naggiar an Simon, T 50, 17.8., Domei Tokio, Prochaine réouverture du consulat général du Japon, 2.10., Naggiar an Bonnet, T 1566-73, 26.10.; T 1533-35, 22.10., T 1544-45, 24.10., T 1595-97, 28.10.1938 (MAE Chine 794, 728, SDN 365, Chine 729); Delsuc an Mandel, T 1300, 25.10., Brévié an Mandel, T 1235, 31.10.1938 (CAOM FM 677, 678); Delsuc an Guerre, T 762, 29.10.1938 (SHAT 11 H 60).

${ }^{240}$ Naggiar an Bonnet, T 1809-14, 24.11., Simon an Knobel, L 161, 30.12.1938, L 25, 30.1.1939; Saugon an Cosme, L 17, 30.1.1940; Simon an Cosme, L 92, 22.6.1939 (MAE Chine 794); Perretier an Delsuc, L 4904, 16.12., Casseville an Mandel, L 260, 1.3.1939 (SHAT 11 H 77, 63); FNEO, compte rendu, 29.3., 1.8.; STS-bulletin, 1.8.1939 (SHM 1 BB4 74, MAE Chine 535); Simon an Knobel, L 15, 16.1., Simon an Cosme, T 140-44, 25.8., L 189, 7.12.1939 (MAEN Pékin A 312, A 311, A 345bis).

${ }^{241}$ Reynaud an Cosme, T 120-24, 7.4.1939 (MAEN Pékin A 493); Cosme an Bonnet, T 501-7, 12.4.1939 (MAE Chine 766); Casseville an Armes Hankéou, T 84, 3.9.1939 (SHAT 11 H 60).
} 
vom Meer entfernt. Frankreich hatte sich über Jahrzehnte auch deshalb dort behauptet, weil es sich stets an Japans Seite hielt. Wie als Beleg dafür hingen seit 1905 am französischen Konsulat die Werbetafeln der französischen Firma Olivier-Chine und der japanischen Reederei Nippon Yusen Kaisha einträchtig nebeneinander. Mit 36 Hektar und 15000 Einwohnern im Juli 1937, davon 70 Franzosen und weitere 250 Ausländer, war die Konzession Frankreichs zweitkleinste in China. Als Japan im August 1937 seine Konzession räumte, gewann Frankreichs Besitzung als einzige ausländische Enklave in Chinas Landesinnern besonderes Gewicht. Nach dem Fall Nankings entsandte Paris ein zweites Kanonenboot, um seine Entschlossenheit zu zeigen, an der Konzession festzuhalten. Als sich die Front im März 1938 der Stadt näherte, beordete Paris weitere $\mathbf{4 0}$ französische Soldaten nach Hankou, das bis dahin 22 französische und 147 indochinesische Infanteristen verteidigt hatten ${ }^{242}$.

Im Juni 1938 bat Henry Japans Regierung beim bevorstehenden Angriff auf die Stadt um Rücksicht auf Frankreichs Konzession. Der erfahrene Konsul Lucien Colin, der seit 1921 in China arbeitete, wurde nach Hankou versetzt. Als größte Gefahr sahen die Franzosen aber nicht japanische Übergriffe, sondern Unruhen der Chinesen und das Eindringen flüchtender chinesischer Soldaten in die Konzession. Um die Massen zu kanalisieren, setzten sich französische Behörden und der Jesuitenpater Jacquinot de Besange dafür ein, in Hankou, wie zuvor in Shanghai, eine Schutzzone für Flüchtlinge zu schaffen. Japan akzeptierte einen Bereich am Jangtse, der eine halbe Million Menschen aufnehmen konnte. Der Pater markierte ihn mit Flaggen. Die Chinesen zogen am 26. Oktober aus Hankou ab. Die französische Konzession schaffte es gerade, vor Ankunft der Japaner martialische Stellungen abzubauen. Naggiar wies an, Panzerfallen und Barrikaden, über die die Presse breit berichtete, zu beseitigen, da diese Mißtrauen gegenüber Japan demonstrierten ${ }^{243}$.

Als die japanischen Truppen sich Hankou näherten, fuhren ihnen Colin, Pater Jacquinot und ein Übersetzer entgegen. Jacquinot, dem die Japaner nach Colins Schilderung größten Respekt entgegenbrachten, erreichte, daß Japans Truppe auf einem Weg in die Stadt einrückte, der weder durch die Schutzzone,

${ }^{242}$ Clifford, Spoilt Children, S. 177; ReNouvin, La question, S. 3; Jacomy an Mandel, T 544, 14.3.; L, 25.4.; Naggiar an Jacomy, T 12, 8.3., T 13, 9.3.1938 (SHAT 11 H 60, 77, 64); FNEO, tableau des nationaux français en Chine, 11.2.1939; Marine an Diplomatie, T 7113, 11.8.1937 (SHM 1 BB4 74, BB9 270); Roy an Daladier, L 58, 15.3.1940; Baudez an Briand, L 1, 6.2.1931; Naggiar an Delbos, T 837, 9.12.1937, Léger an Naggiar, T 135, 7.3.1938 (MAE Chine 799, 796, 714, 798); Diplomatie an Colonies, 7.3.1938 (CAOM FM 677); SouCHARD, Canton et Hankéou, S. 49.

${ }^{243}$ Henry an Bonnet, L 94, 14.6., Perretier, instruction secrète pour le commandant d'Hankéou, 15.6., note, décision prise par l'ambassadeur, 16.7., Naggiar an Bonnet, T 858-61, 29.6.; T 1089-91, 4.8., T 1157-59, 16.8.; T 1235-43, 3.9., Henry an Bonnet, T 489-90, 6.9.; T 509, 20.9., Naggiar an Bonnet, T 1275-76, 9.9., T 1448-50, 10.10., T 1463, 13.10., T 1558-65, T 1574-75, 26.10.; T 1525-27, 21.10.; T 1556, 26.10.1938 (MAE Chine 789, 726, 727, 798, 728, 729). 
noch durch die Konzession führte. Übergriffe auf Zivilisten blieben aus. Noch am Abend suchte Japans Kommandant Konsul Colin auf, versicherte seine friedlichen Absichten und vereinbarte, daß japanische Fahrzeuge eine Straße in der Konzession passieren durften. Abgesehen von Schäden am Konsulat, die einige Chinesen verursacht hatten, überstand das französische Gebiet den Sturm des Krieges unversehrt. Dabei dürfte eine Rolle gespielt haben, daß sich unter den japanischen Offizieren Oberst Tajima befand, Französisch-Dozent an der Kriegsakademie und Ritter der Ehrenlegion. Henry nannte ihn einen großen Freund Frankreichs. US-Generalkonsul Davies und der stellvertretende US-Militärattaché Dorn bespöttelten die Konzession als Relikt der Geschichte, aber die Franzosen hatten sich in schwieriger Lage behauptet ${ }^{244}$.

$\mathrm{Zu}$ Beginn gestaltete sich die japanisch-französische Koexistenz in Hankou problemlos: Naggiar hatte Colin angewiesen, den Japanern soweit wie möglich entgegenzukommen und kameradschaftliche Kontakte zwischen den Armeen zu fördern. Colin solle engste Verbindung zum japanischen Konsul halten, inoffizielle Beziehungen zu den Marionettenbehörden aufbauen und schärfstens gegen jene Chinesen in der Konzession vorgehen, die Japan feindlich gesonnen seien. Die Kontakte entwickelten sich so gut, daß japanische und französische Offiziere über den Transport französischer Einheiten sprachen und die Japaner anboten, einen französischen Hauptmann nach Shanghai zu fliegen. Japans Marine brachte 65 Kisten mit Lebensmitteln, Kleidung und Medikamenten nach Hankou und erlaubte dem Kriegsschiff Amiral Charner die Fahrt nach Shanghai ${ }^{245}$.

Ab dem 7. Dezember 1938 setzte Japan die Franzosen unter Druck: Es verweigerte bis zum 26. Januar 1939 die Versorgung der Konzession mit Wasser, schränkte tagelang Lebensmittelslieferungen ein und ließ nur noch Europäer die Konzession betreten und verlassen. Die 80000 chinesischen Bewohner durften das Gebiet nicht verlassen, Europäer von außerhalb durften nicht nach Hankou reisen. Die Japaner steliten keine Forderungen, aber ihre Presse schrieb, die Enklave sei Heimstätte antijapanischer Kräfte. Die Franzosen bauten eine neue Wasserversorgung auf und pflegten noch engere Kontakte zu den Japanern. Colin lud einige japanische Offiziere zum Essen ein.

\footnotetext{
${ }^{244}$ Naggiar an Bonnet, T 1591, 28.10; T 1582, 27.10., T 1624-27, 1.11., T 1644 47, 2.11.; Henry an Bonnet, T 659, 29.11.1938 (MAE Chine 795, 798, Japon 98); John Paton DAviES Jr., Dragon by the Tail. American, British, Japanese and Russian Encounters with China and one another, London 1974, S. 200; DoRN, The Sino-Japanese War, S. 222; Colin an Bonnet, L 38, 4.11.1938 (MAE Chine 730).

${ }^{245}$ Naggiar an Bonnet, T 1684-87, 9.11.; Naggiar an Colin, T 158-160, 16.11., T 1779-82, 21.11., STS-bulletin, 1.12.1938 (MAE Japon 127, Chine 799, 798, 534); Colin an Naggiar, T 402, 23.11.1938 (MAEN Pékin A 345 bis); Militär Tienstin an Militär Hankou, T 63-64, 9.11.; Perretier an Casseville, L 4904, 16.12.1938, compte rendu relatif à la situation du détachement français d'Hankéou 1.12.1938-31.1.1939; Casseville an Mandel, L 260, 1.3.1939 (SHAT $11 \mathrm{H} \mathrm{60,77,63).}$
} 
Die Grenze der Konzession ging oft mitten durch Häuser. Um zu verhindern, daß Chinesen durch die Gebäude in die Konzession kamen, ließ Colin an ihnen Gitter aufstellen. Colin und Le Bigot klagten, daß ihre Bemühungen um den Erhalt der Konzession von Europäern und Amerikanern nicht unterstützt würden. Diese sähen mit Neid, daß sich die concession als Insel inmitten des japanischen Herrschaftsbereichs behaupte und zum Handelszentrum entwickle. Colin resümierte am 9. Dezember 1938: »[L]e maintien de notre établissement du moyen Yangtsékiang, avec tout l'honneur qu'il apporte au pavillon français, peut sans exagération, être qualifié de miraculeux ${ }^{246}$.

Die Bewahrung der Konzession war weniger ein Wunder als die Folge des örtlichen apaisement: Hunderte japanischer Lastwagen befuhren täglich die Konzession. Am 20. Dezember 1938 und am 12. Januar 1939 durchsuchte die französische Polizei auf japanische Bitten zahlreiche Häuser, im zweiten Fall in Anwesenheit japanischer Gendarmen. Geschäftsträger Knobel segnete die Haltung des Konsuls ab und kritisierte allein die Anwesenheit der japanischen Polizisten, weil sie die französische Autorität untergrabe. Wer Herr der Konzession war, demonstrierten die Japaner am 8. Januar 1939, als 4000 Mann und 54 Panzer mit Marschmusik eineinhalb Stunden lang durch französisches Gebiet paradierten. Colin duldete das Defilee. Le Bigot versuchte die Wirkung in Paris zu begrenzen. Er schrieb, die ausländische Presse schlachte eine einfache Durchfahrt als Parade aus. Ganz auf sich allein gestellt, mußten die Franzosen japanischen Wünschen nachkommen. Die Japaner konnten aber nicht verstehen, wie ein hoher japanischer Offizier sagte, daß Paris die strategisch wichtige Tschechoslowakei kampflos aufgab, während es an der kleinen, unbedeutenden Konzession in Hankou hartnäckig festhielt ${ }^{247}$.

Nach der Parade vom 8. Januar kamen immer öfter japanische Polizisten in die Konzession und nahmen Chinesen fest. Als Colin dies den Japanern am 15. Februar untersagte, verhängte Japan eine komplette Blockade: In die Konzession kamen keine Lebensmittel mehr, was bei 49000 chinesischen Bewohnern bedrohlich war. Fünf Tage später wurde die Blockade aufgehoben, als Colin japanischen Soldaten gestattete, einen Teil der Konzession in Zivil zu betreten. Ausländer mußten den Japanern nun abends und nachts einen Passagierschein zeigen, wenn sie das französische Gebiet verlassen wollten.

\footnotetext{
${ }^{246}$ Militär Hankou an Militär Shanghai, T 321, 10.12.1938 (SHAT 11 H 77); Colin an Bonnet, T 1906, 8.12., T 1918, 10.12., T 1922-26, 11.12., Knobel an Bonnet, T 1982-88, 16.12.; Colin an Knobel, L 40, 9.12; Knobel an Bonnet, T I991-92, 17.12.1938; FNEO, compte rendu, 29.3.1939 (MAE Chine 799, 514, Japon 128; SHM 1 BB4 74); CARSALADE DU PONT, La marine française, S. 149.

${ }^{247}$ Knobel an Bonnet, T 2013-16, 21.12.1938; T 63-64, 13.1., T 140, 25.1., T 144, 26.1.; STS-Bulletin, 22.1., 15, 1.2.; Knobel an Bonnet, T 50-53, 12.1., T 86-89, 15.1.1939 (MAE Chine 771, 772, 534, Japon 128); Militär Hankou [an Perretier], T, 9.1.[1939] (SHAT 11 H 77); FNEO, compte rendu, 1.2.1939 (SHM 1 BB4 74); Josselyn an Hull, 10.2.1939 (SD 893.00 PR Hankow/139, 10.2.1939).
} 
Offenkundig war Japan nicht entschlossen, die Konzession auszulöschen. Mit einem geschickten Vorgehen könne man den Zustand noch Jahre fortsetzen, schrieb Leutnant Linard. Hauptmann Puch stimmte zu, allerdings sei die Konzession in der Lage eines Hochseilartisten, dessen Seil von Japan ständig bewegt werde. Le Bigot schrieb zutreffend: "La >collaboration entre notre concession et les Japonais«. Die Franzosen verboten die Öffnung chinesischer Schulen und gestatteten, daß Japans Armee in der Konzession ein chinesisches Regierungsgebäude als Krankenhaus nutzte. Die Franzosen hatten eine für Japan akzeptable Ordnung geschaffen. Die Chinesen nahmen Colin die Zusammenarbeit mit Japan wohl nicht einmal übel: Als Dank für den Erhalt der Konzession überreichten 200 angesehene Bürger der Stadt dem Konsul einen bestickten Sonnenschirm aus Seide ${ }^{248}$.

Obwohl Cosme und der Quai d'Orsay zur Kooperation mit Japan rieten, trat Colins Nachfolger Reynaud, der im März 1939 die Leitung der Konzession übernahm, fester gegenüber Japan auf. Er unterband die freie Durchfahrt der japanischen Fahrzeuge durch die Konzession und die Abhaltung einer Parade am 7. Juli 1939. Als Japan eine kleine Kundgebung mit zwei Panzern und zehn Lastwagen beantragte, stimmte Reynaud zu, ließ aber die während des Durchmarsches verteilte Flugblätter und Fahnen einsammeln und projapanische Demonstranten festnehmen. Die Marionettenbehörden schäumten, verlangten ihre Anerkennung und eine Entschuldigung. Reynaud blieb stur, die Chinesen gaben klein bei. Im August 1939 erlaubte der Konsul Japan die Nutzung der großen Straßen der Konzession. Dafür zahlte der chinesische Stadtrat 30000 Dollar Straßenbenutzungsgebühr an die Franzosen ${ }^{249}$. Eine japanische Militärparade zum Jahrestag der Besetzung Hankous Ende Oktober 1939 erlaubte Reynaud, die Genehmigung einer Parade im März 1940 verzögerte er. Nach dem Kriegsausbruch in Europa wurde die Zusammenarbeit zwischen der japanischen und der französischen Polizei noch enger: Auf japanische Bitten durchsuchte die französische Polizei im Oktober 130 Häuser und nahm im Dezember 22 Chinesen fest, die, so hieß es, gegen Japan gearbeitet hatten; fünf angeblich geständige Chinesen wurden ausgeliefert. Im März 1940 überwachte ein japanischer Hauptmann eine Durchsuchungsaktion

\footnotetext{
${ }^{248}$ FNEO, compte rendu, 1.3., 29.3., 5.5., 5.6.1939 (SHM 1 BB4 74); Linard, rapport, 1.3., Puch, note, 2.3.1939 (SHAT 11 H 77); Reynaud an Cosme, L 18, 15.3.1939 (MAEN Pékin A 345); Reynaud an Knobel, L 15, 6.3., Reynaud an Bonnet, L 19, 23.3.; Cosme an Bonnet, T 509, 13.4., Léger an Cosme, T136-37, 14.4., Reynaud an Cosme, L 30, 23.5.1939 (MAE Chine 799); Havas, la reconnaisance des habitants chinois envers M. Colin, 21.2.1939 (MAE Chine 514).

${ }^{249}$ Cosme an Bonnet, $T$ 756, 3.7., note de la sous-direction d'Asie-Océanie, 4.7.; Havas, incident franco-japonais à Hankéou, 7.7.1939 (MAE Japon 129, Chine 799); North China Daily News, 11.7.1939 (AA Botsch Peking Pol 5-10); Reynaud an Cosme, L 49, 8.7., L 68, 24.8.1939 (MAE Chine 1069, 798); FNEO an EMG.2, T 7778, 14.7.1939 (SHM 1 BB9 47); Jarvis an Hull, 14.7.1939 (SD 793.94/15216); FNEO, compte rendu, 1.8., 1.9.1939 (SHM 1 BB4 74).
} 
der französischen Polizei. Die Japaner waren zufrieden. Das Klima war so gut, daß sich die japanische Armee förmlich entschuldigte, als einer ihrer Unteroffiziere betrunken einen vietnamesischen Soldaten verletzte ${ }^{250}$. Hankous Entlegenheit trug zu der spannungsfreien Atmosphäre bei: Die Japaner hatten tief in Feindesland kein Bedürfnis, sich mit den fügsamen Franzosen anzulegen, zumal sie im Zweifel ihren Willen durchzusetzen vermochten. Die Franzosen konnten im entfernten Hankou nachgiebiger sein als in Shanghai, wo die internationale Presse Fälle von Prinzipienlosigkeit genau registrierte.

Da Japan einen Konflikt mit den USA vermeiden wollte, besaß Paris in Shanghai mit seiner starken britischen und amerikanischen Präsenz mehr Spielraum. Der Winter 1938/39 verlief in Shanghai so friedlich, daß sich die internationale Gesellschaft, einschließlich vieler japanischer Offiziere, im November 1938 wieder dem Pferderennsport widmen und Naggiar den Ehrenvorsitz des neuen Internationalen Pferderennsportvereins übernehmen konnte. Über seinen Stellvertreter Augé pflegte Generalkonsul Marcel Baudez inoffiziellen Kontakt zu den Shanghaier Marionettenbehörden. Gerüchten, Japan wolle Shanghai blockieren, schenkte niemand große Beachtung ${ }^{251}$.

$\mathrm{Da} \beta$ die französische Position in den Konzessionen relativ unangetastet blieb, verdankte die französische Regierung wohl auch der Tatsache, daß sie Tokio ihre Entschlossenheit signalisierte, sie werde die Konzessionen nicht kampflos räumen. Das klarste Signal bestand darin, daß die französischen Truppen in unveränderter Stärke in China blieben. Mandel verlangte nach dem Ende der Sudetenkrise, zwei Bataillone aus China nach Indochina zu verlegen. Immerhin, schrieb Mandel, habe Léger in der Krise zugestimmt, das Militär in China zu reduzieren. Baue man aber Truppen $a b$, tue man dies besser in ruhigen Zeiten. Als der Quai d'Orsay dies ablehnte, schaltete Mandel Daladier ein. Das Militär habe nur noch symbolischen Wert und müsse auch deshalb nach Indochina verlegt werden, da Frankreichs Interessen stärker in der Kolonie als in den Konzessionen konzentriert seien. Der Quai d'Orsay sehe die Lage in Asien zu sehr durch die Perspektive der Konzessionen. Daladier folgte Mandels Argumenten. Er regte im November 1938 an, die Truppen in China, die zu Beginn des Konflikts 1937 um zwei Bataillone aufgestockt worden waren, um die gleiche Stärke zu reduzieren. Dies schwäche Frankreichs Position in China kaum, stärke aber Indochina - ohnehin die einzige Position in Ostasien, die man verteidigen könne. General Bührer, Admiral Darlan,

${ }^{250}$ Reynaud an Cosme, L 82, 30.10.1939; Cosme an Daladier, T 171-74, 3.3., T 177, 4.3., T 190 , 8.3.1940; Reynaud an Cosme, L 96, 21.12.1939, Georges-Picot an Reynaud, T219, 26.3., T 230-31, 27.3.1940; Reynaud an Cosme, L 73, 18.9.1939; Roy an Daladier, L 8, 17.3.1940 (MAE Chine 1069, 799). QUGLEY zufolge führte Japan in chinesischen Banken in Frankreichs Konzession Beschlagnahmen durch (The Far Eastern War, S. 149). Belege in französischen Akten gibt es dafir nicht.

${ }^{251}$ Augé an Bonnet, L 222, 25.11.; Baudez an Bonnet, L 251, 25.12.1938 (MAE Chine 805, 1063). 
Generalstabschef Gamelin und General Colson vom Armee-Generalstab stimmten dem Abzug von zwei Bataillonen $\mathrm{zu}^{252}$.

Naggiar hingegen argumentierte, Festigkeit gegenüber Japan benötige Militär. Eine politique de liquidation in China gefährde auch die Positionen in Hongkong und Indochina. Léger stimmte zu. Die Präsenz französischer Truppen in China sei unverzichtbar, schrieb er Mandel:

La défense de nos intérêts, la sauvegarde de notre dignité et de notre prestige demandent que rien n'affaiblisse actuellement, aux yeux des Japonais comme à ceux des Chinois, les positions morales et matérielles que nous avons jusqu'à présent su intégralement maintenir et sur lesquelles s'équilibre toute notre action politique et diplomatique en Extrême-Orient ${ }^{253}$.

Léger setzte sich durch. Abgezogen wurde bis Ende November 1938 nur die Artillerie aus Tientsin, was der Quai d'Orsay bereits gebilligt hatte. Jeder weitere Truppenrückzug war untersagt. Die Marine wies den ihr unterstehenden Kommandeur der Odent-Kaserne in Chungking aber im Dezember 1938 an, in dringenden Fällen dürfe er die Kaserne ohne Rücksprache räumen. Vor dieser Anweisung wurde der Quai d'Orsay nicht einmal angehört ${ }^{254}$.

Ab Frühjahr 1939 überlegten die Regierungen in Paris und London, ob sie die Konzessionen gegen japanische Gewalt behaupten sollten. Botschafter Phipps deutete Chauvel Mitte April an, daß London den Kampf ablehne. Ende April räumte das Foreign Office ein, man erwäge im Fall eines Konflikts mit Japan einen Truppenrückzug aus China. Britische Zivil- und Militärbehörden in Shanghai verlangten Pläne für ihre Evakuierung. Anfang Mai beschloß das Committee of Imperial Defence, einem japanischen Übergriff auf die Konzessionen keinen bewaffneten Widerstand entgegenzusetzen. Mitte Juni legte Botschafter Clark Kerr einen Evakuierungsplan für Shanghai vor ${ }^{255}$.

Vor den britisch-französischen Stabsgesprächen Ende Juni 1939 in Singapur verlangte auch Oberst Casseville, Evakuierungen zu planen. Die Konzessionen seien nicht zu verteidigen, die Briten bereiteten ihren Abzug vor. Zumindest solle man die Zahl der zu opfernden Truppen begrenzen. Zuvor hatte Decoux

\footnotetext{
${ }^{252}$ Mandel an Bonnet, L 2/3, 10.10., Mandel an Daladier, L 64/3, 27.10., Daladier an Bonnet, L 5271, 24.11.; Bührer an Gamelin, L 72, 12.10.; Procès-verbal de la réunion des chefs d'état-major généraux du 25.11.1938 (SHAT 11 H 64, 2 N 246, 7 N 4169); Darlan, note sur la défense des colonies, novembre 1938, Gamelin an Darlan, L 70, 18.1.1939 (SHM 1BB2 210, 182).

${ }^{253}$ Naggiar an Bonnet, T 1451-53, 10.10.1938 (MAEN Londres C 482); Bonnet an Mandel, L 1235, 12.10., Léger an Mandel, L 1271, 20.10., Léger an Daladier, L 4003, 12.12.1938 (SHAT 11 H 64).

${ }^{254}$ Delsuc an Brévié, T 754, 13.10., T, 26.10., T 723, 3.12., Delsuc an Mandel, T 722, 3.12.1938; Casseville an Perretier, T 10, 20.4.1939 (SHAT 11 H 60); Delsuc an Mandel, T 1357, 10.11., T 777, 8.12.1938 (CAOM FM 677); Le Bigot an Knobel, L 191, 15.12.1938 (MAE Chine 563).

25s Phipps an Halifax, 18.4.1939 (FO 371/23517, F 3776/2882/10); Note de la sous-direction d'AsieOcéanie, 18.4., Léger an Corbin, D 768, 6.5.1939 (DDF XV, 429; XVI, 94); Corbin an Bonnet, T 1364, 22.4.1939 (MAE Chine 563); Phillips an Halifax, 19.4., Broadmead an Halifax, 24.4., COC Hongkong an War Office, 26.4., Committee of Imperial Defence an Howe, 8.5., Clark Kerr an Halifax, 19.6.1939 (FO 371/23520, F 3918, 3949, 4064, 4331, 7973/3918/10).
} 
auf Anordnung der Marineführung in Paris seine Verbände angewiesen, im Falle eines Krieges mit Japan nur symbolischen Widerstand zu leisten. Anfang Mai einigten sich die britischen und französischen Generalstäbe in London, bei einer japanischen Intervention China zu evakuieren ${ }^{256}$.

In der britisch-französischen Konferenz in Singapur beharrte das französische Militär aber darauf, um die Konzessionen zu kämpfen. Weil Oberst Casseville an dem Treffen nicht teilgenommen hatte, fuhr der britische Oberkommandierende General Grasett nach Tientsin, um Casseville zu überzeugen. Der Oberst räumte ein, Widerstand gegen Japan sei sinnlos. Dennoch werde seine Truppe so handeln, wie der Generalkonsul anordne. Cosme hielt die britische Politik für gefährlich: Falls Japan die westlichen Mächte bekriege, könne man die Konzessionen nicht verteidigen. Wahrscheinlich sei aber, daß Japan nur kleine Zwischenfälle provoziere, um die Mächte zu verdrängen. Japan greife nicht zur Gewalt, wenn es mit bewaffnetem Widerstand rechne. Die britische Anweisung, der Gewalt zu weichen, dürfe deshalb nur im Kriegsfall gelten ${ }^{257}$.

Mitte Juli 1939 vereinbarten das britische und das französische Außenministerium, die Frage auf Regierungsebene zu entscheiden ${ }^{258}$. Die Ausgangslage beider Regierungen war höchst unterschiedlich: Die Briten standen in Tientsin unter unmittelbarem Druck und sahen eine militärische Konfrontation als reale Gefahr. Die Franzosen hingegen fühlten sich nicht direkt bedroht. Oberst Casseville, der gegenüber Grasett die Haltung der französischen Diplomatie verteidigt hatte, forderte Ende Juli aber erneut, die Truppen frühzeitig aus China abzuziehen, da diese im Konfliktfall vor der Alternative zwischen Internierung und Tod stünden. In jedem Fall, telegraphierte Casseville, benötige er klare Befehle, wie er sich im Konflikt verhalten solle. In seiner Anweisung von Mitte Juli hatte Mandel als Vorgesetzter der Kolonialtruppen die Verteidigung der Konzession nicht mehr vorgesehen. Er ließ Casseville nur die Alternative zwischen dem Abzug vor der Intervention Japans oder der Räumung der Konzession in einem Krieg. Ende Juli schlug Mandel vor, aus

${ }^{256}$ Casseville an Decoux, Note, 4.6., Casseville an Bührer, L 82-1/2-S, 21.6.1939 (SHAT 11 H 80); FNEO an EMG.2, T 7516, T 7520, 28.4., EMG.3 an FNEO, T 5273, 29.4.; Decoux an Cosme, T 7526, 29.4.1939 (SHM 1 BB9 45, 185, 46); Lelong an Gamelin, D 110, 5.5.1939 (DDF XVI, 79); Gamelin an Diplomatie, L 1129, 2.6.1939 (SHAT 5 N 579).

${ }^{257}$ Grasett an War Office, 2.7., 23.7.1939 (FO 371/23520, F 6814/3918/10; FO 371/23518, F 7914/3139/10); Casseville an Guerre, T 32, 11.7., T 40, 12.7., Casseville an Decoux, T 36, 11.7.1939 (SHAT 11 H 60); Cosme an Bonnet, T 800-2, 13.7.1939 (MAE Chine 832); Cosme an Bonnet, T 809-11, 15.7., Léger an Corbin, T 1474-77, 15.7.1939 (MAEN Londres C 482); Ronald an Campbell, 24.8.1939 (FO 371/23521, F 8703/3918/10).

${ }^{258}$ Halifax an Phipps, Draft, 13.7.1939 (FO 371/23520, F 6814/3918/10); Lelong an Gamelin, L 252, 20.7.1939 (SHAT 7 N 3439); Cosme an Bonnet, T 830-33, 20.7.1939 (MAE Chine 761); Corbin an Bonnet, T 2293-94, 21.7.1939 (MAEN Londres C 482); Diplomatie an Guerre, L 3084, 22.7.1939 (MAE Chine 1067); Admirality an Foreign Office, 28.7.1939 (FO 371/23521, F 8184/3918/10). 
Hankou, Kanton und Peking die Truppen fast komplett abzuziehen, und zu erklären, man werde die Konzessionen in Tientsin und Shanghai entschlossen verteidigen. Man solle dennoch die Evakuierung Tientsins planen und zwei Bataillone aus China abziehen. Gamelin, Darlan und Bührer schlossen sich am 1. August 1939 dieser Ansicht an. Der Quai d'Orsay entschied jedoch, die bisher erfolgreiche Haltung des entschlossenen Widerstands beizubehalten ${ }^{259}$.

Die Beharrlichkeit, mit der sich der Quai d'Orsay den Forderungen des Militärs und des Kolonialministers widersetzte, überrascht um so mehr, als Ende Juni das "Bulletin quotidien« des Außenministeriums und auch eine Arbeit des Generalstabs der Luftwaffe urteilten, die Zeit der Konzessionen in China ende, egal, wer in dem Krieg siege. Die "Gazeta Polska« in Warschau verbreitete, im Quai d'Orsay halte man das System der Konzessionen für einen Anachronismus, der verschwinden werde. Die Führung des Quai d'Orsay allerdings hielt den Gedanken eines japanischen Angriffs auf die Konzessionen schlicht für unrealistisch. Zudem hatte seit 1937 die politische Bedeutung der westlichen Enklaven noch zugenommen. Clark Kerrs Urteil über die Franzosen, " [the] situation of their concession is for them a question of political prestige and so far as can be seen they are determined to hold it«, traf die Position des Quai d'Orsay genau. Ein Abzug drohte noch einmal, als die britische Regierung Mitte August beschloß, ihre Truppen aus Nordchina zu evakuieren. Am 24. August 1939 wurde Campbell angewiesen, Paris vom gemeinsamen Abzug zu überzeugen ${ }^{260}$. Mit der Entspannung in Asien durch den HitlerStalin-Pakt war der Rückzug westlicher Truppen zunächst kein Thema mehr. Der Quai d'Orsay hatte sich gegen die Abzugspläne des französischen Heeres und des Foreign Office durchgesetzt.

Ende 1938 wurden die Behörden in Shanghai mit einem ganz anderen Problem konfrontiert: Nach dem Pogrom gegen die jüdische Bevölkerung in Deutschland am 9. November 1938 wollten viele Juden ihre Heimat verlassen, wurden jedoch weltweit abgewiesen. Die einzige Stadt der Welt, die kein Eintrittsvisum verlangte, war Shanghai. Kurz vor Weihnachten 1938 kamen die ersten 500 jüdischen Flüchtlinge an, Anfang Januar 1939 waren es bereits 2000, im März 4000. Die Behörden in Shanghai hatten viele hunderttausend chinesische Flüchlinge geduldet, doch die ankommenden Juden wurden als

\footnotetext{
${ }^{259}$ Yvon an EMA, L 69, 21.7.1939 (SHAT 11 H 62); Casseville an Mandel, T 134, 22.7., Casseville an Cosme, L 133, 22.7.; Casseville an Guerre, T 54, 31.7.1939 (SHAT 11 H 80, 60); Colonies an Marine, L 184, très secret, 26.7.1939 (SHM 1BB2 182); Procès-verbal de la réunion des chefs d'EMG, 1.8.1939 (SHAT 2 N 225); Diplomatie an General Jamet, D 392, 4.8.1939 (DDF XVII, 429).

${ }^{260}$ Bulletin quotidien des affaires étrangères, 26.6., EMAA.2, synthèse de renseignements, 30.6.1939 (SHAT 7 N 3308, SHAA 2 B 81); Noël an Bonnet, T 914, 16.6.1939 (MAE Chine 832); Clark-Kerr an Halifax, 22.8., Halifax an Craigie, T 504, Clark Kerr, T 757, most secret, 14.8., Ronald an Campbell, 24.8.1939 (FO 371/23521, F 9304, 8992, 8703/3918/10).
} 
wirtschaftliche Konkurrenz für die Weißen in der Stadt gesehen. Das International Settlement schlug vor, die Juden abzuweisen, die weder Geld noch Arbeitsvertrag besaßen. Baudez stimmte zu: Shanghai könne die Last jüdischer Emigration nicht tragen, da sie bereits gegenüber den chinesischen Flüchtlingen großzügig gewesen sei. Sich um diese Menschen zu kümmern, sei wichtiger, als die Juden Europas aufzunehmen, so Baudez. Die Einwanderung werde den Antisemitismus anheizen, erste antisemitische Flugblätter seien bereits aufgetaucht. Tatsächlich bildete sich eine Bewegung in Shanghai, um die Zahl deutscher jüdischer Einwanderer zu begrenzen ${ }^{261}$.

Auf Drängen der Behörden in Shanghai trat das amerikanische Außenministerium an jüdische Kreise in den USA heran; britische und französische Diplomaten in Berlin, Wien, Prag und Rom baten die jüdischen Gemeinschaften, ihre Mitglieder zum Bleiben zu bewegen ${ }^{262}$. Weitere Maßnahmen gegen die Einreise jüdischer Flüchtlinger ergriffen die Franzosen nicht. Ab August 1939 verlangte die Internationale Konzession mit Billigung der örtlichen jüdischen Gemeinde von Zuwanderern den Nachweis von 400 US-Dollar, wenn diese keine Verwandten in Shanghai oder einen Arbeitsvertrag besaßen. Die schließlich 16000 bis 18000 jüdischen Flüchtlinge lebten überwiegend im japanisch kontrollierten Stadtteil Hongkew. 4000 Juden, so David Kranzlers Schätzung, lebten in Frankreichs Konzession ${ }^{263}$. Warum sich die Franzosen in Shanghai den Juden gegenüber großzügiger zeigten als die Angelsachsen, ist unklar. Vermutlich zog die französische Konzession mit ihren höheren Mieten eher wohlhabende, steuerzahlende Flüchtlinge an, zumal sich viele Zuwanderer als tüchtige Handwerker und Händler, Ärzte und Unternehmer zeigten ${ }^{264}$.

Die Internationale Konzession wurde im Februar 1939 von einer Welle des chinesischen Terrorismus erschüttert. Mitte Februar wurde der Außenminister

\footnotetext{
${ }^{261}$ Baudez an Bonnet, L 253, 28.12.; STS-bulletin 22.1., 1.2., 1.4.1939 (MAE Chine 805, 534); ab Anfang Oktober 1938 attackierten Flugblätter antisemitischen Inhalts die französische Polizei.

${ }^{262}$ WOOD, No Dogs, S. 280; Baudez an Bonnet, T 1-2, 4.1., T 8, 19.1., Hoppenot an Corbin, T 22-35, Saint-Quentin, T, 5.1., Léger an Rom, T 33-34, Berlin, Prag, Wien, 16.1.1939 (MAE Chine 805).

${ }^{263}$ David KRANZLER, Japanese, Nazis and Jews. The Jewish Refugee Community of Shanghai, 19381945, New York 1976, S. 114f., S. 272f;; Felix GRUENBERGER zufolge zogen »einige« Flüchtlinge in Frankreichs Konzession (The Jewish Refugees in Shanghai, in: Jewish Social Studies 12 [1950], S. 329-348 [S. 333]). Zu den Flüchtlingen zuletzt FREYEISEN, Shanghai, S. 390f., Emest G. HEPPNER, Fluchtort Shanghai. Erinnerungen 1938-1948, Bonn 1998. Die Zahl von 16000 bis 18000 Flüchtlingen ist in der Literatur verbreitet, Frankreichs Generalkonsul gab 16800 an (Baudez an Reynaud, $L$ 35, 21.3.1940, MAE Chine 1064). Von 18000 bis 20000 ging der US-Generalkonsul aus (Butrick an Hull, 11.6.1940, FRUS 1940, IV, S. 742), HENRIOT (Le paradis des étrangers, S. 43) und BRosSELLET (Les Français de Shanghai, S. 25) nehmen die Zahl von 20000 jüdischen Flüchtlingen an; WEI Betty Peh T'i schätzt ihre Anzahl auf 25000 (Old Shanghai, Hongkong, Oxford, New York 1993 [Images of Asia], S. 47).

${ }^{264}$ Siegfried ENGLERT, Sechs dürfen unter einem Gebetsschal beten. Zur Geschichte der Juden in Shanghai 1937-1945, in: DERS., Folker REICHERT (Hg.), Shanghai. Stadt über dem Meer, Heideiberg ${ }^{2} 1996$, S. 109-122 (S. 116).
} 
der projapanischen »Reformierten Regierung « Cheng Lu Opfer. Cheng hatte einen Jura-Abschluß in Paris erworben und war von 1920 bis 1927 chinesischer Gesandter in Paris gewesen. Nach dem Mord im Settlement drohte Japans Regierung einzugreifen, falls die Behörden nicht durchgriffen. Französischen, britischen und amerikanischen Diplomaten war klar, daß Chiang Kaishek hinter den Anschlägen steckte. Knobel drohte, die Urheber weiterer Attentate liefere er den chinesischen Marionettenbehörden aus. Bonnet billigte dies: Stoppe Chungking den Terrorismus nicht, dürfe Knobel die Täter übergeben, um ein Exempel zu statuieren. Die Behörden der Internationalen Konzession erlaubten im Februar japanischen Soldaten, im Settlement zu patrouillieren und seine Eingänge zu kontrollieren, jedoch nur in Zivil, um einen Rest westlicher Autorität zu bewahren. Des Terrorismus beschuldigte Chinesen sollten ausgeliefert werden, wenn Japan Beweise vorlege - für Bernhard Wasserstein ein klarer Fall verwerflicher Kollaboration. Die Japaner strapazierten das Zugeständnis, indem sie im März im Settlement selbst zwei Chinesen festnahmen und die Herausgabe zwei weiterer Beschuldigter erzwangen. Léger legte Wert darauf, daß Frankreich in den Streit zwischen Japan und dem Settlement nicht verwickelt wurde. Paris werde sich nur einschalten, wenn London förmlich darum bitte und sich die USA beteiligten. Gemeinsam forderten die drei Regierungen lediglich die chinesische Regierung auf, die Terrorakte in Shanghai einzustellen. Auch den deutschen Diplomaten fiel auf, daß Japan die französische Konzession in Shanghai kaum unter Druck setzte. Generalkonsul Fischer erklärte dies damit, daß das Settlement als

ein auf einem reichlich veralteten Statut beruhender, auf sich selbst gestellter Organismus weit mehr Angriffsflächen bot als die französische Niederlassung, deren Verwaltung die französische Regierung durch ihre hiesigen staatlichen Organe bei fast völliger Ausschaltung von Selbstverwaltungskörperschaften selbständig leiten läßt ${ }^{265}$.

Hinzu kam, daß Frankreich den Japanern beinahe täglich demonstrierte, daß es bereit war, sich in ihre Ordnung einzufügen: Am 9. und 10. März 1939 besuchten Japans Generalkonsul, der ihm hörige chinesische Bürgermeister und Journalisten Frankreichs Generalkonsul und verlangten, auch die französische Konzession solle japanische Polizeikontrollen zulassen. Doch Japan ging es

\footnotetext{
${ }^{265}$ Henry an Bonnet, T 120, 21.2.; Henry an Bonnet, T 123-24, 22.2., T 126, 23.1., Cosme an Knobel, T 24-25, 21.3., Knobel an Bonnet, T 264-66, 23.2., T 391-93, 11.3., T 400-1, 15.3.; T 252-54, 21.2., Bonnet an Knobel, T 82, 23.2., Henry an Bonnet, T 127-28, 24.2.; Léger an Henry, T 106-7, 24.2.; STS-bulletin 1.3., 1.4.1939 (MAE Chine 785, 1063, 805, 535); Craigie an Halifax, 28.2.; FNEO, compte rendu, 1.3.; Stadtrat Shanghai an Japans Konsul, L, 3.3.1939 (DBFP, $3^{\text {rd }}$ series, VIII, 513, SHM I BB4 74, SHAT 11 H 63); LEE, Britain and the Sino-Japanese War, S. 182; WAKEMAN, The Shanghai Badlands, S. 58f.; Bernhard WASSERSTEIN, Ambiguities of Occupation: Foreign Resisters and Collaborators in Wartime Shanghai, in: YEH Wen-hsin (Hg.), Wartime Shanghai, London, New York 1998, S. $24-41$ (S. 29); Fischer an Ribbentrop, 31.10.1939 (AA Pol VIII 58 A 3).
} 
nur um den Effekt in der Öffentlichkeit. Der japanische Geschäftsträger Morishima sagte seinem französischen Kollegen Knobel, man schätze, wie sehr die französischen Behörden japanische Einrichtungen schützten. Knobel erwiderte, in Fragen des Prinzips gebe er nicht nach, er sei aber bereit, in lokalen Fragen den Japanern so weit wie möglich entgegenzukommen. Ein japanischer Sprecher nahm die Franzosen von den Angriffen auf das Settlement aus. Auch die japanische Presse bezichtigte zwar die Internationale, aber nicht die französische Konzession einer antijapanischen Haltung ${ }^{266}$.

Angesichts des japanischen Drucks verstärkten die Franzosen die Repression chinesischer Organisationen. Der Marine-Geheimdienst warnte, nach Kriegsende werde China den Konzessionsmächten weniger für den Schutz danken als Rache suchen für ihre Unterwerfung unter Japans Forderungen. Das Klima zwischen französischen Behörden und chinesischer Regienung verschlechterte sich, als Chiang Kai-shek die Einwohner der Konzessionen im Februar 1939 dazu aufrief, sich gegen Japan zu erheben. Léger bat Chinas Regierung, die Verstöße gegen die Neutralität der Konzessionen einzustellen. Nach der deutschen Besetzung Prags am 15. März 1939 forderten japanische Extremisten, die Armee solle gegen die Konzessionen losschlagen. Französische Behörden gingen erneut massiv gegen chinesische Agitateure vor, wofür der japanische chargé d'affaires dankte. Die Franzosen verhafteten einzelne Chinesen und wiesen andere aus der Konzession aus. Zugleich griffen die Japaner zur Selbstjustiz und entführten am 9. Mai fünf Chinesen aus dem Settlement, obwohl dessen Behörden bereits Mitte April freiwillig einen Chinesen ausgeliefert hatten, der in einen Anschlag verwickelt war $^{267}$.

Cosme hörte am 9. Mai vom deutschen Geschäftsträger und dem belgischen Botschafter, angesichts des chinesischen Terrorismus - von Frühjahr bis Herbst 1939 wurden im International Settlement 37 Chinesen, in der Concession française elf Chinesen ermordet - habe die japanische Regierung der Armee einen Überfall auf die Konzessionen erlaubt. Der Botschafter forderte daraufhin ein noch schärferes Vorgehen gegen den chinesischen Terror. Wenn man den japanischen Angriff verhindern wolle, müsse man die Schuldigen entweder nach einem Verfahren ausliefern, oder man übergebe in flagranti ertappte Terroristen sofort an Japan, wie dies das Settlement praktiziere. Beide Vorschläge lehnte Bonnet ab, weil dies die französische Kontrolle in der

\footnotetext{
${ }^{266}$ Knobel an Bonnet, T 385-87, 10.3., Bürgermeister Fou Siao An an Baudez, L, 10.3.1939 (MAE Chine 1063); FNEO, compte rendu, 29.3.1939 (SHM 1 BB4 74); Note, visite de M. Morishima, chargé d'affaires du Japon, 15.3., Knobel an Bonnet, T 429-30, 26.3.1939 (MAE Chine 1063, 805).

${ }^{267}$ STS-bulletin, 20.3., 1.4.; Knobel an Cosme, T 412-14, 20.3., Knobel an Bonnet, T 439-42, 29.3., L 168, 20.5., Baudez an Bonnet, T 23-24, 26.4., L 60, 20.5.; Léger an Cosme, T 153, 27.4., Cosme an Bonnet, T 558-60, 28.4.; L 159, 18.5.1939 (MAE Chine 535, 1063, 805, 806); Halifax an Phipps, 14.3.1939 (DBFP, $3^{\text {rd }}$ series, VIII, 564); WAKEMAN, The Shanghai Badlands, S. 69, S. 74.
} 
Konzession untergrabe. Baudez verkündete dennoch, wer sich politisch betätige, werde der Konzession verwiesen. Die Bedrohung Shanghais schwand, als US-Außenminister Cordell Hull am 12. Mai Tokio vor einer Status-Veränderung des Settlement warnte und als die Amerikaner fünf Tage später in Kulangsu ihr Eintreten für die Konzessionen zeigten. Paris legte seine Distanz zum Settlement $a b$ und trat im Mai und im Juni amerikanischen Demarchen in Tokio zur Lage der Internationalen Konzession bei ${ }^{268}$.

Cosme hielt Bonnets Ablehnung systematischer Ausweisungen chinesischer Terroristen für falsch, da Chinas Regierung den Terrorismus in Shanghai schüre. Agitateure verdienten keine Schonung. Am 19. Mai gingen Polizei und Armee der französischen und der Internationalen Konzession gegen »terroristische und kriminelle Elemente « vor. Damit hatten die Franzosen aus Sicht Chinas offenbar überzogen. Chiang Kai-shek protestierte so heftig, daß der Botschafter sofort nach Chungking reiste, um das französische Verhalten $\mathrm{zu}$ erklären. Daß von den Vertretern der drei westlichen Demokratien in Shanghai Cosme derjenige war, der Japans Forderungen am weitesten entgegenkam, war auch die Einschätzung des italienischen Botschafters Taliani ${ }^{269}$.

$\mathrm{Zu}$ Cosmes Strategie gehörte es, daß er Zwischenfälle, wie die Erschießung eines französischen Polizisten durch japanische Soldaten, herunterspielte, und daß er Ende Mai auf japanisches Drängen von dem Wasserwerk Tongkadou in Nantao die französische Marineinfanterie abzog, die die Einrichtung in dem chinesischen Stadtteil seit August 1937 bewacht hatte ${ }^{270}$. Was Chiang konkret entzürnte und Cosmes Reise nach Chungking auslöste, ist unklar. In Chungking erreichte er jedoch die Zusage Chiang Kai-sheks, des Außen- und des Verkehrsministers, China werde die französische Konzession nicht weiter durch antijapanische Aktivitäten gefährden ${ }^{271}$.

Während Cosmes Aufenthalt in Chungking verlangte Japan die Auslieferung eines des Mordes bezichtigten Chinesen, dessen Schuld Baudez für erwiesen hielt. Bonnet lehnte die Auslieferung ab, weil sie einen Präzedenzfall

\footnotetext{
${ }^{268}$ Baudez an Daladier, T 80, 20.10., L 104, 7.11., Henry an Bonnet, T 330, 5.6., Chauvel an Henry, T 239, 6.6.1939 (MAE Chine 1064); Cosme an Bonnet, T 597-601, 9.5.1939 (MAE RFD 28); Bonnet an Cosme, T 171-72, 9.5.1939; Baudez an Bonnet, T 27, 12.5.1939 (MAE Chine 805); Gauss an Hull, 12.5., Yarnell an Leahy, 12.5., Hull an Grew, 12.5., Bullitt an Hull, 20.5.1939 (FRUS 1939, IV, S. 45, S. 56f.); Saint-Quentin an Bonnet, T 819-22, 17.5., Léger an Cosme, T 186, 18.5., Henry an Léger, L 94, 23.5.; Léger an Henry, T 219-20, Cosme, T 194-95, 20.5.1939 (MAE Chine 1063, 761).

${ }^{269}$ Cosme an Bonnet, T 619-22, 15.5., T 662, 21.5.; Havas, l'épuration de Changhai, 19.5., Cosme an Bonnet, L 170, 26.5.1939 (MAE Chine 805, 1063); FNEO, compte rendu, 5.6.1939 (SHM I BB4 74); Taliani an Ciano, 5.6.1939 (DDI Serie 8, XII, 116).

${ }^{270}$ Baudez an Bonnet, T 750, 29.6.; Gauss an Hull, 7.7.; FNEO, compte rendu 29.3., 5.5.1939 (MAE Chine 805, SD 893.00 PR/Shanghai/129, SHM 1 BB4 74); Cosme erklärte, der Posten sei durch mehrere Patrouillen am Tag ersetzt worden, Decoux zufolge wurde die Wache ersatzlos aufgelöst (Cosme an Bonnet, T 686-87, 27.5., FNEO, compte rendu, 5.6.1939 [MAE Chine 1063, SHM 1 BB4 74]).

${ }^{271}$ Cosme an Bonnet, T 32, 17.6., T 35, 18.6., T 52, 23.6.1939 (MAE Chine 785, 1064, 677).
} 
schaffe. Stattdessen solle ein chinesisches Gericht in der Konzession den Täter verurteilen. Cosme widersprach: Ebenso falsch wie die Auslieferung des Beschuldigten an Japan sei es, ihn einem Gericht zu überstellen, dessen Richter in Chungking ernannt würden. Man dürfe Japan keinen Vorwand liefern. Baudez warnte, daß chinesische Gerichte in Shanghai ähnliche Fälle bislang endlos vertagten. Was mit dem Täter letztlich geschah, blieb im Dunkeln.

Die Polizei im Settlement hatte kaum Skrupel: Sie übergab im November 1939 zwei Chinesen an Japan, die sie im Juni 1939 bei dem Versuch, Wang Ching-wei zu töten, gefaßt hatte. Im Juni 1940 verurteilte ein japanisches Gericht beide Männer zum Tode ${ }^{272}$. Vermutlich verhielten sich die französischen Behörden in Fällen, die keine Aufmerksamkeit erregten, ähnlich: Im Juni 1939 berichtete der französische Diplomat Boissezon aus Shanghai, es sei üblich, chinesische Verdächtige örtlichen Marionetten-Gerichten zu übergeben. Bonnet schrieb Corbin, Japan habe in Shanghai die Auslieferung eines Chinesen vom französischen Generalkonsul gefordert, »qui semble avoir résolu le problème par les moyens locaux dont il dispose « - eine Formulierung, die auf die Abschiebung hindeutet. In Tientsin lobte Japans Generalkonsul bei seinem deutschen Kollegen Stoller den neuen französischen Konsul Colin:

Während der frühere französische Konsul [Lépissier] starr an den diesbezüglichen Rechten Frankreichs festhielt, weise der jetzige alle von der japanischen Polizei verdächtigten Chinesen so aus der Konzession aus, daß sie von den Japanern verhaftet werden könnten.

Die Regierung in Tokio lobte auch intern die Kooperation der französischen Behörden. Die Asienabteilung im Quai d'Orsay stellte die Praxis in Tientsin intern so dar: Fasse man einen chinesischen »Terroristen « in der Konzession, werde er gewarnt, daß man ihn beim nächsten Erscheinen auf französischem Gebiet der chinesischen Polizei übergebe. Dann bringe man ihn an die Konzessionsgrenze. Wenn die von Agenten informierte japanische Polizei die Auslieferung verlange, könne man belegen, daß der Verdächtige bereits ausgewiesen $\operatorname{se}^{273}$. Die Aussage des japanischen Generalkonsuls in Tientsin gegenüber Stoller läßt anderes vermuten. Es ist deshalb wahrscheinlich, daß die französischen Behörden chinesische Beschuldigte informell den Japanern zuführten. Die Japaner erschossen die Beschuldigten oft sofort.

Ende September 1939 nahmen die Franzosen in ihrer Konzession in Tientsin auf japanische Bitten den Telegraphenbüro-Leiter Wang Jo-shi fest, den Japan

\footnotetext{
${ }^{272}$ Baudez an Bonnet, T 36, 17.6., Bonnet an Baudez, T 31, 19.6., Bonnet an Cosme, T 22-26, 21.6., T 262-67, 28.6., Cosme an Bonnet, T 56-57, 24.6.; T 38-39, 20.6.; T 42, 21.6., Baudez an Bonnet, T 40, 21.6.1939 (MAE Chine 805, 785, 1064); WAKEMAN, The Shanghai Badlands, S. 78, S. 88.

${ }^{273}$ Boissezon an Bonnet, T 720, 13.6., Bonnet an Corbin, T 1146 49, 14.6.1939 (MAE Chine 1066, 837); Stoller an Ribbentrop, 17.7.1939 (AA Pol II Po 3 England Bez GB-Japan 3); Unterlage von der Ministersitzung über die Unterstützung Chiangs durch Frankreich [Februar/März 1940] (JA, S 1.1.1.028, S. 574f.); Note de la sous-direction d'Asie-Océanie, 19.6.1939 (MAE Chine 832).
} 
des Mordes bezichtigten. Nach dem üblichen Verfahren wurde Wang für eine Woche zur Vernehmung an Japan überstellt. Wang räumte die Vorwürfe ein. Er durfte in die Konzession zurückkehren. Wellington Koo und Charles Lépissier hatten sich für Wang eingesetzt. Cosme erläuterte, die Konzession müsse mit den örtlichen Regimen so zusammenarbeiten, wie man dies vor 1937 getan habe. Léger war einverstanden und riet, in Zukunft Zwischenfälle za vermeiden, indem man des Terrorismus Verdächtige ausweise, ehe Japan Fragen stelle. Cosme versicherte am 24 . Oktober, dies versuche Colin, doch in den Fällen, in denen dies nicht funktioniere,

nous serons fatalement conduits à admettre, sous une forme officieuse et discrète, une coopération avec la police japonaise pour tout ce qui touche aux perquisitions, aux arrestations et à l'interrogatoire des personnes suspectes de menées antijaponaises ou d'actes de terrorisme. Cette attitude [...] me paraît seule susceptible de nous permettre d'empêcher une ingérence effective du Japon dans notre concession et d'éviter d'avoir à souscrire à ce sujet un arrangement officiel comportant des engagements formels ${ }^{274}$.

Folgenlos notierte ein Mitarbeiter des Quai d'Orsay neben dem Absatz »erreur« und »dangereux «. Im Februar 1940 übergaben die Franzosen in Tientsin 19 Chinesen, denen ein versuchter Bombenanschlag zur Last gelegt wurde.

Diese Auslieferung, über die die Presse berichtete, war kaum die einzige. Trotz aller Rechtfertigungen war nach den Maßstäben, die die Forschung für Europa aufgestellt hat, Frankreichs Politik in den Konzessionen das klassische Beispiel einer Kollaboration mit der Besatzungsmacht. Wenn René Rémond die Auslieferung deutscher Flüchtlinge aus Frankreich an die deutsche Polizei 1940 für unauslöschlich unehrenhaft nennt, gilt das gleiche Urteil auch für die französischen Behörden in China ${ }^{275}$.

Aber selbst der fügsamen französischen Konzession in Shanghai drohte im Sommer 1939 Gefahr. Italiens Botschafter berichtete im Juni 1939 aus Tokio, das japanische Militär und einige Diplomaten im Gaimusho seien entschlossen, die Konzessionen auszulöschen. Ende August hörten Auriti und Gauss, Japan plane eine Blockade der Konzessionen, die nur die Briten treffen solle. Japan verlegte 6000 Soldaten nach Shanghai, um die Konzession abzuriegeln,

\footnotetext{
${ }^{274}$ Affleck an Clark Kerr, 9.7.1938 (FO 371/22148, F 7483/717/10), zit. nach SHAI, Origins of the War, S. 209; Chauvel an Cosme, T 468, 3.10., Cosme an Daladier, T 1081-82, 4.10., Léger an Cosme, T 486, 11.10., T 503, 18.10., Lépissier an Chauvel, L, 27.10.; Cosme an Daladier, T 1094, 9.10., T 1127-30, 16.10., L 364, 24.10., T 1219, 31.10.; Cosme an Daladier, T 111, 10.12., T 143, 26.12.1939 (MAE Chine 1068, 832, 1069); Yvon an EMA.2, L 188, 1.11.1939 (SHAT 7 N 3292).

${ }^{275}$ North China Star, French Police Hand Over 19 Chinese to District Court, 16.2.1940 (MAE Chine 1069); Werner RöHR, Okkupation und Kollaboration, in: Okkupation und Kollaboration (1938-1945). Beiträge zu Konzepten und Praxis der Kollaboration in der deutschen Okkupationspolitik, zusammengestellt und eingeleitet von Werner RöHR. Ergänzungsband 1 der achtbändigen Dokumentenedition "Europa unterm Hakenkreuz. Die Okkupationspolitik des deutschen Faschismus (1938-1945)«, Berlin, Heidelberg 1994, S. 59-84 (S. 7If.); RÉMOND, Frankreich im 20. Jahrhundert, S. 332.
} 
nachdem britische Posten am 19. August zwei Polizisten der MarionettenStadtverwaltung erschossen hatten. Die Lage des Settlement war bedroht wie nie zuvor. Schon am 16. August hatte Japan begonnen, 15000 Soldaten mit Panzern und Artillerie vor Hongkong zu konzentrieren. Der italienische Generalkonsul meldete, die Briten bereiteten die Evakuierung ihrer Truppen vor. Als in diesem kritischen Moment Hitler sein Bündnis mit Stalin bekanntgab, beendete Japan die Manöver um Hongkong und verschob die Blockade Shanghais. Die französischen Behörden hielten ihre Konzession nie für unmittelbar gefährdet. Baudez wußte zwar von Gerüchten, Japan wolle die Konzessionen abriegeln, hielt die Lage aber für nicht beunruhigend, weil Tokio bemüht sei, die USA nicht zu provozieren, und deshalb in Shanghai stillhalte ${ }^{276}$.

Das französische Militär hatte auch 1939 seinen Anteil daran, daß die Spannungen zwischen Japanern und Franzosen in China begrenzt blieben. So intensiv wie vor der Sudetenkrise wurden die Kontakte zwischen französischen und japanischen Militärs nicht mehr. Vor allem in Nordchina waren die Beziehungen abgebrochen, wie Oberst Herman-Frantz Delsuc im Dezember 1938 beklagte. Doch feindlich standen sich die Verbände nicht gegenüber. Der Oberkommandierende der französischen Truppen in China, Oberst Casseville, versicherte General Homma seine Wertschätzung, in Shanghai lobten der kommandierende General Sakurei und Marineattaché Vize-Admiral Nomura bei einem üppigen dîner mit führenden französischen Offizieren die militärische Kameraderie und die exzellenten Beziehungen zwischen den Verbänden. Als bei anderer Gelegenheit der Alkohol die Zunge Sakureis gelöst hatte, versicherte der General den Franzosen, selbst wenn beide Regierungen politische und wirtschaftliche Differenzen hätten, seien sich die Militärs doch einig. Ende Juli 1939 lobte Militärattaché Yvon die korrekten Beziehungen zwischen japanischem und französischem Militär ${ }^{277}$.

Gerade, als Mitte August der japanische Truppenaufmarsch vor Hongkong und Shanghai sowie häufige Überflüge Indochinas durch japanische Flugzeuge eine Großoffensive gegen westliche Interessen in Ostasien ankündigten, entspannte der überraschende Abschluß des Hitler-Stalin-Paktes die Konfrontation zwischen Japan und dem Westen schlagartig. Tokio fand sich isoliert wieder. Die demokratischen Mächte hatten damit die bis dahin schwerste Auseinandersetzung mit Japan im 20. Jahrhundert ohne Verluste - abgesehen von

\footnotetext{
${ }^{276}$ Auriti an Ciano, 19.6., 1.9., Di Melito an Ciano, 3.9.1939 (DDI Serie 8, XII, 273, XIII, 526, 625); Baudez an Bonnet, T 51-52, 22.8., L 80, 30.6.1939 (MAE Chine 1068, 1064); UTLEY, Going to War, S. 74f.; Gauss an Hull, 24.8., Southard an Hull, 22.8.1939 (SD 793.94/15321, 15317).

${ }_{277}$ Delsuc an Casseville, T 775-76, 6.12.1938; Casseville an Homma, L 402, 12.4., Perretier an Casseville, L, 25.5.1939 (SHAT 11 H 60, 63); Yvon an EMA.2, L 74, 30.7.1939 (SHAT 7 N 3292).
} 
der deutlichen Einbuße an Prestige - überstanden, vor allem weil auch Japan vor einem militärischen Konflikt zurückschreckte.

Frankreich hatte im November 1938, als die USA begannen, deutlicher gegen Japan Position zu beziehen, die Ausrichtung seiner Fernostpolitik leicht korrigiert: Paris suchte deutlich die Gemeinsamkeit mit Japans Gegnern USA und Großbritannien. Daß das französische rapprochement an Amerika und England in Tokio dazu führte, daß Frankreich als zunehmend antijapanisch eingeschätzt wurde, wie der deutsche Botschafter Ott bemerkte ${ }^{278}$, nahm Paris in Kauf, denn die sichtbare Nähe zu den USA schien in Asien wie in Europa zusätzliche Sicherheit zu bieten. In Asien zu den USA und Großbritannien auf Distanz zu gehen, war schon aus Gründen der Verhältnisse in Europa keine tragfähige Option, erst recht nicht, als Japan mit der Besetzung Hainans am 10. Februar und der Annexion der Spratlys am 31. März 1939 demonstrierte, $\mathrm{da} ß$ es französische Interessen in Ostasien weniger respektierte als bisher. Mit einer Reihe politischer Maßnahmen sorgte das französische Außenministerium dafür, daß die festere Haltung Frankreichs nicht als Parteinahme für China erschien: Frankreich lieferte Japan in großem Umfang Rohstoffe, leistete China kaum Wirtschaftshilfe und kollaborierte in seinen vier Konzessionen mit der japanischen Armee. Japan zeigte, trotz erheblicher Pressionen, mit dem Respekt vor den französischen Interessen in den Konzessionen, vor den katholischen Missionen sowie im Umgang mit den Franzosen und Vietnamesen auf den Paracels und den Spratlys, daß es grundsätzlich bereit war, mit Paris einen akzeptablen modus vivendi zu finden.

${ }^{278} \mathrm{Ott}$ an Ribbentrop, 14.3.1939 (ADAP D IV, 549). 